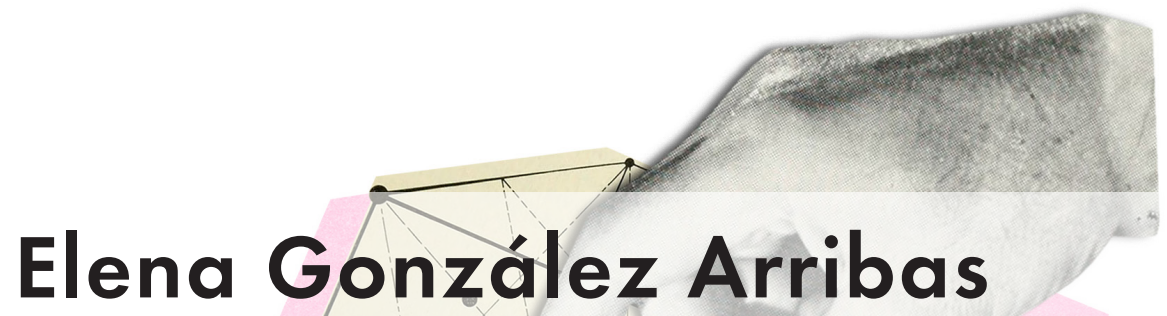

Flexible and transparent biological electric power sources based on nanostructured electrodes

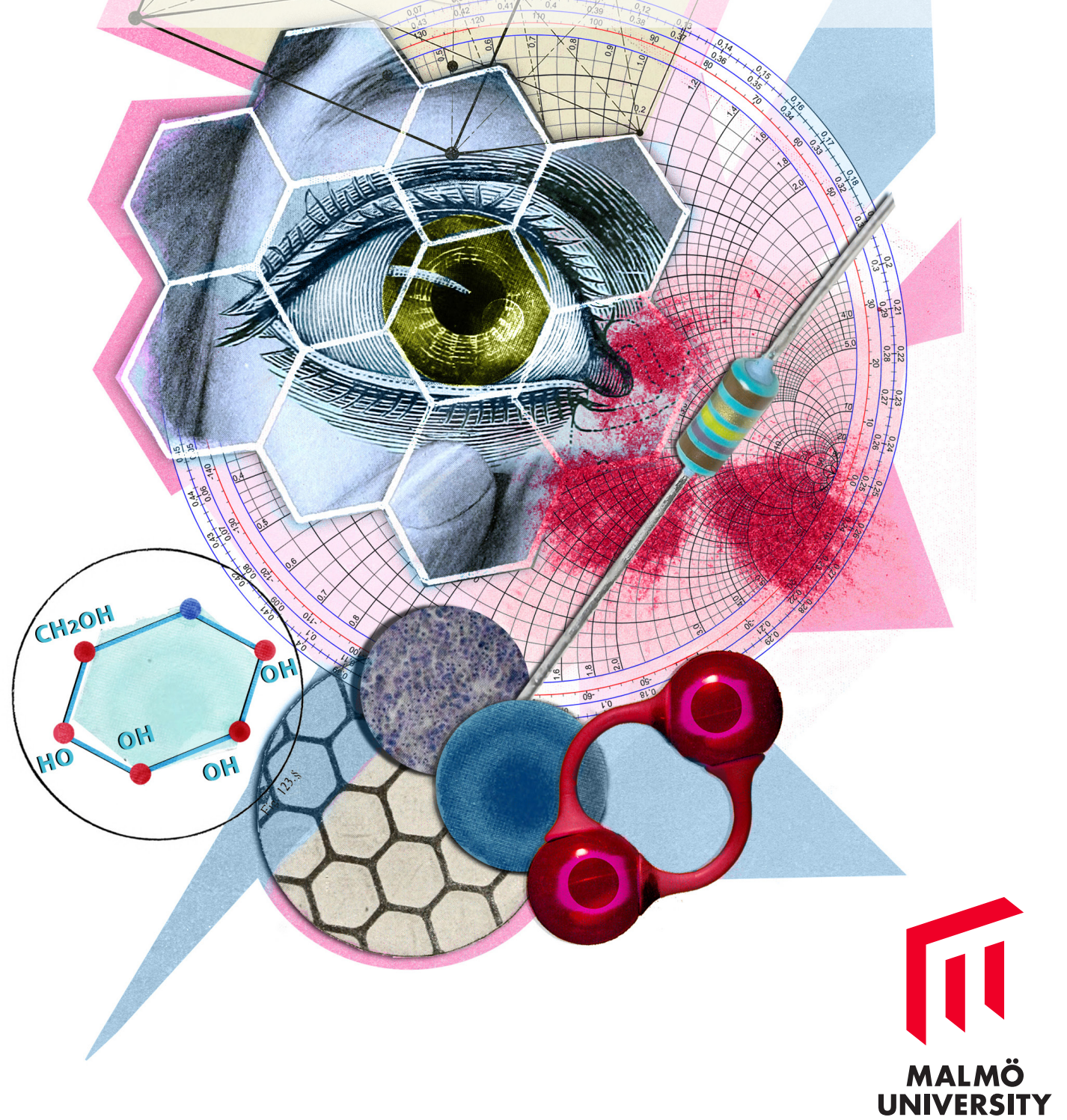



FLEXIBLE AND TRANSPARENT BIOLOGICAL ELECTRIC

POWER SOURCES BASED ON NANOSTRUCTURED

ELECTRODES 
Malmö University

Health and Society, Doctoral Dissertation 2018:3

(c) Copyright Elena González Arribas 2018

Front cover illustration: "In the eye" by Amanda Paniagua Liarte

ISBN 978-9I-7IO4-828-8 (print)

ISBN 978-9I-7IO4-829-5 (pdf)

ISSN $1653-5383$

Holmbergs, Malmö 2018 


\title{
Elena González Arribas Flexible and transparent biological electric power sources based on nanostructured electrodes
}

\author{
Malmö University, 2018 \\ Faculty of Health and Society \\ Department of Biomedical Science
}


To my family and in memory of my grandfather, Benito González López

Para mi familia y en memoria de mi abuelo, Benito González López 
"Y quizá hayas andado el camino ya, cuando mires atrás. Si estás atrapado en las sombras, aguarda, aguarda. Del lodo crecen las flores más altas.”

Lodo, una canción de Xoel López

"And maybe you've already walked the path, when you look back. If you are stuck in the shadows, hang on, hang on. The highest flowers grow from the mud. "

Lodo, a song by Xoel López 



\section{CONTENTS}

LIST OF PUBLICATIONS AND CONTRIBUTION ........................... 9

ABBREVIATIONS ......................................................... 12

ABSTRACT ….......................................................... 14

POPULÄRVETENSKAPLIG SAMMANFATTNING ......................... 15

BIOENERGY .......................................................... 17

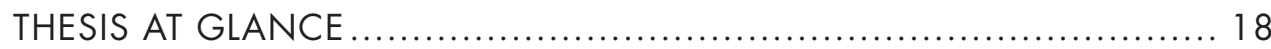

BIOLOGICAL ELECTRIC POWER SOURCES ........................... 20

Classification based on biocatalyst ...................................................... 20

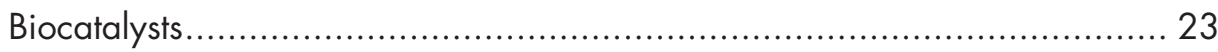

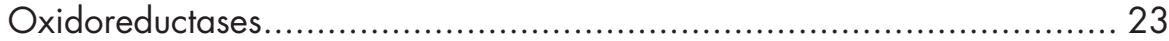

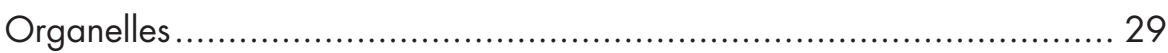

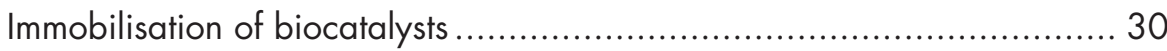

Classification based on operational principle ......................................... 33

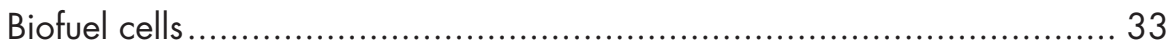

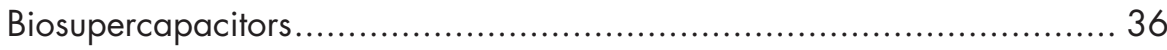

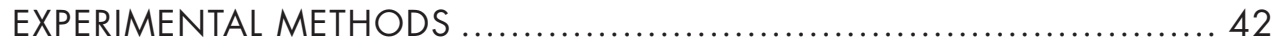

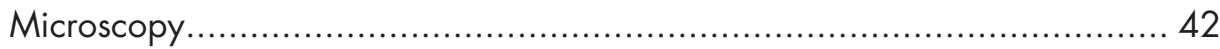

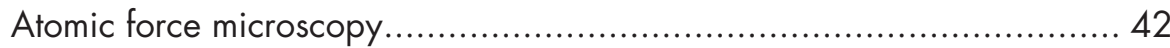

Scanning electron microscopy ........................................................ 43

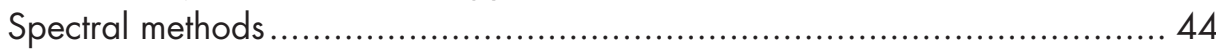

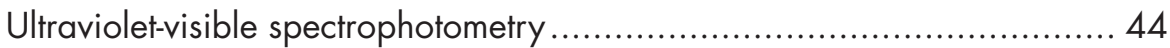

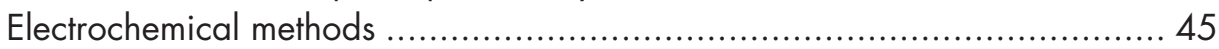

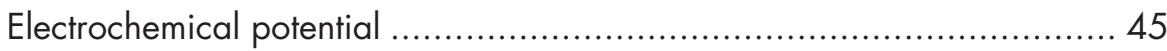

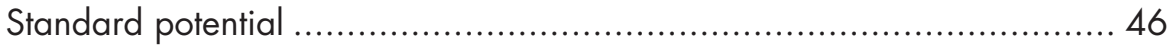

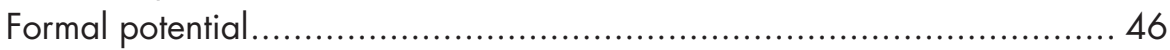

Open circuit potential and voltage ................................................. 47 
Devices to study electrode reactions and to test electrochemical systems ....... 48

Two-electrode systems..................................................... 49

Three-electrode systems....................................................... 49

Electrochemical techniques ................................................... 51

Voltammetry ...................................................................... 51

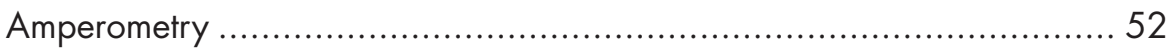

Potentiometry ........................................................... 53

RESULTS AND DISCUSSION ........................................... 54

Summary of the research papers ............................................. 54

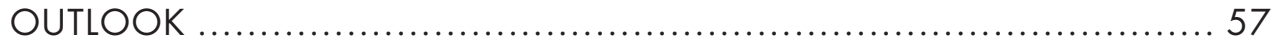

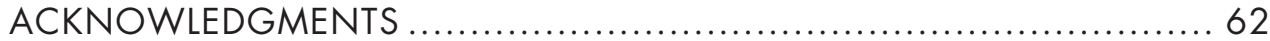

REFERENCES .................................................... 67

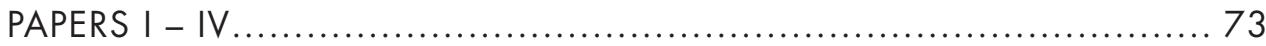




\section{LIST OF PUBLICATIONS AND CONTRIBUTION}

\section{Paper I:}

E. González-Arribas, D. Pankratov, S. Gounel, N. Mano, Z. Blum, S. Shleev, Transparent and capacitive bioanode based on specifically engineered glucose oxidase. Electroanalysis, 23 (2016) 1290-1297.

- Contribution to paper I:

Took part in the designing of experiments and performed all experimental part, except SEM imaging. Participated in the data processing, writing of the experimental part of the paper and prepared all graphic materials.

Review I:

D. Pankratov, E. González-Arribas, Z. Blum, S. Shleev, Tear based bioelectronics. Electroanalysis, 28 (2016) 1250-1266.

- Contribution to review I:

Performed a literature overview and took a large part in writing of the Chapter 4. 


\section{Paper II:}

E. González-Arribas, T. Bobrowski, C. Di Bari, K. Sliozberg, R. Ludwig, M. D. Toscano, A. L. De Lacey, M. Pita, W. Schuhmann, S. Shleev, Transparent, mediator- and membrane-free enzymatic fuel cell based on nanostructured chemically modified indium tin oxide electrodes. Biosensors and Bioelectronics, 97 (2017) 46-52.

\section{- Contribution to paper II:}

Took part in designing of experiments, performed some experiments. Participated in the evaluation of results, writing of the manuscript, and prepared graphic materials.

\section{Review II:}

S. Shleev, E. González-Arribas, M. Falk. Biosupercapacitors. Current Opinion in Electrochemistry, 5 (2017) 226-233.

\section{- Contribution to review II:}

Performed a literature review, helped with some graphic materials and took a small part in writing of the manuscript.

\section{Paper III:}

T. Bobrowski, E. González-Arribas, R. Ludwig, M. D. Toscano, S. Shleev, W. Schuhmann, Rechargeable, flexible and mediator-free biosupercapacitor based on transparent ITO nanoparticle modified electrodes acting in $\mu \mathrm{M}$ glucose containing buffers. Biosensors and Bioelectronics, 101 (2018) 84-89.

\section{- Contribution to paper III:}

Took part in designing of experiments and performed a significant part of the experimental work. Participated in the evaluation of results and preparation of graphic materials. 


\section{Paper IV:}

E. González-Arribas, O. Aleksejeva, T. Bobrowski, M. D. Toscano, L. Gorton, W. Schuhmann, S. Shleev. Solar biosupercapacitor, 74 (2017) 9-13.

\section{- Contribution to paper IV:}

Took part in designing of experiments and performed a significant part of the experimental work, viz. fabricated and characterised biocathodes and the complete biodevice. Participated in the evaluation of results, writing of the manuscript and prepared some graphic materials.

Other publications not included in this thesis:

1. D. Pankratov, R. Sundberg, J. Sotres, I. Maximov, M. Graczyk, D.B. Suyatin, E. González-Arribas, A. Lipkin, L. Montelius, S. Shleev. Transparent and flexible, nanostructured and mediatorless glucose/oxygen enzymatic fuel cells. Journal of Power Sources, 294 (2015) 501-506.

2. Y.M. Parunova, S.O. Bushnev, E. Gonzalez-Arribas, P. Falkman, A.V. Lipkin, V.O. Popov, S. Shleev, D. Pankratov. Potentially implantable biocathode with charge-storing function based on nanocomposite polyaniline/carbon nanotubes. Russian Journal of Electrochemistry, 52 (2016) 1166-1171.

3. D. Pankratov, E. González-Arribas, Y.M. Parunova, M.A. Gorbacheva, Y.S. Zeyfman, S.V. Kuznetsov, A. Lipkin, S.Shleev. New nanobiocomposite materials for bioelectronics devices. Acta Naturae, 24 (2015) 98-101. 


\section{ABBREVIATIONS}

$\begin{array}{ll}\text { AFM } & \text { atomic force microscopy } \\ \text { An } & \text { Aspergillus niger } \\ \text { APTES } & \text { (3-aminopropyl)triethoxysilane } \\ \text { BFC } & \text { biofuel cell } \\ \text { BOx } & \text { bilirubin oxidase } \\ \text { BSC } & \text { biosupercapacitor } \\ \text { Ca }_{\text {a }} & \text { capacitance density } \\ \text { CDh } & \text { cellobiose dehydrogenase } \\ \text { CE } & \text { counter electrode } \\ \text { Ct } & \text { Corynascus thermophilus } \\ \text { CV } & \text { cyclic voltammetry } \\ \text { CYT } & \text { cytochrome } \\ \text { DET } & \text { direct electron transfer } \\ \text { Dh } & \text { dehydrogenase } \\ \text { EDC } & \text { 1-ethyl-3-(3-dimethylaminopropyl)carbodiimide } \\ \text { EDL } & \text { electric double layer } \\ \text { EDLC } & \text { electric double layer capacitor } \\ \text { EFC } & \text { enzymatic fuel cell } \\ \text { ET } & \text { electron transfer } \\ \text { FAD } & \text { flavin adenine dinucleotide } \\ \text { GDh } & \text { glucose dehydrogenase } \\ \text { GLYMO } & \text { (3-glycidyloxypropyl)trimethoxysilane } \\ \text { GOx } & \text { glucose oxidase } \\ \text { IET } & \text { intramolecular electron transfer } \\ \text { ITO } & \text { indium tin oxide } \\ \text { ITONP } & \text { ITO nanoparticle } \\ & \\ \end{array}$




$\begin{array}{ll}\mathrm{LMPO}_{2} & \text { lytic polysaccharide monooxygenase } \\ \text { LSV } & \text { linear sweep voltammetry } \\ \text { MCO } & \text { multicopper oxidase } \\ \text { MET } & \text { mediated electron transfer } \\ M t & \text { Myrothecium verrucaria } \\ \text { MWCNT } & \text { multi-walled carbon nano-tubes } \\ \text { NHS } & \text { N-Hydroxysuccinimide } \\ \text { NP } & \text { nanoparticle } \\ \text { OCP } & \text { open circuit potential } \\ \text { OCV } & \text { open circuit voltage } \\ \text { Pa } & \text { Penicillium amagasakiense } \\ \text { PEDOT } & \text { poly(3,4-ethylenedioxythiophene) } \\ \text { PPQ } & \text { pyrroloquinoline quinone } \\ \text { qa } & \text { anodic charge } \\ \text { qc } & \text { cathodic charge } \\ \text { RE } & \text { reference electrode } \\ \text { SEM } & \text { scanning electron microscopy } \\ \text { TM } & \text { thylakoid membrane } \\ \text { TTF-TCNQ } & \text { tetrathiafulvalene-tetracyanoquinodimethane } \\ \text { UV-Vis } & \text { ultraviolet-visible spectrophotometry } \\ \text { WE } & \text { working electrode }\end{array}$




\section{ABSTRACT}

The thesis is focused on biological electric power sources based on transparent and flexible nanostructured electrodes. The power generating part of these biodevices was decorated with different biomaterials electrically wired to transparent electrodes based on either thin gold films, or indium tin oxide. Planar electrodes were additionally nanostructured by applying different nanomaterials to the electrode surfaces (such as indium tin oxide nanoparticles, graphene, carbon nanotubes) or by using nanoimprint lithography to increase the real surface area and thus boost enzyme loading. Bilirubin oxidase was used a cathodic biocatalyst for oxygen electroreduction, whereas different biomaterials were exploited as anodic bioelements, viz. redox enzymes (cellobiose and glucose dehydrogenase, as well as glucose oxidases) and thylakoid membranes, for glucose electrooxidation and light harvesting, respectively. Charge-storing parts of biodevices were based on electroconducting polymers, e.g. poly(3,4-ethylenedioxythiophene), carbon nanotubes, graphene, and indium tin oxide nanoparticles. The bioelectrodes were characterised in detail electrochemically, and also using scanning electron microscopy and atomic force microscopy. Transparent, membrane-free enzymatic fuel cells, as well as chemical and solar biosupercapacitors were assembled and basic parameters of biodevices, viz. open-circuit voltages, power and charge density, as well as stability, were studied in continuous and pulse operating modes. 


\section{POPULÄRVETENSKAPLIG SAMMANFATTNING}

Portabel medicinteknisk utrustning framträder alltmer som en av de mest lovande metoderna för vårdövervakning och personlig behandling. Förebyggande vård och hantering av kroniska sjukdomar är resurskrävande och en överföring av det konventionella sjukhuscentrerade sjukvårdssystemet till ett individcentrerat vårdsystem skulle vara samhällsekonomiskt gynnsam. I ett sådant scenario representerar bärbara mätenheter en teknik för övervakning av patienter på ett icke-invasivt och lättanvänt sätt. Denna teknik har möjlighet att tillhandahålla långsiktiga hälsostatusövervakningar och förmedla realtidsdata som läkare kan analysera för att ge patienterna återkoppling utan att behöva träffa patienterna lika ofta. Dessutom är många utan kroniska sjukdomar också intresserade av att övervaka kroppens hälsotillstånd för att förhindra sjukdomar och uppnå en högre livskvalitet.

Dagens bärbara enheter integrerar elektronik med låg strömförbrukning och trådlös teknik, s.k. "low power wireless technology", för att överföra information från enheten till en mottagare. Elektronik behöver tillförlitliga strömkällor för att säkerställa funktionen, och biologiska kraftkällor är särskilt lämpliga alternativ att använda i bärbara enheter, eftersom de har hög prestanda när de används under fysiologiska förhållanden.

Olika biologiska kraftkällor har tillverkats och testats i denna avhandling. Materialen som används för att tillverka dem är 
transparenta och flexibla. Dessa två egenskaper bidrar starkt till användarvänligheten och ökar därmed benägenheten att använda sådana kraftkällor. De biologiska kraftkällorna omvandlar kemisk energi till elektrisk energi genom att oxidera glukos och reducera syre under förhållanden som liknar dem som föreligger i mänsklig tårvätska. Detta arbete bidrar till att öka kunskapen om flexibla, transparenta och nanostrukturerade material som används för tillverkning av biologiska kraftkällor. 


\section{BIOENERGY}

This work has been developed within the framework of a Marie Curie Initial Training Network, BIOENERGY (Biofuel cells: From fundamentals to applications in bioelectrochemistry).

I have been working as a European fellow during three years in collaboration with nine other internationally renowned research teams from Germany, Sweden, Ireland, UK, France, Poland, Spain, and Austria, and three industrial partners from UK and Spain.

The European project has facilitated collaboration between the research groups and industrial partners, and did provide workshops as a training vehicle for the fellow.

The institutions and main objectives to accomplish during collaborations were:

- Collaboration with Institute of Catalysis and Petrochemistry (ICP), CSIC, Spain involved optimisation of chemical modification of transparent indium tin oxide (ITO) electrodes to immobilise different biocatalysts.

- Collaboration with Ruhr-University Bochum, Germany involved nanostructuration of surfaces using two different strategies for ITO nanoparticle (ITONP) deposition, biocatalysts covalent immobilisation and performance tests of the resulting enzymatic fuel cell. 


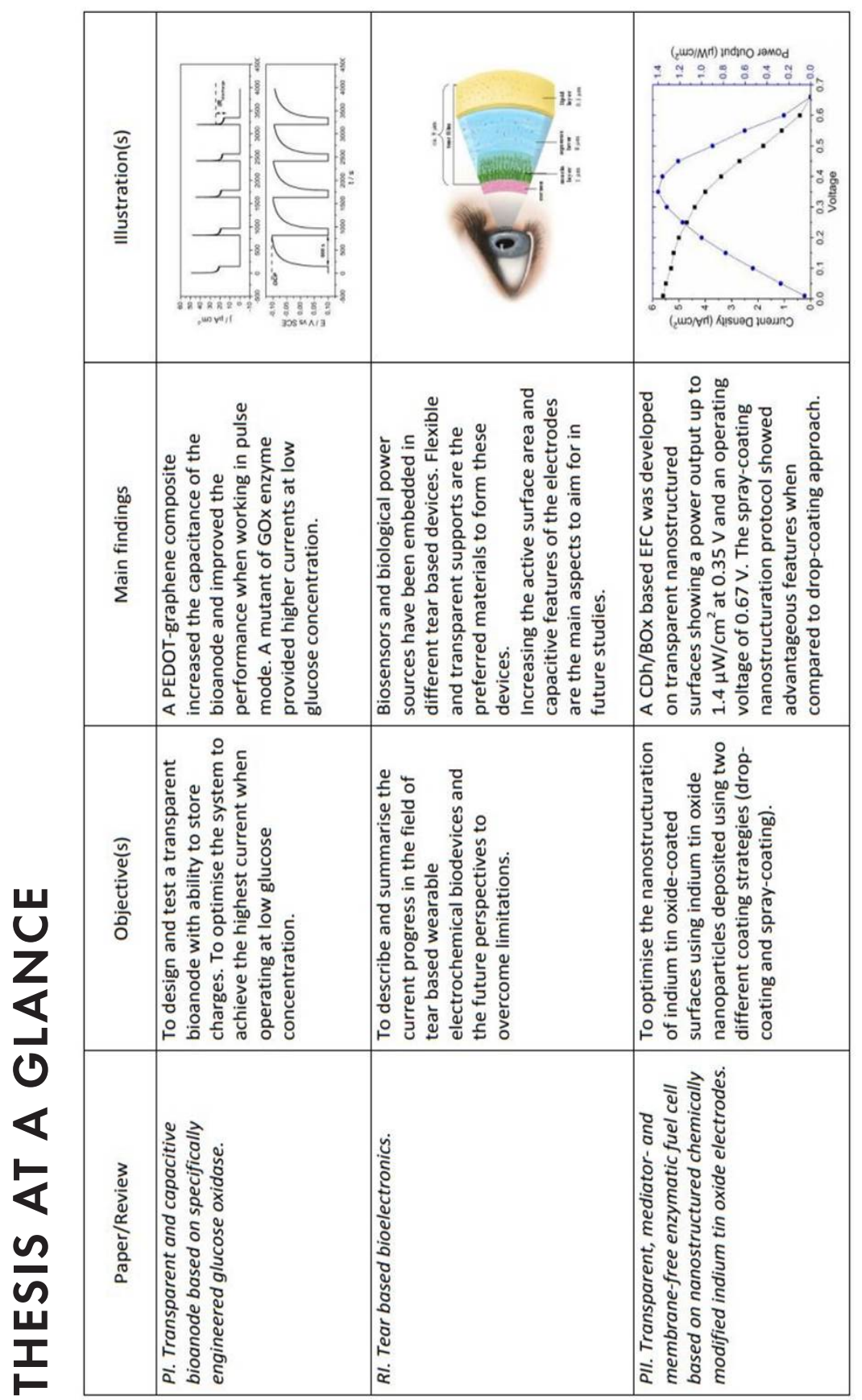




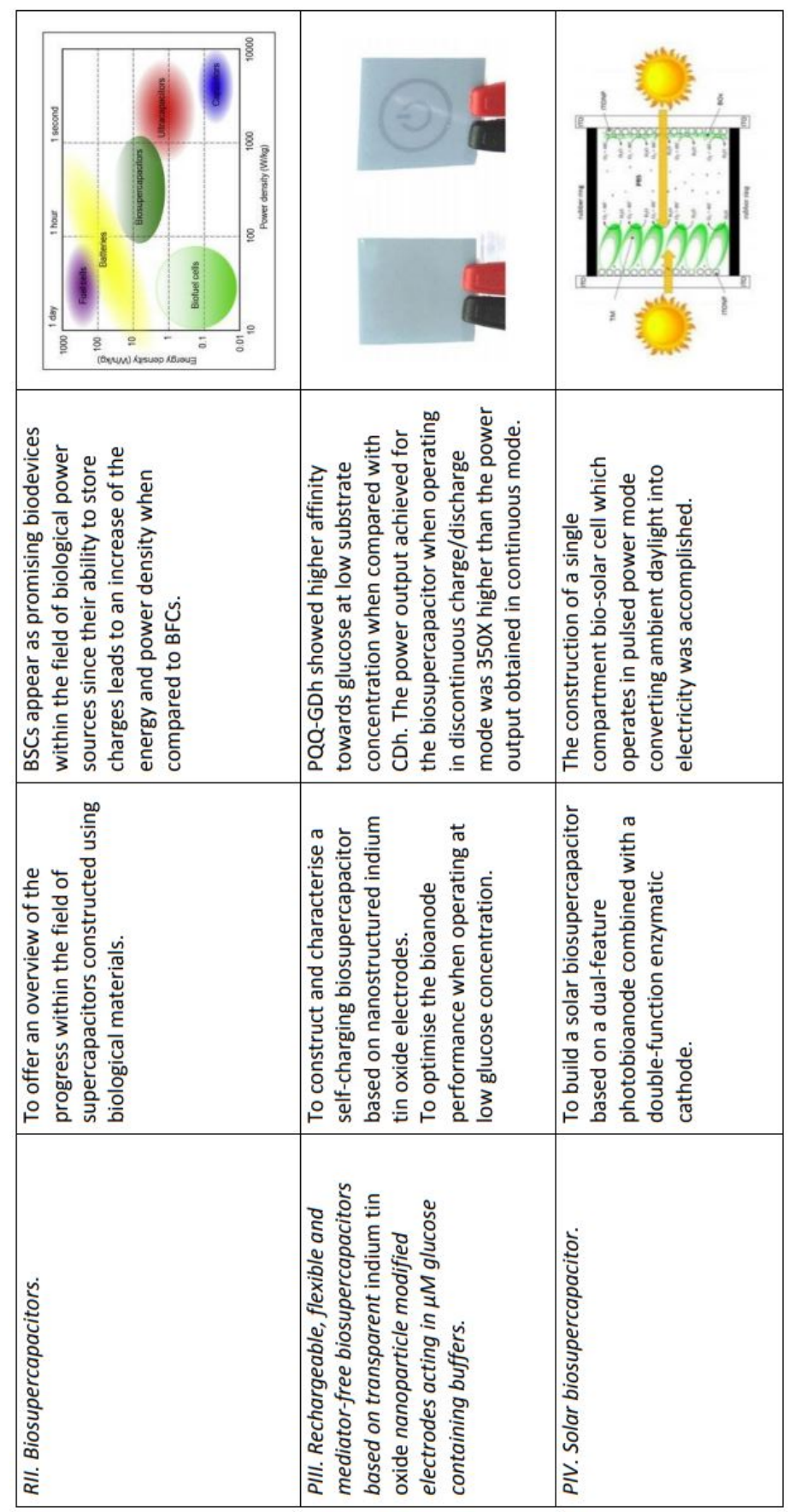




\section{BIOLOGICAL ELECTRIC POWER SOURCES}

In this section, the relevance of the investigation on biological power sources, as well as the configuration of the specific bioelectrochemical systems developed, will be discussed.

\section{Classification based on biocatalyst}

Biological electric power sources cover an area of applications that previously developed conventional electric power sources do not readily match. Briefly, biological power sources have the ability of converting solar or chemical energy into electrical energy, using biocatalysts from different types of biological material including cells, organelles, and proteins (Figure 1). In this work, the focus is on biofuel cells (BFCs) that use enzymes as biocatalysts, i.e. enzymatic fuel cells (EFC), as well as on biosupercapacitors (BSCs), which employ both redox enzymes and organelles.

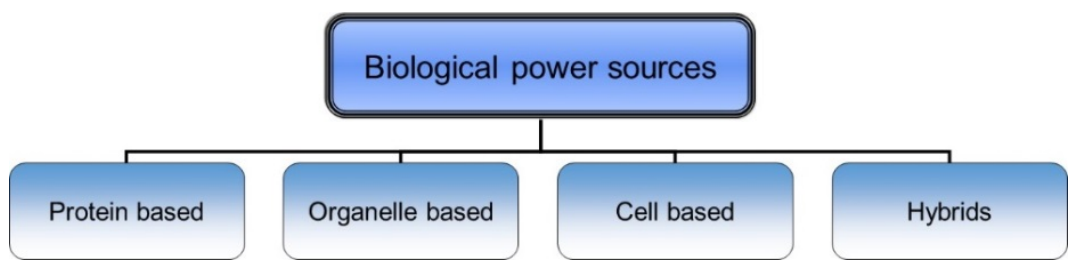

Figure I. Classifications of electric power biodevices based on biocatalyst used. 
The biocatalysts mentioned outperform the metal catalysts used in conventional fuel cells in terms of reaction rates (Masa and Schuhmann, 2016; Shleev et al., 2016), and operate under milder conditions, viz. temperatures in the range $20-40{ }^{\circ} \mathrm{C}$ and neutral $\mathrm{pH}$ (Barton et al., 2004; Falk et al., 2013; Heller, 2004; Xu et al., 2017). Additionally, the biocatalysts group is very diverse, when it comes to the different redox reactions that they can catalyse. Moreover, biocatalysts show specificity towards different biofuels present in e.g. human physiological fluids (Falk et al., 2013), and towards oxygen as a general biooxidant. Thus, biocatalysts appear to be the best choice to develop electric power sources with potential applications in devices operating under physiological conditions.

However, regarding power and energy density, the values achieved from biodevices are very low when compared with conventional electric power sources (Figure 2). By definition, electric power is the rate at which electrical energy is transferred to an electric circuit (Fowle, 1978). This rate is low in the case of biological power sources due to inadequate communication between the active site of the biocatalysts and the electric circuit, specifically the conductive support that configures the electrode (Figure 3) (Masa and Schuhmann, 2016; Shleev et al., 2016), and other factors, e.g. high internal resistance of biodevices. 


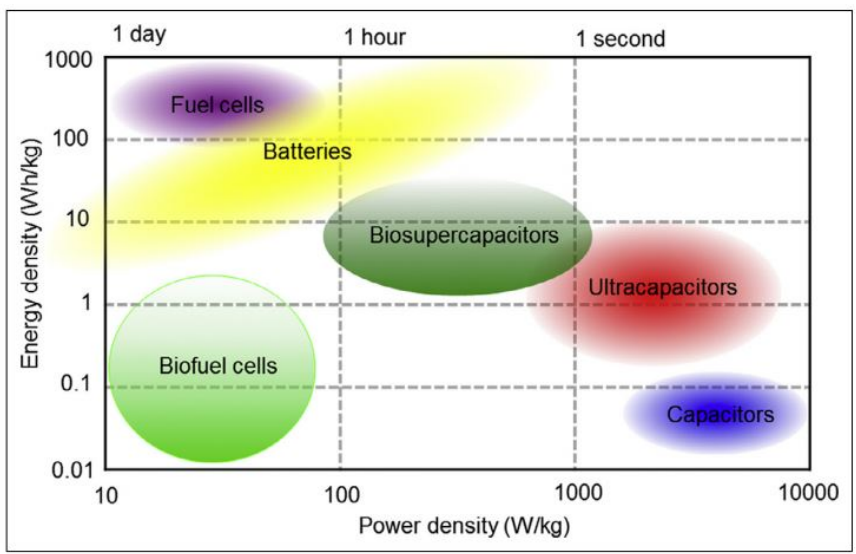

Figure 2. Ragone plot for different energy storage and conversion devices.

The catalytic mechanisms of the biocatalysts used in this work, the strategies employed to overcome the electron transfer (ET) limitation, and the different types of biological power sources completed are detailed below. The design of the bioelectrocatalytic devices included selecting materials and surface modifications that targeted increased power output and stability, as well as to favour possible wearable device applications. 


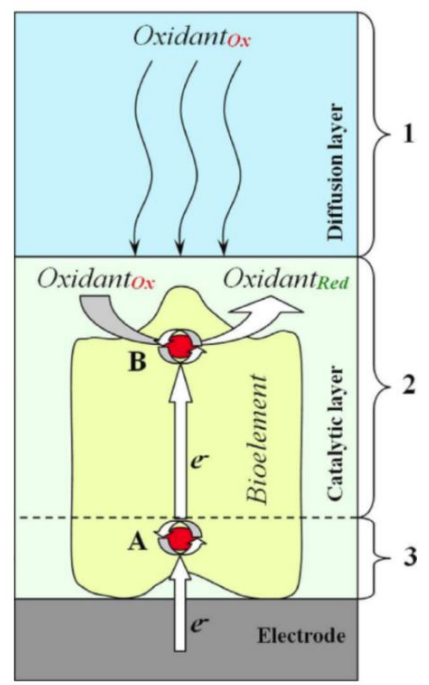

Figure 3. Schematic representation of the mechanism of a cathodic

bioelectrocatalytic system which contain several redox centers ( $A$ and B) (Shleev et al., 20I6).

\section{Biocatalysts}

Electrocatalysis is a type of catalysis that results in the improvement of the rate of an electrochemical reaction taking place on an electrode surface. The term biocatalysis refers to the same process but concerning the acceleration of electrochemical reactions carried out by biological catalysts (Masa and Schuhmann, 2016; Tarasevich, 1985). The biocatalysts used in this work include redox enzymes (oxidoreductases) and organelles.

\section{Oxidoreductases}

Oxidoreductases are catalytic proteins that catalyse a coupled oxidation and reduction. (Price and Stevens, 1982; Toone and Editor, 2007). They transfer at least one electron between two or more substrates, mediated by a cofactor (Milton and Minteer, 2017). 
The cofactors vary the oxidation state while catalysis is taking place, and there are several possible cofactors for oxidoreductases (Rasmussen et al., 2016). In this work, the oxidoreductases used incorporate the following cofactors:

- Flavin adenine dinucleotide (FAD) in glucose oxidase (GOx) (paper I) and in the dehydrogenase (Dh) domain of cellobiose dehydrogenase (CDh) (paper II and, III)

- Pyrroloquinoline quinone (PQQ) and FAD in glucose dehydrogenase (GDh) (paper III)

- Heme in the cytochrome (CYT) domain of CDh (paper II and III)

- $\quad$ Copper ions in bilirubin oxidase (BOx) (paper II, III and IV)

As regards enzymatic bioelectrocatalytic oxidation and reduction, the electrode acts as one of the substrates, behaving as electron acceptor or donor, respectively (Milton and Minteer, 2017). However, the enzyme cannot establish direct communication with the electrode in every case, owing to the fact that the active site of some enzymes appears to be deeply buried within the protein, at a distance that does not allow proper electric communication with the electrode (Bartlett et al., 1988; Barton et al., 2001; Masa and Schuhmann, 2016). Therefore, the design of the bioelectrochemical systems developed in this work has been adapted to a particular biocatalyst, as explained below.

\section{Anodic enzymes}

\section{Glucose oxidase}

$\mathrm{GOx}$, i.e. $\beta$-D-glucose:oxygen-1-oxidoreductase, is the anodic enzyme used in paper I. In the paper, GOx from two different fungal species, viz. Aspergillus niger and Penicillium amagasakiense, were used. Both oxidoreductases are globular proteins with an average diameter of $8 \mathrm{~nm}$ (Bourdillon et al., 1980; Wilson and Turner, 1992). The enzyme is a dimer composed of two identical subunits, each containing two FAD cofactors. The FAD is bound tightly in GOx and undergoes reduction and oxidation without dissociating from the apoenzyme (Swoboda, 1969). 
GOx catalyses the oxidation of $\beta$-D-glucose to glucono- $\delta$-lactone, which subsequently hydrolyses spontaneously to gluconic acid (Leskovac et al., 2005). The two protons and electrons gained from glucose oxidation fully reduce the FAD cofactor to $\mathrm{FADH}_{2}$, that in turn is re-oxidised by reducing oxygen to hydrogen peroxide (Figure 4) (Wilson and Turner, 1992).

In addition to oxygen, the enzyme GOx can be oxidised by a large number of other electron acceptors. In paper I, an organic salt, tetrathiafulvalene-tetracyanoquinodimethane (TTF-TCNQ) is used as diffusional electron acceptor that shuttles the electrons from the active site of the enzyme to the surface of the developed electrodes, carrying out mediated electron transfer (MET) (Chaubey and Malhotra, 2002; Pauliukaite et al., 2007). In this organic salt, TTF is an electron donor and TCNQ is an acceptor (Jaeger and Bard, 1980).

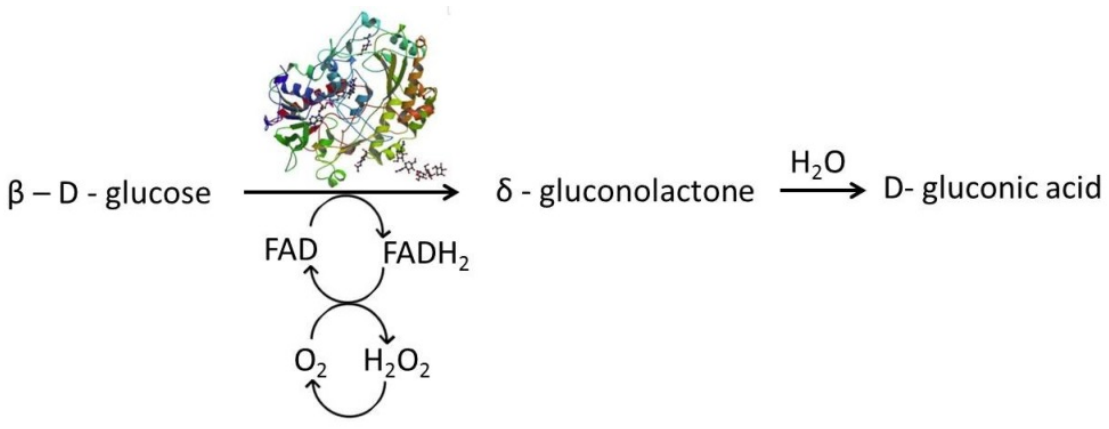

Figure 4. Catalytic mechanism of GOx. Glucose oxidation is coincidental with $F A D$ reduction (PDB file for $G O_{x}$ image: $\left.{ }_{1} C F_{3}\right)$. 
In paper I, a specifically engineered GOx from Penicillium amagasakiense (Courjean and Mano, 2011; Suraniti et al., 2013) is used with the purpose of catalytic efficiency towards glucose, and decreasing Michaelis constant, $K_{\mathrm{M}}$, in order to improve the performance of the bioanode when subjected to low glucose concentrations.

\section{Cellobiose dehydrogenase}

$\mathrm{CDh}$, is an extracellular oxidoreductase secreted by wood degrading fungi (Henriksson et al., 2000). Cellobiose is the natural substrate of $\mathrm{CDh}$. CDh is a monomeric enzyme composed of two domains: Dh and CYT. The former is the catalytically active domain since it contains the redox active cofactor FAD. The cofactor is non-covalently bound to Dh and it is nested within the protein structure (Tan et al., 2015).

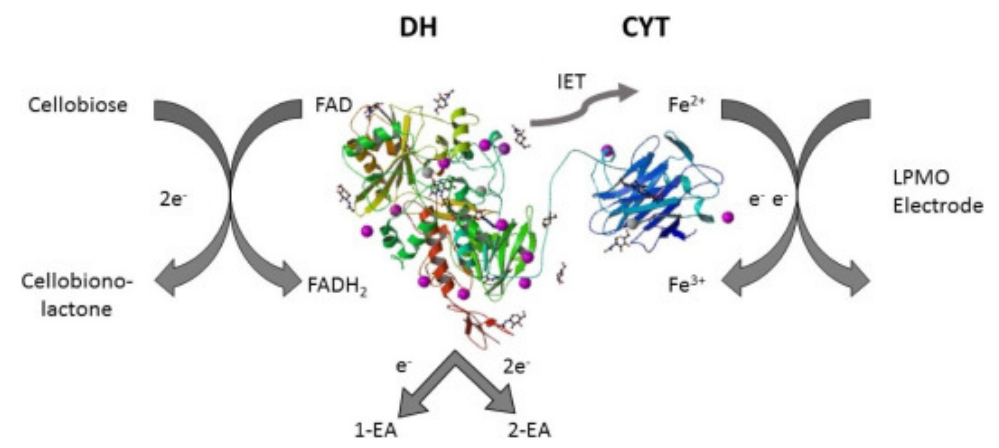

Figure 5. The catalytic mechanism of CDh from Neurospora crassa ( $\mathrm{NcCDh}$ ) in which two electrons are obtained from the carbohydrate oxidation and transferred to the FAD cofactor present in Dh domain and thereupon transferred to one or two electron acceptors (I-EA and 2-EA) or to the CYT domain which transfers one electron at a time either to an LMPO or to an electrode (Grippo et al., 20I7). 
The Dh domain is connected by a flexible linker to a CYT domain (Zámocký et al., 2008). To re-oxidase $\mathrm{FADH}_{2}$ to $\mathrm{FAD}$, CYT plays an important role, acting as an electron mediator, with an iron containing heme group. This metal ion interconverts between $\mathrm{Fe}^{2+}$ (reduced) and $\mathrm{Fe}^{3+}$ (oxidised) states in order to transfer electrons (Henriksson et al., 2001) from the Dh domain to an electron acceptor. The two domains are separated by a distance of $9 \AA$, allowing efficient intramolecular electron transfer (IET) (Tan et al., 2015).

$\mathrm{CDh}$ catalyses the oxidation of cellobiose to cellobionolactone, while gaining two electrons. When present in wood degrading fungi, $\mathrm{CDh}$ transfers the two electrons to electron acceptors, lytic polysaccharide monooxygenases (LMPOs), as a consequence of the oxidation reaction (Figure 5) (Flitsch et al., 2013).

In papers II and III, CDh from ascomycete Corynascus thermophilus $(\mathrm{Ct} \mathrm{CDh})$ was used as anodic enzyme to oxidise glucose, since $\mathrm{Ct} \mathrm{CDh}$ is known to be a variant with high catalytic activity for this substrate at neutral pH (Coman et al., 2010). CtCDh was able to communicate with the electrode without mediators, in a direct electron transfer (DET) reaction. The two protons and two electrons gained from glucose oxidation fully reduce the FAD cofactor to $\mathrm{FADH}_{2}$ (Zámocký et al., 2008).

\section{Pyrroloquinoline quinone-glucose dehydrogenase}

$\mathrm{GDh}$, i.e. D-glucose: (pyrroloquinoline-quino) 1-oxidoreductase, is a dimeric quinoprotein with two identical subunits that require the presence of a quinone as cofactor to act as a catalyst (Oubrie et al., 1999), and the quinone, PQQ, acts as a redox shuttle (Laurinavicius et al., 2004). PQQ dependent GDh has been broadly used to replace GOx (Tsujimura et al., 2006) because GDh does not rely on molecular oxygen as the electron acceptor (Schubart et al., 2012). 


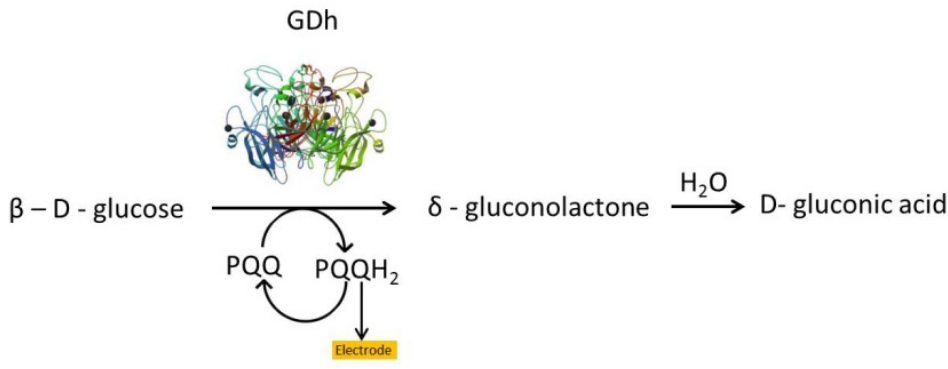

Figure 6. Catalytic mechanisms of PQQ-GDh (PDB file for PQQ dependent GDh image: $5 \mathrm{MIN}$ ).

The enzyme oxidises a broad range of carbohydrates to the corresponding lactones, with concomitant reduction of PQQ to $\mathrm{PQQH}_{2}$ and it is able to donate electrons to various artificial electron acceptors (Figure 6) (Matsushita et al., 1989; Oubrie et al., 1999). In paper III, PQQ-GDh was used as anodic enzyme for glucose oxidation and DET was achieved between the enzyme and the surface of the electrode, corroborating previous reports (Murata et al., 2009; Razumiene et al., 2006; Zayats et al., 2005).

\section{Cathodic enzyme}

\section{Bilirubin oxidase}

$\mathrm{BOx}$, with the systematic name bilirubin:oxygen oxidoreductase, is a monomeric redox enzyme that belongs to the group of multicopper oxidases (MCOs) (Shleev et al., 2005). Specifically, BOx is a MCO that carries four copper ions, i.e. T1, T2 and the binuclear T3 site (Milton and Minteer, 2017; Shimizu et al., 1999; Shleev et al., 2005; Solomon et al., 1996). T1 is the copper ion that accepts electrons from reduced substrates or electrodes, consecutively transferring electrons via an IET pathway to the T2/T3 cluster (Ramirez et al., 2008). The latter cluster is finally responsible for the four-electron reduction of oxygen to water (Figure 7) (Cracknell et al., 2011; Shimizu et al., 1999). 
MCOs, and specifically BOx, have been widely used as cathodic enzymes for oxygen bioelectroreduction in BFCs (Coman et al., 2010; Coman et al., 2008; Falk et al., 2012a; Falk et al., 2012b; Wang et al., $2012 \mathrm{~b})$. In this work, $\mathrm{BOx}$ from Myrothecium verrucaria (MvBOx) has been used in papers II and III in EFCs, and in paper IV in a solar biosupercapacitor.
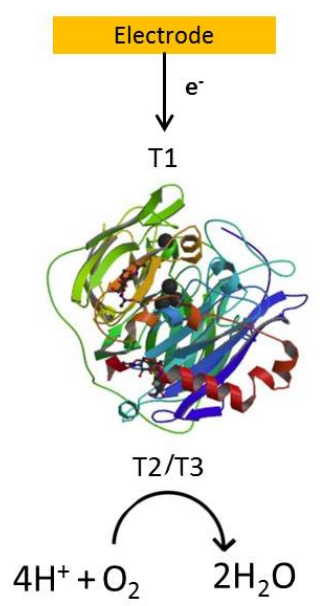

Figure 7. Catalytic mechanism of $B O x(P D B$ file for $B O x$ image: $2 X L L)$.

\section{Organelles}

The term organelle refers to specialised subunits within eukaryotic cells that carry out specific functions (Kerfeld et al., 2005). One of these specialised subunits, thylakoids, are responsible for the light-dependent reactions during photosynthesis (Govindjee et al., 2016). Thylakoids consist of a thylakoid membrane (TM) and thylakoid lumen. In this thesis, thylakoid membranes were immobilised on an electrode surface to obtain DET (paper IV).

A thylakoid membrane carries photosynthetic pigments and integral proteins including photosystems I and II, ATP synthase, a cytochrome b6f complex, and mobile electron carriers, such as plastoquinone and 
plastocyanin (Figure 8). According to a previously published investigation (Rasmussen and Minteer, 2014), electrons from the first five photosynthesis ET steps are donated to electrodes with immobilised TM.

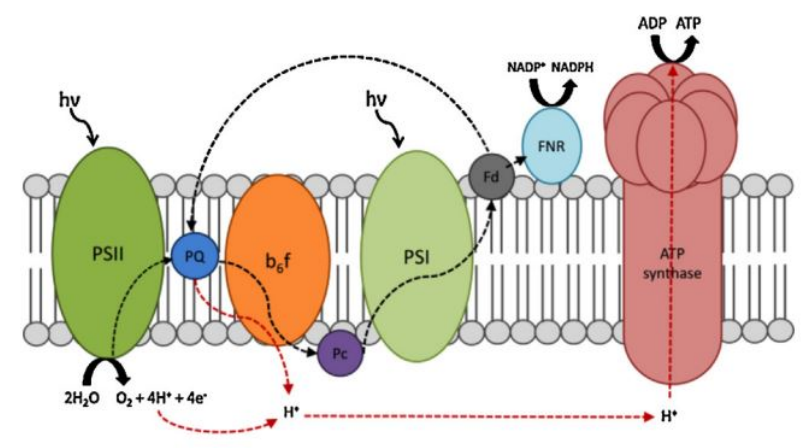

Figure 8. Schematic representation of TM with the components involved in the light-dependent reactions of photosynthesis. Dashed black arrows: electron flow; dashed red arrows: proton flow (Rasmussen and Minteer, 20I4).

Even when the biological components are deemed as suitable materials to catalyse reactions of interest, their usage might be hampered by limited long-term stability (Bornscheuer, 2003) due to chemical, thermal (Jesionowski et al., 2014) or mechanical changes. As detailed below, the particular procedure employed to immobilise biocatalysts to or within the supports is crucial to overcome stability and ET limitations, and to ensure performance enhancements of the biodevices.

\section{Immobilisation of biocatalysts}

The process of immobilisation involves attachment of a biocatalyst on a conductive surface to generate heterogeneous biocatalytic systems. The main objective of immobilisation is to secure the most robust and stable composite, to avoid perturbation when the overall conditions change. 
There are different types of immobilisation procedures (Figure 9), of which the following have been used in the current work:

- Physical absorption in which a physical interaction is established between the electrode surface and the biocatalyst. This interaction includes intramolecular interaction forces, ionic interactions and hydrogen bonding, and hence the immobilisation will be less robust (Datta et al., 2013; Haider and Husain, 2008; Sardar and Gupta, 2005).

- Covalent immobilisation methods based on the reaction between enzyme amino acid side chains, e.g. arginine, aspartic acid or histidine, with functional groups present on the surface of the electrodes that have been chemically modified. This type of immobilisation is stronger and avoids leakage of the biocatalyst (Sheldon, 2007).

- Physical entrapment with biopolymers, specifically with gelatine which is a protein-based hydrocolloid material (Datta et al., 2013; Sheldon, 2007) that retains the biocatalysts.

- Crosslinking, specifically with glutaraldehyde, a molecule that contains two aldehyde groups that can form covalent imine bonds with amine groups from two different enzyme molecules (Figure 10) (Szamocki et al., 2007). This process generates a network of cross-linked enzymes.

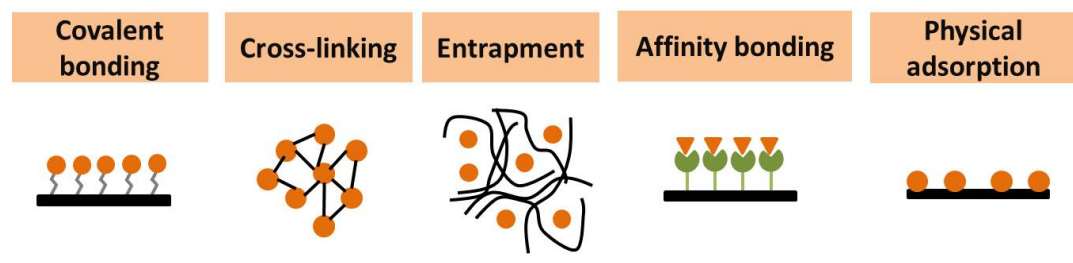

Figure 9. Schematic representation of the different protein immobilisation procedures. 
In paper I. a GOx solution was dropped on the electrodes, enzyme molecules were crosslinked and physically entrapped in a protective layer of gelatine.

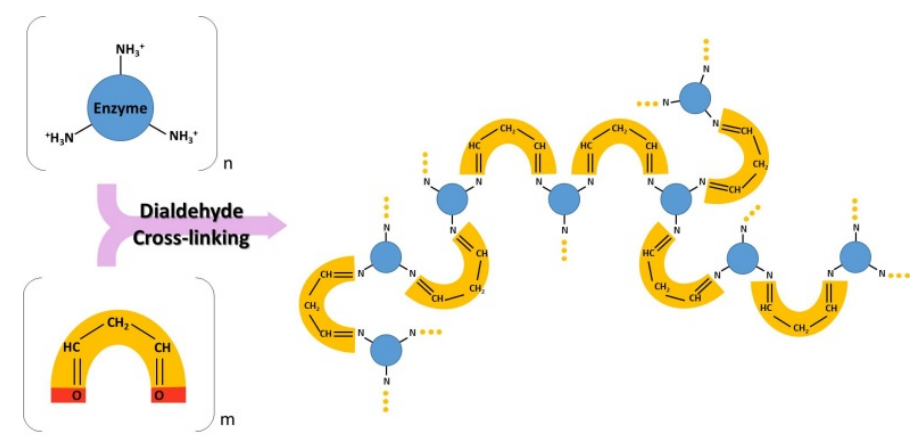

Figure Io. Chemical reaction that leads to crosslinking of enzymes generating a copolymer enzyme-glutaraldehyde.

In papers II and III, CDh was covalently attached using aspartic and glutamic acid residues present on the enzyme that were exposed to a carbodiimide coupling agent and an auxiliary nucleophile (Figure 2, top of paper II). The reactants used were 1-ethyl-3-(3dimethylaminopropyl)carbodiimide (EDC) and N-Hydroxysuccinimide (NHS) to generate an ester on the protein. The active ester present on the protein can then react with amino groups on the chemically modified [(3-aminopropyl)triethoxysilane (APTES)] electrode surface. Both, EDC and NHS are water soluble and can be used in aqueous media. There is the risk that the NHS esters formed on the protein molecule may couple to other proteins. A different covalent immobilisation protocol was used in the same papers for the cathodic biocatalyst $\mathrm{BOx}$ and for the anodic enzyme PQQ-GDh (Figure 2, bottom of paper II). In this case, the surface was chemically modified with (3-glycidyloxypropyl)trimethoxysilane (GLYMO) and hydroxylated epoxy groups are expected to bind to amino groups present on PQQ-GDh or BOx surfaces by generating secondary amino groups (Abad et al., 2002). 
Once the proper biocatalysts are selected and appropriate immobilisation protocols are developed and optimised, the resulting bioelectrocatalytic systems can be used to configure different biological power sources, as explained further below.

\section{Classification based on operational principle}

Biological power sources can be classified in two groups, viz. BFCs and biosupercapacitors (BSCs), Figure 11. BFCs can be conventional and also charge-storing, when low and high capacitive bioelectrodes are used, respectively. BSCs are devices based on highly capacitive electrodes. Based on charging principles, these biodevices can be classified as self-charging and conventional (without the ability to selfcharge) electric power sources.

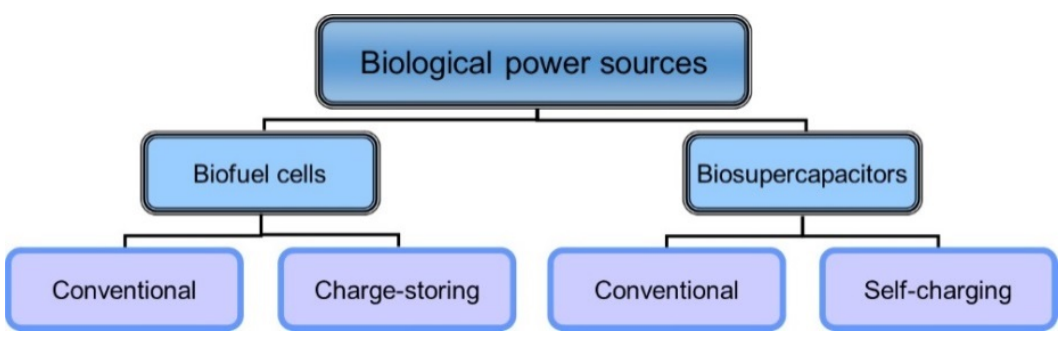

Figure II. Classifications of electric power biodevices based on operational principle.

\section{Biofuel cells}

As already mentioned, BFCs are power sources able to convert chemical energy to electric energy using a biological material present on one electrode, at least (Shleev et al., 2015), and usually at two electrodes. On one of the electrodes the biomaterial catalyses the oxidation of a certain biofuel and on the other electrode a different biocatalyst catalyses the reduction of a biooxidant. In this way, flows of electrons 
and ions are established through the external circuit and the electrolyte, respectively, as a consequence of the redox reactions taking place on both electrodes.

The difference between the equilibrium redox potential of a halfreaction and the potential at which the redox reaction is actually observed, is called overpotential (Madan, 2015). In order to improve voltage and power outputs of BFCs, one should select enzymes with the lowest overpotentials for the oxidation and reduction reactions, thus maximising the voltage, current, and power outputs of biodevices (Figure 12).
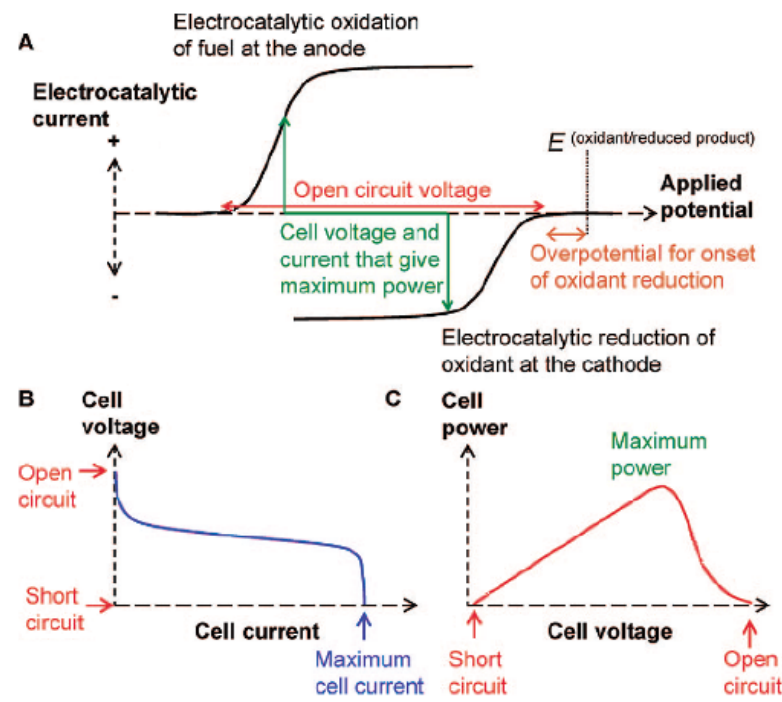

Figure I2. Features that determine the performance of an EFC (Adapted with permission from (Cracknell et al., 2008). Copyright 2008 American Chemical Society). 
It is known that BFCs deliver low power/current density but this is not a serious limitation if the goal is to apply BFCs as power sources for low energy demanding devices, such as biosensors or other low energy consuming electronics (Barton et al., 2004; Gellett et al., 2010). Smart approaches have already been developed, e.g. self-powered sensors that use the analyte to be detected, as the fuel for the anodic electrode (Grattieri and Minteer, 2018; Katz et al., 2001).

\section{BFCs as power sources for wearable devices}

Personalised medicine is being established as a way of improving the quality of life of patients by self-monitoring, employing user-friendly biomedical devices. Among the bioelectronics that are being designed and developed, wearable devices seem to be a convenient alternative, since they can be worn by the user with minimal invasion and no requirement of expertise skills (Bandodkar, 2017; Falk et al., 2012a; Katz et al., 2015; Willner and Katz, 2006).

The proposed wearable devices rely on microelectronics that need to be suitably powered. A promising option is to implement energy sources able to harvest electrical energy from chemical energy available in physiological settings. In this thesis, the focus is on potential applications of transparent, flexible, and nanostructured biological power sources for wearable devices, such as smart electronic contact lenses. On a self-contained ocular device, a tear-based biological power source would generate stable power in pulse mode during several hours as shown in paper III. However, apart from space limitations, other issues, including consumption of biofuels and the biooxidants, must be accounted for. The low concentration and low restoration rates of biofuels present in tears leads to low power output by the EFC, when performing in continuous mode.

In an ideal prototype of a smart electronic contact lens, an embedded sensor would detect a particular analyte relevant for the subject and forward the information wirelessly to a receiver. The sensor can detect the analyte, and act as one of the electrodes of the EFC at the same 
time. In this way the device is generating energy while detecting/consuming the analyte. Several biofuels are available in human lachrymal fluid, e.g. glucose, dopamine, ascorbic acid, while molecular oxygen is the biooxidant (Falk et al., 2012a).

Different strategies have been adopted to overcome problems regarding the power output needed to sustain the performance of the biodevice. The direction that our research group promotes is the development of thin, flexible and transparent biological power sources able to work in pulse mode, taking advantage of the capacitive features of the electrodes (Pankratov et al., 2014a; Pankratov et al., 2014b). Biological power sources, assembled with highly capacitive electrodes constitute BSCs, a term that is explained in more detail below.

\section{Biosupercapacitors}

A conventional capacitor is an element of an electrical circuit composed by two metal sheets or plates, separated by a dielectric material, that can be polarised by applying an electric field (Winter and Brodd, 2004). Therefore, in a conventional capacitor a potential has to be applied externally to accumulate opposite charges on each plate, see Equation 1:

$C=\frac{Q}{E}$

While the charging process is taking place, an excess of electrons appears at one plate and a deficiency of electrons (excess of electron holes) on the other one. In this type of capacitor, charges are accumulated uniquely in the electric field between the plates (Winter and Brodd, 2004).

Supercapacitors, also named electrochemical capacitors, do not have a dielectric material but an electrolyte ionically connecting the plates. Once the external voltage is applied, a charging process is initiated and the electrodes are polarised, accumulating positive charges on the positive electrode and negative charges on the negative electrode (Wang et al., 2012a; Winter and Brodd, 2004). 
A unique feature of the biosupercapacitors in the present work is that there is no need to apply an external voltage to charge these devices since the immobilised enzymes polarise both plates by catalysing redox reactions that leads to an accumulation of charges of opposite sign on the electrodes. The capacitive features, viz. ability to store electric charges, of biosupercapacitors rely on different types of capacitance based on reversible charge-transfer reactions (pseudocapacitance) and/or electric double layer capacitance (Pankratov et al., 2014a; Pankratov et al., 2014b) as in the "non-bio" electrochemical capacitors.

The capacitance of the electrodes for biological power sources is tightly related to the materials used to construct them.

In order to understand the different types of capacitance and the criteria to select the appropriate capacitive material for electrodes, some important theoretical concepts are clarified below.

\section{Electrical double layer}

When any type of electrode is immersed in an electrolyte solution, a specific interfacial region, the double layer, is formed. The electrical properties of this layer influence the electrochemical measurements. In the electrochemical setup used to measure the current that flows at a working electrode (WE), the electrical double layer (EDL) can be considered as a capacitor. This EDL capacitor must be charged in order to obtain a desired potential at the WE. This involves the flow of a capacitive current in the electrical circuit, not related to any redox process. The capacitive current can be used for analytical purposes since it incorporates information about the double layer (Bak et al., 2011; Kyotani et al., 1996; Wang et al., 2012a).

There are several models published in the literature to describe the structure of the double layer, but there is no general model that applies to all cases. The combination of several factors, such as type of material of the WE, type of solvent or supporting electrolyte, determine the structure of the double layer. 
Helmholtz was first in introducing to the scientific community the concept of a double layer at the surface of a metal in contact with an electrolyte. His model included a compact layer of ions in contact with the charged metal surface. Gouy and Chapman proposed later a model that includes a diffuse double layer in which the ions move to certain distance from the surface of the electrode. The physicist Stern described the double layer with a model that combined the two previous ones, the rigid Helmholtz layer and the diffuse layer of Gouy and Chapman. Many more models followed later, to complete the description of the double layer (Pletcher and Editor, 2009).

A simplified model is shown in Figure 13 including two planes as proposed by Helmholtz:

- Inner Helmholtz plane (IHP): electrode surface reached only by solvent molecules. It is formed by specifically adsorbed ions.

- Outer Helmholtz plane (OHP): formed by charged species that can approach the electrode just to certain distance since they are anions and cations surrounded by solvent molecules.

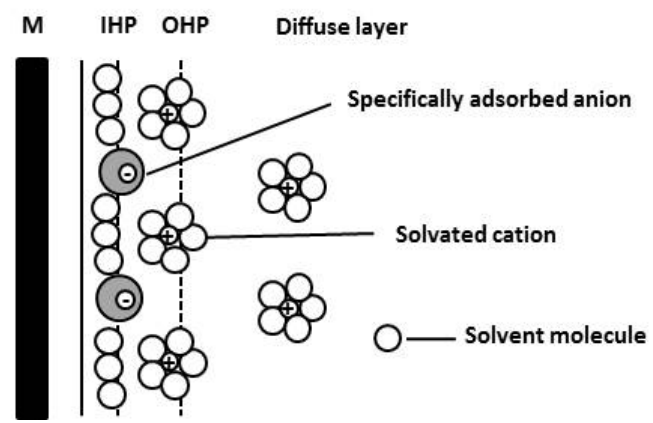

Figure 13. Scheme representing the different layers within the electric double layer (M= metal). 


\section{Faradaic and non-faradaic processes}

The reactions governed by Faraday's law (Equation 2) are called faradaic processes. In these reactions the charges are transferred across the electrode-solution interface due to the ET that constitutes oxidation or reduction reactions.

$$
I \times t=n \times z \times F
$$

Where $I$ is current; $\mathrm{t}$ is time; $n$ is the number of moles of the product; $z$ is the valency of ions of the product; $F$ is Faraday's constant equivalent to $96500 \mathrm{C} \mathrm{mol}^{-1}$.

Non faradaic processes do not involve charge-transfer reactions. However, they take place when a changing potential or solution composition modifies the structure of the electrode-solution interface, due to adsorption or desorption processes that translates to external current flow even though charge does not cross the interface (Bard and Faulkner, 2001).

Hence, the following classification for capacitors based on type of capacitance can be established (Frackowiak and Beguin, 2001; Wang et al., 2012a; Zhang and Zhao, 2009):

- Electric double layer capacitors (EDLCs): store energy by accumulating ions present in the electrolyte, physically absorbed/desorbed to form a double layer on electrodes with specific surface area. In this case charges are stored electrostatically.

- Pseudocapacitors: in this case charges are stored electrochemically by faradaic redox reactions with chargetransfer between the electrolyte and the electrode.

- Hybrid capacitors: combine an electrode that store charges electrochemically with an electrode that store them electrostatically (Pankratov et al., 2014a). 


\section{Capacitive nanostructured materials}

The selection of the proper conductive and capacitive materials is relevant in order to maximise the capacitance of the devices.

The capacitance of the electrodes for BSCs strongly depends on the surface area of the electrode, accessible to the electrolyte. There are three general groups of materials used in this work for BSCs:

- Carbon based materials with high specific surface area. These materials have the advantage of being abundant, inexpensive, and easy to produce. In addition they are non-toxic with excellent electric conductivity, combined with high chemical stability and wide operating temperature range (Kyotani et al., 1996; Ruiz et al., 2007). They store charges mostly in an ECDL at the electrode/electrolyte interface, and hence, the capacitance depends largely on the surface area accessible to the electrolyte ions (Wang et al., 2012a). Multiwall carbon nanotubes (MWCNTs) and graphene flakes are high surface area carbonbased materials used in paper I.

- Conducting polymers are faradaic materials. They are inexpensive, have high conductivity in an appropriately doped state, high voltage window and high storage capacity (Kalaji et al., 1999). Conducting polymers show capacitive behaviour through redox processes; when oxidation takes place, ions are transferred to the polymer backbone and when reduction occurs, ions are released to the electrolyte. These redox reactions take place in the entire polymer bulk, not just on the surface (Wang et al., 2012a). In paper I, the conductive polymer poly(3,4-ethylenedioxythiophene) (PEDOT) was used. When PEDOT is electrochemically deposited on an electrode, a highly porous amorphous film is obtained, which allows higher capacitance values than for electrodes based on activated carbons ( $\mathrm{Li}$ et al., 2005). In paper I, a combination of 
capacitance through redox processes and through ECDL was accomplished by forming a PEDOT-graphene composite.

- Metal oxides can provide higher energy density for electrochemical supercapacitors than conventional carbon materials, and metal oxides are more stable than conducting polymers (Wang et al., 2012a). They store energy electrostatically, but also support electrochemical faradaic reactions between electrode and ions within an appropriate potential window (Bak et al., 2011). The metal oxide chosen has to be electrically conductive and two or more oxidation states must be accessible. When electrodes where constructed using metal oxide nanoparticles (NPs), as in paper II, III and IV with ITONPs, the ability of storing charges in both faradaic and non-faradaic modes was promoted.

In addition to capacitance, important features of supercapacitors in our studies were operational stability (when applying several charge/discharge cycles) and transparency. In the case of biosupercapacitors, as already mentioned, there is no need of applying an external voltage since the biocatalysts polarise the electrodes. In paper I with a capacitive bioanode and in paper III with an EFC/biosupercapacitor, self-charging of the cells was monitored with potentiometry at zero current. Discharge was triggered by applying a potential pulse using amperometry (paper I) or by connecting the circuit to an external resistor (paper III and IV). The electroanalytical methods are explained in the next section. 


\section{EXPERIMENTAL METHODS}

\section{Microscopy}

\section{Atomic force microscopy}

Atomic force microscopy (AFM) is a tool that allows the visualisation at the nanoscale. It works by raster scanning a surface with a sharp tip (the radius of its apex is typically in the range of a few nanometers) attached at the free end of a soft micro-cantilever. In most AFM setups, the sample is placed on top of a piezoelectric tube (the scanner), so that its position can be controlled with sub-nanometer precision. A similar precision is achieved in the monitoring of the deflection of the cantilever, commonly with an optical detection system.

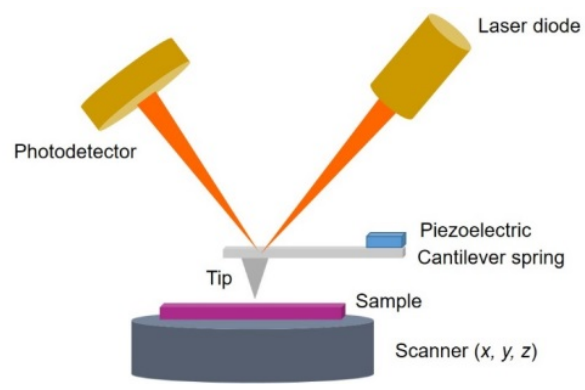

Figure 14. AFM experimental setup. 
This consists in focusing a laser beam on the free end of the cantilever, and monitoring the reflected beam with a segmented photodetector (Figure 14). Both the positioning system and the photodetector signals are connected to an electronic unit that is computer-controlled. AFM can be operated in a variety of modes.

In this thesis, tapping mode has been used. In tapping mode, the amplitude of the oscillation of the micro-cantilever, and thus the average distance between tip and sample, is kept constant while scanning the sample by adjusting its vertical position during the process. The topography of the sample is then reconstructed by inverting its vertical movements during the scan.

AFM has been used in this thesis as a useful tool to characterise nanostructured surfaces. In paper II (supporting information), 2D and 3D representations of the nanostructured surface of electrodes were obtained, with the corresponding height profiles. This characterisation allowed the determination of the thickness and degree of uniformity of the layer of ITONP used to nanostructure the electrodes.

\section{Scanning electron microscopy}

Scanning electron microscopy (SEM) uses an electron beam to scan the surface of the sample. The atoms of the sample become excited by the electron beam, emitting secondary electrons. An electron detector collects the secondary electrons that allows rendering of an image (Figure 15). 


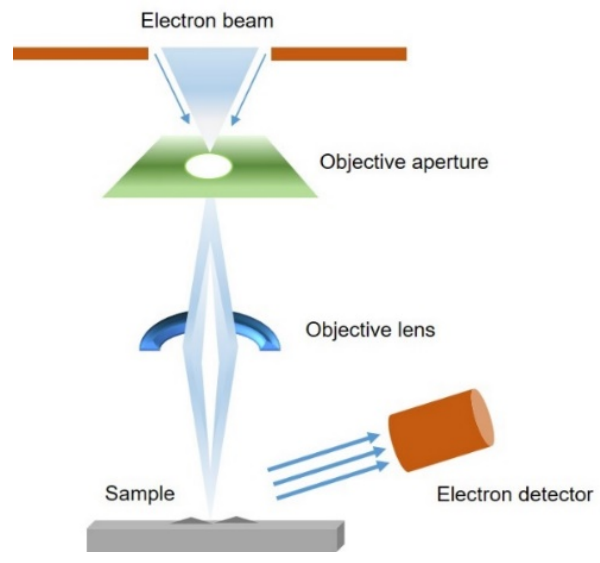

Figure 15. Simplified scheme of SEM experimental setup.

In papers I and II SEM images allowed us to characterise the conductive nanostructured surfaces used in our studies. Samples were characterised in high vacuum mode.

\section{Spectral methods}

While there are several spectral methods, widely used in research nowadays, ultraviolet-visible (UV-Vis) spectrophotometry was exploited in this thesis.

\section{Ultraviolet-visible spectrophotometry}

Spectrophotometry is the quantitative measurement of absorption and transmission properties of materials as function of wavelength. The absorption of UV-Vis radiation by a material involves the excitation of electrons in atoms and molecules. The light will be absorbed just if it has the amount of energy needed to excite the electrons from a lower to a higher energy level. The wavelength of light that has the energy required to cause one of the electronic transitions will be absorbed. UVVis spectrophotometry was used in this thesis to measure the absorbance of light by a sample, performing scans within a certain range of the spectrum. The UV light region appears in the wavelength 
range $c a \cdot 190-400 \mathrm{~nm}$ and the visible light in the range $c a \cdot 400-800 \mathrm{~nm}$. Absorption and transmission spectra have been obtained and interpreted in some of the papers in this thesis. Specifically, in paper I and II, UV-Vis spectrophotometry has been used to evaluate the transmittance and absorbance of the different conductive surfaces used to shape transparent electrodes.

\section{Electrochemical methods}

Electrochemical methods have been employed to study different systems in this work. In order to apply these methods and interpret the obtained results it is important to understand fundamental principles of electrode reactions and the electrical properties of electrode-solution interfaces.

Parameters, such as electrochemical potential, standard potential and formal potential are important terms in electrochemistry, as explained below.

\section{Electrochemical potential}

For a better understanding of electrochemical potential, firstly the definition of chemical potential has to be considered. From a thermodynamic point of view, the chemical potential is the rate of change of the free energy needed to be cumulated or released by a species during a chemical reaction or a phase transition (Huebner and Barfield, 2014). Generally, there is a tendency to move from a higher energy level to a lower energy level, releasing free energy. However, in the term "chemical potential" the electric forces that are present in the surroundings of an ion, influencing its motion, are not considered. Consequently, the electrochemical potential includes the energy contribution of electrostatics in addition to the energy quantity determined by the chemical potential. In electrochemistry, ions move from a region with higher electrochemical potential to a region with lower electrochemical potential. 


\section{Standard potential}

Specifically and by convention, the standard potential $\left(\mathrm{E}^{\circ}\right)$ is the measure of the electrode potential for a half-reaction of a redox process under standard conditions, i.e. $25{ }^{\circ} \mathrm{C}$, at $1 \mathrm{~atm}$ pressure and with solutes at an effective concentration of $1 \mathrm{~mol} \mathrm{dm}^{-3}$ (Bard and Faulkner, 2001). The potential in electrochemical experiments can be driven at the electrode (by an external power supply) to negative potentials causing the electrons to reach levels of energy high enough to be transferred to empty electronic states on species present in the electrolyte. This flow of electrons from the electrode to the electrolyte is a reduction current. Alternatively, the potential can be driven to positive potentials so the electrons on species present in the electrolyte will transfer to the electrode for a more favourable energy level, that translates into a flow of electrodes from the electrolyte to the electrode, which is an oxidation current (Bard and Faulkner, 2001). The potentials, at which these oxidation and reduction processes take place, are tightly related to the standard potential of a chemical species. The standard potential of a cell or half-reaction is obtained under conditions, where all species are in their standard states (Bard and Faulkner, 2001).

\section{Formal potential}

The formal potential $\left(\mathrm{E}^{\circ}\right.$ ) relates to specific conditions, which divert from the standard conditions already mentioned.

Formal potential is a very convenient parameter to evaluate half-cell potentials since very often the activity coefficients of the chemical species involved are unknown. The formal potential incorporates the standard potential and activity coefficients, $\gamma_{i}$. 
For instance, if we consider the half-reaction:

oxidant $+e^{-} \rightarrow$ reductant

If the kinetics of ET are fast, the concentration of the oxidant ([Ox]) and the concentration of the reductant ([Red]) at the electrode surface can be assumed to be at equilibrium with the electrode potential, as governed by the Nernst equation for the half-reaction, which includes concentrations instead of activities and formal potential instead of standard potential:

$$
E=E^{0}+\frac{R T}{n F} \ln \frac{a_{o x}}{a_{\text {red }}}=E^{0}+\frac{R T}{n F} \ln \frac{\gamma_{o x}[o x]}{\gamma_{\text {red }}[\text { red }]}
$$

Which is

$E=E^{0 \prime}+\frac{R T}{n F} \ln \frac{[o x]}{[\text { red }]}$

Where

$E^{0 \prime}=E^{0}+\frac{R T}{n F} \ln \frac{\gamma_{O x}}{\gamma_{\text {red }}}$

The way of determining values of standard potentials for half-reactions and cells is by measuring formal potentials values at different ionic strengths and extrapolating them to zero ionic strength, where the activity coefficients are close to unity (Bard and Faulkner, 2001).

\section{Open circuit potential and voltage}

Open circuit potential (OCP) and open circuit voltage (OCV) are the difference of potential between two terminals, when no external electric current flows between the terminals. It implies that a pair of redox forms linked by a given half-reaction (redox couple) is present at each electrode, establishing a true equilibrium. 
For instance, two half-reactions in the case of glucose/oxygen BFCs are the following:

gluconolactone $+2 \mathrm{H}^{+}+2 e^{-} \rightarrow$ glucose

$\mathrm{O}_{2}+4 \mathrm{H}^{+}+4 e^{-} \rightarrow \mathrm{H}_{2} \mathrm{O}$

The standard redox potentials of these reactions are $-0.05 \mathrm{~V}$ and 1.23 $\mathrm{V}$, whereas the formal redox potentials (at $\mathrm{pH} 7.4$ ) are $-0.41 \mathrm{~V}$ and $0.77 \mathrm{~V}$, respectively. Both half-reactions will take place, establishing an equilibrium of electrons donated for electrons accepted and the potential at which the half-reactions takes place will determine the OCV established between the two electrodes (Equation 9):

OCV $=O C P_{\text {cathode }}-O C P_{\text {anode }}$

Indeed, the maximal OCV of a glucose/oxygen BFC is $1.18 \mathrm{~V}$.

An OCP of an electrode or OCV of a biodevice is the potential/voltage, which is measured, when a high impedance voltmeter is placed across the cell. The internal resistance of the voltmeter (e.g. a voltmeter in a potentiostat) is so high that no appreciable current passes during the measurement.

\section{Devices to study electrode reactions and to test electrochemical systems}

In the basic experimental system used in this work, an instrument called a potentiostat was used. Potentiostats are able to measure OCPs and OCVs in a two-electrode setup. Moreover, these devices are used in three-electrode setups to control the voltage across the working electrode-counter electrode (WE-CE) pair. In this way, the potential difference between the WE and the reference electrode (RE) can be maintained. Potentiostats can also be seen as an instrument that forces a certain current to flow through the WE to achieve a desired potential. Using this setup, different electrochemical techniques can be exploited to better understand bioelectrocatalytic systems. 
The next section presents some concepts regarding electrochemical cells and electrochemical systems, which were used in these studies, viz. two and three electrode systems.

\section{Two-electrode systems}

Some of the electrochemical experiments carried out in the frame of this thesis were performed using two-electrode systems. Specifically, in the cases when no external current or potential was applied to the system, connecting a bioanode as WE and biocathode as RE and just monitoring the OCP or OCV of the complete EFC or biosupercapacitor at zero current. These procedures were used in papers I, II, III and IV.

\section{Three-electrode systems}

Three-electrode systems were employed to measure potential-current relationships of the WE, which are determined by electrochemical reactions occurring at the electrode. Simultaneously, the same current must flow through the CE, at the surface of which other electrochemical reactions take place. To control the potential of the WE throughout the measurement, a third electrode, a reference electrode (RE), is used (Figure 16). Almost no current flows through the RE and its potential remains constant under all conditions so the potential of the WE can always be measured with respect to the potential of the RE (Scholz, 2005). 


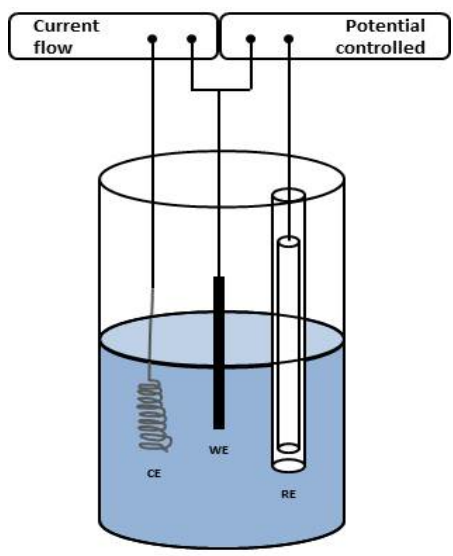

Figure 16. A three-electrode system, including WE, RE and CE.

As a consequence of an external applied potential between the RE and the WE, a current flow appears through the external circuit. The number of electrons that flow through the external circuit is measured as the total charge in Coulombs (C) passed through the circuit. The precise relationship between these two parameters is:

$C=6.24 \times 10^{18} e^{-}$

Due to the law of conservation of mass, the number of electrons that cross the electrode-solution interface are stoichiometrically related to the amount of reactant consumed and product generated. The relationship between charge and amount of product formed is given by Faraday's law (Equation 2).

Therefore, the amount of a given reactant consumed at an electrode during electrolysis is directly proportional to the quantity of electricity, which passes through the electrolyte solution. 


\section{Electrochemical techniques}

In this section, the techniques used to study the electrochemical systems and the devices mentioned above are explained.

\section{Voltammetry}

This technique involves the control of the potential of a WE to measure the resulting current flow through the system, providing useful information on the redox reactions of the system. Some of the most common applications are linear sweep voltammetry (LSV), where the potential is linearly varied over time, and cyclic voltammetry (CV), where the potential is scanned as in LSV and then continued in the reverse direction. In $\mathrm{CV}$, the process of potential cycling can be repeated as needed (Pyun et al., 2012).

$\mathrm{CV}$ allows the characterisation of processes occurring at the electrode surface or at the electrode-solution interface. It is a good technique for determination of absorbed intermediates at different potentials, and for getting information about the reaction mechanisms and electrocatalytic activity of the electrode or species absorbed on it (Pyun et al., 2012).

One can get information regarding the reversibility or irreversibility of the processes just by applying a difference potential to the WE linearly with time at constant rates. Herein, these techniques have been used to uncover the mechanisms of the ET of redox enzymes and some of the thermodynamic properties, e.g. redox potential. For electrodes with immobilised enzymes, it is also possible to control the direct ET between the enzyme and the electrode by applying different potentials. In papers I, II, III and IV, CV was used to characterise the faradaic and non-faradaic processes taking place at the electrode surfaces. In paper I and III, CV was applied at different scan rates and used to calculate the capacitance density $\left(\mathrm{C}_{\mathrm{a}}\right)$. 
Taking into account the asymmetrical character of the CV traces obtained, integral areas, which represent the sum of both anodic $\left(\mathrm{q}_{\mathrm{a}}\right)$ and cathodic $\left(\mathrm{q}_{\mathrm{c}}\right)$ charges, were calculated according to Equation 11:

$C_{a}=\frac{Q}{2\left(E_{1}-E_{2}\right) A}$

Where $C_{\mathrm{a}}$ is the capacitance density, $Q$ is the charge; $A$ is the geometric surface area of the electrode; $\left(E_{2}-E_{1}\right)$ is the width of the applied potential window.

In paper I (supporting information), LSV was performed to monitor the increase of bioelectrocatalytic oxidation current of the anode, immersed in artificial human tears.

\section{Amperometry}

Amperometric techniques are based on the application of a potential while current is recorded as a function of time (Bard and Faulkner, 2001). This technique is also known as current transient technique. In single-potential amperometry, a certain potential is applied to WE and a current change with time is recorded. The applied potential can be known, when using a RE, or unknown, when using a pseudo-RE.

In paper I, amperometry is used to monitor the variation of bioelectrocatalytic current of the electrode when adding different concentrations of the substrate that the immobilised GOx is able to oxidise, when applying a constant potential higher than the potential for substrate oxidation. Additionally, amperometry was employed to discharge the bioanode by applying a constant potential. The resulting discharge curve was used to calculate the total charge stored in the electrode by integrating the area of the first discharging cycle and applying Equation 12:

$$
Q=\int I d t
$$


In paper III, amperometry was used to record and compare the bioelectrocatalytic currents obtained for the anodic biocatalysts $\mathrm{CDh}$ and PQQ-GDh, when adding different concentrations of glucose and when applying a constant potential. In papers II and III, the polarisation curves for the optimised EFC were obtained by applying constant potentials from OCV of the cell $(0.67 \mathrm{~V})$ to $0.01 \mathrm{~V}$ with $0.05 \mathrm{~V}$ step, monitoring and recording the steady-state currents at each applied potential.

\section{Potentiometry}

In this technique, a constant current is applied to the WE causing a variation of the potential that is monitored against a $R E$ as function of time (Pyun et al., 2012). In this work, potentiometry has been used at zero current as a way of monitoring the OCP or OCV of different electrodes with immobilised biocatalysts.

The charge and discharge dynamics of biofuel cells and biosupercapacitors can be characterised by measuring the voltage potentiometrically, while allowing charging of the system, and then applying a discharge step. In the systems characterised in this thesis, there is no need of applying any charging input since the biocatalysts immobilised on the electrodes allow the system to self-charge. For the discharge, different resistors have been used (Jiahui, 2015). In paper I, charge/discharge cycling was performed to characterise the charging dynamics of the capacitive bioanode by monitoring the OCP of the electrode against a RE. In this case, the discharge was performed by switching to the amperometric method, applying a higher potential compared to OCP. In paper III, the charge/discharge cycling was used to characterise the voltage of the complete EFC for more than 17 hours. Discharge was performed by connecting the system to an external $1 \mathrm{~K} \Omega$ resistor during $2 \mathrm{~s}$ after allowing the cell to self-charge, and monitoring the OCV at zero current potentiometrically during 600 s. In paper IV, the OCV of the biodevice was monitored while letting it self-charge during different times and discharge by applying $1 \mathrm{M} \Omega$ resistance. 


\section{RESULTS AND DISCUSSION}

\section{Summary of the research papers}

This thesis is focused on transparent, capacitive and conductive surfaces to be used to construct enzymatic electrodes, serving as efficient bioanodes and biocathodes of biological electric power sources that work under so called physiological conditions, i.e. electrolytes at $\mathrm{pH} 7.4$ containing $0.15 \mathrm{mM} \mathrm{NaCl}$ (osmolarity of about $300 \mathrm{mOsm} / \mathrm{kg}$ ).

The potential of the biodevices to be implemented on future prototypes of smart electronic contact lenses is highlighted. As stated in review I, the physiological temperature of tear fluid is about $35^{\circ} \mathrm{C}, \mathrm{pH} 7.5 \pm 0.1$, and osmolarity $318 \pm 16 \mathrm{mOsm} / \mathrm{kg}$. In spite of the fact that lachrymal fluid does contain a lot of different compounds, it is still less complex and also less corrosive than blood, with the added benefit of being available without requiring surgery. Therefore, contact lenses are attractive platforms for assembling non-invasive self-contained devices for different applications.

Along the thesis, the highest limitation to overcome was the fact of low glucose concentration in human lachrymal liquid, i.e. the electrolyte in which smart electronic contact lenses would operate. Different strategies to overcome the problem of low biofuel concentration have been presented in papers I, II and III.

In paper I, a composite with the conducting polymer PEDOT combined with graphene flakes was realised, as a way of increasing the 
capacitance i.e. the charge storage feature of the biomodified electrode. The bioanode was optimised aiming to achieve a good compromise between its capacitive features and transparency. The capacitances of PEDOT and PEDOT-graphene films were investigated and compared. The results showed a significant increase of the capacitance for PEDOTgraphene films. Different anodic biocatalysts were immobilised on the surface of the capacitive electrodes for investigating the bioelectrocatalytic currents at different glucose concentrations. The recombinant GOx mutant from Penicillium amagasakiense, showed the highest bioelectrocatalytic current output at low glucose concentrations, with a current density close to $10 \mu \mathrm{A} / \mathrm{cm}^{2}$, when operating in continuous mode. The bioanode was also tested in pulse mode in artificial human tears, providing current densities of $21 \mu \mathrm{A} / \mathrm{cm}^{2}$. Transparency values were relatively high for the optimised system, up to $83 \%$ of maximal transparency, when considering just the capacitive and bioelectrocatalytic layers.

In paper II, ITONPs were used as a way of increasing the double layer capacitance. $\mathrm{CDh}$ and $\mathrm{BOx}$ were covalently attached to the chemically modified nanostructured and transparent surface. This paper is focused on the optimisation of the nanostructuration process and chemical modification of the electrode surface for covalent immobilisation of the enzymes. Two different strategies for electrode nanostructuring were used, viz. spray-coating and drop-coating. The spray-coated biodevice showed superior characteristics since it provided a more homogeneous and higher nanostructured surface area, as confirmed by SEM, AFM, and electrochemically. The optimised biodevice with $\mathrm{CDh}$ and $\mathrm{BOx}$ biocatalysts covalently immobilised on the nanostructured surface showed an OCV of $0.67 \mathrm{~V}$ and a power output of up to $1.4 \mu \mathrm{W} / \mathrm{cm}^{2}$ at an operating voltage of $0.35 \mathrm{~V}$.

In contrast to Paper II, Paper III focuses on the development and characterisation of the biosupercapacitive feature of the ITO based device. Charging/discharging cycles were used to study the long-term stability and biodevice performance in pulse mode. BOx was used as the cathodic enzyme, immobilised using the same procedure as in paper II. However, not only $\mathrm{CDh}$ but also PQQ-GDh were used as anodic 
elements, aiming to find the more suitable biocatalyst to oxidise glucose in an electrolyte at low concentration. PQQ-GDh exhibited a lower apparent $K_{\mathrm{M}}$ value for glucose conversion and higher catalytic currents at $50 \mu \mathrm{M}$ glucose concentration, simulating the glucose concentration in human tears. The power density obtained by the optimised complete biodevice at the mentioned glucose concentration was $30 \mu \mathrm{W} / \mathrm{cm}^{2}$, when operated in pulse charge/discharge mode. This value represents a significant enhancement, when compared with the power output of $0.086 \mu \mathrm{W} / \mathrm{cm}^{2}$ achieved for the biodevice operating in continuous mode under the same conditions. Performing charge/discharge cycling with the modified flexible and transparent biosupercapacitor at $50 \mu \mathrm{M}$ glucose, generated sufficient power to drive a flexible low voltage liquid crystal display.

Review II describes recent progress in the development of biosupercapacitors - supercapacitors assembled using biological materials. It covers different aspects, from the historical development of traditional capacitors to the state of the art of the emergent biosupercapacitors.

Finally, paper IV discloses an entirely new kind of bioelectronic device a solar biosupercapacitor, which is built from a dual-feature photobioanode combined with a double-function enzymatic cathode. The biosupercapacitor is a single-compartment bio-solar cell able to convert ambient daylight into electricity, which is capacitively stored in the conversion modules. The self-charging biosupercapacitor was shaped using transparent and nanostructured, highly capacitive, ITO electrodes. Thylakoid membranes and BOx were used as anodic and cathodic biocatalysts, respectively. Both bioelements were physically absorbed on the electrode surface. The complete biodevice was tested using ambient light. When illuminated, an OCV of $0.2 \mathrm{~V}$ was obtained and the biosupercapacitor became fully charged after $c a .10 \mathrm{~min}$. At the mentioned operating voltage, the initial current density was ca. 30 $\mathrm{mA} / \mathrm{m}^{2}$. The biodevice was also tested by charge/discharge cycling, showing some degradation; the power output decreased from 6 $\mathrm{mW} / \mathrm{cm}^{2}$ to $3 \mathrm{~mW} / \mathrm{cm}^{2}$ and the charging time increased from $10 \mathrm{~min}$ up to $40 \mathrm{~min}$. 


\section{OUTLOOK}

The scientific community faces a major challenge of finding the optimum power sources for specific applications, such as wearable devices or miniaturised personal electronics. This thesis is focused on the strategies needed for the development of highly efficient and simultaneously, transparent and flexible biological power sources.

Many different research groups have been working on the optimisation of BFCs as power sources for the purposes stated.

Conventional fuel cells rely on expensive precious-metal catalysts or operate on fossil fuels, whereas in BFCs the energy conversion is driven by biological catalysts that appear to be a more sustainable option (Leech et al., 2012; Rasmussen et al., 2016; Shleev et al., 2015).

The different possible biocatalysts used in BFCs include enzymes, organelles and whole living cells. The active sites of redox enzymes, biocatalysts predominantly used in this thesis, can theoretically be more efficient than conventional "non-bio" catalysts, showing higher rates of reaction (Leech et al., 2012; Shleev et al., 2016). However, the efficiency of bioelectrocatalytic reactions is compromised by inadequate communication with electrodes (Konkena et al., 2016; Mano et al., 2003; Shleev et al., 2016). This ET limitation leads to BFCs with very low power density and energy density.

In addition, the de-activation of enzymes, suboptimal immobilisation procedures, and the leakage of components from the electrodes negatively affect the stability of the power output of the biodevices. 
Therefore, all these aspects have to be optimised. Researchers are developing strategies to overcome these limitations. For instance, nanowiring of redox enzymes can significantly increase their maximum turnover rates (Gutierrez-Sanchez et al., 2012; Mao et al., 2003; Xiao et al., 2003), while covalent bonding, cross-linking or entrapment of the biocatalysts appear as more robust immobilisation approaches to improve stability issues (Scouten et al., 1995). In any case, most of the BFCs already developed achieve operating voltages of $0.2-0.3 \mathrm{~V}$ (Shleev, 2017), being able to power low energy consumption electronics; on the other hand, stacking of cells will be needed to achieve sufficient voltage to power higher energy consumption electronic devices (Sakai et al., 2009).

In our research group, the focus is on enhancing the capacitive features of the biodevices to configure biosupercapacitors (Pankratov et al., 2014a; Pankratov et al., 2014b), which provide much higher power output levels than BFCs, when operating in pulse mode. Different strategies can be employed to enhance the capacitance of the biodevices. Biomaterials themselves can be used as capacitive elements (Pankratov et al., 2014b), as well as the conducting supports at which biomaterials are immobilised. In this work, different materials have been used aiming to increase the capacitance values. Conductive polymers, AuNPs, ITONps and graphene flakes are some of them.

Despite the apparent limitations, biocatalysts offer several advantages that clearly present a scenario of potential applications unique for biological power sources. Biocatalysts are able to operate at neutral $\mathrm{pH}$, low temperatures and in complex electrolytes, like human physiological fluids, which represents a clear advantage (Bullen et al., 2006; Chibata et al., 1986; Mano et al., 2002; Osman et al., 2011). Additionally, the presence of a proton-exchange membrane is needed in conventional fuel cells to separate catalyte from analyte. This is due to the lack of selectivity of the "non-bio" catalysts. On the contrary, BFCs do not need the presence of a membrane since they have the added advantage of specificity towards certain substrates (Minteer et al., 2007). The omission of a membrane ensures lower scale limits for miniaturisation of BFCs than for conventional fuel cells (Shleev, 2017). The ability of 
BFCs to operate under physiological conditions (Coman et al., 2010) and their potential for miniaturisation, reveal a promising scientific landscape to power microelectronics for wearable and implantable devices that conventional fuel cells cannot cover (Shleev, 2017).

Milli- and microscale electronics including bioelectronics have progressed substantially regarding miniaturisation and power delivery. Researchers are moving forward to develop low-energy/low-power consuming electronics and high energy density power sources (Bandodkar, 2017; Dong et al., 2016). For instance, wearable electrochemical devices combine low-power requirements, feasibility of miniaturisation, simplicity, and low production costs (Bandodkar et al., 2015).

Following the wearable trend, with characteristics such as flexibility, transparency, and elasticity, the emerging devices are honed to ensure comfort of the users. Thin, flexible and stretchable devices containing biosensors or biological power sources have been developed (Figure 17) and they count on several advantages when it comes to biodegradability and biocompatibility when compared with conventional batteries or fuel cells (Bandodkar, 2017). 

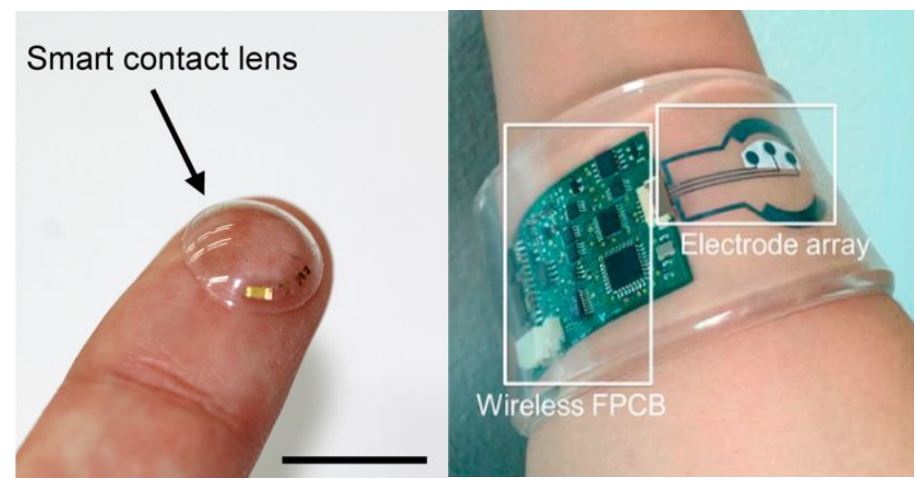

Figure 17. Left: soft, smart contact lens system using stretchable and transparent devices. Scale bar, I cm (Park et al., 20I8). Right: wearable, flexible sensor array applied to a human subject (Kim et al., 20I8)

In any case, a new horizon is being drawn in which different implants, skin-worn electronic devices and smart clothing interact among themselves and with human bodies, monitoring physical and biological signals, establishing the new concept of bodyNET (Chu et al., 2017). In this emerging scenario, flexible, stretchable electronics play an important role (Figure 18). They are the so-called elastronics that arise as a convenient, low cost option for wearable electronics.

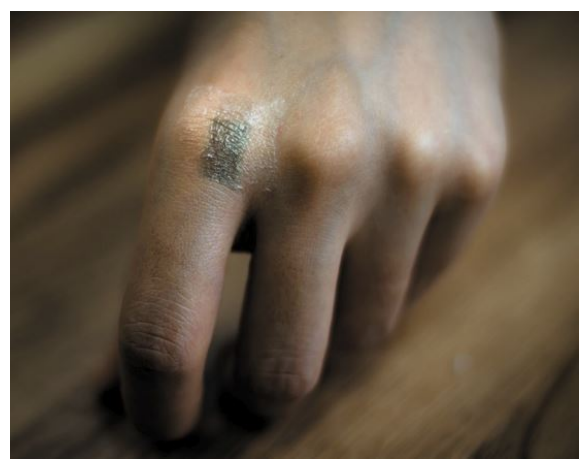

Figure I8. Elastronic transistor that behave like skin (Chu et al., 20I7) 
This thesis is just one brick in the wall that contributes with new knowledge in the field of flexible, transparent and nanostructured highly capacitive materials for bioelectronics. It is not easy to predict the relevance of bioelectronics in the future, but they definitely appear as strong candidates to be employed in the format of wearable flexible biosensors and biological power sources (Jia et al., 2013; Kim et al., 2018; Kim et al., 2015; Park et al., 2018) functioning together with other devices within the so-called bioNET (Figure 19).

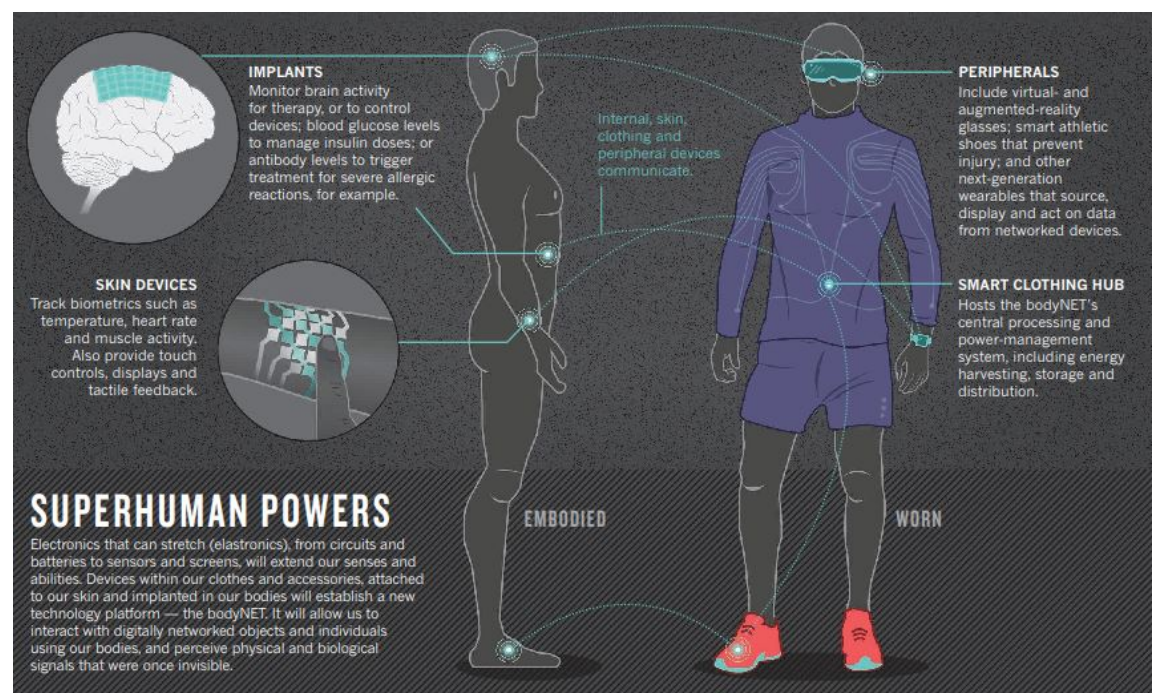

Figure 19. Schematic representation of the future use of different smart electronic gadgets interacting among themselves and with human bodies within the so-called bodyNET (Chu et al., 20I7). 


\section{ACKNOWLEDGMENTS}

If there is something that this experience abroad taught me is to be thankful. Very often for the things that I left behind but also for the new things that I found. To be thankful for the obstacles on my way because they taught me a lot about myself and made me stronger. To be thankful for the challenges because they motivated me and gave me something to overcome every day. To be thankful for the people surrounding me (in Sweden and from the distance) because they were my support, my light, my oxygen, my strength, and also my teachers in live.

To my supervisor, Sergey Shleev, because of trusting me from the beginning and giving me freedom but at the same time guiding me and trying to get the best out of our time working together. Thank you for appreciating my job, giving positive feedback when something was well done. Thank you for always finding time to supervise no matter how busy you are. It is very nice to just cross the corridor and knock on your door whenever I need guidance.

To our head of department and my examiner, Zoltan Blum, because of all our very interesting casual conversations about history, politics, science, meaning of life and other deep intense stuff. Thank you for being so patient when it comes to all the required work for the proper functioning of the department. 
To all the persons that helped me scientifically: Wolfgang Schuhmann, Lo Gorton, Roland Ludwig, Nicolas Mano, Antonio López de Lacey, Marcos Pita, Peter Falkman, Javier Sotres, Miguel Duarte Toscano, Kirill Sliozberg, Yulia Parunova, Sébastien Gounel, Tim Bobrowski, Chiara Di Bari, Dmitry Pankratov and Zoltan Blum.

To the colleagues at the department: Ravi, Petri, Iréne, Javier, Peter, Håkan, Anette, Magnus, Eva, Tove, Maria, Lars, Lennart and both Annas for the nice chats in the corridors and during lunch and fika time. Special thanks to Iréne for helping me to improve my Swedish and being so attentive (Tack så mycket!), to Anette for helping us with the shipments, Peter for being so nice and effective fixing any kind of setback and to Ravi for becoming a friend.

To Antonio, the receptionist, muchas gracias por darme la bienvenida cada mañana con música alegre, un abrazo y una sonrisa. Los días empiezan mucho mejor cuando te encuentro en la entrada y nos ponemos al día. Gracias de verdad por cuidar tanto de todo el mundo.

To my closest fellow researchers at the department: Dmitry, Zahra, Stefan, Cathrine, Alexander, Natalia, Yana, Magnus, Lejla, Abdullah, Sudhir, Siriram, Sebastian, Rayan, Olga, Mitra, Sing Yee, Celina, and Yuencheng. Special thanks to Olga, Mitra, Sing Yee and Celina for their friendship and their important support.

Thank you to all the nice people I met from Lund University including Lo, Paolo, Galina, Valentina, Kamrul, Christopher and Roberto.

To my researcher colleagues that became friends along the years: Vida, Grzegorz, Tim, Danea, Bianca, Carla, Inma and Patrick. I am sure that we will keep on meeting in different countries as we have been doing until now. I am very happy of having so cool international friends. Special thanks to Tim, for a very nice collaboration together, for being such a good friend and helping me so much during my secondment in Bochum. 
To my trainer Hanna Ahlstedt, because of teaching me how much life can improve just by starting the day with a bit of exercise and good mood. Thank you for helping me to overcome limitations while having fun.

To my friends in Spain, because it is so nice that the distance did not separate us but brought us even closer. Andrea, Ana, Alicia, Elena, Laura, Cristina, Anabel, Cassandra, Paula, Naiara, Ana Cristina, Pipi y María. Andrea, te llamo amiga pero podría llamarte hermana. Gracias por estar ahí incondicionalmente y ser un pilar indispensable en mi vida. Por muchos años más de amistad/hermandad. "Ana playa”, lo que unió Oropesa del Mar, que no lo separe nadie. Nuestra amistad comenzó siendo de verano y envíos postales para pasar a ser una amistad de todas las estaciones, conversaciones vitales y quedadas viajeras. Gracias por tanta confianza y por estar ahí después de tantos años. Alicia, Elena y Laura, mis “amuglitas" de toda la vida. Puedo pronosticar muchos más viajes playeros, amigos invisibles y otras tradiciones que vayan surgiendo hasta que seamos "abuelis". Cristina y Anabel, mis "clavelitos", lo mejor de mi experiencia Erasmus. Una extremeña, una andaluza y una madrileña que se ríen juntas de sus desdichas. ¡Y qué sano es reírse de uno mismo! Gracias por todos esos audios terapéuticos y vuestra amistad sin prejuicios. Cassandra, gracias por guardar siempre algún día cuando voy a España para tomarnos un café y ponernos al día. Siempre has sido y serás una de mis "visitas obligadas". Paula, Naiara y Ana Cristina, lo que me une a Alicante. Siempre tendré un buenísimo recuerdo de mis años allí y es, en gran parte, por vosotras. Gracias por estar ahí a pesar del tiempo y la distancia. Pipi, gracias por ser una inspiración y fuente de muchas de mis reflexiones. María, gracias por ser la mejor vecina y amiga. Ha sido genial crecer juntas y sigue siendo genial saber que te tengo como amiga después de tantos años.

To my friends in Sweden, Mahta, Awatef, Adriana and Isa. Thank you for making my life in Sweden so nice! Special thanks to Isa for always being there to patiently listen to me in the good and the bad days. ¡Gracias amiga! I am sure that this friendship born in Sweden will last no matter where we end up. 
To my fellows within the Marie Curie ITN project, Marta, Chiara, Valentina, Francesca, Galina, Magdalena, Nikola, Till, Xinxin, Ivan, Asier, Magnus, Su, Ali. Thank you to the European Commission for giving me the chance of meeting these great persons, getting to know new cultures, new ways of working, as well as learning which is the state of the art of our field and how to communicate scientific findings. Special thanks to Asier, Ivan and Chiara for the never ending laughter, "tardes de cañas" and time spent together. Chiara, thank you for your friendship, your scientific support and for creating the club "gourmet foodies" aka "gorditas al acecho de nuevos restaurantes"! There are many more restaurants to visit together.

To my parents, Pedro e Isabel, porque gran parte de lo que soy es por vosotros. Con vuestros valores y ejemplo me habéis enseñado cómo ser curiosa y abierta de mente pero crítica y cauta, amable y alegre pero fuerte y coherente, capaz de hacer sacrificios que traerán futuras recompensas pero manteniendo el equilibrio para ser capaz de disfrutar de las cosas buenas de la vida.

Estoy aquí escribiendo estas líneas por vosotros dos. Gracias por tanto amor y dedicación a vuestros hijos.

To my brother Álvaro, because I feel, even from the distance, how we are taking care of each other and appreciating each other's advice and counselling. I rely on you as you rely on me. I am very happy knowing that we have had such a nice bond since the day that you were born until the present day, and for the days to come. Thank you for being there unconditionally.

To Fanny, gracias por ser tan dulce y cuidar tan bien de mi hermano. Eres la mejor cuñada que me podría haber tocado. Gracias por ser tan atenta y detallista con todos nosotros.

To my whole family, familia González y familia Arribas. Tíos, tías, primos, primas y abuelito, gracias por ser todos tan majos, venir a visitarme cuando ha sido posible, darme ánimos y confiar tanto en mí como investigadora y como persona. Gracias por mandarme mensajes, 
fotos y audios desde la distancia porque ha hecho que me sienta muy acompañada. Aunque viva lejos os quiero mantener siempre bien cerca.

To Gyuri, Sylvia and Ribi, thank you for being my family in Malmö. Thank you for all the dinners and time spent together. It is very nice to have a family "adopting" me while mine is far away. Tack så mycket!

To David, thank you for being such a cool partner. You add so many good things to my life: so much music, laughter, joy, enthusiasm, commitment and passion. I celebrate having known you because I met someone that shares my philosophy of life in so many ways! We are a great team. You are the most honest, open-minded, smart and kindhearted person that I know. Thank you for being by my side in the good and the bad days, applauding the moments in which I was taking control of my life. We still have plenty of places to visit and much more food to cook and try (and I cannot promise anything but maybe, one day, I will enjoy watching Star Trek). I love you / Te quiero / Jag älskar dig / Szeretlek $\odot$ 


\section{REFERENCES}

Abad, J.M., Velez, M., Santamaria, C., Guisan, J.M., Matheus, P.R., Vazquez, L., Gazaryan, I., Gorton, L., Gibson, T., Fernandez, V.M., 2002. J Am Chem Soc $124,12845-12853$.

Bak, S.-M., Kim, K.-H., Lee, C.-W., Kim, K.-B., 2011. J. Mater. Chem. 21, 19841990.

Bandodkar, A.J., 2017. J. Electrochem. Soc. 164, H3007-H3014.

Bandodkar, A.J., Jia, W., Wang, J., 2015. Electroanalysis 27, 562-572.

Bard, A.J., Faulkner, L.R., 2001. Dianhuaxue 7, 255.

Bartlett, P.N., Whitaker, R.G., Green, M.J., Frew, J., 1988. J. Chem. Soc., Chem. Commun., 76.

Barton, S.C., Gallaway, J., Atanassov, P., 2004. Chem. Rev. (Washington, DC, U. S.) $104,4867-4886$.

Barton, S.C., Kim, H.-H., Binyamin, G., Zhang, Y., Heller, A., 2001. Journal of the American Chemical Society 123, 5802-5803.

Bornscheuer, U.T., 2003. Angewandte Chemie International Edition 42, 33363337.

Bourdillon, C., Bourgeois, J.P., Thomas, D., 1980. J. Am. Chem. Soc. 102, 42314235.

Bullen, R.A., Arnot, T.C., Lakeman, J.B., Walsh, F.C., 2006. Biosensors and Bioelectronics 21, 2015-2045.

Chaubey, A., Malhotra, B.D., 2002. Biosensors and Bioelectronics 17, 441-456.

Chibata, I., Tosa, T., Sato, T., 1986. J. Mol. Catal. 37, 1-24.

Chu, B., Burnett, W., Chung, J.W., Bao, Z., 2017. Nature (London, U. K.) 549, 328-330.

Coman, V., Ludwig, R., Harreither, W., Haltrich, D., Gorton, L., Ruzgas, T., Shleev, S., 2010. Fuel Cells 10, 9-16. 
Coman, V., Vaz-Dominguez, C., Ludwig, R., Harreither, W., Haltrich, D., De Lacey, A.L., Ruzgas, T., Gorton, L., Shleev, S., 2008. Phys. Chem. Chem. Phys. 10, 6093-6096.

Courjean, O., Mano, N., 2011. Journal of Biotechnology 151, 122-129.

Cracknell, J.A., McNamara, T.P., Lowe, E.D., Blanford, C.F., 2011. Dalton Transactions 40, 6668-6675.

Cracknell, J.A., Vincent, K.A., Armstrong, F.A., 2008. Chem Rev 108, 2439-2461.

Datta, S., Christena, L.R., Rajaram, Y.R.S., 2013. 3 Biotech 3, 1-9.

Dong, L., Xu, C., Li, Y., Wu, C., Jiang, B., Yang, Q., Zhou, E., Kang, F., Yang, Q.H., 2016. Advanced Materials 28, 1675-1681.

Falk, M., Andoralov, V., Blum, Z., Sotres, J., Suyatin, D.B., Ruzgas, T., Arnebrant, T., Shleev, S., 2012a. Biosensors and Bioelectronics 37, 38-45.

Falk, M., Blum, Z., Shleev, S., 2012b. Electrochimica Acta 82, 191-202.

Falk, M., Narváez Villarrubia, C.W., Babanova, S., Atanassov, P., Shleev, S., 2013. ChemPhysChem 14, 2045-2058.

Flitsch, A., Prasetyo, E.N., Sygmund, C., Ludwig, R., Nyanhongo, G.S., Guebitz, G.M., 2013. Enzyme and Microbial Technology 52, 60-67.

Fowle, F.F., 1978. The New Standard Handbook for Electrical Engineers. 4th Ed. Iron Age Book Dept.

Frackowiak, E., Beguin, F., 2001. Carbon 39, 937-950.

Gellett, W., Kesmez, M., Schumacher, J., Akers, N., Minteer, S.D., 2010. Electroanalysis 22, 727-731.

Govindjee, Blankenship, R.E., Berkowitz, G.A., Portis, J.A.R., Shopes, R.J., 2016.

Grattieri, M., Minteer, S.D., 2018. ACS Sens. 3, 44-53.

Grippo, V., Ma, S., Ludwig, R., Gorton, L., Bilewicz, R., 2017. Bioelectrochemistry

Gutierrez-Sanchez, C., Pita, M., Vaz-Dominguez, C., Shleev, S., De Lacey, A.L., 2012. J. Am. Chem. Soc. 134, 17212-17220.

Haider, T., Husain, Q., 2008. Int. J. Pharm. 359, 1-6.

Heller, A., 2004. Phys. Chem. Chem. Phys. 6, 209-216.

Henriksson, G., Hildén, L., Ljungquist, P., Ander, P., Pettersson, B., 2001. Cellobiose Dehydrogenase as a Ligninase. Oxidative Delignification Chemistry, pp. 456-473. American Chemical Society.

Henriksson, G., Johansson, G., Pettersson, G., 2000. Journal of Biotechnology 78, 93-113.

Huebner, W.F., Barfield, W.D., 2014. Opacity. Springer New York.

Jaeger, C.D., Bard, A.J., 1980. J. Am. Chem. Soc. 102, 5435-5442.

Jesionowski, T., Zdarta, J., Krajewska, B., 2014. Adsorption 20, 801-821. 
Jia, W., Valdés-Ramírez, G., Bandodkar, A.J., Windmiller, J.R., Wang, J., 2013. Angewandte Chemie International Edition 52, 7233-7236.

Jiahui, L., 2015. The Ohio State University.

Kalaji, M., Murphy, P.J., Williams, G.O., 1999. Synth. Met. 102, 1360-1361.

Katz, E., Bückmann, A.F., Willner, I., 2001. Journal of the American Chemical Society 123, 10752-10753.

Katz, E., Pingarrón, J.M., Mailloux, S., Guz, N., Gamella, M., Melman, G., Melman, A., 2015. The Journal of Physical Chemistry Letters 6, 1340-1347.

Kerfeld, C.A., Sawaya, M.R., Tanaka, S., Nguyen, C.V., Phillips, M., Beeby, M., Yeates, T.O., 2005. Science (Washington, DC, U. S.) 309, 936-938.

Kim, J., Campbell, A.S., Wang, J., 2018. Talanta 177, 163-170.

Kim, J., de Araujo, W.R., Samek, I.A., Bandodkar, A.J., Jia, W., Brunetti, B., Paixão, T.R.L.C., Wang, J., 2015. Electrochemistry Communications 51, 41-45.

Konkena, B., Masa, J., Xia, W., Muhler, M., Schuhmann, W., 2016. Nano Energy 29, 46-53.

Kyotani, T., Tsai, L.-f., Tomita, A., 1996. Chem. Mater. 8, 2109-2113.

Laurinavicius, V., Razumiene, J., Ramanavicius, A., Ryabov, A.D., 2004. Biosensors and Bioelectronics 20, 1217-1222.

Leech, D., Kavanagh, P., Schuhmann, W., 2012. Electrochimica Acta 84, 223-234.

Leskovac, V., Trivic, S., Wohlfahrt, G., Kandrac, J., Pericin, D., 2005. Int. J. Biochem. Cell Biol. 37, 731-750.

Li, W., Chen, J., Zhao, J., Zhang, J., Zhu, J., 2005. Mater. Lett. 59, 800-803.

Madan, R.L., 2015. Physical Chemistry. 0000.

Mano, N., Mao, F., Heller, A., 2002. Journal of the American Chemical Society $124,12962-12963$.

Mano, N., Mao, F., Heller, A., 2003. Journal of the American Chemical Society 125, 6588-6594.

Mao, F., Mano, N., Heller, A., 2003. Journal of the American Chemical Society 125, 4951-4957.

Masa, J., Schuhmann, W., 2016. Nano Energy 29, 466-475.

Matsushita, K., Shinagawa, E., Adachi, O., Ameyama, M., 1989. Biochemistry 28, 6276-6280.

Milton, R.D., Minteer, S.D., 2017. J R Soc Interface 14

Minteer, S.D., Liaw, B.Y., Cooney, M.J., 2007. Current Opinion in Biotechnology $18,228-234$.

Murata, K., Kajiya, K., Nakamura, N., Ohno, H., 2009. Energy Environ. Sci. 2, 1280-1285. 
Osman, M.H., Shah, A.A., Walsh, F.C., 2011. Biosens. Bioelectron. 26, 3087-3102.

Oubrie, A., Rozeboom, H.J., Kalk, K.H., Olsthoorn, A.J.J., Duine, J.A., Dijkstra, B.W., 1999. The EMBO Journal 18, 5187-5194.

Pankratov, D., Blum, Z., Shleev, S., 2014a. ChemElectroChem 1, 1798-1807.

Pankratov, D., Blum, Z., Suyatin, D.B., Popov, V.O., Shleev, S., 2014b. ChemElectroChem 1, 343-346.

Park, J., Kim, J., Kim, S.-Y., Cheong, W.H., Jang, J., Park, Y.-G., Park, J.-U., Na, K., Bien, F., Kim, Y.-T., Lee, C.Y., Heo, J.H., Lee, J.H., 2018. Sci Adv 4, eaap9841.

Pauliukaite, R., Malinauskas, A., Zhylyak, G., Spichiger-Keller, U.E., 2007. Electroanalysis 19, 2491-2498.

Pletcher, D., Editor, 2009. A first course in electrode processes, 2nd Edition. Royal Society of Chemistry.

Price, N.C., Stevens, L., 1982. Fundamentals of Enzymology. Oxford Univ. Press.

Pyun, S.I., Shin, H.C., Lee, J.W., Go, J.Y., 2012. In: Springer (Ed.), Electrochemistry of Insertion Material for Hydrogen and Lithium, pp. 11-32, Berlin, Heidelberg.

Ramirez, P., Mano, N., Andreu, R., Ruzgas, T., Heller, A., Gorton, L., Shleev, S., 2008. Biochim. Biophys. Acta, Bioenerg. 1777, 1364-1369.

Rasmussen, M., Abdellaoui, S., Minteer, S.D., 2016. Biosensors and Bioelectronics 76, 91-102.

Rasmussen, M., Minteer, S.D., 2014. Electrochim. Acta 126, 68-73.

Razumiene, J., Vilkanauskyte, A., Gureviciene, V., Barkauskas, J., Meskys, R., Laurinavicius, V., 2006. Electrochimica Acta 51, 5150-5156.

Ruiz, V., Blanco, C., Raymundo-Pinero, E., Khomenko, V., Beguin, F., Santamaria, R., 2007. Electrochim. Acta 52, 4969-4973.

Sakai, H., Nakagawa, T., Mita, H., Matsumoto, R., Sugiyama, T., Kumita, H., Tokita, Y., Hatazawa, T., 2009. ECS Trans. 16, 9-15.

Sardar, M., Gupta, M.N., 2005. Enzyme Microb. Technol. 37, 355-359.

Scholz, F., 2005. Electroanalytical Methods: Guide to Experiments and Applications, 2nd printing. Springer.

Schubart, I.W., Göbel, G., Lisdat, F., 2012. Electrochimica Acta 82, 224-232.

Scouten, W.H., Luong, J.H.T., Brown, R.S., 1995. Trends Biotechnol. 13, 178-185.

Sheldon, R.A., 2007. Adv. Synth. Catal. 349, 1289-1307.

Shimizu, A., Kwon, J.-H., Sasaki, T., Satoh, T., Sakurai, N., Sakurai, T., Yamaguchi, S., Samejima, T., 1999. Biochemistry 38, 3034-3042.

Shleev, S., 2017. ChemPlusChem 82, 522-539. 
Shleev, S., Andoralov, V., Pankratov, D., Falk, M., Aleksejeva, O., Blum, Z., 2016. Electroanalysis 28, 2270-2287.

Shleev, S., Bergel, A., Gorton, L., 2015. Bioelectrochemistry 106, 1-2.

Shleev, S., Tkac, J., Christenson, A., Ruzgas, T., Yaropolov, A.I., Whittaker, J.W., Gorton, L., 2005. Biosens. Bioelectron. 20, 2517-2554.

Solomon, E.I., Sundaram, U.M., Machonkin, T.E., 1996. Chem. Rev. (Washington, D. C.) $96,2563-2605$.

Suraniti, E., Courjean, O., Gounel, S., Tremey, E., Mano, N., 2013. Electroanalysis $25,606-611$.

Swoboda, B.E., 1969. Biochim Biophys Acta 175, 365-379.

Szamocki, R., Velichko, A., Muecklich, F., Reculusa, S., Ravaine, S., Neugebauer, S., Schuhmann, W., Hempelmann, R., Kuhn, A., 2007. Electrochem. Commun. 9, 2121-2127.

Tan, T.-C., Kracher, D., Gandini, R., Sygmund, C., Kittl, R., Haltrich, D., Hällberg, B.M., Ludwig, R., Divne, C., 2015. Nature Communications 6, 7542.

Tarasevich, M.R., 1985. Comprehensive Treatise of Electrochemistry, Plenum Press New York ed. Springer, Boston, MA.

Toone, E.J., Editor, 2007. Advances in Enzymology and Related Areas of Molecular Biology, Volume 75. John Wiley \& Sons, Inc.

Tsujimura, S., Kojima, S., Kano, K., Ikeda, T., Sato, M., Sanada, H., Omura, H., 2006. Biosci., Biotechnol., Biochem. 70, 654-659.

Wang, G., Zhang, L., Zhang, J., 2012a. Chem. Soc. Rev. 41, 797-828.

Wang, X., Falk, M., Ortiz, R., Matsumura, H., Bobacka, J., Ludwig, R., Bergelin, M., Gorton, L., Shleev, S., 2012b. Biosensors and Bioelectronics 31, 219-225.

Willner, I., Katz, E., 2006. Bioelectronics: From Theory to Applications. Wiley.

Wilson, R., Turner, A.P.F., 1992. Biosensors and Bioelectronics 7, 165-185.

Winter, M., Brodd, R.J., 2004. Chem. Rev. (Washington, DC, U. S.) 104, 4245 4269.

Xiao, Y., Patolsky, F., Katz, E., Hainfeld, J.F., Willner, I., 2003. Science 299, 1877 1881.

Xu, Q., Zhang, F., Xu, L., Leung, P., Yang, C., Li, H., 2017. Renewable and Sustainable Energy Reviews 67, 574-580.

Zámocký, M., Schümann, C., Sygmund, C., O’Callaghan, J., Dobson, A.D.W., Ludwig, R., Haltrich, D., Peterbauer, C.K., 2008. Protein Expression and Purification 59, 258-265.

Zayats, M., Katz, E., Baron, R., Willner, I., 2005. J. Am. Chem. Soc. 127, 1240012406.

Zhang, L.L., Zhao, X.S., 2009. Chem. Soc. Rev. 38, 2520-2531. 


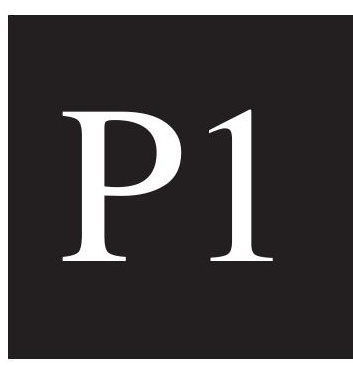



DOI: 10.1002/elan.201600096

\title{
Transparent and Capacitive Bioanode Based on Specifically Engineered Glucose Oxidase
}

\author{
Elena González-Arribas, ${ }^{[\mathrm{a}]}$ Dmitry Pankratov, ${ }^{[\mathrm{a}, \mathrm{b}, \mathrm{c}]}$ Sébastien Gounel, ${ }^{[\mathrm{d}]}$ Nicolas Mano, ${ }^{[\mathrm{d}]}$ Zoltan Blum, ${ }^{[\mathrm{a}]}$ \\ and Sergey Shleev*[a, b, c]
}

\begin{abstract}
Here we detail an optimized transparent capacitive glucose oxidizing bioanode, capable of supplying current densities of $10 \mu \mathrm{A} \mathrm{cm}^{-2}$ at applied potentials of $0.1 \mathrm{~V}-0.2 \mathrm{~V}$ versus saturated calomel electrode, when continuously performing in a simple phosphate buffer, pH 7.4 and artificial human tears, both with a glucose concentration of $0.05 \mathrm{mM}$ only. When operating in pulse mode, the bioanode was able to deliver current densities as high as $21 \mu \mathrm{Acm}^{-2}$ at the beginning of the pulse with $571 \mu \mathrm{Ccm}^{-2}$ total charges stored. The biogenic part of the enzymatic device was a recombinant glucose oxidase mutant from Penicillium amagasakiense with high catalyt-
\end{abstract}

ic efficiency towards glucose, up to $14.5 \cdot 10^{4} \mathrm{M}^{-1} \mathrm{~s}^{-1}$. The non-biogenic part of the anodic system was based on a poly(3,4-ethylenedioxythiophene)-graphene nanocomposite, as a highly capacitive component with a capacitance density in the $1 \mathrm{mF} \mathrm{cm}^{-2}$ range, multi-walled carbon nanotubes, as an additional nanostructuring element, and a conductive organic complex, as an electron shuttle between the redox enzyme and the electrode surface. The bioanode could potentially serve as a prototype of a double-function enzymatic anode for hybrid electric power biodevices, energizing smart contact lenses.

Keywords: Biocatalysis · Transparent $\cdot$ Capacitive $\cdot$ Protein Engineering $\cdot$ Contact Lenses

\section{Introduction}

Modern wearable/personal electronics rely on powerful and long-lasting sources of electric energy [1]. For certain applications, e.g., power sources for electronic contact lenses, additional features such as transparency and biocompatibility are required [2]. Transparency is required for cosmetic reasons mainly, since the pupil of the eye is relatively small compared to the total eye area, whereas biocompatibility is critically important.

Human lachrymal liquid is an ideal vehicle for non-invasive biomedical analysis [3,4] and augmented contact lenses with appropriate embedded sensors can serve as self-reliant, i.e., self-powered and wirelessly communicating, sensing devices. Other possible applications include electronic lenses with remedial purposes, like drug delivery and vision correction, as well as more mundane purposes, e.g., on-lens monitors for user entertainment and human supervision.

In 2011 an idea to use a fuel cell (FC) incorporated into an electronic contact lens as an in-built electric power source for novel tear-based bioelectronic devices was proposed [5], and was soon experimentally confirmed using an enzymatic FC [6]. In general, enzymatic FCs, directly converting chemical energy into electric energy, are promising power sources for different type of devices operating in vivo and ex vivo [7-12]. However, given the complex materials and form factor restrictions offered by a contact lens, even state-of-the-art power management technology is inadequate, and to realize the full potential of smart lenses, radical technological steps need to be taken. Bridging the conceptual gap between FCs and su- percapacitors (SCs), an ingenious novel approach to onlens power management was recently presented a charge-storing biological FC, or differently put, a selfcharging biological SC, i.e., a hybrid electric power biodevice [2]. These biodevices are based on double-function electrodes, that is electrodes manifesting simultaneous electrocatalytic and charge-storage features [13]. Several recent reports detail separate double-function electrodes [14-16] and complete hybrid electric power biodevices $[13,17-20]$, but so far the only bioelectrodes and biodevices reported were opaque. Moreover, in some of these reports, the devices were microorganism based $[14,15,20]$, which are unlikely to be used for contact lens applications. Among the many biological catalysts available, oxidoreductases are outstanding and could be used to create powerful FCs; in fact, FCs based on oxidoreductases outperform most FCs based on non-biogenic and biogenic el-

[a] E. González-Arribas, D. Pankratov, Z. Blum, S. Shleev Biomedical Sciences, Health and Society, Malmö University, 20560 Malmö, Sweden

*e-mail: sergey.shleev@mah.se

[b] D. Pankratov, S. Shleev

A. N. Bach Institute of Biochemistry, 119071 Moscow, Russia

[c] D. Pankratov, S. Shleev Kurchatov NBIC Centre, National Research Centre "Kurchatov Institute", 123182 Moscow, Russia

[d] S. Gounel, N. Mano CNRS, CRPP, UPR 8641, 33600 Pessac, France

Supporting information for this article is available on the WWW under http://dx.doi.org/10.1002/elan.201600096. 


\section{Full Paper}

ements [21]. Redox enzymes are natural renewable catalysts, which can be produced at low costs. Additionally, they allow construction of single compartment biological FCs, removing voltage losses that cannot be avoided in multi compartment systems, and thus permits the design of technically less challenging devices [22]. Finally, many oxidoreductases are highly active at close to neutral $\mathrm{pH}$ values and $35^{\circ} \mathrm{C}$, i.e., conditions at which an on-lens biodevice is supposed to operate, since the physiological temperature of tear fluid is about $35^{\circ} \mathrm{C}$ [23] and its $\mathrm{pH}$ is around 7.5 [24].

To the best of our knowledge there are no reports concerning specific engineering of dual-feature bioelectrodes and hybrid biodevices for smart contact lenses. Below we present the realization of the very first transparent and capacitive enzymatic anode. Our study was also aimed at optimizing the bioanode performance in tear fluid, taking into account the minute concentrations of potential biofuels in human lachrymal liquid.

\section{Experimental}

\subsection{Reagents}

Phosphate buffer (PB) was prepared with water (18 M $\Omega$ $\mathrm{cm}$ ) purified using a PURELAB UHQ II system ELGA Labwater (High Wycombe, UK). $\mathrm{Na}_{2} \mathrm{HPO}_{4} \cdot 2 \mathrm{H}_{2} \mathrm{O}$ was purchased from Riedel-de Haën (Seelze, Germany). Ethanol $95 \%$ was from Kemetyl AB (Haninge, Sweden). Acetonitrile CHROMASOLV ${ }^{\circledast}$ Plus for HPLC ( $\geq 99,9 \%$; $\mathrm{ACN})$, toluene anhydrous (99,8\%), 3,4-ethylenedioxythiophene (EDOT), polyethylene glycol 20000 (PEG BioUltra 20000), 7,7,8,8-tetracyanoquinodimethano (TCNQ), tetrathiafulvalene (97\%; TTF), $\mathrm{AuCl}_{3} 3 \mathrm{H}_{2} \mathrm{O}, \mathrm{LiClO}_{4}$, $\mathrm{KH}_{2} \mathrm{PO}_{4}, \mathrm{NaCl}, \mathrm{KCl}$, and gelatin from porcine skin were purchased from Sigma-Aldrich (St. Louis, MO, USA). Tetrahydrofuran, LiChrosolv, and trisodium citrate, $\mathrm{Na}_{3} \mathrm{C}_{6} \mathrm{H}_{5} \mathrm{O}_{7} 2 \mathrm{H}_{2} \mathrm{O}$, were from Merck (Solna, Sweden). Artificial human tears were purchased from Ursa Bioscience (Bel Air, MD, USA). Argon (Ar, 99,9999\%) was from AGA Gas AB (Sundbyberg, Sweden).

Graphene (grade AO-1, dry black nanopowder, $1.6 \mathrm{~nm}$ flakes-trial thickness, less than 3 monolayers) was obtained from Graphene Supermarket (Long Island, NY, USA). Two types of multiwall carbon nanotubes (MWCNTs) from Sigma-Aldrich were used; outer diameter (O. D.) $10-15 \mathrm{~nm}$, inner diameter (I. D.) $2-6 \mathrm{~nm}$, length $0.1-10 \mu \mathrm{m}$, and purity $>90 \%$, as well as MWCNTs with O. D. $=20-30 \mathrm{~nm}$, I. D. $1-2 \mathrm{~nm}$, length $0.5-2 \mu \mathrm{m}$, and purity $95+\%$.

\subsection{Enzymes}

Recombinant glucose oxidases (GOxs) from Penicillium amagasakiense, a wild type $\left(P a \mathrm{GOx}_{\mathrm{wt}}\right)$ and a mutated enzyme $\left(P a \mathrm{GOx}_{\mathrm{mut}}\right)$, were isolated and purified as described previously [25]. Commercially available GOx

\section{ELECTROANALYSIS}

from Apergillus niger (type VII, AnGOx) was purchased from Sigma-Aldrich and used as received.

\subsection{Synthesis of Gold Nanoparticles}

Gold nanoparticles (AuNPs) of $20 \mathrm{~nm}$ were synthesized following the method previously described in Ref. [26], using $\mathrm{Na}_{3} \mathrm{C}_{6} \mathrm{H}_{5} \mathrm{O}_{7}$ as the reducing agent. The resultant AuNP suspension was concentrated (50-fold) by centrifugation at $10,000 \mathrm{~g}$ for $30 \mathrm{~min}$, then $98 \%$ of the supernatant was removed, and the precipitate was re-suspended by sonication using an ultrasonic cleaner, XB2 from VWR International Ltd. (East Grinstead, West Sussex, UK).

\subsection{Electrodes}

For assembly of opaque devices, polycrystalline gold (Au) disk electrodes with a geometric area of $0.0314 \mathrm{~cm}^{2}$ from Bioanalytical Systems (West Lafayette, IN, USA) were used. They were polished with $0.3 \mu \mathrm{m}$ agglomerated alpha alumina suspension from Struers (Copenhagen, Denmark) and thoroughly cleaned with ethanol and ultrapure water under ultrasound using the XB2 ultrasonic cleaner.

All electropolymerization procedures were performed by scanning the potential from $0.2 \mathrm{~V}$ to $1.3 \mathrm{~V}$ ( $v s$. $\mathrm{Hg}\left|\mathrm{Hg}_{2} \mathrm{Cl}_{2}\right| \mathrm{KCl}_{\text {sat }}, \mathrm{SCE}, 0.242 \mathrm{~V}$ vs. NHE). Just one cycle at a scan rate of $100 \mathrm{mV} \mathrm{s}^{-1}$ was carried out in order to obtain an as thin and transparent film as possible. An Ar saturated solution for electropolymerization consisted of $20 \mathrm{mM}$ EDOT, $1 \mathrm{mM} \mathrm{PEG}$, and $0.1 \mathrm{M} \mathrm{LiClO}_{4}$ in $100 \mathrm{mM}$ $\mathrm{PB}, \mathrm{pH} 7.4$ [27]. The co-solvent PEG was added to disperse the monomer EDOT in the aqueous solution, whereas $\mathrm{LiClO}_{4}$ was used as the doping salt.

Two types of polymer were synthesized, a poly(3,4-ethylenedioxythiophene) (PEDOT) film and a 1:5 graphene:PEDOT $(w / w)$ composite; for the latter, the electropolymerization solution was mixed with graphene and sonicated during $1 \mathrm{~h}$.

To synthesize a redox mediator, TCNQ and TTF, $1.2 \mathrm{mg} \mathrm{mL}^{-1}$ each, were dissolved in THF and ACN, respectively. The desired quantity of both compounds was dropped over the polymer film, using twice the amount of TTF compared to the amount of TCNQ.

For electrodes with a nanomaterial layer, $2 \mu \mathrm{L}$ of either a MWCNT or AuNP containing solution were dropped over the mediator layer. Since MWCNTs are insoluble in water, solutions of $1 \mathrm{mg} \mathrm{mL}^{-1}$ in toluene were made for both types of MWCNTs.

For bio-modification, a solution of $10 \mathrm{mg} \mathrm{mL}^{-1} \mathrm{GOx}$ in $100 \mathrm{mM} \mathrm{PB}, \mathrm{pH} 7.4$, was prepared, dropped on the electrode surfaces, and kept in a refrigerator during $1 \mathrm{~h}$ in order to physically immobilize the enzymes. After that a solution of $2.5 \%$ of gelatin $(w / v)$ in water was dropped on the electrode and dried at room temperature for $1 \mathrm{~h}$. Finally, the electrode was immersed in a $5 \%$ glutaraldehyde solution for $60 \mathrm{~s}$ and generously cleaned with ultrapure water [28]. 


\section{Full Paper}

\subsection{Electrochemical Measurements}

Electrochemical measurements were performed using a $\mu$ Autolab Type III/FRA2 potenciostat/galvanostat from Metrohm Autolab B. V. (Utrech, Nederlands). Before each measurement $20 \mathrm{~min}$ Ar bubbling was performed in order to remove $\mathrm{O}_{2}$. The reference and counter electrodes were a SCE and a $\mathrm{Pt}$ wire, respectively.

To study the bioelectrocatalytic response of the electrodes, cyclic voltammetry was performed in a potential window between $-0.2 \mathrm{~V}$ to $0.2 \mathrm{~V}$ vs. SCE in $100 \mathrm{mM} \mathrm{PB}$, pH 7.4 with different glucose concentrations; 0, 0.05, 5, 50 , and $500 \mathrm{mM}$. The glucose concentrations 0.05 and $5 \mathrm{mM}$ were chosen knowing them to be the approximate glucose concentrations in human tears and blood, respectively [29], whereas higher glucose concentrations, 50 and $500 \mathrm{mM}$, were used to test substrate limitations of enzymatic electrodes.

The capacitance of PEDOT and PEDOT-graphene films was investigated by recording cyclic voltammograms $(\mathrm{CVs})$ in a potential window between $-0.2 \mathrm{~V}$ and $0.2 \mathrm{~V}$ vs. $\mathrm{SCE}$ in $100 \mathrm{mM} \mathrm{PB}, \mathrm{pH} 7.4$, with different scan rates, $1 \mathrm{mV} \mathrm{s}^{-1} ; 10 \mathrm{mVs}^{-1}$ and $100 \mathrm{mVs}^{-1}$. Three repetitions for each electrode at different scan rates were performed. Taking into account the asymmetrical character of the obtained CVs, integral areas, which represent the sum of both anodic $\left(q_{\mathrm{a}}\right)$ and cathodic $\left(q_{\mathrm{c}}\right)$ charges [30], were used for calculations using Equation 1.

$\mathrm{C}_{\mathrm{a}}=\frac{\mathrm{Q}}{2\left(\mathrm{E}_{2}-\mathrm{E}_{1}\right) * \mathrm{~A}}$

where $C_{\mathrm{a}}$ is the capacitance density, $\mathrm{Q}$ is the charge; $\mathrm{A}$ is the geometric surface area of the Au electrode; $\left(E_{2}-E_{1}\right)$ is the applied potential window width [31].

To perform charge-discharge experiments, chronopotentiometric and chronoamperometric measurements were carried out in artificial human tears. Discharging was achieved by applying potential pulses at $0.1 \mathrm{~V}$, whereas self-charging was performed at zero current until a constant OCP value was reached.

During electrochemical measurements buffers were thermostated using an Assistent WTE var 3185 thermostat from Glaswarenfabrik Karl Hecht GmbH (Sondheim v.d. Rhön, Germany).

\subsection{Enzymatic Assay}

To assay the biocatalytic activity of redox enzymes in a homogeneous glucose containing solution, an oxygraph Clark-type electrode from Hansatech Instruments LTD (Norfolk, UK) was used along with the Assistent WTE var 3185 thermostat. The assay was carried out at $35^{\circ} \mathrm{C}$ using $10 \mathrm{mM} \mathrm{PB} \mathrm{pH} \mathrm{7.4,} \mathrm{containing} 137 \mathrm{mM} \mathrm{NaCl}$ and $2.7 \mathrm{mM} \mathrm{KCl}$ with an enzyme concentration of $0.05 \mathrm{mM}$.
ELECTROANALYSIS

\subsection{SEM Studies}

Scanning electron microscopy (SEM) was performed with an ultra-high resolution scanning electron microscope, EVO LS10 from Zeiss (Jena, Germany), operating in high vacuum mode, a $\mathrm{LaB}_{6}$ filament, field immersion mode with $20 \mathrm{kV}$ accelerating voltage and $36 \mathrm{pA}$ beam current.

\subsection{Spectrophotometric Measurements}

For the transparency measurements, commercially available glass slides with evaporated Au were used as working electrodes. Glasses were cut in pieces of $10 \mathrm{~mm} \times$ $25 \mathrm{~mm}$. Au was deposited by using a high resolution sputter coater AGB7234 from Agar Scientific (Essex, UK) with a plasma current of $30 \mathrm{~mA}$ during $60 \mathrm{~s}$. The electrodes were further washed with deionized water and dried in air. The conductive support made in this way was used as the electrode during the composite electropolymerization. Mediator, enzyme, and gelatin layers were immobilized on the surface, as described above. A Cary ${ }^{\circledR} 50 \mathrm{UV}$ Vis spectrophotometer from Varian, Inc. (Utrech, Netherlands) was used to measure the electrode transmittance (\% T) in the $390-700 \mathrm{~nm}$ wavelength range.

\section{Results and Discussion}

In order to engineer new hybrid bioelectronic devices, i.e., transparent charge-storing enzymatic FCs operating in human tears, a good starting point is to design separate transparent, highly capacitive and bioelectrocatalytically active enzymatic electrodes. This is a challenging scientific-technological task per se because of several, sometimes conflicting simultaneous requirements (vide supra). As regards real practical applications, biocompatibility issues should also be considered, i.e., cytotoxicity and inflammatory response.

To a first approximation a capacitive bioelectrocatalytically active enzymatic electrode should contain three main layers, a support, and capacitive and bioelectrocatalytic layers. All layers of the electrode should be transparent enough in order to shape the desired biodevice, and the exposed outer layers, the capacitive layer and especially the bioelectrocatalytic layer, should also be biocompatible.

\subsection{Conducting Support}

As a conductive support a sputtered thin Au layer on the top of glass slides was used (Fig. 1). On the one hand, $\mathrm{Au}$ is highly conducting and also biocompatible [32]. On the other hand, as can be seen from Fig. 1, the Au electrodes were transparent just to a certain extent, with a maximal transmittance at $505 \mathrm{~nm}$ of $37 \%$ only (Table 1 ). The spectrum in Fig. 1 is in good agreement with published transmittance spectra of thin layers of thermally evaporated $\mathrm{Au}$ on glass substrates [33] with peaks at about $500 \mathrm{~nm}$. 


\section{Full Paper}

Table 1. Maximum transmittance values at $505 \mathrm{~nm}$ measured for different electrodes shown in Fig. 1A

\begin{tabular}{lll}
\hline No. & Sample & $\mathrm{T} \%$ \\
\hline 1 & $\mathrm{Au}$ & 37 \\
2 & $\mathrm{Au} /$ PEDOT-graphene & 25 \\
3 & $\mathrm{Au} /$ PEDOT-graphene/TTF-TCNQ/MWCNTs/AnGOx & 20 \\
\hline
\end{tabular}

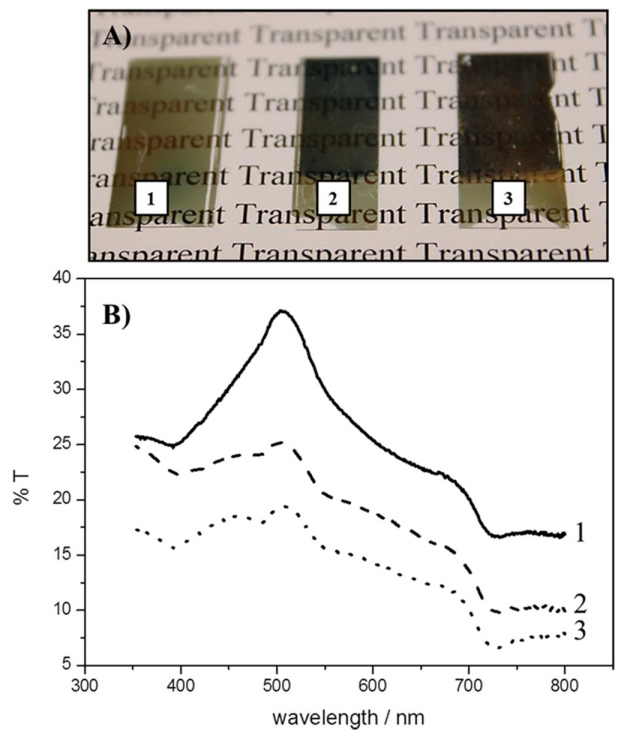

Fig. 1. (A) Photographic image of the different electrodes assembled on Au coated glass as a supporting material, and (B) transmittance spectra of the electrodes. 1 - Au, 2 - Au/PEDOTgraphene, 3 - Au/PEDOT-graphene/TTF-TCNQ/MWCNTs/ AnGOx.

In our studies the $37 \%$ transmittance value at $505 \mathrm{~nm}$, points to a quite thick layer of evaporated $\mathrm{Au}$, i.e., $>10 \mathrm{~nm}$. A thin layer of Au will be much more transparent, but it would also be unstable and a poorer conductor As an alternative approach, indium tin oxide can be used. However, one of the main goals of the current work was to assemble and optimize transparent capacitive and bioelectrocatalytical layers of enzymatic electrodes, rather than to design and test the final biodevice ready for commercial usage. Indeed, the approach with $\mathrm{Au}$ was far from an ideal but nevertheless fully sufficient to study the main layers in detail and, thus, to achieve the scientific goal.

\subsection{Capacitive Layer}

A capacitive layer of a biodevice can be based on doublelayer, pseudo, or hybrid capacitances. As a pseudocapaci-

\section{ELECTROANALYSIS}

tive material PEDOT, a conjugated polymer with good electric conductivity and also known to be biocompatible $[34,35]$, was synthesized and used. PEDOT is chemically stable and can also form almost transparent thin films [36]. In order to increase the total capacitance a PEDOTgraphene nanocomposite material with hybrid capacitance was also synthesized following a recently reported protocol [37]. The capacitance of PEDOT and PEDOTgraphene films on Au was investigated using cyclic voltammetry (Supporting Fig. S1) and averaged results are presented in Table 2.

Table 2. Average values of $C_{\mathrm{a}}\left(\mu \mathrm{Fcm}^{-2}\right)$ of $\mathrm{Au} / \mathrm{PEDOT}$ and $\mathrm{Au} /$ PEDOT-graphene electrodes at different scan rates.

\begin{tabular}{llll}
\hline Sample & $100 \mathrm{mV} \mathrm{s}^{-1}$ & $10 \mathrm{mV} \mathrm{s}^{-1}$ & $1 \mathrm{mV} \mathrm{s}_{-1}$ \\
\hline Au/PEDOT & $181 \pm 2$ & $240 \pm 5$ & $347 \pm 7$ \\
Au/PEDOT-graphene & $280 \pm 3$ & $433 \pm 2$ & $986 \pm 8$ \\
\hline
\end{tabular}

Significantly higher capacitance values were registered for PEDOT-graphene films (Table 2), most likely owing to an increase of the surface area, derived from the presence of graphene nano-flakes entrapped in the polymer layer (Fig. 2A).

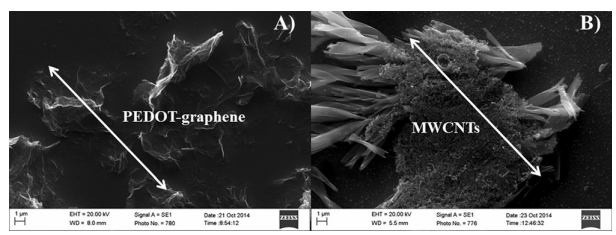

Fig. 2. SEM images of nanostructured electrode surfaces. (A) PEDOT-graphene composite, and (B) MWCNTs attached to TTF-TCNQ crystals.

The spectrum of the PEDOT-graphene layer in the visible region points to the formation of oxidized polymer on the Au surface (Fig. 1), as apparent from the much higher transmittance values at short wavelengths, compared to long wavelength values [38]. Taking into account capacitance (Table 2) and transparency values (Table 1) of the PEDOT-graphene composite, that material was chosen for further studies.

\subsection{Bioelectrocatalytic Layer}

In our investigations a bioelectrocatalytic layer with two sub-layers, a nanomaterial and a redox enzyme, was used. Thus, optimization of both sub-layers was performed, as described below. 


\section{Full Paper}

\subsubsection{Nanomaterials}

To increase enzyme loadings, and possibly to raise the double-layer capacitance even further, different nanomaterials, AuNPs and MWCNTs with different diameters (vide supra), were deposited on top of the PEDOT-graphene composite layer. The ensemble was also complemented with TTF-TCNQ crystals (Fig. 2B) in order to realize proper electron transfer between the complex electrode surface and the active site of the enzyme.

It has been shown that TCNQ and TTF may be regarded as low-toxicity compounds [39]. Several cytotoxicological studies concluded that AuNPs were nontoxic or did only marginally influence cell viability [40-42]. Carbon based bio-materials also show excellent biocompatibility [43]. However, some recent comprehensive studies indicate cellular toxicity of AuNPs of certain sizes at certain concentrations [44]. In a recent review it is suggested that most biocompatibility studies do not offer clear statements on the safety of nanomaterials. Consequently, the author concludes that most studies are either self-contradictory or arrive at completely erroneous conclusions [45]. Nevertheless, it is expected that nanomaterials will be further exploited in biomedical devices, with no or insignificant side effects.

During the optimization stage, a commercially available redox enzyme, $A n \mathrm{GOx}$, was exclusively used. To check the electrocatalytic current outputs from bio-electrodes CVs were recorded at $35^{\circ} \mathrm{C}$ in $100 \mathrm{mM} \mathrm{PB}$, pH 7.4, using different glucose concentrations. A well-pronounced increase of the current density with increasing glucose concentration was observed (Fig. 3). This substrate current dependence was attributed to the electrocatalytic oxidation of glucose by $A n \mathrm{GOx}$, mediated by TTF-TCNQ. The bioelectrochemical process can be described according to the reaction scheme below (Equations 2.1-2.4) [28]:

$$
\begin{aligned}
& \mathrm{S}_{\text {bulk }} \stackrel{\text { diffusion }}{\longrightarrow} \mathrm{S}_{\text {surface }} \\
& \mathrm{S}_{\text {surface }}+\mathrm{E}_{\mathrm{ox}} \stackrel{\mathrm{k}_{1}}{\longrightarrow} \mathrm{ES} \stackrel{\mathrm{k}_{\text {cat }}}{\longrightarrow} \mathrm{E}_{\text {red }}+\mathrm{P} \\
& \mathrm{E}_{\text {red }}+\mathrm{M}_{\mathrm{ox}} \stackrel{\mathrm{k}_{2}}{\longrightarrow} \mathrm{E}_{\mathrm{ox}}+\mathrm{M}_{\text {red }} \\
& \mathrm{M}_{\text {red }} \stackrel{\mathrm{k}_{3}}{\longrightarrow} \mathrm{M}_{\mathrm{ox}}+\mathrm{ne}^{-}
\end{aligned}
$$

where $\mathrm{S}$ is the substrate (glucose), $\mathrm{E}$ is the enzyme $(\mathrm{GOx})$, ES is the enzyme-substrate complex, $\mathrm{P}$ is the product (gluconolactone), and $\mathrm{M}$ is the mediator (TTFTCNQ)

Even with the lowest glucose concentration $(0.05 \mathrm{mM})$ the bioanode did perform and current was generated. For the highest glucose concentration, i.e., $500 \mathrm{mM}$, values for the catalytic response were very close to those obtained for $50 \mathrm{mM}$ glucose (Fig. 3). The highest current densities at $0.05 \mathrm{mM}, 5 \mathrm{mM}$ and $50 \mathrm{mM}$ were obtained for MWCNTs with O.D. $20-30 \mathrm{~nm}$. Thus, the system Au/
ELECTROANALYSIS
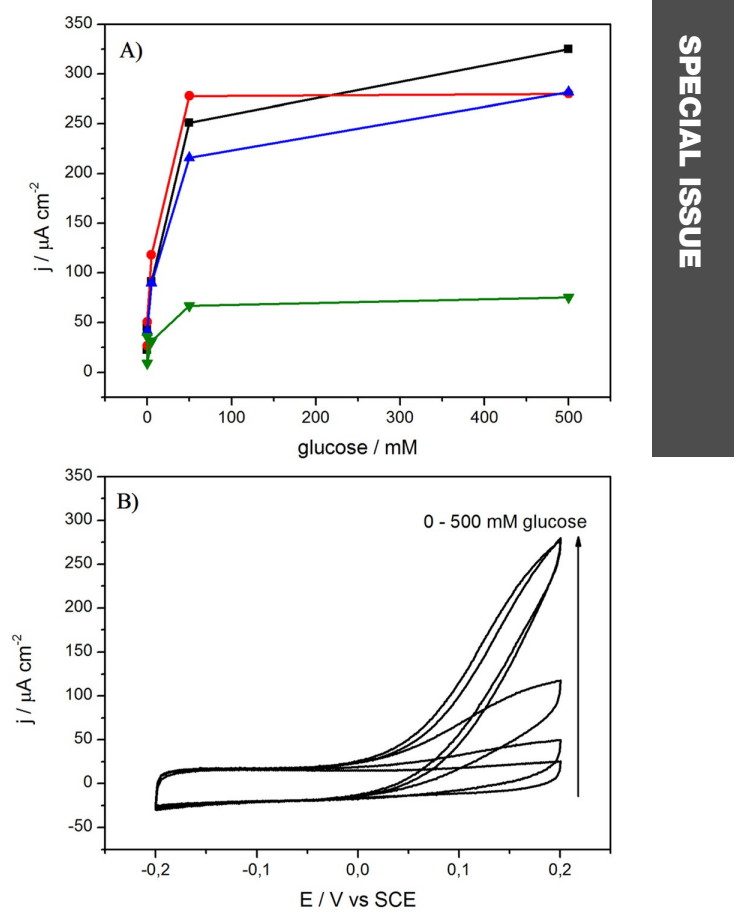

Fig. 3. (A) Plot of the dependence of the catalytic current on five different glucose concentrations $(0,0.05,5,50$, and $500 \mathrm{mM})$ in $100 \mathrm{mM} \mathrm{PB}, \mathrm{pH} 7.4,35^{\circ} \mathrm{C}$, obtained from $\mathrm{CVs}$ at $0.2 \mathrm{~V}$ vs. SCE for the working electrode Au/PEDOT-graphene/TTF$\mathrm{TCNQ} /$ nanomaterial layer/AnGOx. The different nanomaterial layers tested were $(\boldsymbol{\nabla})$ no nanomaterial, $(\mathbf{\Delta})$ gold nanoparticles $(\mathrm{d}=15-20 \mathrm{~nm}),(\boldsymbol{\square})$ MWCNTs (O. D. $=10-15 \mathrm{~nm})$, and (•) MWCNTs (O. D. $=20-30 \mathrm{~nm}$ ). (B) Example of CVs of the working electrode Au/PEDOT-graphene/TTF-TCNQ/MWCNTs (O. D. $=20-30) / A n \mathrm{GOx}$ in $100 \mathrm{mM} \mathrm{PB}, \mathrm{pH} 7.4,35^{\circ} \mathrm{C}$, containing five different glucose concentrations $(0,0.05,5,50$, and $500 \mathrm{mM})$ at a scan rate of $10 \mathrm{mVs}^{-1}$.

PEDOT-graphene/TTF-TCNQ/MWCNT(O. D. $=20$

$30 \mathrm{~nm}) / A n \mathrm{GOx} /$ gelatin was selected as the optimal for further investigations (from here and below Au/PEDOTgraphene/TTF-TCNQ/MWCNT).

\subsubsection{Biocatalysts}

In previous studies it was shown that in mediated systems $P a \mathrm{GOx}_{\mathrm{mut}}$, in which lysine is substituted with glutamic acid in the position 424 , demonstrated higher catalytic efficiency towards glucose $\left(9.6-14.5 \cdot 10^{4} \mathrm{M}^{-1} \mathrm{~s}^{-1}\right)$ compared to $P a \mathrm{GOx}_{\mathrm{wt}}\left(9.5-12.0 \cdot 10^{4} \mathrm{M}^{-1} \mathrm{~s}^{-1}\right)$ and especially $A n \mathrm{GOx}$ (1.8-3.2 $\left.\cdot 10^{4} \mathrm{M}^{-1} \mathrm{~s}^{-1}\right)$ [46]. Moreover, the mutant also had a lower $K_{\mathrm{M}}$ value compared to wild-type oxidoreductases. 


\section{Full Paper}

Thus, an initial comparison of biocatalytic activities of available biocatalysts, $A n \mathrm{GOx}, P a \mathrm{GO}_{\mathrm{wt}}$, and $P a \mathrm{GOx}_{\mathrm{mut}}$, was performed, but in a homogeneous mediator-less reaction at low glucose concentration, i.e., $0.05 \mathrm{mM}$, matching the bio-fuel concentration in tear fluid [29]. As expected, higher rates of oxygen consumption for both $\mathrm{PaGOxs}$ were obtained, when compared to $A n \mathrm{GOx}$ (Supporting Fig. S2). The calculated values were $81 \mathrm{pMs}^{-1}, 92 \mathrm{pMs}^{-1}$, and $159 \mathrm{pMs}^{-1}$ for $A n \mathrm{GOx}, P a \mathrm{GO}_{\mathrm{wt}}$, and $P a \mathrm{GOx}_{\mathrm{mut}}$, respectively. Thus, the commercially available enzyme $(A n \mathrm{GOx})$ was excluded from further studies.

The optimized nanostructured electrode, Au/PEDOTgraphene/TTF-TCNQ/MWCNT, was used to study the difference in biocatalytic responses using $\mathrm{PaGOxs}$. As can be seen from Fig. 4, the electrode with immobilized $\mathrm{Pa}$ $\mathrm{GOx}_{\mathrm{mut}}$ showed the highest bioelectrocatalytic current output at low glucose concentration with a current density close to $10 \mu \mathrm{Acm}^{-2}$, whereas $P a \mathrm{GO}_{\mathrm{wt}}$ was a much better biocatalyst at high bio-fuel concentrations. A current density value as high as $25 \mu \mathrm{A} \mathrm{cm}^{-2}$ at an applied potential of $0.1 \mathrm{~V} v$ s. SCE, i.e., with $0.1 \mathrm{~V}$ lower overpotential compared to $A n G O x$ (Fig. 3), was observed for the optimized electrode with $\mathrm{PaGOx}_{\text {mut }}$, operating in artificial human tears (Supporting Fig. S3). This was, however, in all likelihood, due to contributions from non-bioelectrocatalytic oxidation of other components, including e.g., ascorbate, presented in the complex electrolyte. Moreover, a significant capacitance contribution to the registered current output should be also taken into account. Nevertheless, the registered current outputs from the optimized transparent bioanodes at low glucose concentrations were much higher compared to previously reported current densities of rigid opaque glucose oxidizing enzymatic electrodes based on AuNPs [6], or flexible transparent enzymatic anodes based on Au nanostructured polymer

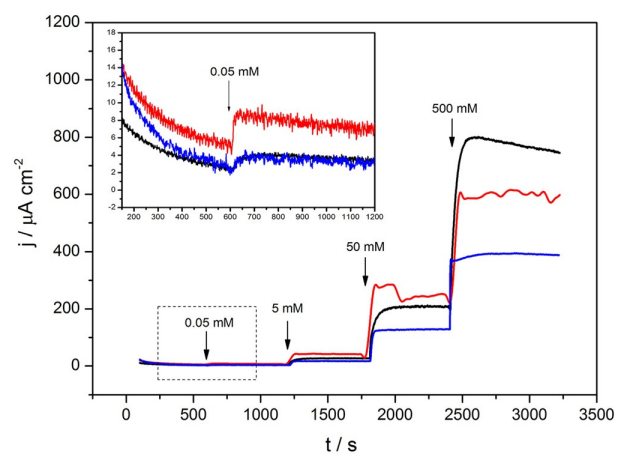

Fig. 4. Amperometric responses obtained at $0.2 \mathrm{~V}$ vs. SCE at different glucose concentrations $(0.05,5,50$, and $500 \mathrm{mM})$ for Au/PEDOT-graphene/TTF-TCNQ/MWCNTs/GOx electrodes, in $100 \mathrm{mM} \mathrm{PB} \mathrm{pH} 7.4,35^{\circ} \mathrm{C} . P a \mathrm{GO}_{\mathrm{wt}}, P a \mathrm{GOx}_{\mathrm{mut}}$, and $A n \mathrm{GOx}$ correspond to black, red, and blue curves, respectively.
ELECTROANALYSIS

electrodes [47], operating in $0.05 \mathrm{mM}$ and $5 \mathrm{mM}$ glucose solutions, respectively.

The results presented in Fig. 4, viz. well-pronounced dependence of bioelectrocatalytic currents on glucose concentration, also indicate a possibility for usage as a self-powered sensor towards glucose, instead of glucose oxidizing bioanode of electric power biodevices. Taking into account the capacitive features, different constructions of glucose sensitive biodevices can be envisioned, i.e. two-electrode based self-powered biosensors, as well as biodevices based on a single electrode, with an external signal reader.

The optimized transparent enzymatic cathode, $\mathrm{Au} /$ PEDOT-graphene/TTF-TCNQ/MWCNTs/PaGOx $\mathrm{Gut}_{\text {m }}$ had a transmittance of $20 \%$ only (Table 1 ). However, if the opacity of the conducting layer ( $\mathrm{Au}$ ) is neglected, e.g., if $\mathrm{Au}$ would be replaced by an indium tin oxide electrode, the transmittance would be as high as $83 \%$.

The biodevice was also tested in pulse mode. Current densities for the biodevice, when the bioelectrode was operating in human artificial tears, changed from 21 to $16 \mu \mathrm{Acm}^{-2}$ from the first to the last discharge cycle, demonstrating some instability in the system, attributable, in all likelihood, to leakage of the mediator (Fig. 5).

The OCP was reached after $600 \mathrm{~s}$ and remained relatively stable during 5 charge-discharge cycles, varying from $-0.103 \mathrm{~V}$ to $-0.095 \mathrm{~V} v s$. SCE. The total charge stored in the electrode was calculated to be $571 \mu \mathrm{C} \mathrm{cm}^{-2}$ (Supporting Fig. S4), in good agreement with the capacitance measured for the non-biomodified electrode ( $c f$. Table 2 and Supporting Table S1).

\section{Conclusions and Perspectives}

In the current work transparent capacitive enzymatic anodes were fabricated, characterized, and optimized. The final biodevice was based on the improved biocatalyst, a recombinant glucose oxidase mutant from Penicilli-
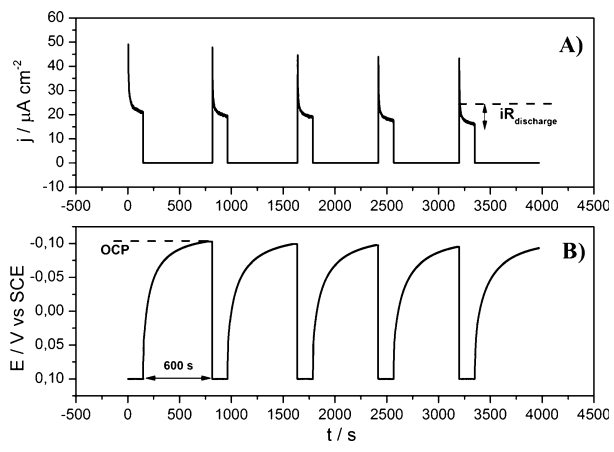

Fig. 5. Discharge-charge cycles of Au/PEDOT-graphene/TTFTCNQ/MWCNTs/PaGOx $\mathrm{mut}_{\text {t }}$ electrode, operating in artificial human tears at $35^{\circ} \mathrm{C}$. 


\section{Full Paper}

um amagasakiense with high catalytic efficiency towards glucose. Taking into account the relatively high biodevice transparency (with a maximal transparency as high as $83 \%$, when accounting only for the capacitive and bioelectrocatalytic layers), the low onset potential for glucose electrooxidation (about $-0.1 \mathrm{~V}$ vs. SCE), the high specific capacitance (about $1 \mathrm{mF} \mathrm{cm}^{-2}$ ), and the high current densities observed in artificial tears (21 and $10 \mu \mathrm{A} \mathrm{cm}^{-2}$ in continuous and pulse modes, respectively), one can conclude that this particular bioanode is well suited for enzymatic charge-storing FCs, as an electric power source for smart electronic contact lenses, as well as for different types of glucose sensitive biosensors, including conventional enzymatic devices, novel self-powered biosensors, and even not yet disclosed biodevices based on a single electrode with an external signal reader.

In general, drawing on the extraordinary features of enzyme based conventional and especially charge-storing FCs, i.e., FC/SC combo, applications are not limited to the contact lens platform or tears as the biofuel source. Focusing on the more convenient ex vivo protocol, saliva and sweat (and urine, for specialty purposes) are readily available, excellent biofuel sources that can be probed using technically undemanding platforms. Depending on the particular application, the FC/SC can either be relied on as a source of energy, or used directly as an analytical tool. In the first case the FC/SC output could be used to drive further probe arrays for e.g., evaluation of fitness indicators or disease markers. In the latter case the FC/ SC output could be directly correlated to the concentration of a particular analyte. In both cases, the FC/SC conveyer could be an electronic diaper or electronic patch, as well as a wristband that secures the capillary force based contact with the physiological fluid.

\section{Acknowledgements}

This work was supported financially by the European Commission (PEOPLE-2013-ITN-607793) to EG-A and $\mathrm{NM}$, by the ANR project RATIOCELLS ( ${ }^{\circ}$ ANR-12BS08-011-01) and la Région Aquitaine to SG et NM, and by the Samsung Electronics Co. Ltd. to DP and SS.

\section{References}

[1] N.-S. Choi, Z. Chen, S. A. Freunberger, X. Ji, Y.-K. Sun, K. Amine, G. Yushin, L. F. Nazar, J. Cho, P. G. Bruce, Angew. Chem., Int. Ed. 2012, 51, 9994.

[2] Z. Blum, D. Pankratov, S. Shleev, Expert Review of Ophthalmology 2014, 9, 269.

[3] R. N. Khuri, Electrochemical strip device for determining tear constituents, US Patent No. 1993-106282 53524111994 , $6 \mathrm{pp}$.

[4] N. M. Farandos, A. K. Yetisen, M. J. Monteiro, C. R. Lowe, S. H. Yun, Adv. Healthcare Mater. 2015, 4, 792.

[5] T. Ruzgas, S. Shleev, T. Arnebrant, Flexible biofuel cell, device and method. WO Patent Application No. 2011EP54554 2011, 31 pp.

\section{ELECTROANALYSIS}

[6] M. Falk, V. Andoralov, Z. Blum, J. Sotres, D. B. Suyatin, T. Ruzgas, T. Arnebrant, S. Shleev, Biosens. Bioelectron. 2012, 37,38 .

[7] F. Davis, S. P. J. Higson, Biosens. Bioelectron. 2007, 22, 1224

[8] J. A. Cracknell, K. A. Vincent, F. A. Armstrong, Chem. Rev. 2008, 108, 2439.

[9] M. Falk, C. W. Narvaez Villarrubia, S. Babanova, P. Atanassov, S. Shleev, ChemPhysChem 2013, 14, 2045.

[10] H. R. Luckarift, P. Atanassov, G. R. Johnson, Enzymatic fuel cells: From fundamentals to applications, John Wiley \& Sons, Inc., Hoboken, New Jersey, 2014, 468 pp.

[11] R. A. S. Luz, A. R. Pereira, J. C. P. de Souza, F. C. P. F. Sales, F. N. Crespilho, ChemElectroChem 2014, 1, 1751.

[12] E. Katz, Bioelectronic Medicine 2015, 2, 1.

[13] D. Pankratov, P. Falkman, Z. Blum, S. Shleev, Energy Environ. Sci. 2014, 7, 989.

[14] A. Deeke, H. J. A. Sleutels Tom, V. M. Hamelers Hubertus, J. N. Buisman Cees, Environ. Sci. Technol. 2012, 46, 3554.

[15] A. Deeke, T. H. J. A. Sleutels, A. Ter Heijne, H. V. M. Hamelers, C. J. N. Buisman, J. Power Sources 2013, 243, 611.

[16] M. Kizling, K. Stolarczyk, J. S. S. Kiat, P. Tammela, Z. Wang, L. Nyholm, R. Bilewicz, Electrochem. Commun. 2015, 50, 55 .

[17] C. Agnes, M. Holzinger, A. Le Goff, B. Reuillard, K Elouarzaki, S. Tingry, S. Cosnier, Energy Environ. Sci. 2014, 7, 1884.

[18] D. Pankratov, Z. Blum, D. B. Suyatin, V. O. Popov, S Shleev, ChemElectroChem 2014, 1, 343.

[19] M. Kizling, S. Draminska, K. Stolarczyk, P. Tammela, Z. Wang, L. Nyholm, R. Bilewicz, Bioelectrochemistry 2015, 106,34 .

[20] C. Santoro, F. Soavi, A. Serov, C. Arbizzani, P. Atanassov, Biosens. Bioelectron. 2016, 78, 229.

[21] H. Oman, MRS Bull. 1999, 24, 33.

[22] A. Heller, Phys. Chem. Chem. Phys. 2004, 6, 209.

[23] J. P. Craig, I. Singh, A. Tomlinson, P. B. Morgan, N. Efron, Eye 2000, 14, 635.

[24] L. G. Carney, T. F. Mauger, R. M. Hill, Invest. Ophthalmol. Vis. Sci. 1989, 30, 747.

[25] O. Courjean, N. Mano, J. Biotechnol. 2011, 151, 122.

[26] W. Haiss, N. T. K. Thanh, J. Aveyard, D. G. Fernig, Anal. Chem. 2007, 79, 4215.

[27] X. X. Xiao, M. E. Wang, H. Li, P. C. Si, Talanta 2013, 116, 1054.

[28] I. Ivanov, T. Vidakovic-Koch, K. Sundmacher, J. Power Sources 2011, 196, 9260.

[29] C. R. Taormina, J. T. Baca, S. A. Asher, J. J. Grabowski, D. N. Finegold, J. Am. Soc. Mass Spectrom. 2007, 18, 332.

[30] W. Chen, Z. L. Fan, L. Gu, X. H. Bao, C. L. Wang, Chem. Commun. 2010, 46, 3905.

[31] Y. P. Fu, X. Cai, H. W. Wu, Z. B. Lv, S. C. Hou, M. Peng, X. Yu, D. C. Zou, Adv. Mat. 2012, 24, 5713.

[32] Shan-hui Hsu, Cheng-Ming Tang, H.-J. Tseng, J. Biomed. Mat. Res. 2006, 79A, 759.

[33] D. Gaspar, A. C. Pimentel, T. Mateus, J. P. Leitao, J. Soares, B. P. Falcao, A. Araujo, A. Vicente, S. A. Filonovich, H. Aguas, R. Martins, I. Ferreira, Sci. Rep. 2013, 3, 1469.

[34] R. Balint, N. J. Cassidy, S. H. Cartmell, Acta Biomater. 2014, 10, 2341.

[35] N. K. Guimard, N. Gomez, C. E. Schmidt, Prog. Polym. Sci. 2007, 32, 876 .

[36] Z. A. King, C. M. Shaw, S. A. Spanninga, D. C. Martin, Polymer 2011, 52, 1302.

[37] D. V. Pankratov, S. V. Shleev, E. Gonzalez-Arribas, M. Parunova Yu, S. Zeyfman Yu, A. V. Lipkin, M. A. Gorbacheva, S. V. Kuznetsov, Acta Naturae 2015, 7, 98. 


\section{Full Paper}

[38] M. F. Zainal, Y. Mohd, Polym.-Plast. Technol. Eng. 2015, 54 , 276.

[39] J. Kulys, V. Simkeviciene, I. J. Higgins, Biosens. Bioelectron. 1992, 7, 495 .

[40] T. B. Huff, M. N. Hansen, Y. Zhao, J.-X. Cheng, A. Wei, Langmuir 2007, 23, 1596.

[41] C. J. Murphy, A. M. Gole, J. W. Stone, P. N. Sisco, A. M. Alkilany, E. C. Goldsmith, S. C. Baxter, Acc. Chem. Res. 2008 $41,1721$.

[42] R. Shukla, V. Bansal, M. Chaudhary, A. Basu, R. R. Bhonde, M. Sastry, Langmuir 2005, 21, 10644.

[43] S. K. Smart, A. I. Cassady, G. Q. Lu, D. J. Martin, Carbon 2006, 44,1034

\section{ELECTROANALYSIS}

[44] T. Mironava, M. Hadjiargyrou, M. Simon, M. H. Rafailovich, Nanotoxicology 2014, 8, 189.

[45] H. F. Krug, Angew. Chem., Int. Ed. 2014, 53, 12304.

[46] E. Suraniti, O. Courjean, S. Gounel, E. Tremey, N. Mano, Electroanalysis 2013, 25, 606.

[47] D. Pankratov, R. Sundberg, J. Sotres, I. Maximov, M. Graczyk, D. B. Suyatin, E. Gonzalez-Arribas, A. Lipkin, L. Montelius, S. Shleev, J. Power Sources 2015, 294, 501.

Received: February 18, 2016 Accepted: March 7, 2016 Published online: April 13, 2016 
R1 

DOI: 10.1002/elan.201501116

\section{Tear Based Bioelectronics}

Dmitry Pankratov, ${ }^{[a, b, c]}$ Elena González-Arribas, ${ }^{[a]}$ Zoltan Blum,,${ }^{[a]}$ and Sergey Shleev*[a, b, c]

\begin{abstract}
This work provides an overview of the recent advances in the field of tear-based wearable electrochemical biodevices, including non-invasive biosensors, biological fuel cells and biosupercapacitors. Contact lenses are attractive platforms for fabricating non-invasive self-contained gadgets for different applications, starting from de-
\end{abstract}

vices with casual or mundane purposes only, like personalized smart lenses with direct (invisible for others) displays, and ending with biomedical devices for continuous fitness status and/or health care monitoring. Key requirements and challenges that confront researchers in this exciting area are discussed.

Keywords: Human tears $\cdot$ Flexible $\cdot$ attachable $\cdot$ adhesiable biodevices $\cdot$ Smart electronic contact lenses $\cdot$ Biological fuel cells . Biosupercapacitors $\cdot$ Electrochemical biosensors $\cdot$ Non-invasive monitoring

\section{Introduction}

Bioelectronics is a rapidly progressing multidisciplinary scientific area, having emerged from the combination of biology, electronics, bio- and nanotechnologies [1]. Bioelectronics aims to integrate biomaterials (proteins, enzymes, organelles, whole living cells, etc) and electric or electronic elements (electrodes, chips, field-effect transistors, piezoelectric crystals, etc) into functional devices [2]. Devices that may function as a discrete biosensor, a biocomputing device (bio-diode, bio-transistor, and bioelectronic circuitry), a biological electric power source (biofuel cell, bio-battery, and biosupercapacitor), as well as a complete self-contained (i.e. self-powered and wireless) bioelectronic device (Fig. 1).

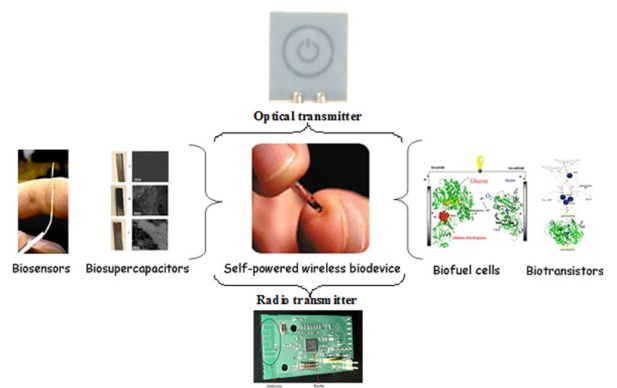

Fig. 1. Schematic illustration of a combination of separate (bio)electronic elements into a functional bioelectronic device. Optical transmitter - a flexible low voltage liquid crystal based display from Acreo AB (Linköping, Sweden); Biosensor - a flexible biosensor from [5]; Biosupercapacitor - a self-charging electrochemical biocapacitor from [6]; Biofuel cell - a DET based enzymatic fuel cell from [7]; Biotransistor - a laccase-gold transistor from [8]; Radio transmitter - a low voltage low power radio transmitter unit from Novosense AB (Lund, Sweden).
One of the intended applications of bioelectronics, which attracts a lot of attention nowadays, is implantable self-contained biodevices. Unfortunately, the main impediment of bioelectronic devices is the limited operational stability. It is clear that the full potential of implantable bioelectronics will be realized only when they become robust and reliable enough for real practical applications. On the one hand, there is a lot of research going on to improve the operational life-time of bioelectronic devices. On the other hand, a limited number of studies address biocompatibility and safety issues. Thus, it seems that practically usable implanted bioelectronics is quite challenging to achieve at least in the immediate future.

At the beginning of the $21^{\text {st }}$ century several scientific papers appeared disclosing flexible, attachable, adhesive electronics. One of the more fascinating papers introduced new classes of electronic systems that achieved thicknesses, effective elastic moduli, bending stiffness, and areal mass densities matched to the human epidermis (Fig. 2) [3]. Following that report, papers concerning biosensors and biofuel cells operating in human sweat and saliva have been recently published [4]. Another interesting direction of ex vivo operating bioelectronics, the focus of this mini-review, is tear based bioelectronics, i.e. bioelectronic devices operating in human lachrymal fluid.

Among different ex vivo operating bioelectronics, tear based bioelectronic devices were fabricated and tested first, already in 2009. As usual in the bioelectrochemical

[a] D. Pankratov, E. González-Arribas, Z. Blum, S. Shleev Malmö University, 20560 Malmö, Sweden

(Sergey Shleev)

*e-mail: sergey.shleev@mah.se

[b] D. Pankratov, S. Shleev

A.N. Bach Institute of Biochemistry, 119071 Moscow, Russia

[c] D. Pankratov, S. Shleev

National Research Center "Kurchatov Institute", 123182

Moscow, Russia 
Dmitry Pankratov is a $\mathrm{PhD}$ student at the Department of Biomedical Sciences, Malmö University, Sweden, under the supervision of Prof. Sergey Shleev. In 2008 he received his M.S degree in Physical Chemistry from Bryansk State University, Russia. From 2009 till 2012 he was a lecturer at the Moscow State University of Mechanical Engineering, Russia. His current research interests include nanostructured enzymatic electrodes and their application in bioelectronic devices.

Elena González-Arribas is a $\mathrm{PhD}$ student at the Department of Biomedical Sciences, Malmö University, Sweden, within BIOENERGY European project under the supervision of Prof. Sergey Shleev. In 2012 she received her B.A. degree in biology from the Complutense University of Madrid, Spain, and her M.S. degree in Environmental and Sustainable Chemistry from Alicante University, Spain, in 2013. She also attended several advanced courses in electro-

chemistry at the same university in 2014. Currently, her research interests involve enzymatic fuel cells, transparent, flexible and nanostructured conductive thin films, and wireless electronics.

Zoltan Blum received his PhD in organic chemistry from Lund University, Sweden, in 1981. After a short spell in the pharmaceutical industry he returned to Lund University and became an Associate Professor in 1990. From 1998 he has held various academic and administrative positions at Malmö University. Currently, his research interests include bioelectronics and its applications.

Sergey Shleev received his $\mathrm{PhD}$ in biochemistry from A.N. Bach Institute of Biochemistry, Russian Academy of Sciences, Moscow, in 2001. After that, he held various positions at Swedish Universities (Lund and Malmö) until 2011, when he became an Associate Professor in biomedical technology at Malmö University, Sweden. During the same year he also habilitated at the Institute of Biochemistry, Russia. From 2013 he is a Professor in biomedical technolo-
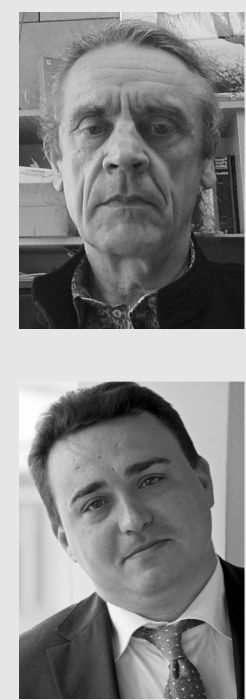

gy at Malmö University. His current main scientific and technological interests are studies of complex redox enzymes and their applications in bioelectronics operating in vivo and ex vivo. field in general, and bioelectronics in particular, the first reports were concerned with glucose sensing. Given that in 2012 the total cost of managing diabetes was $\$ 245$ billion in the U.S. alone, glucose sensors are only to be expected. Prior to a detailed analysis of tear based bioelectronic devices fabricated and tested to date, it is only pertinent to briefly describe the human eye and its tear film, which includes an aqueous layer, i.e. lachrymal fluid, where biodevices are intended to operate.

\section{Human Tear Film}

Human tears (lachrymal fluid/liquid) is an complex physiological fluid ( $98 \%$ water), which contains both low and high molecular weight compounds ( $2 \%$ solids), viz. water, electrolytes, small organic molecules, proteins, enzymes, secreted by lachrymal glands [9]. Many of these compounds have diagnostic potential, as summarized in Table 2 in the recent review concerning contact lens sensors [10]. In addition to dopamine, mentioned in the table, other neurotransmitters have also been found in tear fluid, even though at lower concentrations, 0.5$1.5 \mu \mathrm{g} / \mathrm{mL}$, e.g., norepinephrine [11]. In glaucoma patients lower than average concentration values for neurotransmitters have been reported, which reflect the attenuated activity of the sympathetic innervation of the eye. Thus, the determination of catecholamines in tears has been advocated as a test in glaucoma diagnosis [11]. Since norepinephrine is a well-known stress marker, and its concentration in the fluid is high enough for relatively simple detection (i.e. in the $\mu \mathrm{M}$ range), the concentration of which might increase even further during psychological and physical pressures, one can also consider the development of non-invasive tear based stress sensors in the future. Otherwise, many diseases and conditions that can be diagnosed by analyzing the composition of tear fluid are adequately summarized in a recent review [10].

When an eye is opened, tear fluid is distributed in the form of a thin film on the surface of the eye-bulb, with an average thickness of about $9-10 \mu \mathrm{m}$, depending on the palpebral fissure width. Lachrymal fluid is one of the main parts of a human tear film that covers the exposed area of the globe of the eye capped with a lipid layer, which prevents film evaporation (Fig. 3) [9].

Lipids are secreted by the meibomian glands (or tarsal glands, $\mathrm{ca}$. 30-40 glands on the upper eyelids and 20-30 glands on the lower eyelids) within the eyelids that are squeezed out when blinking [12]. The depth of the mucous layer over the cornea is about $0.8-1.0 \mu \mathrm{m}$ [13] Below we describe major physical and chemical parameters of human lachrymal fluid, which are crucial for operation of bioelectronics.

The physiological temperature of tear fluid is about $35^{\circ} \mathrm{C}[14], \mathrm{pH} 7.5 \pm 0.1$ [15], osmolarity $318 \pm 16 \mathrm{mOsm} /$ $\mathrm{kg}$ [16], and it is total volume is only about $6.2 \pm 2.0 \mu \mathrm{L}$ [9]. In spite of the fact that lachrymal fluid does contain a lot of different compounds it is still less complex and also less corrosive than blood, with the added benefit of 

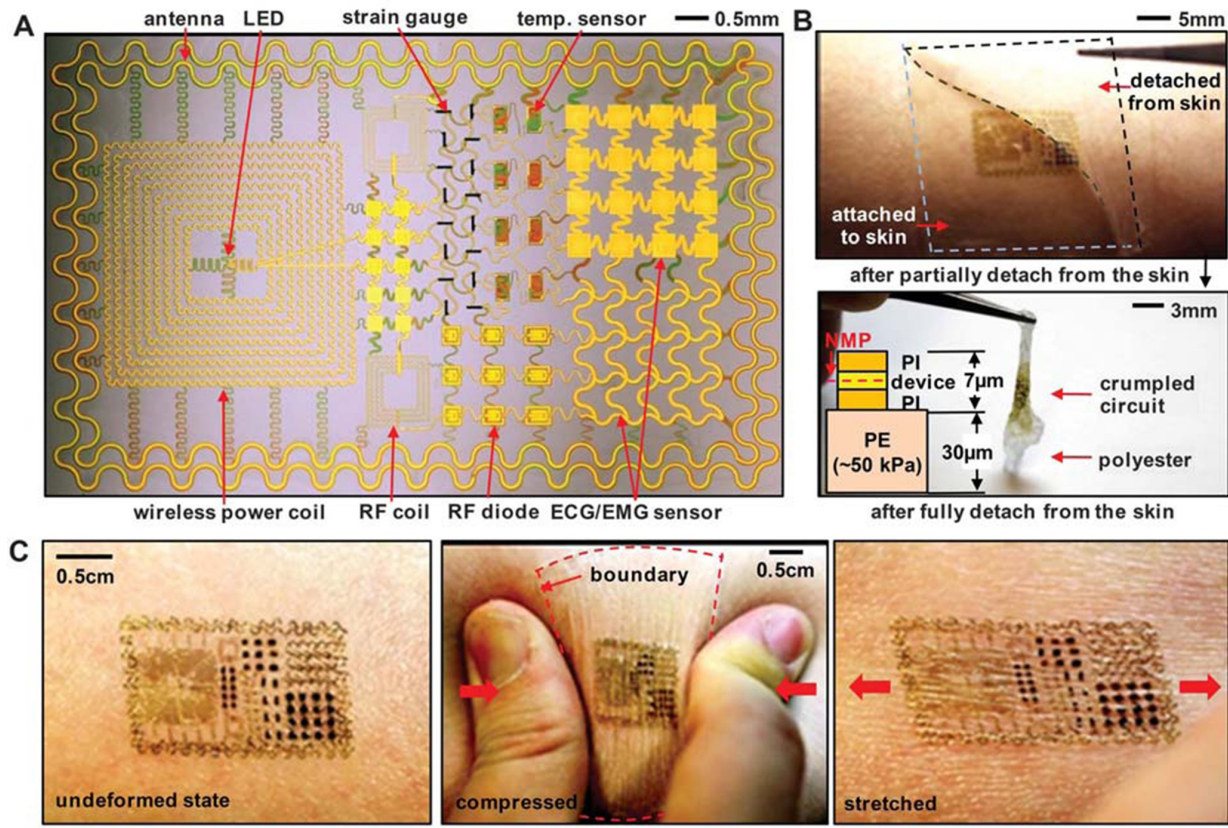

after fully detach from the skin
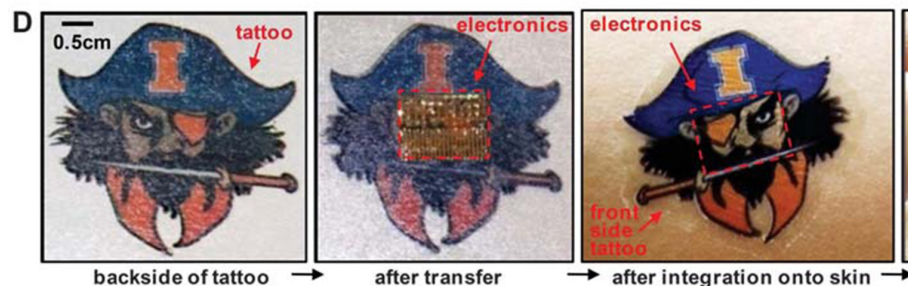

stretched

Fig. 2. (A) Image of a demonstration platform for multifunctional electronics with physical properties matched to the epidermis Mounting this device on a sacrificial, water-soluble film of polyvinyl alcohol, placing the entire structure against the skin, with electronics facing down, and then dissolving the polyvinyl alcohol leaves the device conformally attached to the skin through van der Waals forces alone, in a format that imposes negligible mass or mechanical loading effects on the skin. (B) Epidermal electronic system partially (top) and fully (bottom) peeled away from the skin. (Inset) A representative cross-sectional illustration of the structure, with the neutral mechanical plane defined by a red dashed line. (C) Multifunctional epidermal electronic system on skin: undeformed (left), compressed (middle), and stretched (right). (D) A commercial temporary transfer tattoo provides an alternative to polyester/ polyvinyl alcohol for the substrate; in this case, the system includes an adhesive to improve bonding to the skin. Images are of the backside of a tattoo (far left), electronics integrated onto this surface (middle left), and attached to skin with electronics facing down in undeformed (middle right) and compressed (far right) states. Reproduced from [3] with permission from Science.

being available without requiring surgery [9]. The relative compositional simplicity of human tears, in addition to a special untifouling mechanism of the eye, viz. a combination of wiping and chemical secretions to clean the cornea [17], mitigates the biofouling problems for tear based bioelectronics compared to implanted biodevices.

It is important to emphasize different lachrymal secretions that can occur, resulting in the formation of three types of tears, viz. basal, reflex and physico-emotional lachrymal fluids [18], since their composition differs to a great extent. Basal tears is the protective tear film, which normally covers the surface of the healthy eye at all times (Fig. 3). Basal tears are produced in small quantities $\left(0.5-2.2 \mu \mathrm{Lmin}^{-1}[9,19]\right)$ to maintain a lachrymal film on the corneal surface for both visual and corneal homeostatic purposes [20]. Reflex tears is an increased 
Table 1. Reported concentrations of some bioanalytes used so far in tear based bioelectronics operating in human lachrymal fluid.

\begin{tabular}{lllll}
\hline $\begin{array}{l}\text { Bioanalyte } \\
\text { (Biofuel) }\end{array}$ & $\begin{array}{l}\text { Reported ranges of } \\
\text { concentrations }(\mathrm{mM})\end{array}$ & $\begin{array}{l}\text { Probable average concentration } \\
\text { in basal tears }(\mathrm{mM})\end{array}$ & $\begin{array}{l}\text { Maximal voltages of } \\
\text { biofuel/oxygen fuel cells [a] }\end{array}$ \\
\hline Glucose & $0.013-0.6$ & 0.03 & 1.179 & $\begin{array}{l}\text { References } \\
\text { Ascorbate }\end{array}$ \\
Lactate & $0.008-0.665$ & 0.02 & 0.735 & {$[9,22]$} \\
\hline
\end{tabular}

[a] Maximal voltages were calculated using half-potentials of redox reactions given in Eqs. 4-7, i.e. the maximal theoretical (open-circuit) voltages of glucose/oxygen, ascorbate/oxygen, and lactate/oxygen devices

Table 2. Electrochemical biosensors intended for glucose determination in human lachrymal fluid.

\begin{tabular}{|c|c|c|c|c|}
\hline Analyte/Enzyme & Linear range of detection, $\mathrm{mM}$ & Sensitivity, $\mu \mathrm{Acm}^{-2} \mathrm{mM}^{-1}$ & Type of testing & Ref. \\
\hline \multirow[t]{5}{*}{ Glucose/Glucose oxidase } & $0.125-20$ & n.d. & In vitro, flowing cell & {$[31]$} \\
\hline & $0.03-5$ & n.d. & Ex vivo, rabbit eye & [39] \\
\hline & $0.01-0.6$ & 240 & In vitro & {$[33]$} \\
\hline & $0.05-2$ & 18 & In vitro, eye model & {$[35,6 \mathrm{~b}]$} \\
\hline & $0.04-0.83$ & 8 & In vitro & {$[40]$} \\
\hline Glucose/Glucose dehydrogenase & $0.01-1$ & * & Ex vivo, human tears & {$[5]$} \\
\hline
\end{tabular}

n.d. - not determined; ${ }^{*}$ - coulometry based biosensor.

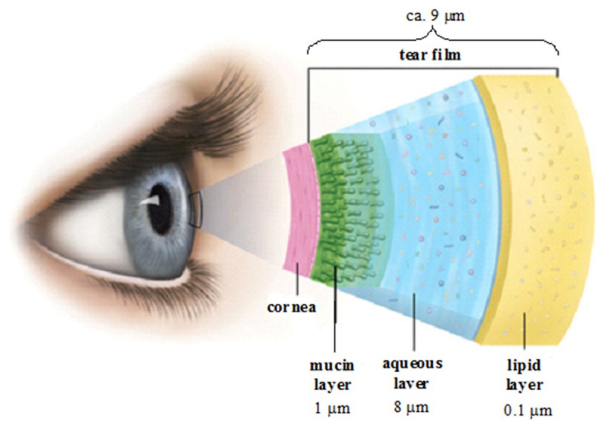

Fig. 3. A schematic illustration of the structure of a tear film of a human eye.

lacrimation (7-23 $\mu \mathrm{L} \mathrm{min}^{-1}$ [19]) due to physical or chemical stimulations. There are many variants of reflex tear induction, but the most evident and known reflex tears are the "irritative tears" produced by damage to the ocular surface by foreign bodies (including contact lenses at some cases [21]), wounds, and inflammation [18]. Psychoemotional tearing is produced by a cerebral stimulus of psychogenic origin. Thus, as basal tears is the result of a spontaneous neuroglandular activity, and as reflex tears is the result of an external sensorial stimulation, psychoemotional tears is the result of a cognitive and emotional brain process, i.e. "useless" for the eye [18].

To the first approximation two pathways for biomolecules to appear in tears should be mentioned [23a]. The first pathway is the secretion of intracellular biomolecules, e.g. lactate, by the lachrymal glands. The second pathway is an almost passive leakage of low-weight electrolytes (cations and anions) from blood plasma. Thus, it is not surprising that the content of reflex tears is much different from that of basal tears [22a]. Many studies on different bioanalytes (which can also serve as biofuels for electric power generation; vide infra) in human tears have been published, with a large discrepancy in the reported values of concentrations (Table 1). The bioanalyte concentrations in tears vary a lot depending on the collection method since any stimulation of the lachrymal glands decreases the efficiency of the filtration barrier. Tear samples can be obtained from human subjects in several ways, but drawbacks are associated with each approach For example, tears can be absorbed into Schirmer strips resting on the lower eyelid and subsequently eluted for biochemical analysis [25]. Although simple to perform, this procedure tends to collect cellular, as well as secreted, proteins, and the physical presence of the strip can cause mechanical stimulation of the corneal and conjunctival epithelium. As a result, the composition of the collected sample may differ from that in pure basal secretion [26]. A common alternative is to use microcapillary tubes to draw tears from the reservoir within the conjunctival sac, usually at the fornices. While generally less invasive than Schirmer strips, attempts to collect basal tears with this method can be tedious, particularly where there is a paucity of flow, as often occurs in dry eye or when the eyes are opened after awakening. To overcome this, it is often necessary to pool samples as a means of generating adequate volume for analysis [25b,27]. When collecting basal tears, it is also challenging to avoid inadvertent contact with the lids, and/or ocular surface, and thus, induce reflex tearing. Moreover, the very small volumes collected, along with low concentrations of bioanalytes in human lachrymal fluid (Table 1), could explain the large 


\section{Review}

discrepancies in different studies. To conclude, one has to admit that real accurate concentrations of even main bioanalytes in human basal tears are unknown so far. Contrary to the biofuel concentrations, the concentration of the biooxidant $\left(\mathrm{O}_{2}\right)$ in lachrymal fluid is quite high and well understood ( $c a .0 .22 \mathrm{mM}$ ) since human tears are air saturated during waking hours [28].

\section{Tear Based Biosensors}

At the beginning of $21^{\text {st }}$ century media was buzzing with reports on 'smart', or more appropriately, electronically augmented contact lenses for bionic eyesight. Already in 2008-2009 the very first prototypes of electronic contact lenses were presented (Fig. 4) by a group of researchers headed by Babak A. Parviz, a pioneer of this research field [29].
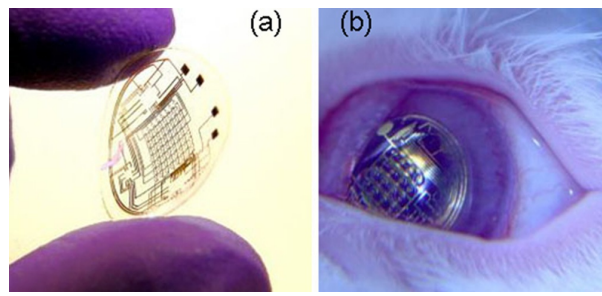

Fig. 4. (a) A photograph of one of the first prototypes of a contact lens containing metal circuit structures. (b) Illustration of $e x$ vivo animal trials (rabbit eye) of the electronic contact lens for 20 minutes at a time with no adverse effects. Reproduced from [29] with permission from IEEE.

In 2011 the group presented the design, construction, and in vivo rabbit testing of a wirelessly powered contact lens display, which consisted of a power harvesting antenna, an integrated circuit radio, metal interconnects, insulation layers, and a transparent sapphire chip containing a custom-designed light-emitting micro-diode (Fig. 5). The display was tested on live, anesthetized rabbits with no observed adverse effects [30]. Tear based electronics has been already commercialized and it is practically exploited nowadays (Fig. 6). To the best of our knowledge, the very first attempts to create an electrochemical biosensor embedded into a contact lens [31] was performed in the same time frame as the development of electronically augmented contact lenses for bionic eyesight [29]. A three electrode based amperometric sensor with an external $\mathrm{Ag} \mid \mathrm{AgCl}$ reference electrode was fabricated on a 100 $\mu \mathrm{m}$ thick poly(ethylene terephthalate) (PET) film [31]. The Pt working electrode was connected to an indium-tin oxide (ITO) surface, where a self-assembled monolayer of glucose oxidase (GOx) was formed using a previously developed procedure [32]. The sensing mechanism was based on the electrochemical oxidation of $\mathrm{H}_{2} \mathrm{O}_{2}$ (reac-

\section{ELECTROANALYSIS}

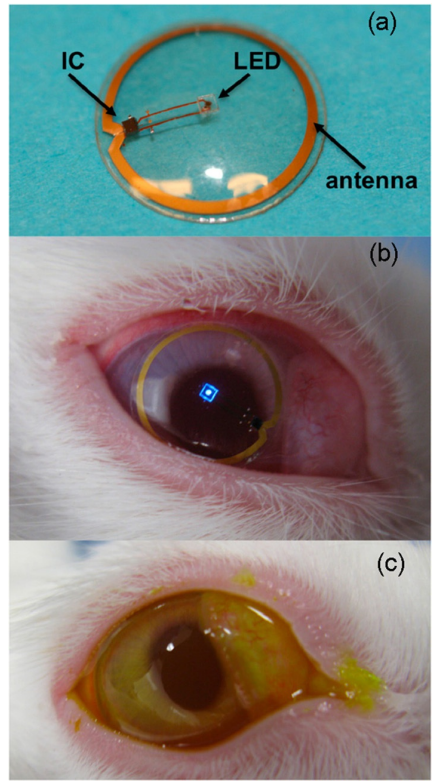

Fig. 5. Single-pixel wireless contact lens display. (a) Photograph of a completed contact lens system. (b) The contact lens display placed on the eye of a live rabbit and powered by a dipole antenna, showing bright emission from the on-lens pixel. (c) Subsequent tests using fluorescein showed no corneal epithelial damage. Reproduced from [30] with permission from IOP Publishing.

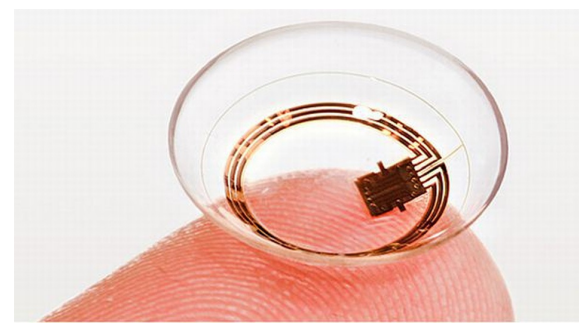

Fig. 6. A photograph of a smart contact lens for ocular pressure monitoring from Sensimed AG (Lausanne, Switzerland).

tion 1), formed as a co-product of glucose oxidation catalyzed by GOx (reaction 2).

$\mathrm{H}_{2} \mathrm{O}_{2} \stackrel{P t}{\longrightarrow} 2 \mathrm{H}^{+}+\mathrm{O}_{2}+2 e^{-}$

$D-$ glucose $\stackrel{G O x}{\longrightarrow} D-$ gluconolactone $+\mathrm{H}_{2} \mathrm{O}_{2}$ 


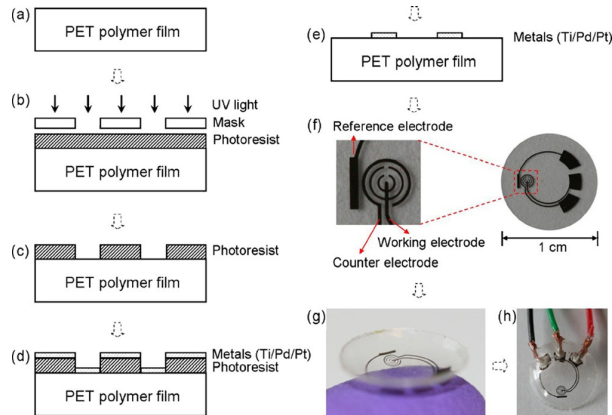

Fig. 7. The sensor fabrication process and results: (a) a clean PET substrate is prepared; (b) the substrate is covered by photoresist and exposed to UV light through a mask; (c) the photoresist is developed; (d) thin metal films are evaporated on the sample; (e) after lift-off the metal pattern remains on the surface. After this step, the sensor is cut out of the polymer substrate and heat moulded to the contact lens shape and functionalized with enzymes; (f) images of a sensor after it has been cut out of the substrate; (g) image of a completed sensor after moulding held on a finger; $(\mathrm{h})$ the sensor may be hardwired for testing. Reproduced from [33] with permission from Elsevier.

The current obtained was directly proportional to the glucose concentration in $0.125-20 \mathrm{mM}$ range, which is too high compared to physiologically relevant glucose concentrations in basal human tears (vide supra). Improving further on the concept [33], the new biosensor was fabricated on a PET film, which was subsequently modified with lithography, e-beam metal evaporation, and lift-off procedures to create a three electrode system with integrated reference electrode (Fig.7), which distinguishes this study from the previous work [31].

Bio-modification was performed by step-by-step drop casting of GOx solution onto the sensing area, utilising a titanium isopropoxide solution to create a GOx/titania sol-gel membrane, and coating with Nafion ${ }^{\oplus}$ layer to decrease influence of other redox active species, like ascorbate, lactate, and urea, present in the lachrymal fluid. Operating under a constant voltage of $+0.4 \mathrm{~V}$ between the working and reference electrodes (an applied potential of about $0.66 \mathrm{~V}$ vs. NHE), the amperometric sensor showed quite promising performance in glucose containing solutions, viz. a sensitivity of $240 \mu \mathrm{Acm}^{-2} \mathrm{mM}^{-1}$ with a response time of $20 \mathrm{~s}$ and good linearity $\left(\mathrm{R}^{2}=0.9988\right)$ between the current and glucose concentration in the physiological glucose range in human tears.

It should be emphasized, however, that influence of interfering redox species pushed the detection limit to $0.2 \mathrm{mM}$ of glucose (vs. $0.01 \mathrm{mM}$ in pure glucose solution without interfering substances). The residual current response was $80 \%$ of the initial after two days of biodevice storage in buffer at $4{ }^{\circ} \mathrm{C}$, and $55 \%$ after four days. In order to minimize the contribution from interfering substances additional control working and counter electrodes (a)

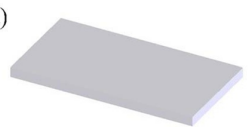

$\llbracket$ Lift off to get the sensor pattern

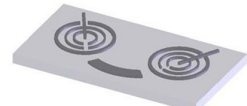

$\sqrt{ }$ Develop a pattern of photoresist $\llbracket$ Pre-treat the sensor selectively

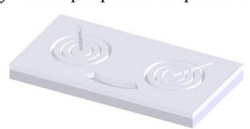

$\sqrt{ }$ Evaporate three metal layers

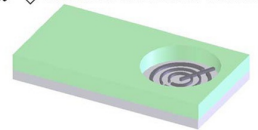

I. Deposit GOD/TI sol-gel film
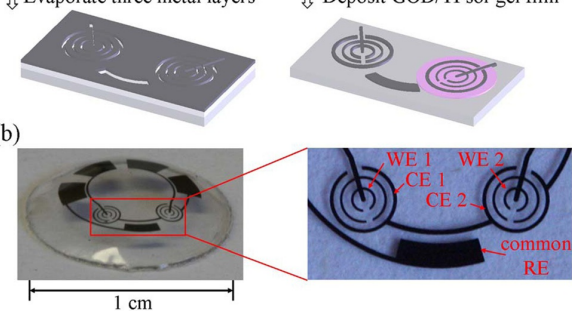

Fig. 8. Fabrication and design of the dual sensor. (a) fabrication and functionalization of the sensor on contact lens; (b) images of a contact lens with integrated sensors (WE - working electrode, $\mathrm{CE}$ - counter electrode, RE - reference electrode). Reproduced from [34] with permission from IEEE.

were implemented into the sensor: i.e. a so called "dual sensor setup" (Fig. 8) [34].

Control electrodes were fabricated using the same approach as for the signal electrodes, but the bio-modification with GOx/titania sol-gel membrane and electrode coating with Nafion was omitted. Background currents obtained on the control working electrode due to the oxidation of ascorbate, lactate, and urea were extracted from bioelectrocatalytic currents obtained from the sensing electrode.

Measurements performed on the physiologically accurate flowing eye model confirmed that such approach allowed extending the detection limit of glucose to $0.1 \mathrm{mM}$ in the presence of interfering species, which is however still too high for real practical applications. Finally, the biosensor was embedded into the wirelessly powered contact lens with an integrated telecommunication circuit (Fig. 9) [35-36]. In these systems control electrodes were covered with deactivated GOx to subtract the back-

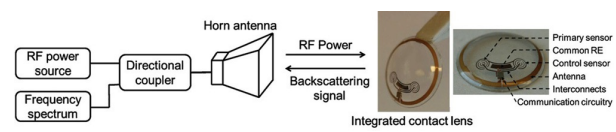

Fig. 9. The wireless test setup for the fully integrated contact lens and measured wireless data transmission results (RE - reference electrode). Reproduced from [35] with permission from IOP Publishing. 
ground current, which is unrelated to the glucose oxidation, with more accuracy.

The sensitivity of the biosensor, tested on the human eye mimicking model, was found to be $18 \mu \mathrm{Acm}^{-2} \mathrm{mM}^{-1}$ with linearity in range of $0-2 \mathrm{mM}$ of glucose in a tear mimicking buffer solution, which contained ascorbate, lactate, and urea as redox active species at concentrations typical for human lachrymal fluid, as well as lysozyme, mucin, and albumin as proteins, which are present in tears and also might affect the biosensor performance. The sensor showed maximal current response at about $35^{\circ}$, close to the physiological temperature of tear fluid (vide supra). The residual bioelectrocatalytic current was $97.4 \%$ of the initial after $12 \mathrm{~h}$ of storage in buffer at $4^{\circ}$, and $84.3 \%, 67.2 \%, 54.2 \%$ after one, two and four days, respectively, without any misalignment of the linear correlation between current and glucose concentration.

The complete on-lens sensing platform was able to operate by consuming just $3 \mu \mathrm{W}$ from an on-chip $1.2-\mathrm{V}$ supply and could even be wirelessly powered at a distance

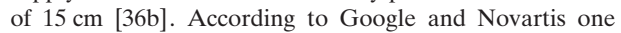
can expect commercially available glucose monitoring contact lenses in the near future [37].

In addition to glucose detection, the sensor design was adapted to create a lactate biosensor integrated into contact lenses (Fig. 10) [38]. The sensing principle was based on the oxidation of $L$-lactate to $L$-pyruvate by molecular oxygen (reaction 3 ) catalyzed by lactate oxidase (LOx) with subsequent electrochemical oxidation of hydrogen peroxide at a Pt working electrode (reaction 1).

$$
\mathrm{L} \text { - lactate }+\mathrm{O}_{2} \stackrel{\text { LOX }}{\longrightarrow} \text { pyruvate }+\mathrm{H}_{2} \mathrm{O}_{2}
$$

Bio-modification of the sensing area was performed by co-immobilization of LOx and bovine serum albumin with simultaneous cross-linking procedure using glutaraldehyde. Thereafter electrodes were sequentially covered with polyurethane and Nafion to prevent enzyme leakage and to reduce the influence of interfering redox species on the sensor performance. The sensitivity was found to be $53 \mu \mathrm{Acm}^{-2} \mathrm{mM}^{-1}$ in a phosphate buffer saline with a response time of $35 \mathrm{~s}$ and linear detection range of 0 $1 \mathrm{mM}$ towards $L$-lactate. The presence of $L$-ascorbic acid in solution led to an interfering signal due to direct oxidation on the Pt surface. This problem was successfully eliminated by using a dual sensor setup (vide supra). The sensor maintained full functionality after $24 \mathrm{~h}$ of storage in buffer at room temperature.

Another approach to integrate a glucose biosensor into a contact lens was developed by Kohji Mitsubayashi et al. [39]. The amperometric biosensor comprised a two electrode system (Pt working and combined $\mathrm{Ag} \mid \mathrm{AgCl}$ reference/counter electrodes) formed on a $70 \mu \mathrm{m}$ thick polydimethyl siloxane (PDMS) membrane attached to the soft contact lens made of the same material (Fig. 11). The sensing mechanism was based on the principle of electrochemical oxidation of hydrogen peroxide on a Pt electrode at a constant voltage between working and refer- (a)

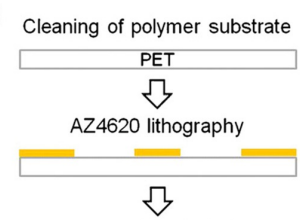

E-beam evaporation of electrode stack

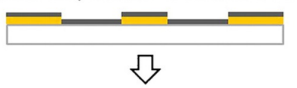

Lift-off \& cleaning

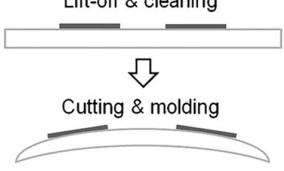

(b)

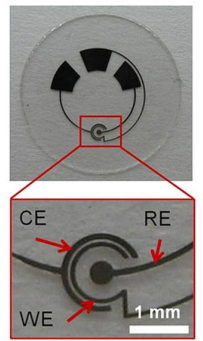

(c)

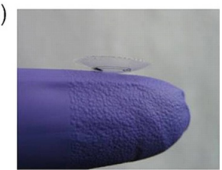

Fig. 10. $L$-lactate sensor on contact lens. (a) Schematic of the fabrication process for sensors on the transparent PET substrate, which is moulded into a contact lens shape. (b) Flat substrate with sensing structure, interconnects and electrode pads for connection to the external potentiostat. (c) A completed contact lens sensor held on a finger (WE - working electrode, CE counter electrode, RE - reference electrode). Reproduced from [36b] with permission from IEEE.

ence/counter electrodes of $+0.4 \mathrm{~V}$, as was described above (reactions 1 and 2). GOx was immobilized onto the electrode surface from a mixture with a co-polymer of 2-methacryloyloxyethyl phosphorylcholine and 2-ethylhexylmethacrylate (PMEH), as well as additionally covered with a PMEH membrane to prevent enzyme leakage.

A linear relation between the output current and glucose level was obtained in buffer solutions with glucose concentrations of $0.03-5 \mathrm{mM}$. Tests of the sensor performance in wearable mode carried out using rabbit models showed direct correlation (around 99\%) between glucose concentrations in standard solutions instilled onto the eyeball surface and values estimated taking into account rabbit's tear turnover rate. It was also demonstrated that glucose concentration in tears traces the changes in blood glucose level with a delay of approximately $10 \mathrm{~min}$. The sensitivity of biosensors created on the PDMS support could be improved further by fabrication of three-dimensional micro-pillar electrodes, which have up to three times higher surface area in comparison with the flat analogues [40].

It should be stressed than non-invasive tear-based bioelectronics does not necessarily translate into wearable devices. Recently, a flexible electrochemical microbiosensor has been designed for quantitative analysis of glucose in a nanovolume of human lachrymal fluid (Fig. 12) [5].

The biodevice was based on glucose dehydrogenase immobilized on a gold microwire modified with carbon nanotubes and an osmium redox polymer. A capillary mi- 
(I) fabrication of flexible electrode

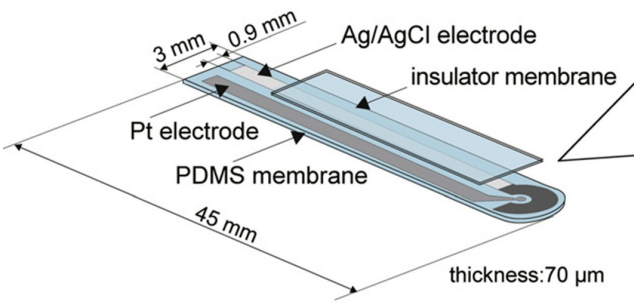

(II) contact lens-type glucose sensor

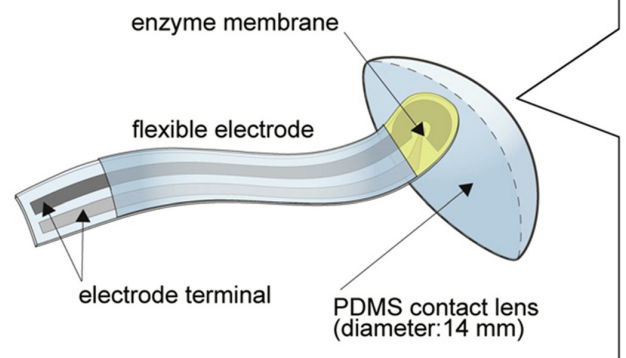

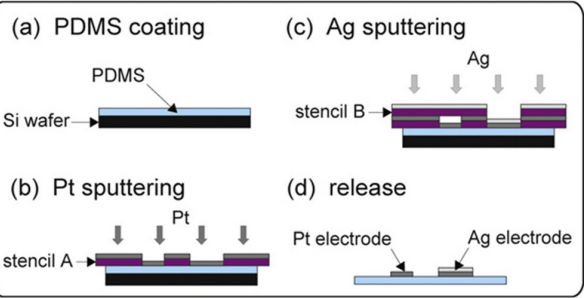

(a) bonding

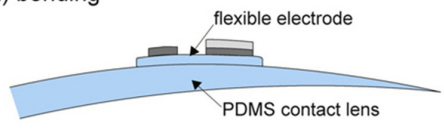

(b) enzyme immobilization

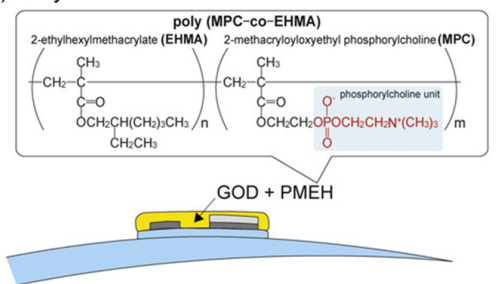

(c) over coating

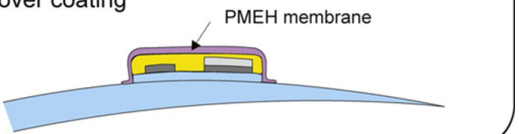

Fig. 11. Fabrication method of the contact lens biosensor. (I) The flexible electrodes (a $200 \mathrm{~nm}$ thick Pt working electrode and a $300 \mathrm{~nm}$ thick $\mathrm{Ag} \mid \mathrm{AgCl}$ counter/reference electrode) were formed onto a $70 \mu \mathrm{m}$ thick PDMS membrane; (II) the flexible electrodes were bonded onto the surface of the PDMS contact lens using PDMS and then GOx was immobilized using PMEH onto the sensing region of the electrodes, Finally, the enzyme membrane was over coated by PMEH. Reproduced from [39a] with permission from Elsevier.

crocell was constructed for sampling tears. The cell had a working volume of $60-100 \mathrm{~nL}$ only, with a sampling deviation of about $7 \%$. To check if the microcell was properly filled with buffer or a tear sample, a control electrode was introduced into the construction (Fig. 12c). The electrode was used to measure the electrical resistance of a fully filled nanovolume cell. The mechanical flexibility is one of the most important features of the prototype and allowed direct collection of tears with minimized risk of damage to the eye (Fig. 12d and 12e). Based on the experimental results, the authors concluded that the flexible and noninvasive prototype may be converted into a userfriendly microbiosensor and applied for detection of blood glucose using human lachrymal fluid [5].

The main properties of bioelectronics (in its narrow definition; vide supra) for bioanalyte determination in lachrymal fluid are summarized in Table 2 . However, the human eye offers a wider diagnostic potential as a sensing site and therefore there are other types of sensors, e.g. optical, capacitive, and piezo-resistive sensors, that have been already implemented into contact lenses and tested in vitro and ex vivo (in vivo) [10].

\section{Biological Electric Power Sources}

\subsection{Tear Based Biofuel Cells}

The development of useful self-contained smart bionic contact lenses is an important direction nowadays, in spite of certain challenges at the current stage of technological development, especially when it comes to bioelectronics implementation. One of the main problems is related to the source of electric power for these complex devices, with issues such as size, thickness, and mass, i.e. the overall form factor, along with many other parameters including biocompatibility and safety. 


\section{Review}

In the case of bionic contact lenses, bioelectric devices, i.e. biological power sources, can be very useful to provide the energy needed, as described below. The power can be generated by converting in situ available chemical energy from different biofuels present in human tears (Table 1) into electric energy, i.e. drawing on the mainstay of fuel cell technology, or in other words, 'open' electrochemical cells (vide infra).
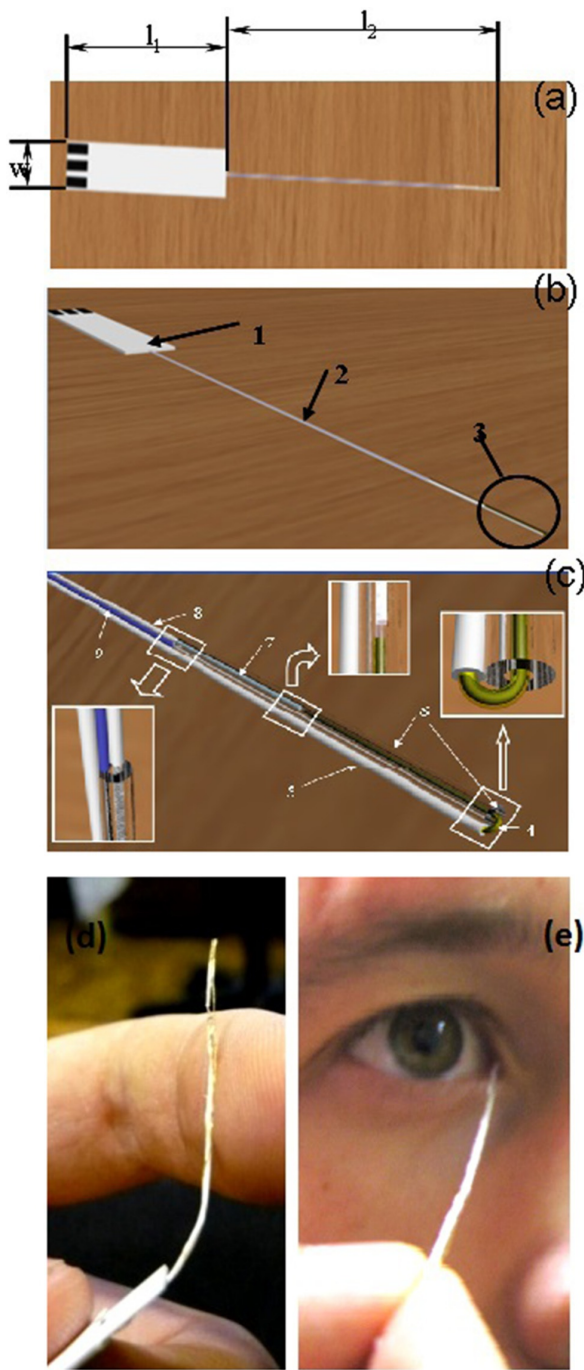

ELECTROANALYSIS

The idea of utilizing biofuels existing in tears to generate electric power is necessitated because of the complex restrictions offered by a contact lens, when conventional, even state-of-the-art, power management technology is at an impasse. In terms of fuel availability, several possible biofuels are present in lachrymal fluid, e.g. glucose, ascorbate, and pyruvate, albeit in limited supply. On the other hand, molecular oxygen dissolved in tear fluid (the ubiquitous biooxidant), needed to accept the electrons extracted from the fuels, is abundantly available. Simplified redox transformations of three biofuels and the biooxidant occurring at the electrodes are given below as Eqs. 4-7; redox potentials of the half-reactions 4-7 ( $\mathrm{pH} 7$, $25^{\circ} \mathrm{C}$, vs. NHE) are $-0.364 \mathrm{~V}, 0.080 \mathrm{~V},-0.185 \mathrm{~V}$ and $0.815 \mathrm{~V}$ respectively.

gluconolactone $+2 \mathrm{H}^{+}+2 e^{-} \rightarrow$ glucose

dehydroascorbate $+2 \mathrm{H}^{+}+2 e^{-} \rightarrow$ ascorbate

pyruvate $+2 \mathrm{H}^{+}+2 e^{-} \rightarrow$ lactate

$\mathrm{O}_{2}+4 \mathrm{H}^{+}+4 e^{-} \rightarrow 2 \mathrm{H}_{2} \mathrm{O}$

It is important to emphasize that as early as in 2010 a patent application entitled 'Flexible Biofuel Cell, Device and Method' was filed, with the priority date 24 March 2010 [41], describing the possible usage of biological fuel cells (BFCs), i.e. biodevices built on biogenic catalysts, such as redox proteins and enzymes, organelles and whole living cells [42], to power bionic contact lenses. The very first paper detailing a BFC as a power source for electronic contact lenses appeared a couple of years later, in 2012 [4a].The authors fabricated a nanostructured (to improve the biodevice characteristics) [43] glucose/ oxygen enzymatic fuel cell (Fig. 13), based on DET (to avoid mediators, thus simplifying the biodevice construction) [7]. Three-dimensional nanostructured microelectrodes built on $100 \mathrm{~nm}$ diameter gold wires covered with $17 \mathrm{~nm}$ gold nanoparticles (AuNPs) biomodified with $\mathrm{Cor}$ -

Fig. 12. Schematic view of the flexible non-invasive micro-biosensor. (a) $l_{1}$ - length of a handle (from $10 \mathrm{~mm}$ up to $50 \mathrm{~mm}$, optimum 20-30 mm), $l_{2}$ - length of a flexible sampling part (from $40 \mathrm{~mm}$ up to $100 \mathrm{~mm}$, optimum is $50-60 \mathrm{~mm}$ ), w - width of the handle (from $5 \mathrm{~mm}$ up to $10 \mathrm{~mm}$ ). (b) 1 - the handle with three electrical contacts, 2 - the flexible sampling part (total diameter from $0.05 \mathrm{~mm}$ up to $0.5 \mathrm{~mm}$ ), 3 - the flexible part of the device with a microcell. (c) Flexible part of the sapling device including a microcell. 4 - working electrode (diameter from $0.01 \mathrm{~mm}$ up to $0.2), 5$ - isolated part of working electrode, 6 - polymeric tube (internal diameter from $0.015 \mathrm{~mm}$ up to 0.25 ), external diameter from $0.02 \mathrm{~mm}$ up to 0.4 , length from 1 up to $40 \mathrm{~mm}$ ) is agglutinated to isolated part of working electrode, 7 - counter and reference electrode (diameter from $0.01 \mathrm{~mm}$ up to $0.2 \mathrm{~mm}$ ), 8 - isolated part of counter and reference electrode, 9 - checking/control electrode (diameter from 0.01 up to $0.2 \mathrm{~mm}$ ). Distance between ends of working and opposite electrodes from $0.01 \mathrm{~mm}$ up to $1 \mathrm{~mm}$. (d) Photograph demonstrating flexibility of the biodevice. (e) Photograph of real sampling. 


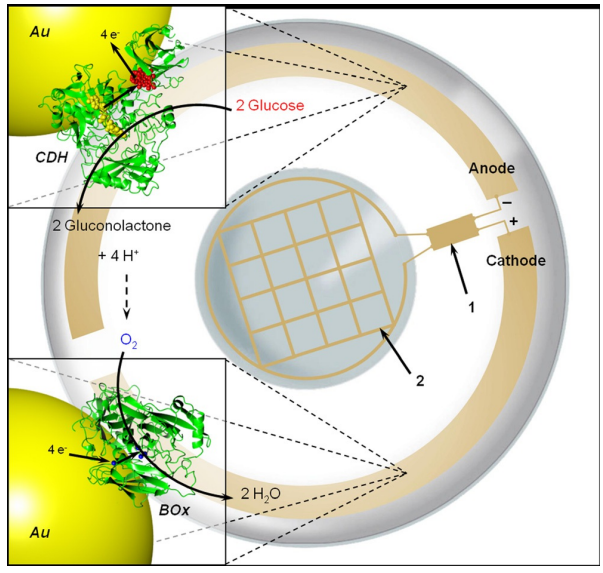

Fig. 13. Principal scheme of an electronic contact lens with an embedded DET based glucose/oxygen enzymatic fuel cell, acting as a green self-sufficient power source. Reproduced from [4a] with permission from Elsevier.

ynascus thermophilus $\mathrm{CDH}$ and Myrothecium verrucaria bilirubin oxidase (BOx) as anodic and cathodic bioelements, respectively, were tested in a microelectrochemical cell with a total volume of just $10 \mu \mathrm{L}$ filled with a native human tear film (Fig. 14).

The following characteristics were registered: $0.57 \mathrm{~V}$ open-circuit voltage, about $1 \mu \mathrm{W} \mathrm{cm}{ }^{-2}$ maximum power density at a cell voltage of $0.5 \mathrm{~V}$, and more than $20 \mathrm{~h}$ operational half-life.

Later the authors also succeeded to affix the microwire based BFC to an authentic human contact lens (Fig. 15).

When operating in artificial human tears from Ursa Bioscience (Bel Air, MD, USA), about $1 \mu \mathrm{W} \mathrm{cm}^{-2}$ maximum power density at a cell voltage of $0.5 \mathrm{~V}$ was registered. At first sight, a $\mu \mathrm{W}$ level power density can be attributed to the low performance bioanode, based on cellobiose dehydrogenase $(\mathrm{CDH})$, a redox enzyme with DET ability but quite low catalytic efficiency towards glucose (low catalytic constants, e.g. 1.9-14.2 $\mathrm{s}^{-1}$ along with high Michaelis constants, e.g. 250-1600 mM) [44]. Indeed, current densities of $\mathrm{CDH}$ based anodes operating in solutions with low glucose concentrations are just in few $\mu \mathrm{A} \mathrm{cm}^{-2}$ range even for nanosctructured biodevices with high enzyme loading [4a]. However, taking into account realistic average characteristics, which determine the power density of a fuel cell operating in a tear film, first and foremost the biofuel concentration and the tear production rate, one would expect a glucose/oxygen based BFC power output much below $1 \mu \mathrm{W}$, when operating in human basal tears (vide infra). Indeed, already existing $\mathrm{CDH}$ based bioanodes, even though they are not highperformance biodevices, should actually utilize all the biofuel in the native human fluid.
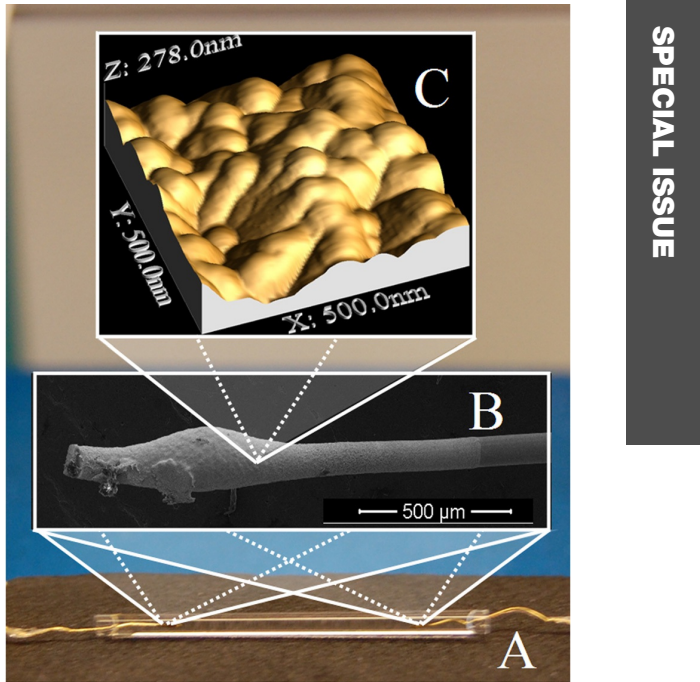

Fig. 14. Set-up used to study enzymatic fuel cell performance in basal human tears. (A) A micro-electrochemical cell. (B) Scanning electron microscopy image of AuNP-modified microscale electrodes with immobilized enzymes. (C) Atomic force microscopy image of enzyme/AuNP-modified Au microwires. Reproduced from [4a] with permission from Elsevier.

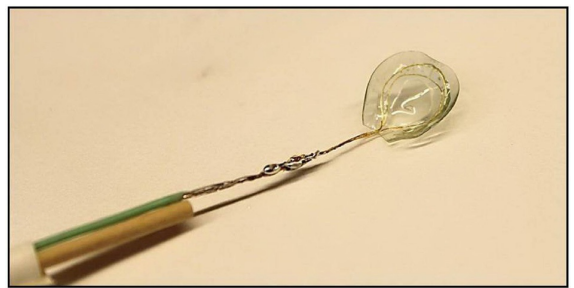

Fig. 15. A photograph of a prototype of a microwire based biofuel cell affixed to a soft contact lens.

Contrary to previous estimations of extractable electric power from human lachrymal fluid, which were done using broad ranges of reported biofuel concentrations and tear production rates [45], more realistic calculations taking into account basal tear lacrimation, i.e. 0.5$2.2 \mu \mathrm{Lmin}^{-1}$, as well as recent data about biofuel concentrations (Fig. 16), indicate that on average the realistic electric power obtained from glucose as a biofuel is less than $0.2 \mu \mathrm{W}$.

Thus, in spite of the fact that tear glucose has no function as a biofuel for cornea cells and indeed can be completely depleted in vivo without any apparent disadvan- 

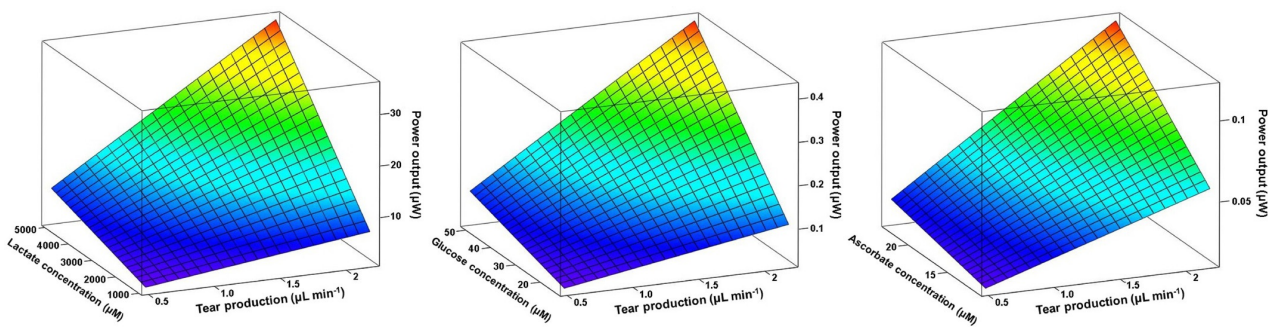

Fig. 16. Calculated fuel cell power output as a function of biofuel concentrations in basal human lachrymal fluid and basal tear lacrimation rates.

tages for human eyes [9], it is an unlikely on-lens energy source, if conventional BFCs are to be employed. It should be also emphasized that in reality the cell voltage, and correspondingly power, will be much lower because of overpotentials needed to drive both anodic and cathodic reactions at reasonable rates, as well as cathode depolarization (the first studies about cathode depolarization when operating in human physiological fluids can be found here $[4 a, 46])$ due to the presence of high potential biofuels (in other words, interferents in the case of biosensing), like lactate, ascorbate, urea (Eqs. 5 and 6), and especially dopamine, since the redox potential of the halfreaction of dopamine oxidation (Eq. 8) is as high as $0.225 \mathrm{~V}$ ( $\mathrm{pH} 7,25^{\circ} \mathrm{C}$, vs. NHE) [47].

dopamine $-o-$ quinone $+2 \mathrm{H}^{+}+2 e^{-} \rightarrow$ dopamine

In order to circumvent the problem of low power glucose based BFCs, more abundant biofuels have been investigated. In some reports it is stated that the ascorbate concentration in human tears can be as high as $0.665 \mathrm{mM}$ [23b]. Indeed, an ascorbate/oxygen fuel cell was fabricated using three-dimensional nanostructured gold electrodes covered with abiotic (conductive organic complex, tetrathiafulvalene-tetracyanoquinodimethane) and biological (redox enzyme, BOx) materials functioning as efficient anodic and cathodic catalysts, respectively (Fig. 17).

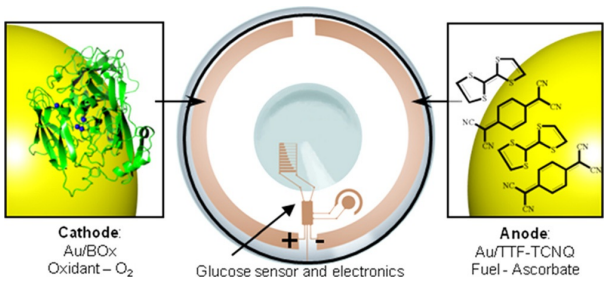

Fig. 17. Principal scheme of an electronic contact lens with an embedded ascorbate/oxygen biofuel cell, acting as a green selfsufficient power source. Reproduced from [47] with permission from the American Chemical Society.
When operated in human tears, the biodevice exhibited the following characteristics: an open circuit voltage of $0.54 \mathrm{~V}$ (maximal theoretical is around 0.74, Table 1), a maximal power density of $3.1 \mu \mathrm{W} \mathrm{cm}^{-2}$ at $0.25 \mathrm{~V}$ and $0.72 \mu \mathrm{W} \mathrm{cm}^{-2}$ at $0.4 \mathrm{~V}$, with a stable current density output of over $0.55 \mu \mathrm{A} \mathrm{cm}^{-2}$ at $0.4 \mathrm{~V}$ for $6 \mathrm{~h}$ of continuous operation [47].

Note that the reported power densities do not reflect extracted electric power from the fluid. Truly microscale electrodes with nA current output were used in these studies to conserve the fuel concentration during measurements and only $\mathrm{nW}$ power was generated. Recent investigations have shown that the ascorbate concentration in tear fluid is only $17 \pm 6 \mu \mathrm{M}$ [23a] and the average realistic electric power obtained from ascorbate as a biofuel in continuous mode is less than $0.06 \mu \mathrm{W}$, i.e. even lower than that from glucose (Fig. 16). Thus, also taking into account biological importance of ascorbate for the human eye, i.e. the antioxidant capacity first of all (indeed it cannot be completely depleted in vivo without disadvantages for human eyes [9]), it is an unlikely on-lens energy source. Tear ascorbate functions as an effective antioxidant against oxidative damage of the cornea, and contact lens wearers are prone to oxidative stress due to the lensinduced hypoxic conditions [48]. Based on the low halfreaction potential of lactate oxidation ( $c f$. Eqs. 7 and 5,6) and the high concentration in tears (Table 1) lactate seems to be the only option as an on-lens energy source, if conventional BFCs are to be employed. Indeed, recently a report concerning an lactate/oxygen $\mathrm{BFC}$ has been published [49].

A contact lens BFC was fabricated using buckypaper electrodes cured on a silicone elastomers of contact lens (Fig. 18a). The buckypaper anode consisted of poly(methylene green) and a hydrogel matrix containing lactate dehydrogenase and nicotinamide adeninedinucleotide hydrate (Fig. 18b). The buckypaper cathode was modified with 1-pyrenemethylanthracene-2-carboxylate, and then BOx was immobilized within a polymer (Fig. 18b). Contact lens biofuel cell testing was performed in a synthetic tear solution at $35^{\circ} \mathrm{C}$, but in spite of the relatively high maximal theoretical voltage of a lactate/oxygen fuel cell, 


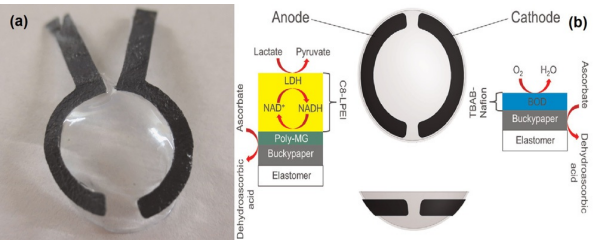

Fig. 18. (a) An image of a contact lens biofuel cell prototype including the connection leads. (b) Contact lens biofuel cell schematic. Reproduced from [49] with permission from Elsevier.

i.e. about $1 \mathrm{~V}$ (Table 1 ), the open-circuit voltage of the biodevice was only around $0.4 \mathrm{~V}$, in all likelihood due to biocathode depolarization (vide supra) and well-pronounced oxidation of a high redox potential biofuel, viz. ascorbate, on the anode. However, because of the high surface area of the electrodes, maximum current and power densities were calculated to be $c a .61 \mu \mathrm{Acm}^{-2}$ and $8 \mu \mathrm{W} \mathrm{cm}^{-2}$, respectively. Continuous operation for $17 \mathrm{~h}$ revealed bioanode instability as the output current rapidly decreased in the first $4 \mathrm{~h}$ and then stabilized for the next $13 \mathrm{~h}$.

The main properties of so far fabricated enzymatic fuel cells operating in human lachrymal fluid are summarized in Table 3. Note that because of the limited amount of lactate in tear fluid, as determined by the tear production rate and the biofuel concentration (Fig. 16), usage of porous electrodes with high surface area will seemingly improve the characteristics of BFC augmented lenses to the fuel depletion limit, whereas huge overpotential losses will drastically reduce the real power output, i.e. the current will increase but only to certain extend, whereas the voltage will definitely drop. Thus, in our opinion, current research should be focused on improvement of open-circuit and especially operating potentials of biocathodes and bioanodes in human tears, rather than apparent increase of current densities in artificial (synthetic) electrolytes in unlimited volumes. Nevertheless, taking into account that the average realistic electric power obtained from lactate as a biofuel is close to $10 \mu \mathrm{W}$ (Fig. 18), a $1 \mathrm{~cm}^{2}$ bioanode in the current configuration would utilize all lactate available in human basal tears and the extractable electric power would be in the microwatts range still. Since there are no other potential candidates as more suitable biofuels (i.e. existing at high concentrations and having low enough redox potentials) few tens of $\mu \mathrm{W}$ is the absolute maximal electric power for conventional human tear based fuel cells operating ex vivo. The only solution to increase power further is usage of modern, recently disclosed biodevices, which are able to operate in both continuous and pulse modes (vide supra). Thus, by running a charge-storing fuel cell in pulse mode, appropriately timing the cycle or pulse length, low and high abundance biofuels can be efficiently converted and the demands of consistent, temporally stable levels of power as regards the sensing, encoding, and transmission events can be reproducibly met.

\subsection{Tear Based Biosupercapacitors}

In the beginning of 2013 an entirely new kind of electric power device was disclosed, in which chemical energy is directly converted into electric energy, which is capacitively stored within a singular contrivance [50]. Such hybrid devices, which can alternatively be named chargestoring fuel cells or self-charging supercapacitors, are built based on dual-function electrodes, viz. electrodes manifesting simultaneous electrocatalytic and charge-storage features. We fabricated and characterized an ascorbate/oxygen membrane based hybrid electric power device built on nanocomposites materials (Fig. 19) [51] Hereafter we also designed and tested a self-charging biosupercapacitor, i.e. a membrane-less hybrid electric power device based on biological catalysts, viz. anodic and cathodic redox enzymes, $\mathrm{CDH}$ and $\mathrm{BOx}$, respectively [52]. Following our reports concerning DET based enzymatic FCs [53], three-dimensional AuNPs based electrodes $[4 a, 43]$, and using an existing classification of electro-

Table 3. iofuel cells operating in human tears

\begin{tabular}{|c|c|c|c|c|c|c|c|}
\hline $\begin{array}{l}\text { Fuel/Oxi- } \\
\text { dant }\end{array}$ & $\begin{array}{l}\text { (Bio)catalysts } \\
\text { (Anode/Cath- } \\
\text { ode) }\end{array}$ & $\begin{array}{l}\text { OCV/ } \\
\text { Voltage at } \\
\text { max } \\
\text { power [V] }\end{array}$ & $\begin{array}{l}\text { Maximal } \\
\text { power } \\
\text { density } \\
{\left[\mu \mathrm{W} \mathrm{m}^{-2}\right]}\end{array}$ & $\begin{array}{l}\text { Residual ac- } \\
\text { tivity after } \\
2 \mathrm{~h} \text { of opera- } \\
\text { tion }[\%]\end{array}$ & Brief description & $\begin{array}{l}\text { Experimental } \\
\text { conditions }\end{array}$ & Ref. \\
\hline $\begin{array}{l}\text { Lactate/ } \\
\text { Oxygen }\end{array}$ & $\mathrm{LDH} / \mathrm{BOx}$ & $0.41 / 0.20$ & 8.0 & $35 \%$ & $\begin{array}{l}\text { MET and cofactor based macroscale bioa- } \\
\text { node built on buckypaper; DET based } \\
\text { macroscale biocathode built on buckypa- } \\
\text { per }\end{array}$ & $\begin{array}{l}\text { Artificial tears at } \\
35^{\circ} \mathrm{C} \text { under stir- } \\
\text { ring }\end{array}$ & [49] \\
\hline $\begin{array}{l}\text { Ascorbate/ } \\
\text { Oxygen }\end{array}$ & $\begin{array}{l}\text { TFF-TCNQ/ } \\
\text { BOx }\end{array}$ & $0.54 / 0.25$ & 3.1 & $20 \%$ & $\begin{array}{l}\text { Organic catalyst based microscale anode } \\
\text { built on AuNP modified Au microwire; } \\
\text { DET based microscale biocathode built on } \\
\text { AuNP modified Au microwire }\end{array}$ & $\begin{array}{l}\text { Natural human } \\
\text { basal tears at } \\
25^{\circ} \mathrm{C} \text { in capillary } \\
\text { microcell }\end{array}$ & [47] \\
\hline $\begin{array}{l}\text { Glucose/ } \\
\text { Oxygen }\end{array}$ & $\mathrm{CDH} / \mathrm{BOx}$ & $0.57 / 0.20$ & 3.5 & $\begin{array}{l}\text { n.d., } 68 \% \\
\text { after } 20\end{array}$ & $\begin{array}{l}\text { DET based microscale bioanode built on } \\
\text { AuNP modified Au microwire; DET based } \\
\text { microscale biocathode built on AuNP } \\
\text { modified Au microwire }\end{array}$ & $\begin{array}{l}\text { Natural human } \\
\text { basal tears at } \\
25^{\circ} \mathrm{C} \text { in capillary } \\
\text { microcell }\end{array}$ & {$[4 \mathrm{a}]$} \\
\hline
\end{tabular}




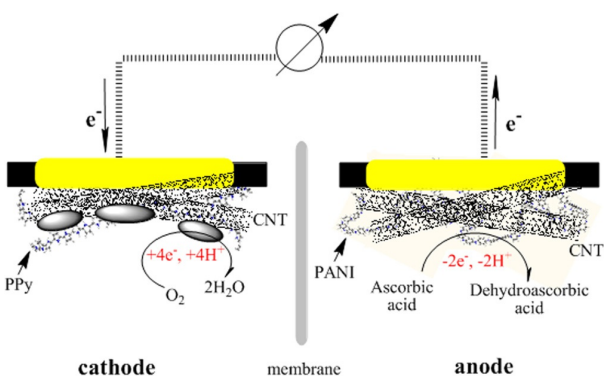

Fig. 19. Schematic representation of the membrane-based ascorbate/oxygen hybrid electric power device. Black - non-conducting part of the gold electrode (plastic holder), yellow - the gold surface, grey ellipses - platinum nanoparticles. Reproduced from [51] with permission from the Royal Society of Chemistry.

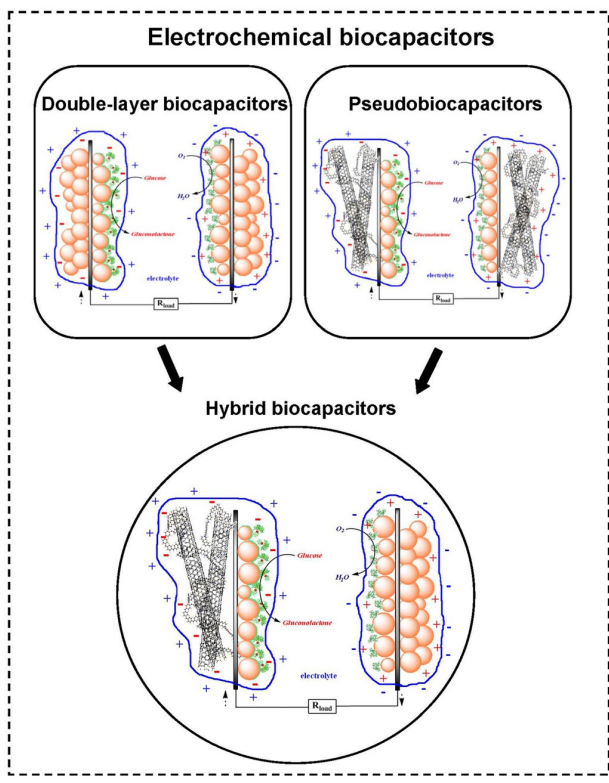

Fig. 20. Proposed hierarchical classification of hybrid electric biodevices with examples of authentic and tested biosupercapacitors. Reproduced from [6] with permission from Wiley VCH.

chemical capacitors, we also suggested a similar classification of intrinsic hybrid biodevices, i.e. self-charging biosupercapacitors/charge-storing BFCs (Fig. 20), exemplified with different glucose/oxygen biodevices using $\mathrm{CDH}$ and $\mathrm{BOx}$ as biocatalysts [6].

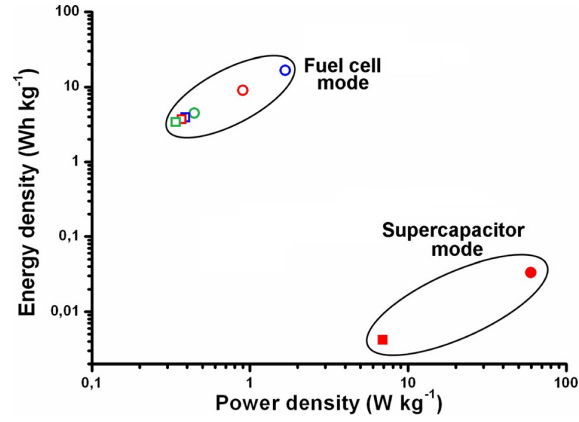

Fig. 21. Ragone chart showing power density versus energy density of a charge-storing biofuel cells/double layer biosupercapacitor operating in fuel cell (continuous) and supercapacitor (pulse) modes. Squares and circles - operating voltage of $0.5 \mathrm{~V}$ and $0.2 \mathrm{~V}$, respectively. Green, blue, and red - phosphate buffer saline, $\mathrm{pH} 7.4$, human lachrymal fluid (according to [4a]), and artificial tears from Ursa Bioscience, respectively.

The double-layer biocapacitor based on $\mathrm{CDH}$ and $\mathrm{BOx}$ (see additional details concerning fabrication and characterisation in [6]) was tested in artificial human tears in both pulse and continuous operation modes; the test results in the form of a Ragone chart are presented in Fig. 21. Thus, the charge-storing biofuel cell/self-charging biosupercapacitor does furnish electrical power when operating in lachrymal fluids. While operating in a fuel cell (continuous) mode the biodevice has high energy and low power densities, whereas in a supercapacitor (pulse) mode it is vice versa. The same trend is also observed for conventional devices. However, both energy and power densities of the BFC are much lower compared to conventional devices built on inorganic and organic catalysts but comparable with old lead-acid batteries. This is a general problem of BFCs, aggravated in this particular case due to low fuel concentrations.

Moreover, the energy and power densities of the selfcharging biosupercapacitor are comparable to conventional capacitors, rather than ultracapacitors. This is attributed to the low specific double-layer capacitance of the biodevice $\left(c a .30 \mathrm{mFg}^{-1}\right)$, which can be improved on by adding a pseudocapacitive feature to the electrodes. Following a very recent report concerning novel nanobiocomposite materials [54], a glucose oxidizing bioanode based on a poly(3,4-ethylenedioxythiophene)/graphene (PEDOT/graphene) composite with immobilized glucose oxidase (GOx) was fabricated and tested (Fig. 22).

As one can see from the figure the biodevice does operate in artificial human tears. Because of the pseudocapacitance, the total specific capacitance (double-layer plus pseudo) of the biodevice was increased to $100 \mathrm{mF} \mathrm{g}^{-1}$. Assuming that the biodevice eventually is to be used on a contact lens, an additional feature, i.e. transparency, was also approached. As one can see from the 


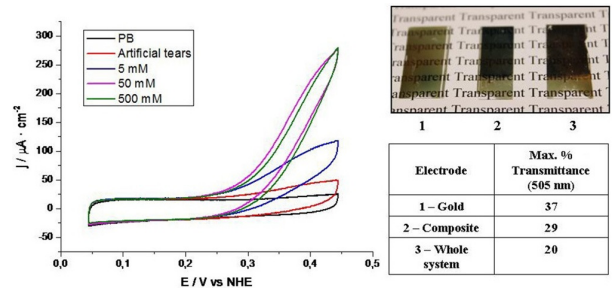

Fig. 22. Investigations of a transparent double-function enzymatic anode. (Left) Cyclic voltammograms of the bioelectrode in $100 \mathrm{mM}$ phosphate buffer, $\mathrm{pH} 7.4$, with and without glucose, as well as in artificial human tears. (Right) transmittance values of bare and modified Au electrodes.

table in Fig. 24, the nanobiocomposite reduced the maximal transmittance of the electrode with only $17 \%$. Thus, fabrication of highly capacitive and transparent enzymatic anode based on nanocomposite materials is actually feasible.

In the end, we report on our recent work concerning transparent, flexible, nanostructured, membrane-less and mediator-free glucose/oxygen enzymatic fuel cells, which can be reproducibly fabricated with industrial scale throughput (Fig. 23) [55]. The electrodes of the BFCs were built on a biocompatible flexible polymer covered with a thin Au layer, using nanoimprint lithography for nanostructuring, while $\mathrm{CDH}$ and $\mathrm{BOx}$ were used as anodic and cathodic biocatalysts, respectively. As evidenced from Fig. 23, the device was transparent; 29-54\% transparency in the visible spectrum. The following aver- age characteristics of the biodevices operating in glucose and chloride containing neutral buffers were registered $0.63 \mathrm{~V}$ open-circuit voltage, and $0.6 \mu \mathrm{W} \mathrm{cm}{ }^{-2}$ maximal power density at a cell voltage of $0.35 \mathrm{~V}$, delivering at least $0.5 \mu \mathrm{W} \mathrm{cm}^{-2}$ after $12 \mathrm{~h}$ of continuous operation. The total capacitance of the electrodes was measured and the BFC was tested in charge-discharge mode; the specific capacitance of the electrodes was found to be $70 \mu \mathrm{F} \mathrm{cm}^{-2}$ and $90 \mu \mathrm{F} \mathrm{cm}^{-2}$ for the bioanode and the biocathode, respectively. The capacitance values are in good agreement with values previously reported for the double-layer capacitance of gold electrodes exposed to protein solutions [56], taking into account that the roughness factor of electrodes modified using nanoimprint lithography is only about 7 .

A charge/discharge curve of the device is presented in Fig. 24. The biodevice was fully self-charged after just $c a$. $40 \mathrm{~s}$. Applying a constant load of $5 \mathrm{M} \Omega$ discharged the biodevice. At an operating voltage of $0.62 \mathrm{~V}$ the initial power density was $92 \mu \mathrm{W} \mathrm{cm}^{-2}$ at the first charge-discharge cycle without significant signal degradation at the consequent cycles (Fig. 24). The electric power was supplied by the enzymatic fuel for just a few sec with an evident fast drop in the power density down to the $0.6 \mu \mathrm{W} \mathrm{cm}^{-2}$ level, i.e. the enzymatic fuel cell base level.

\section{Conclusions and Further Perspectives}

For real practical applications one should design flexible and preferably transparent bioelectronic devices. Because of our initially chosen substrate, i.e. Au (Figs. 22-23), the bioelectrodes were quite opaque at the thicknesses required for good conductivity ( $c a .40-80 \mathrm{~nm}$ ). In the future
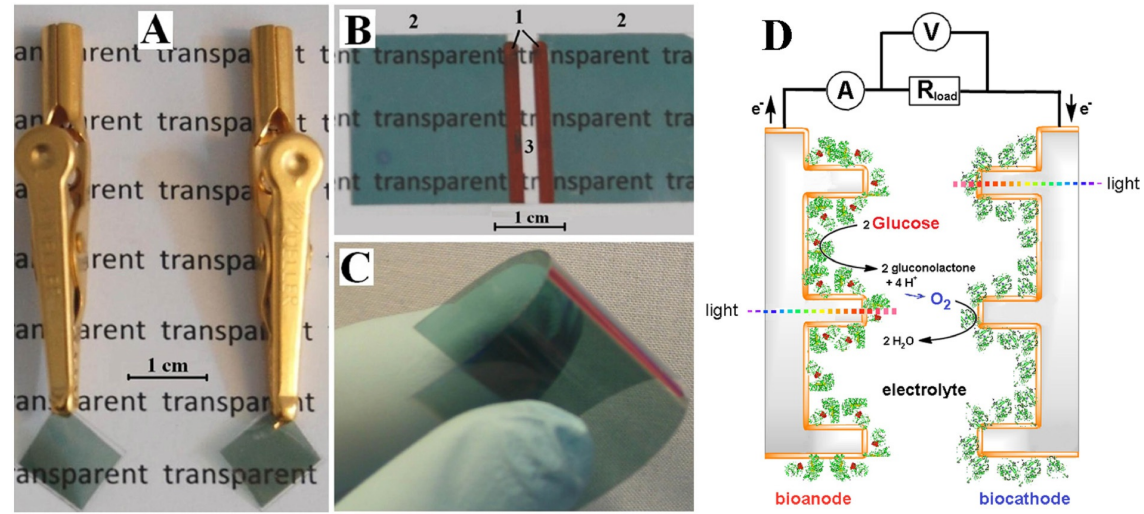

Fig. 23. Photographic images of separate electrodes (A) connected to alligator clips along with a complete transparent flexible device (B, C). 1 - biocompatible transparent polymer, 2 - current collectors (metallised thick (opaque) layer of Au on the polymer), 3 - transparent electrodes (metallised thin layer of Au on the polymer). (D) A principal scheme of a compartment- and mediator-less, flexible and transparent glucose/oxygen enzymatic fuel cell based on nanostructured electrodes. Reproduced from [55] with permission from Elsevier. 


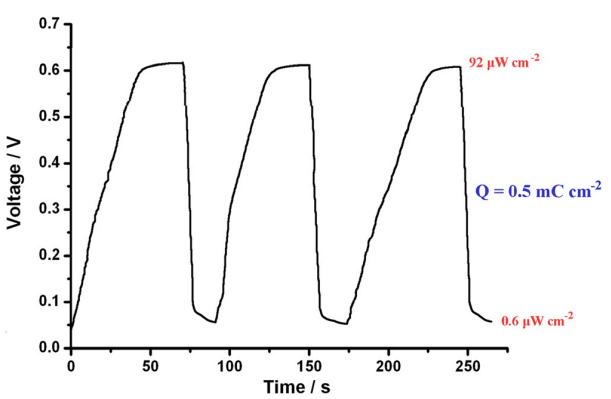

Fig. 24. Charge/discharge curve of a nanoimprint lithography based enzymatic fuel cell. Self-charging in $50 \mathrm{mM}$ glucose/air saturated phosphate buffer saline, $\mathrm{pH} 7.4$; when fully self-charged the biodevice was discharged at a constant load of $5 \mathrm{M} \Omega$

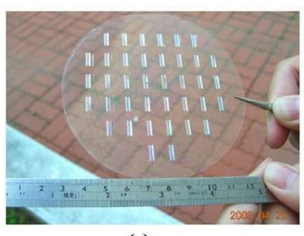

(a)

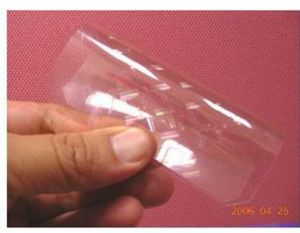

(b)
Fig. 25. (a) The patterns transferred on a flexible transparent indium tin oxide coated poly(ethylene terephthalate) film through imprinting lithography. (b) No visual damage on the surface after distortion and bending of the film. Reproduced from [57] with permission from IOP Publishing Ltd.

one should use intrinsically transparent highly conducting materials, like a thin layer of ITO, deposited on biocompatible polymers, building on the fact that many displays of modern gadgets rely on thin layers of ITO. Moreover, transparent ITO coated poly(ethylene terephthalate) film based electrodes with nanostructured surfaces using nanoimprint lithography have been designed (Fig. 25), being also flexible due the thin layer of the material.

As discussed above, in all likelihood, the roughness of nanoimprint lithography based electrodes will not be enough, if advanced biological electrical power sources are to be designed. To increase the real surface area of electrodes (for high enzyme loading and high doublelayer capacitance) further nanostructuring with conducting ITO NPs can be done [58]. Note that immobilization of NPs results in high real surface area of the electrodes, i.e. roughness factors up to 100 [59] and even higher [60], compared to about 7 in the case of Au nanoimprint lithography (vide supra). To obtain a pseudocapacitive feature the electrodes can be modified with transparent thin film nanocomposite materials built on conducting organic polymers (PEDOT, polyaniline, etc)/nanomaterials (carbon nanotubes and graphene). These studies are in the scope of further investigations in our laboratories.

We believe that bionic contact lenses hold great promise for the future. Non-invasive sensing of various biomarkers, especially if the information gathered can be effortlessly and accurately utilized, will most certainly disrupt the existing protocols and practices. Focusing on non-invasiveness, and aiming at limited involvement of the individual, the combined efforts will most likely revolutionize the maintenance and treatment of any number of ailments. The strict spatial confinement of a contact lens is singularly well suited as a test bed for the development of micro- and nano-sized implements, and the lessons learned will benefit all areas of eye based bioelectronics.

$\begin{array}{ll}\text { Abbreviations } \\ \text { AuNP } & \text { gold nanoparticle } \\ \text { BFC } & \text { biological fuel cell } \\ \text { BOx } & \text { bilirubin oxidase } \\ \text { CDH } & \text { cellobiose dehydrogenase } \\ \text { DET } & \text { direct electron transfer } \\ \text { GDH } & \text { glucose dehydrogenase } \\ \text { GOx } & \text { glucose oxidase } \\ \text { ITO } & \text { indium-tin oxide } \\ \text { LDH } & \text { lactate dehydrogenase } \\ \text { LOx } & \text { lactate oxidase } \\ \text { NHE } & \text { normal hydrogen electrode } \\ \text { PEDOT } & \text { poly(3,4-ethylenedioxythiophene) } \\ \text { PDMS } & \text { polydimethyl siloxane } \\ \text { PET } & \text { poly(ethyleneterephthalate) } \\ \text { PMEH } & \text { poly(2-methacryloyloxyethyl phosphoryl- } \\ & \text { choline-co-2-ethylhexyl methacrylate) } \\ \text { TTF-TCNQ } & \text { tetrathiafulvalene-tetracyanoquinodime- } \\ & \text { thane }\end{array}$

\section{Acknowledgements}

This work was supported financially by the Samsung Electronics Co., Ltd. and by the Russian Foundation for Basic Research (13-04-12063 and 14-04-32235).

\section{References}

[1] I. Willner, E. Katz, Angew. Chem., Int. Ed. 2000, 39, 11811218.

[2] E. Katz, Electroanalysis 2006, 18, 1855-1857.

[3] D. H. Kim, Science 2011, 333, 838-843.

[4] a) M. Falk, V. Andoralov, Z. Blum, J. Sotres, D. B. Suyatin, T. Ruzgas, T. Arnebrant, S. Shleev, Biosens. Bioelectron. 2012, 37, 38-45; b) W. Jia, G. Valdes-Ramirez, A. J. Bandodkar, J. R. Windmiller, J. Wang, Angew. Chem., Int. Ed. 2013, 52, 7233-7236; c) A. J. Bandodkar, V. W. S. Hung, W. Jia, G. Valdes-Ramirez, J. R. Windmiller, A. G. Martinez, J. Ramirez, G. Chan, K. Kerman, J. Wang, Analyst 2013, 138 , 123-128; d) M. Falk, D. Pankratov, L. Lindh, T. Arnebrant, S. Shleev, Fuel Cells 2014, 14, 1050-1056; e) W. Jia, X Wang, S. Imani, A. J. Bandodkar, J. Ramirez, P. P. Mercier, 
J. Wang, J. Mater. Chem. A 2014, 2, 18184-18189; f) A. J. Bandodkar, J. Wang, Trends Biotechnol. 2014, 32, 363-371; g) A. J. Bandodkar, W. Z. Jia, J. Wang, Electroanalysis 2015 27, 562-575; h) J. Kim, S. Imani, W. R. de Araujo, J. Warchall, G. Valdes-Ramirez, T. R. L. C. Paixao, P. P. Mercier, J. Wang, Biosens. Bioelectron. 2015, 74, 1061-1068; i) J. Kim, W. R. de Araujo, I. A. Samek, A. J. Bandodkar, W. Jia, B. Brunetti, T. R. L. C. Paixao, J. Wang, Electrochem. Commun. 2015, 51, 41-45; j) J. Wang, P. Mercier, Salivary biosensors and biofuel cells, International Patent WO2015112638, 2015.

[5] V. Andoralov, S. Shleev, T. Arnebrant, T. Ruzgas, Anal. Bioanal. Chem. 2013, 405, 3871-3879.

[6] D. Pankratov, Z. Blum, S. Shleev, ChemElectroChem 2014 1, 1798-1807.

[7] V. Coman, C. Vaz-Dominguez, R. Ludwig, W. Harreither, D. Haltrich, A. L. De Lacey, T. Ruzgas, L. Gorton, S Shleev, Phys. Chem. Chem. Phys. 2008, 10, 6093-6096.

[8] S. Shleev, T. Ruzgas, Angew. Chem., Int. Ed. 2008, 47 , $7270-7274$.

[9] E. R. Berman, Biochemistry of the eye, Plenum Press, New York, 1991.

[10] N. M. Farandos, A. K. Yetisen, M. J. Monteiro, C. R. Lowe, S. H. Yun, Adv. Healthc. Mater. 2015, 4, 792-810.

[11] S. Agarwal, A. Agarwal, D. J. Apple, L. Buratto, J. L. Alio, S. K. Pandey, A. Agarwal, Textbook of ophthalmology, 1st ed., Jaypee Brothers Publishers, New Delhi, 2002

[12] I. A. Butovich, Prog. Lipid Res. 2011, 50, 278-301.

[13] B. A. Nichols, M. L. Chiappino, C. R. Dawson, Invest. Ophthalmol. Vis. Sci. 1985, 26, 464-473.

[14] J. P. Craig, I. Singh, A. Tomlinson, P. B. Morgan, N. Efron, Eye 2000, 14, 635-641.

[15] L. G. Carney, T. F. Mauger, R. M. Hill, Invest. Ophthalmol. Vis. Sci. 1989, 30, 747-754.

[16] W. J. Benjamin, R. M. Hill, Invest. Ophthalmol. Vis. Sci 1983, 24, 1624-1626.

[17] G. D. Bixler, B. Bhushan, Philos. Trans. R. Soc. A-Math Phys. Eng. Sci. 2012, 370, 2381-2417.

[18] J. Murube, Ocul. Surf. 2009, 7, 60-66.

[19] C. A. Paterson, M. C. O'Rourke, Arch. Ophthalmol. 1987 105, 376-377

[20] M. Zierhut, M. E. Stern, D. A. Sullivan, Immunology of the lacrimal gland, tear film and ocular surface, Taylor \& Francis, London, 2005.

[21] A. Phillips, Contact lenses, Elsevier, New York, 2007

[22] a) N. J. van Haeringen, E. Glasius, Albrecht Von Graefes Arch. Klin. Exp. Ophthalmol. 1977, 202, 1-7; b) C. R. Taormina, J. T. Baca, S. A. Asher, J. J. Grabowski, D. N. Finegold, J. Am. Soc. Mass Spectrom. 2007, 18, 332-336.

[23] a) C. K. M. Choy, I. F. F. Benzie, P. Cho, Curr. Eye Res. 2003, 27, 55-60; b) R. Gogia, S. P. Richer, R. C. Rose, Curr Eye Res. 1998, 17, 257-263.

[24] N. J. Van Haeringen, Surv. Ophthalmol. 1981, 26, 84-96.

[25] a) S. Li, R. Sack, T. Vijmasi, S. Sathe, A. Beaton, D. Quigley, M. Gallup, A. McNamara Nancy, Optom. Vis. Sci. 2008 $85,653-660 ;$ b) K. B. Green-Church, K. K. Nichols, N. M. Kleinholz, L. Zhang, J. J. Nichols, Mol. Vision 2008, 14, $456-470$.

[26] M. Markoulli, E. Papas, A. Petznick, B. Holden, Curr. Eye Res. 2011, 36, 198-207.

[27] R. Sack, L. Conradi, A. Beaton, S. Sathe, N. McNamara, A. Leonardi, Exp. Eye Res. 2007, 85, 528-538.

[28] N. Efron, Contact lens practice, 1st ed., Elsevier, Butterworth-Heinemann, 2002

[29] B. A. Parviz, Ieee Spectrum 2009, 46, 36-41.
[30] A. R. Lingley, M. Ali, Y. Liao, R. Mirjalili, M. Klonner, M. Sopanen, S. Suihkonen, T. Shen, B. P. Otis, H. Lipsanen, A. Parviz, J. Micromech. Microeng. 2011, 21, 125014/1-8.

[31] A. J. Shum, M. Cowan, I. Lahdesmaki, A. Lingley, B. Otis, B. A. Parviz, Biosensing II 2009, 7397, 73970K1-8.

[32] A. P. Fang, H. T. Ng, S. F. Y. Li, Biosens. Bioelectron. 2003 19, 43-49.

[33] H. F. Yao, A. J. Shum, M. Cowan, I. Lahdesmaki, B. A Parviz, Biosens. Bioelectron. 2011, 26, 3290-3296.

[34] H. Yao, A. Afanasiev, I. Lahdesmaki, B. A. Parviz, Ieee 24th International Conference on Micro Electro Mechanical Systems (Mems) 2011, 25-28.

[35] H. Yao, Y. Liao, A. R. Lingley, A. Afanasiev, I. Lahdesmaki, B. P. Otis, B. A. Parviz, J. Micromech. Microeng. 2012 22, 075007

[36] a) B. Otis, Y.-T. Liao, B. A. Parviz, H. Yao, Wireless powered contact lens with glucose sensor, USA Patent US20120245444, 2012; b) Y. T. Liao, H. F. Yao, A. Lingley, B. Parviz, B. P. Otis, IEEE J. Solid-State Circuit 2012, 47, $335-344$

[37] a) G. P. Release, What is Google doing with a smart contact lens?, 2014; b) N.I.A.P. Release, 2014.

[38] N. Thomas, I. Lahdesmaki, B. A. Parviz, Sens. Actuator BChem. 2012, 162, 128-134.

[39] a) M. X. Chu, K. Miyajima, D. Takahashi, T. Arakawa, K. Sano, S. Sawada, H. Kudo, Y. Iwasaki, K. Akiyoshi, M. Mochizuki, K. Mitsubayashi, Talanta 2011, 83, 960-965; b) M. X. Chu, T. Shirai, D. Takahashi, T. Arakawa, H. Kudo, K. Sano, S. Sawada, K. Yano, Y. Iwasaki, K. Akiyoshi, M. Mochizuki, K. Mitsubayashi, Biomed. Microdevices 2011, 13, 603-611.

[40] J. N. Patel, B. L. Gray, B. Kaminska, B. D. Gates, J. Diabetes Sci. Technol. 2011, 5, 1036-1043.

[41] T. Ruzgas, S. Shleev, T. Arnebrant, Flexible biofuel cell, device and method, International Patent WO2011117357, 2011.

[42] S. Shleev, A. Bergel, L. Gorton, Bioelectrochemistry 2015 $106,1-2$.

[43] X. Wang, M. Falk, R. Ortiz, H. Matsumura, J. Bobacka, R. Ludwig, M. Bergelin, L. Gorton, S. Shleev, Biosens. Bioelectron. 2012, 31, 219-225.

[44] R. Ludwig, W. Harreither, F. Tasca, L. Gorton, ChemPhys Chem 2010, 11, 2674-2697.

[45] Z. Blum, D. Pankratov, S. Shleev, Expet Rev. Ophthalmol. 2014, 9, 269-273

[46] V. Coman, R. Ludwig, W. Harreither, D. Haltrich, L. Gorton, T. Ruzgas, S. Shleev, Fuel Cells 2010, 10, 9-16.

[47] M. Falk, V. Andoralov, M. Silow, M. D. Toscano, S. Shleev, Anal. Chem. 2013, 85, 6342-6348.

[48] A. Venkata Sai Jyothi, A. Narayanasamy, V. Srinivasan, K. Iyer Geetha, R. Sivaramakrishnan, M. Subramanian, R. Mahadevan, Indian J. Ophthalmol. 2009, 57, 289-292.

[49] R. C. Reid, S. D. Minteer, B. K. Gale, Biosens. Bioelectron 2015, 68, 142-148.

[50] S. Shleev, D. Pankratov, Z. Blum, Charge-storing fuel cell, International Patent WO2014167063, 2014.

[51] D. Pankratov, P. Falkman, Z. Blum, S. Shleev, Energy Environ. Sci. 2014, 7, 989-993.

[52] D. Pankratov, Z. Blum, D. B. Suyatin, V. O. Popov, S Shleev, ChemElectroChem 2014, 1, 343-346.

[53] M. Falk, Z. Blum, S. Shleev, Electrochim. Acta 2012, 82, $191-202$

[54] D. V. Pankratov, E. Gonzalez-Arribas, Y. M. Parunova, M. A. Gorbacheva, Y. S. Zeyfman, S. V. Kuznetsov, A. V. Lipkin, S. V. Shleev, Acta Naturae 2015, 7, 98-101. 


\section{Review}

[55] D. Pankratov, R. Sundberg, J. Sotres, I. Maximov, M. Graczyk, D. B. Suyatin, E. González-Arribas, A. Lipkin, L. Montelius, S. Shleev, J. Power Sources 2015, 294, 501-506.

[56] S. E. Moulton, J. N. Barisci, A. Bath, R. Stella, G. G. Wallace, Electrochim. Acta 2004, 49, 4223-4230.

[57] W. C. Liao, S. L.-C. Hsu, Nanotechnology 2007, 18, 065303/ $1-5$.

[58] J. Niedziolka, K. Szot, F. Marken, M. Opallo, Electroanalysis 2007, 19, 155-160.

\section{ELECTROANALYSIS}

[59] V. Andoralov, M. Falk, D. B. Suyatin, M. Granmo, J. Sotres, R. Ludwig, V. O. Popov, J. Schouenborg, Z. Blum, S. Shleev, Sci. Rep. 2013, 3, 3270 .

[60] K. Murata, K. Kajiya, N. Nakamura, H. Ohno, Energy Environ. Sci. 2009, 2, 1280-1285.

Received: November 26, 2015

Accepted: December 26, 2015 Published online: January 20, 2016 

P2 



\section{Transparent, mediator- and membrane-free enzymatic fuel cell based on nanostructured chemically modified indium tin oxide electrodes}

Elena González-Arribas ${ }^{\mathrm{a}, 1}$, Tim Bobrowski ${ }^{\mathrm{b}, 1}$, Chiara Di Bari ${ }^{\mathrm{c}}$, Kirill Sliozberg ${ }^{\mathrm{b}}$, Roland Ludwig ${ }^{\mathrm{d}}$, Miguel D. Toscano ${ }^{\mathrm{e}}$, Antonio L. De Lacey ${ }^{\mathrm{c}}$, Marcos Pita ${ }^{\mathrm{c}}$, Wolfgang Schuhmann ${ }^{\mathrm{b}, *}$, Sergey Shleev ${ }^{\mathrm{a}, \mathrm{f}, \mathrm{g}, *, *}$

a Biomedical Science, Health and Society, Malmö University, 20560 Malmö, Sweden

${ }^{\mathrm{b}}$ Analytical Chemistry - Center for Electrochemical Sciences (CES), Ruhr-Universität Bochum, D-44780 Bochum, Germany

${ }^{c}$ Instituto de Catálisis y Petroleoquímica, CSIC, C/Marie Curie 2, L10, 28049 Madrid, Spain

a Department of Food Science and Technology, BOKU-University of Natural Resources and Life Sciences, Muthgasse 18, 1190 Vienna, Austria

e Novozymes A/S, Krogshoejvej 36, 2880 Bagsverd, Denmark

${ }^{\mathrm{f}}$ A.N. Bach Institute of Biochemistry, 119071 Moscow, Russia

$\mathrm{g}^{\mathrm{A}}$ Kurchatov NBIC Centre, National Research Centre "Kurchatov Institute", 123182 Moscow, Russia

\section{A R T I C L E I N F O}

\section{Keywords:}

Indium tin oxide

Nanoparticle

Membrane-free

Mediator-free

Transparent enzymatic fuel cell

\begin{abstract}
A B S T R A C T
We detail a mediator- and membrane-free enzymatic glucose/oxygen biofuel cell based on transparent an nanostructured conducting supports. Chemically modified indium tin oxide nanoparticle modified electrodes were used to substantially increase the active surface area without significantly compromising transparency. Two different procedures for surface nanostructuring were employed, viz. spray-coating and drop-coating. The spray-coated biodevice showed superior characteristics as compared to the drop-coated enzymatic fuel cell, as a result of the higher nanostructured surface area as confirmed by electrochemical characterisation, as well a scanning electron and atomic force microscopy. Subsequent chemical modification with silanes, followed by the immobilisation of either cellobiose dehydrogenase from Corynascus thermophiles or bilirubin oxidase from Myrothecium verrucaria, were performed to obtain the bioanodes and biocathodes, respectively. The optimised biodevice exhibited an OCV of $0.67 \mathrm{~V}$ and power output of up to $1.4 \mu \mathrm{W} / \mathrm{cm}^{2}$ at an operating voltage of $0.35 \mathrm{~V}$. This is considered a significant step forward in the field of glucose/oxygen membrane- and mediator-free, transparent enzymatic fuel cells.
\end{abstract}

\section{Introduction}

Biological fuel cells (BFCs) in general, and enzymatic fuel cells (EFCs) in particular, have been envisioned as electrical power sources for self-contained bioelectronics including biomedical devices operating in vivo and ex vivo (Castorena-Gonzalez et al., 2013; Cosnier et al., 2016, 2014; Falk et al., 2013b, 2014; Halámková et al., 2012; Heller, 2004; Katz, 2014; Leech et al., 2012; Rasmussen et al., 2016; Shleev, 2017).

For certain applications, e.g. wearable electronics (Bandodkar and Wang, 2014, 2016; Pankratov et al., 2016) and biosolar cells (Somasundaran et al., 2011), the transparency of the EFC should be taken into account. The use of transparent conductive nanomaterials allows improving the aesthetic and cosmetic issues that are relevant in the case of smart electronic contact lenses (Blum et al., 2014; Parviz, 2009) and body-attachable wearable electronic platforms (Kim et al., 2015; Trung et al., 2016).

The electric power is generated by converting in situ available chemical energy from different biofuels present in human tears into electric energy. Several possible biofuels are present in lachryma liquid, e.g. glucose, lactate, ascorbate and pyruvate, as well as neurotransmitters, although they appear in limited supply, while a biooxidant, molecular oxygen $\left(\mathrm{O}_{2}\right)$, dissolved in tear fluid is abundantly available (Pankratov et al., 2016). The very first publications detailin BFCs as power sources for electronic contact lenses appeared in 20122013: nanostructured glucose/oxygen (Falk et al., 2012) and ascorbate/oxygen (Falk et al., 2013a) BFCs based on direct electron transfer (DET) reactions were fabricated and tested in human lachrymal liquid.

\footnotetext{
E-mail addresses: wolfgang.schuhmann@ rub.de (W. Schuhmann), sergey.shleev@mah.se (S. Shleev).

1 These authors contributed equally to this work.

${ }^{*}$ Corresponding author at: Analytical Chemistry - Center for Electrochemical Sciences (CES), Ruhr-Universität Bochum, D-44780 Bochum, Germany.

*** Corresponding author at: Biomedical Science, Health and Society, Malmö University, 20560 Malmö, Sweden. 
Despite a need for transparent biodevices, to the best of our knowledge, there are only two reports in the literature regarding transparent EFCs (Amao and Takeuchi, 2008; Pankratov et al., 2015). Among the transparent and conducting supports indium tin oxide (ITO) is the most commonly employed (Gilstrap et al., 2008) in transparent electrochemical devices, since it presents a high optical transparency and conductivity (Dattoli and Lu, 2011). ITO also offers several other attractive physical properties, e.g. high stability under physiological conditions (Yang and Li, 2005). Despite the attractive properties of ITO, to the best of our knowledge, there are no reports in the literature regarding EFCs fabricated using ITO surfaces nanostructured with indium tin oxide nanoparticles (ITO NPs). Below we detail the very first transparent, mediator- and membrane-less EFCs based on nanostructured chemically modified ITO electrodes with covalently attached anodic and cathodic redox enzymes.

\section{Material and methods}

\subsection{Reagents}

$N$-ethyl- $N^{\prime}$-(3-dimethylaminopropyl) carbodiimide hydrochloride (EDC), ethanol (absolute), (3-glycidyloxypropyl)trimethoxysilane (GLYMO), $\geq 98 \%$, Indium tin oxide (ITO) conductive glasses (15$25 \Omega /$ sq), methanol and $N$-hydroxysuccinimide (NHS), $98 \%$ were purchased from Sigma-Aldrich (Steinheim, Germany). Acetic acid, dichloromethane, p.a., potassium chloride, sodium bicarbonate, and sodium hydroxide were acquired from J.T. Baker (Deventer, The Netherlands). Argon (Ar, 99.998\%) and $\mathrm{O}_{2}$ (> 99.5\%) were obtained from Air Liquide (Düsseldorf, Germany), disodium phosphate, monopotassium phosphate, sodium acetate, $99.0 \%$ and toluene were from VWR-Chemicals (Langenfeld, Germany), D(+)-glucose, monohydrate and TRIS, ultrapure, were from Applichem (Darmstadt, Germany), (3aminopropyl)triethoxysilane (APTES), 99\% was from ABCR (Karlsruhe, Germany), ITO nanoparticles (ITO NPs, product number 4111CB, 99.99\%, 20-70 nm) were from Skyspring Nanomat. (Texas, USA), sodium chloride, $99.5 \%$ was from Carl Roth (Karlsruhe, Germany), sodium carbonate from Merck (Darmstadt, Germany), and 2-(N-morpholino)ethanesulfonic acid (MES) from Biomol (Hamburg, Germany).

\subsection{Enzymes}

Cellobiose dehydrogenase from Corynascus thermophilus (CDH) expressed in Pichia pastoris was obtained as previously described (Coman et al., 2010) and used for the fabrication of the transparent ITO bioanodes. In the initial aliquot the enzyme was dissolved in $50 \mathrm{mM}$ sodium acetate buffer, pH 5.5 in a concentration of $25 \mathrm{mg} / \mathrm{mL}$. An aliquot of $3.61 \mathrm{mg} / \mathrm{mL}$ of Myrothecium verrucaria bilirubin oxidase (BOx) was used for the fabrication of the ITO biocathodes. The enzyme was produced recombinantly in Aspergillus oryzae, as previously published (Xu et al., 1996), purified using a previously reported protocol (Falk et al., 2013a), and stored in $20 \mathrm{mM}$ tris buffer, $100 \mathrm{mM} \mathrm{Na}_{2} \mathrm{SO}_{4}, \mathrm{pH} 8$.

\subsection{Nanostructuring process of ITO coated glass electrodes}

ITO conductive glasses were cut into chips of $10 \mathrm{~mm} \times 25 \mathrm{~mm} \times$ $1.1 \mathrm{~mm}$. The following cleaning procedure involved sonication in ethanol and subsequently in methylene chloride, $15 \mathrm{~min}$ each and additionally storing in ultrapure water for $20 \mathrm{~min}$. After this, a working area of $10 \mathrm{~mm} \times 10 \mathrm{~mm}$ was selected for electrode nanostructuring (Fig. 1).

Dispersions with different percentages ( 3 wt\% and $\sim 15$ wt\%) of ITO NPs in methanol were prepared for the nanostructuring process aiming on two different mass loadings $\left(0.25 \mathrm{mg} / \mathrm{cm}^{2}\right.$ and $1.25 \mathrm{mg} /$ $\mathrm{cm}^{2}$ ) on the surface of ITO thin film coated glasses. The dispersions

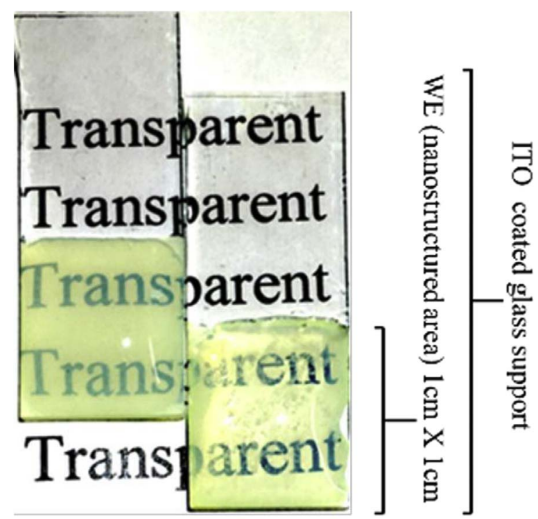

Fig. 1. Photographic images of ITO nanoparticle spray-coated (left) and drop-coated electrode (right).

were immersed in an ultrasonic bath for $20 \mathrm{~min}$ for an efficient homogenisation. Afterwards, for fabrication of the drop-coated ITO NP electrodes, $10 \mu \mathrm{L}$ of the dispersion were dropped on the selected working area of the ITO coated glasses. After drying in air, the nanostructured surfaces were employed for chemical modification.

In parallel, to fabricate the spray-coated electrodes, ITO thin film coated glasses were fixed on a solid copper heating block and heated up to $70{ }^{\circ} \mathrm{C}$. While stirring the sample, a suspension of ITO NPs $(2 \mathrm{mg} / \mathrm{mL}$ in methanol) was sprayed in a step by step procedure onto the electrode surface with the help of a compressed air nozzle. Thereby, the spray head was moved in an array of $1.2 \mathrm{~cm} \times 1.2 \mathrm{~cm}$ with a fixed z-height above each electrode. This process was repeated several times, until the desired electrode loadings $\left(0.25 \mathrm{mg} / \mathrm{cm}^{2}\right.$ and $\left.1.25 \mathrm{mg} / \mathrm{cm}^{2}\right)$ were reached. Parameters and further information can be found in Supporting information (SI), viz. in SI Table S1 and Fig. S1.

\subsection{Evaluation of the transparency}

Quantitative transparency measurements employing UV-vis spectroscopy in air were performed with a set of enzyme-free modified ITO NP drop-coated electrodes, related to bare ITO quartz glass electrodes. A Cary 50 UV-vis spectrophotometer from Varian (Utrecht, The Netherlands) was used for that purpose. Absorbance values for five prepared electrodes for each mass loading were measured in the wavelength range between 200 and $1100 \mathrm{~nm}$ and averaged. Transmittance values were calculated by using the logarithmic relation between these quantities.

\subsection{Chemical modification of electrodes for enzyme immobilisation}

Chemical modification of the nanostructured surfaces was optimised for each biocatalyst. For the chemical modification of the anodes, the cleaned ITO glasses were immersed in toluene with $1 \%(v / v)$ APTES overnight and stirred at room temperature. To carry out the chemical modification of cathodes, the cleaned ITO glasses were immersed for $20 \mathrm{~min}$ under stirring in toluene with $0.1 \%(v / v)$ GLYMO at $70{ }^{\circ} \mathrm{C}$. The silanised ITO glasses were then rinsed with toluene in both cases.

\subsection{Enzyme immobilisation}

For $\mathrm{CDH}$ immobilisation, the enzyme solution was diluted in the 

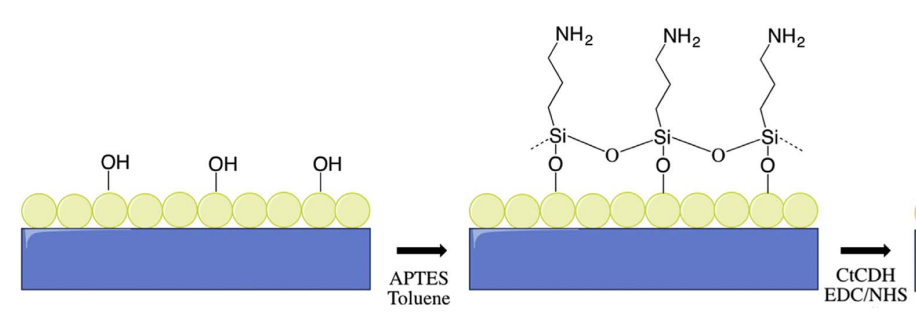
APTES
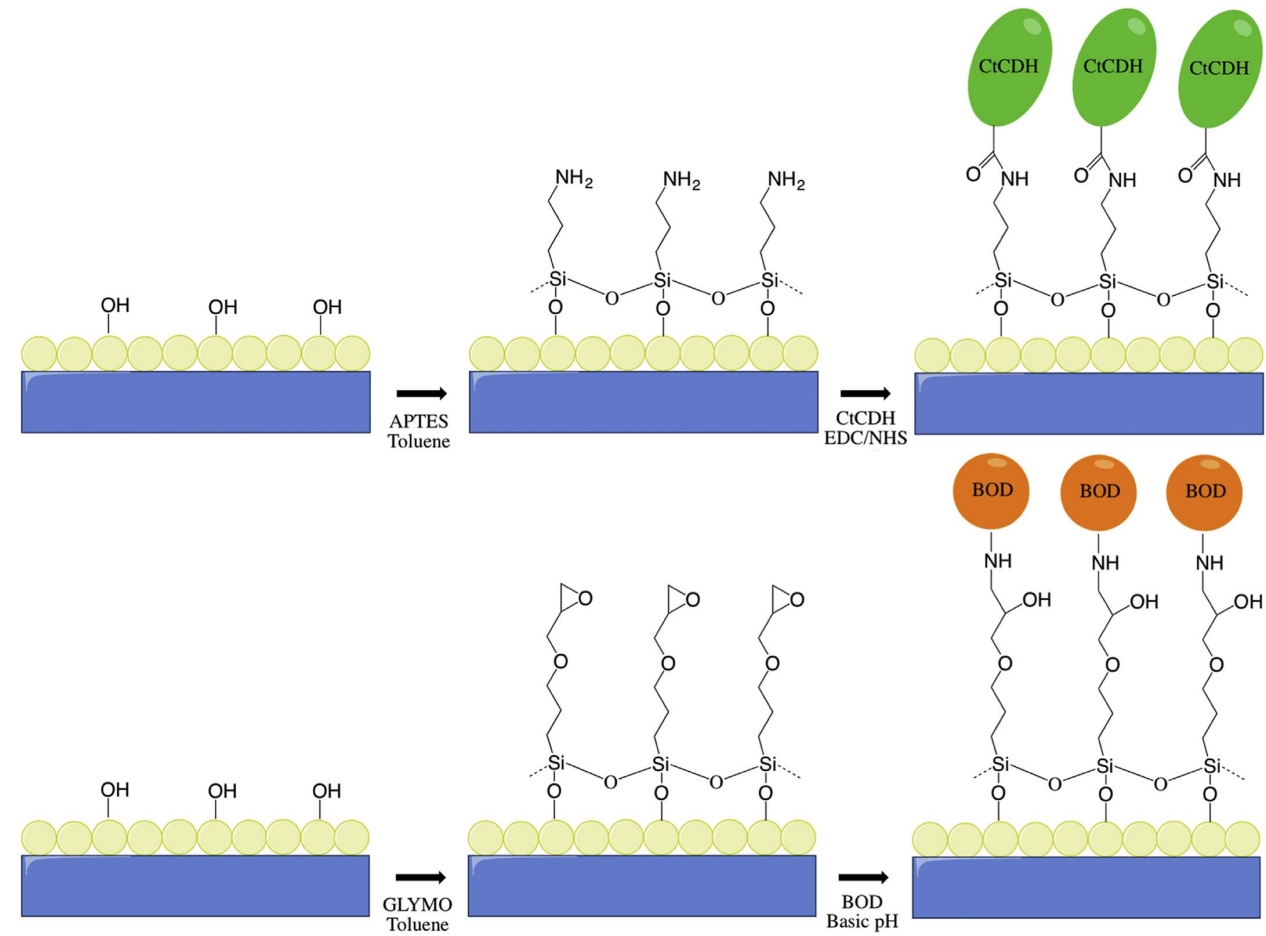

Fig. 2. Chemical modification of the nanostructured transparent electrodes for BOx (top).and $\mathrm{CDH}$ (bottom) covalent immobilisation.

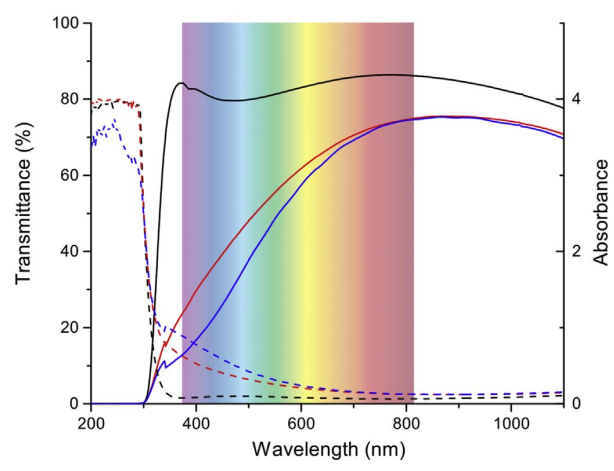

Fig. 3. UV-vis spectra of ITO glasses. Transmittance (solid lines) and absorbance (dashed lines) $v s$. wavelength of differently loaded ITO glasses. Black curves: bare ITO, red curves: $0.25 \mathrm{mg} / \mathrm{cm}^{2}$ ITO NPs, blue curves: $1.25 \mathrm{mg} / \mathrm{cm}^{2}$ ITO NPs. (For interpretation of the references to color in this figure legend, the reader is referred to the web version of this article.)

same buffer until a concentration of $5 \mathrm{mg} / \mathrm{mL}$ was reached. $10 \mu \mathrm{L}$ of the diluted enzyme solution were dropped onto the silanised ITO surface and $30 \mu \mathrm{L}$ of a solution of $36 \mathrm{mM}$ EDC and $17 \mathrm{mM}$ NHS in
MES buffer were dropped on top of the enzyme layer (GutiérrezSánchez et al., 2012). The reaction took place for $150 \mathrm{~min}$ at room temperature under moisturised conditions to avoid drying of the reacting solution. It was expected that the exposed negatively charged residues of $\mathrm{CDH}$, such as aspartic or glutamic acid, would react with the $\mathrm{NH}_{2}$ of APTES (Fig. 2 right).

For the BOx immobilisation, the volume of the initial aliquot was diluted to $3 \mathrm{mg} / \mathrm{mL}$ by adding $50 \mathrm{mM}$ bicarbonate-carbonate buffer, $\mathrm{pH}$ 9.4. $30 \mu \mathrm{L}$ of BOx solution were dropped onto the silanised ITO surface and reacted for $2 \mathrm{~h} 30 \mathrm{~min}$ at room temperature under moisturised conditions to avoid evaporation. With increasing of the $\mathrm{pH}$ value achieved with the dilution, promotion of the hydrolysis of epoxy groups present in the GLYMO layer was expected. The hydrolysed epoxy groups bound to the amine groups presented in enzyme surface by generating secondary amine groups (Fig. 2, left) (Abad et al., 2002). The previously mentioned protocols were carried out to achieve stability of the immobilisation and the preferential orientation of the enzyme allowing efficient DET (Gutiérrez-Sánchez et al., 2012).

\subsection{Electrochemical characterisation}

All electrochemical characterisations were performed using a $\mu$ Autolab Type III/FRA2 potentiostat/galvanostat from Metrohm Autolab (Utrecht, The Netherlands) employing a three electrode setup with an ITO nanostructured electrode as working, a platinum mesh as counter, and a $\mathrm{Ag} / \mathrm{AgCl}(3 \mathrm{M} \mathrm{KCl})$ as reference electrodes, respectively. 


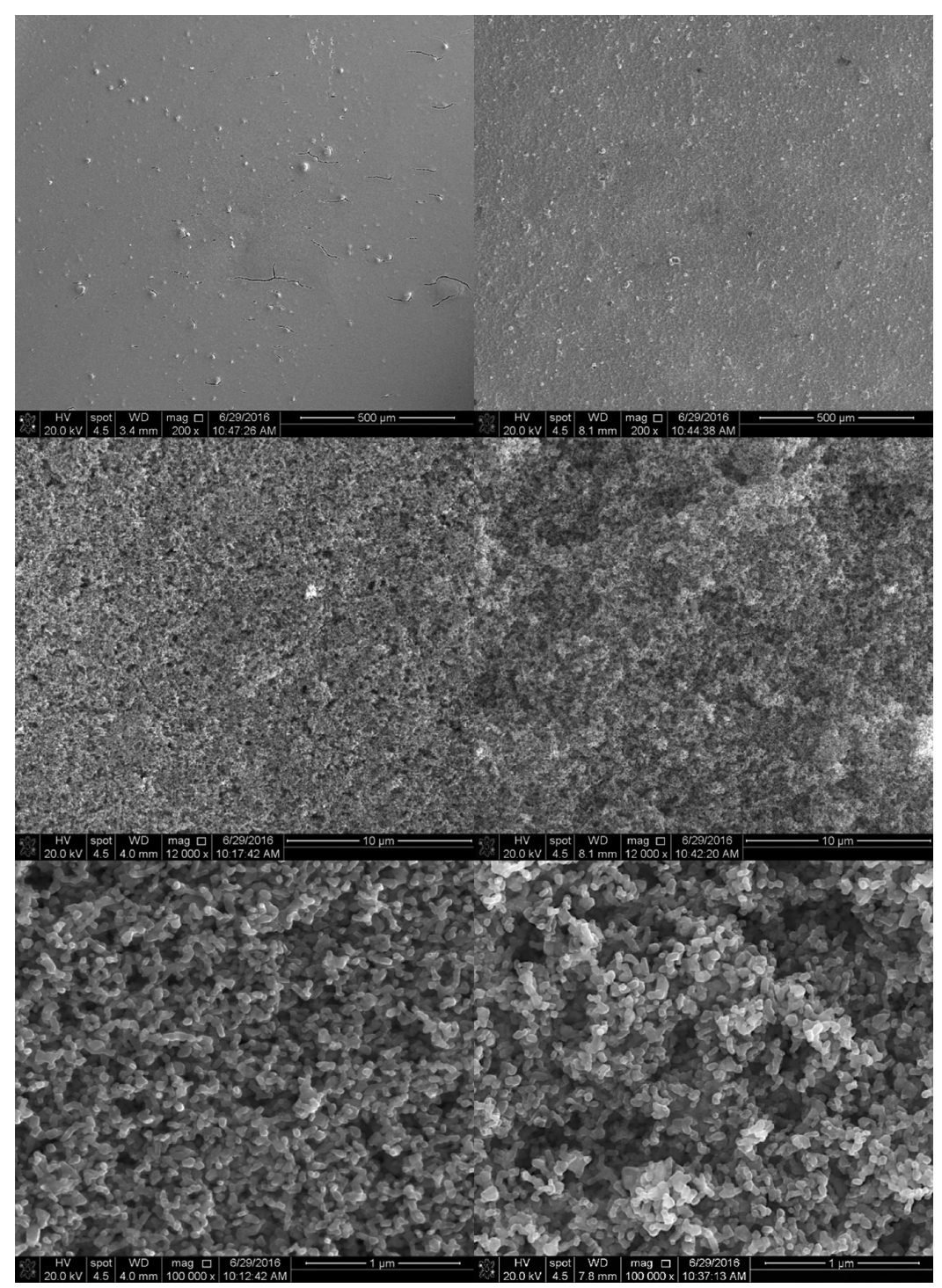

Fig. 4. SEM images of drop-coated (left) and spray-coated (right) ITO NP modified electrodes with different magnification. From top to bottom: 200×, 12,000×, 100,000×.

The electrodes were immersed in phosphate buffered saline (PBS) (12 mM phosphate, $137 \mathrm{mM} \mathrm{NaCl}, 2.7 \mathrm{mM} \mathrm{KCl}$ ), $\mathrm{pH}$ 7.4. Prior to the characterisation of anodes, Ar was bubbled into the electrochemical cell for $20 \mathrm{~min}$. Two different concentrations of glucose acting as substrate $(0.05 \mathrm{mM}$, and $50 \mathrm{mM})$ were added to the buffer. For cathode characterisation, either $\mathrm{Ar}$ or $\mathrm{O}_{2}$ were bubbled for 20 min to study the bioelectrocatalytic response in presence or absence of oxygen as electron acceptor. Electrochemical characterisation was carried out using cyclic voltammetry (CV) at a scan rate of $10 \mathrm{mV} / \mathrm{s}$. All potentials are given $v s$. the normal hydrogen electrode (NHE). 


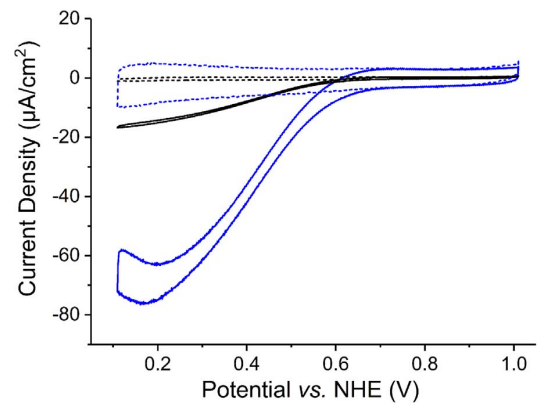

Fig. 5. Cyclic voltammograms of drop-coated BOx modified ITO electrodes modifie with different ITO NPs loadings. Dashed lines: Ar saturated PBS. Solid lines: $\mathrm{O}_{2}$ saturated PBS. Black and blue CVs correspond to 0.25 and $1.25 \mathrm{mg} / \mathrm{cm}^{2}$ of ITO NPs, respectively. (For interpretation of the references to color in this figure legend, the reader is referred to the web version of this article.)

\subsection{Enzymatic fuel cell tests}

The enzymatic fuel cells were evaluated by means of chronoamperometry, with the bioanode connected as working electrode and the biocathode as combined reference/ counter electrode. Measurement were performed in air-saturated PBS buffer, $\mathrm{pH} 7.4$, containing $50 \mathrm{mM}$ glucose. Corresponding polarisation curves were obtained by applying successive potential pulses in a range starting from open circuit voltage $(\mathrm{OCV})$ of the system, down to $0.01 \mathrm{~V}$ vs. $\mathrm{Ag} / \mathrm{AgCl} / 3 \mathrm{M} \mathrm{KCl}$ in $0.05 \mathrm{~V}$ intervals and recording the equilibrium steady-state currents reached at each applied potential.

\subsection{SEM studies}

Scanning electron microscopy (SEM) was performed with two different setups. An ultra-high resolution scanning electron microscope, EVO LS10 from Zeiss (Jena, Germany) operating in high vacuum mode with a LaB6 filament, field immersion mode with $20 \mathrm{kV}$ accelerating voltage was used for the first measurements. Later investigations were conducted with an environmental scanning electron microscope (eSEM) FEI Quanta 3D (Hillsboro, Oregon, USA) using the same parameters.

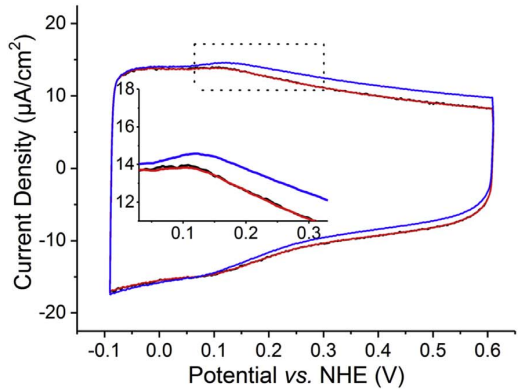

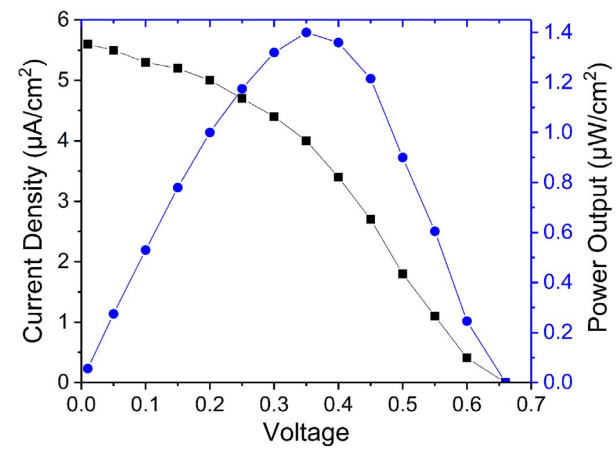

Fig. 7. Polarisation (black) and corresponding power output (blue) curves of the optimised transparent glucose/oxygen biofuel cell $\left(1.25 \mathrm{mg} / \mathrm{cm}^{2}\right.$ of ITO NPs, spraycoated electrodes), operating in $50 \mathrm{mM}$ glucose containing air-saturated PBS, $\mathrm{pH} 7.4$. (For interpretation of the references to color in this figure legend, the reader is referred to the web version of this article.)

\section{Results and discussion}

Spectrophotometric studies showed insignificant differences between the electrodes drop-coated with low and high amounts of ITO NPs. While the average transmittance of the bare electrodes is constantly higher than $80 \%$ in the visible light spectrum, it drops from $70 \%(\lambda=800 \mathrm{~nm})$ to $30 \%(\lambda=400 \mathrm{~nm})$ (Fig. 3, red curve) for the electrodes covered with $0.25 \pm 0.03 \mathrm{mg} / \mathrm{cm}^{2}$ and below $20 \%$ at $400 \mathrm{~nm}$ for the highly covered electrodes with $1.25 \pm 0.05 \mathrm{mg} / \mathrm{cm}^{2}$ loading (Fig. 3, blue curve). However, the average transmittance even for highly NP loaded electrodes is above $55 \%$ in the visible spectrum, which represents a significant step forward regarding transparent and conducting supports used to fabricate separate enzyme electrodes (González-Arribas et al., 2016) and complete EFCs (Pankratov et al, 2015).

Despite the promising transparency provided by the drop-coated nanostructured electrodes an alternative electrode-coating approach was used, aiming at higher reproducibility and a more homogeneous coating. A spray nebulizer with temperature control of the target surface (Raicopol et al., 2015; Sliozberg, 2016) was used to spray-coat the samples. The same NP surface loadings as used by drop-coating $\left(0.25 \mathrm{mg} / \mathrm{cm}^{2}\right.$ and $\left.1.25 \mathrm{mg} / \mathrm{cm}^{2}\right)$ were obtained by spray-coating starting from a $2 \mathrm{mg} / \mathrm{mL} \mathrm{NP}$ concentration in methanol and applying

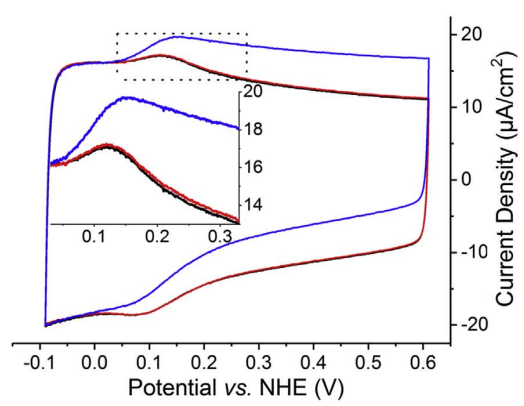

Fig. 6. Cyclic voltammograms of $\mathrm{CDH}$ modified nanostructured $\left(1.25 \mathrm{mg} / \mathrm{cm}^{2} \mathrm{ITO} \mathrm{NPs}\right)$ electrodes. Right: spray-coated electrode, left: drop-coated electrode. Black, red, and blue curves correspond to $0,0.05$, and $50 \mathrm{mM}$ glucose in PBS, respectively. (For interpretation of the references to color in this figure legend, the reader is referred to the web version of this article.) 
optimised spraying parameters (Table S1 and Fig. S3). Macroscopically, the spray-coated electrodes showed an improved ITO NPs homogeneity (Fig. 1).

SEM images of the ITO NP drop- and spray-coated electrodes reveal significant differences in their structural characteristics. The micro-scale structure of the drop-coated electrodes is smoother and flatter than that of the spray-coated electrodes (Fig. 4). The images with $100,000 \times$ magnification show a different particle distribution depending on the preparation method. The differences in distribution and smoothness are attributed to the heating of the support electrode during spray-coating. Heating leads to a rapid solvent evaporation from the deposited aerosol. Thus, the sprayed NPs immediately stuck to the surface, hence suppressing aggregation. In contrast, aggregation occurs for the drop-coated NPs due to a slow drying process. The resulting highly nanostructured structure of the spray-coated NP ITO electrodes provide a significantly higher surface area than the smoother drop-coated NP layer. Moreover, several cracks and defects appear at the surface of the drop-coated electrode, caused by the non-uniformly dried surface. These defects do not appear for the spray-coated electrodes, which suggested improved electrochemical performance and stability of the spray-coated electrodes. The layer thickness of the $1.25 \mathrm{mg} / \mathrm{cm}^{2}$ loaded electrodes was determined by AFM to be 7.3$7.7 \mu \mathrm{m}$ for the spray-coated electrodes and $6.5-9.0 \mu \mathrm{m}$ for the dropcoated electrodes, respectively, with even some areas higher than $10 \mu \mathrm{m}$ due to NP agglomeration (SI Figs. S2a and S2b).

The structural differences between the drop- and spray-coated electrodes obtained even at the same mass-loadings lead to differences regarding their electrochemical behaviour when applied as current collector for a transparent EFC. After immobilisation of the enzymes, viz. BOx and $\mathrm{CDH}$, respectively, on the ITO NPs modified surfaces, both the anodic and cathodic half-cells were characterised electrochemically. The enzymes were immobilised following protocols as shown in Fig. 2.

First, differences in the current response of low and highly loaded ITO NP electrodes at different potentials were investigated. Cyclic voltammograms (CVs) of drop-coated biocathodes were recorded from $0.8 \mathrm{~V}$ to $-0.1 \mathrm{~V}$ vs. $\mathrm{Ag} / \mathrm{AgCl} / 3 \mathrm{M} \mathrm{KCl}$ at $10 \mathrm{mV} / \mathrm{s}$ scan rate (Fig. 5). The background current obtained under Ar-saturated PBS solution for each ITO NPs loading $\left(0.25 \mathrm{mg} / \mathrm{cm}^{2}\right.$ and $\left.1.25 \mathrm{mg} / \mathrm{cm}^{2}\right)$ showed the expected increase in the capacitive current due to the substantially increased electroactive surface area. The catalytic currents recorded in $\mathrm{O}_{2}$ saturated PBS showed an about 10-fold increase for the higher ITO NPs loading as compared to the lower one. Similar differences between low and highly NPs loaded electrodes were observed for the CDH modified bioanodes (SI Fig. S3). These results, along with the minor differences in the transparency between the lowest and highest ITO NPs loading, justify the further use of the $1.25 \mathrm{mg} / \mathrm{cm}^{2} \mathrm{NP}$ loaded electrodes for further optimising both the anode and cathode of the anticipated EFC.

The drop-coated and spray-coated ITO NPs modified electrodes loaded with $1.25 \mathrm{mg} / \mathrm{cm}^{2}$ ITO NPs were chemically modified for further covalent enzyme attachment. Fig. 6 shows the CVs of $\mathrm{CDH}-$ modified drop-coated and spray-coated ITO NPs bioanodes. The catalytic current responses were recorded with before and after addition of $0.05 \mathrm{mM}$ and $50 \mathrm{mM}$ glucose to the electrolyte. The observed background currents of the spray-coated electrodes (Fig. 6, right) are significantly higher as compared to the drop-coated electrodes (Fig. 6, left). Moreover, the reversible redox reactions of the haem group of $\mathrm{CDH}$ on top of the capacitive waves showed higher current responses in the case of the spray-coated electrodes. This indicates that the sprayed electrodes allows for a higher loading with the enzyme despite both nanostructured electrodes were modified with the same mass of ITO NPs. Accordingly, the catalytic currents in presence of $50 \mathrm{mM}$ glucose recorded with the spray-coated electrodes were about 3-fold higher than those from the drop-coated bioanodes. Measurements at only $0.05 \mathrm{mM}$ glucose concentration demonstrated almost no catalytic response from the drop-coated $\mathrm{CDH}$ modified electrodes, whereas a slight catalytic current increase could be stil noticed in the case of the spray-coated electrode (Fig. 6, insets).

Similar to the bioanodes, the spray-coated biocathode yielded a superior performance as compared with the drop-coated biocathode (SI Fig. S4). However, bioelectrocatalytic currents were up to five times lower for the anodes as compared with the cathodes, which clearly identifies the anode reaction to be limiting in the resulting enzymatic fuel cell (vide infra).

During the characterisation of the half-cells, the mass loading of $1.25 \mathrm{mg} / \mathrm{cm}^{2}$ showed the highest current densities for both bioanode and biocathode. Moreover, spray-coating of the ITO NPs instead of drop-coating them yielded higher background currents and, more importantly, drastically enhanced performance of the limiting bioanode. Fig. 7 shows the current and power output of a transparent $\mathrm{CDH} /$ BOx biofuel cell based on the $1.25 \mathrm{mg} / \mathrm{cm}^{2}$ ITO NPs loaded spraycoated electrodes. A notoriously high OCV of $0.67 \mathrm{~V}$ was reached, while the maximum power output was determined to be $1.4 \mu \mathrm{W} / \mathrm{cm}^{2}$ at an operating voltage of $0.35 \mathrm{~V}$. The generated values are competitive towards previously described transparent glucose/oxygen EFCs (Amao and Takeuchi, 2008; Pankratov et al., 2015). Especially the high OCV of the EFC is well fitting into the state of the art for $\mathrm{CDH} / \mathrm{BOx}$ biofuel cells (Shao, 2013). This leads to the conclusion that transparent biodevices may exhibit a power comparable to opaque EFCs, and thus, can be applied for energy demanding applications with need for transparent supports.

\section{Conclusions}

We demonstrate that a transparent, nanostructured, membraneand mediator-free glucose/oxygen $\mathrm{EFC}$ is able to generate electric power in glucose containing phosphate buffered saline. Planar ITO thin-film-covered quartz glass electrodes were nanostructured with ITO NPs using two different approaches, viz. drop-coating and spraycoating, respectively. Chemical modification procedures for proper orientation of cathodic and anodic redox enzymes, viz. BOx and $\mathrm{CDH}$, respectively, during their immobilisation on ITO NPs modified electrodes were adapted from previously developed protocols and further optimised for nanostructured surfaces. The optimised spraycoating technique resulted in a higher surface area due to an increase of the electrode surface roughness and a highly flocculent structure, as well as a higher homogeneity and reproducibility of the obtained electrodes leading concomitantly to significantly higher catalytic currents. Even at low glucose concentration of e.g. $0.05 \mathrm{mM}$, which corresponds to the concentration in human tears, the spray-coated ITO NPs based electrodes showed a catalytic current response. Additional improvements of the fundamental characteristics of transparent EFCs, as well as the development of flexible biodevices mimicking human contact lenses, are in the scope of our present research.

\section{Acknowledgements}

This work was supported in part by the European Commission through the Marie-Curie Project "Bioenergy" (PITN-GA-2013-607793), by the Swedish Research Council (621-2013-6006), and by the Cluster of Excellence RESOLV (EXC 1069) funded by the Deutsche Forschungsgemeinschaft (DFG).

\section{Appendix A. Supporting information}

Supplementary data associated with this article can be found in the online version at doi:10.1016/j.bios.2017.05.040. 


\section{References}

Abad, J.M., Velez, M., Santamaria, C., Guisan, J.M., Matheus, P.R., Vazquez, L., Gazaryan, I., Gorton, L., Gibson, T., Fernandez, V.M., 2002. J. Am. Chem. Soc. 12 (43), 12845-12853.

Amao, Y., Takeuchi, Y., 2008. Int. J. Hydrog. Energy 33 (11), 2845-2849.

Bandodkar, A.J., Wang, J., 2014. Trends Biotechnol. 32 (7), 363-371.

Bandodkar, A.J., Wang, J., 2016. Electroanalysis 28 (6), 1188-1200.

Blum, Z., Pankratov, D., Shleev, S., 2014. Expert Rev. Ophthalmol. 9 (4), 269-273.

Castorena-Gonzalez, J.A., Foote, C., MacVittie, K., Halámek, J., Halámková, L.,

Martinez-Lemus, L.A., Katz, E., 2013. Electroanalysis 25 (7), 1579-1584.

Coman, V., Ludwig, R., Harreither, W., Haltrich, D., Gorton, L., Ruzgas, T., Shleev, S 2010. Fuel Cells 10 (1), 9-16.

Cosnier, S., Gross, J., Le Goff, A, A., Holzinger, M., 2016. J. Power Sources 325 , 252-263.

Cosnier, S., Le Goff, A. Holzinger, M., 2014. Electrochem. Commun. 38, 19-23.

Dattoli, E.N., Lu, W., 2011. MRS Bull. 36 (10), 782-788.

Falk, M., Andoralov, V., Blum, Z., Sotres, J., Suyatin, D. B., Ruzgas, T., Arnebrant, T., Shleev, S., 2012. Biosens. Bioelectron. 37 (1), 38-45.

Falk, M., Andoralov, V., Silow, M., Toscano, M.D., Shleev, S., 2013a. Anal. Chem. 85 (13), $6342-6348$.

Falk, M., Narváez Villarrubia, C.W., Babanova, S., Atanassov, P., Shleev, S., 2013b. ChemPhysChem 14 (10), 2045-2058.

Falk, M., Shleev, S., Narváez Villarrubia, C.W., Babanova, S., Atanassov, P., 2014 Biological fuel cells for biomedical applications. In: Luckarift, H.R., Atanassov, P., Johnson, G.R. (Eds.), Enzymatic Fuel Cells. John Wiley \& Sons, Inc., Hoboken, New Jersey, USA, 422-450.

Gilstrap, R.A., Capozzi, C.J., Carson, C.G., Gerhardt, R.A., Summers, C.J., 2008. Adv. Mater. 20 (24), 4163-4166.

González-Arribas, E., Pankratov, D., Gounel, S., Mano, N., Blum, Z., Shleev, S., 2016. Electroanalysis 28 (6), 1290-1297.

Gutiérrez-Sánchez, C., Jia, W., Beyl, Y., Pita, M., Schuhmann, W., De Lacey, A.L., Stoica,
L., 2012. Electrochim. Acta 82, 218-223.

Halámková, L., Halámek, J., Bocharova, V., Szczupak, A., Alfonta, L., Katz, E., 2012. J. Am. Chem. Soc. 134 (11), 5040-5043.

Heller, A., 2004. Phys. Chem. Chem. Phys. 6 (2), 209-216.

Katz, E., 2014. Implanted biofuel cells operating in vivo. In: Katz, E. (Ed.), Implantable Bioelectronics. Wiley-VCH Verlag GmbH \& Co. KGaA, Weinheim, German, 363-379.

Kim, J., Lee, M.-S., Jeon, S., Kim, M., Kim, S., Kim, K., Bien, F., Hong, S.Y., Park, J.-U. 2015. Adv. Mater. 27 (21), 3292-3297.

Leech, D., Kavanagh, P., Schuhmann, W., 2012. Electrochim. Acta 84, 223-234. Pankratov, D., González-Arribas, E., Blum, Z., Shleev, S., 2016. Electroanalysis 28 (6), $1250-1266$.

Pankratov, D., Sundberg, R., Sotres, J., Maximov, I., Graczyk, M., Suyatin, D.B., González-Arribas, E., Lipkin, A., Montelius, L., Shleev, S., 2015. J. Power Sources 294, 501-506.

Parviz, B.A., 2009. IEEE Spectr. 46 (9), 36-41.

Parviz, B.A., 2009. IEEE Spectr. 46 (9), 36-41.
Raicopol, M., Bălănucă, B., Sliozberg, K., Schlüter, B., Gârea, S.A., Chira, N., Schuhmann, W., Andronescu, C., 2015. Corros. Sci. 100, 386-395.

Rasmussen, M. Abdellaoui, S., Minteer, S.D. 2016. Biosens. Bioelectron. 76, 91-102. M. Shao, Dissertation, Ruhr University, Bochum, 2013

Shleev, S., 2017. ChemPlusChem 82 (4), 522-539.

K. Sliozberg, Dissertation, Ruhr University, Bochum, 2016

Somasundaran, P., Chin, M., Latosiewicz, U.T., Tuller, H.L., Barbiellini, B.

Renugopalakrishnan, V., 2011. Nanoscience and engineering for robust biosola cells. In: Reisner, D. (Ed.), Bionanotechnology II: Global Prospects. CRC Press, Boc Raton, FL.

Trung, T.Q., Ramasundaram, S., Hwang, B.-U., Lee, N.-E., 2016. Adv. Mater. 28 (3), 502-509.

Xu, F., Shin, W., Brown, S.H., Wahleithner, J.A., Sundaram, U.M., Solomon, E.I., 1996. Biochim. Biophys. Acta 1292 (2), 303-311.

Yang, L., Li, Y., 2005. Biosens. Bioelectron. 20 (7), 1407-1416. 




\section{Review Article Biosupercapacitors Sergey Shleev ${ }^{1,2,3, *}$, Elena González-Arribas ${ }^{1}$ and Magnus Falk ${ }^{1}$}

This article reviews recent progress in the development of biosupercapacitors - supercapacitors fabricated using biological materials. In conventional biosupercapacitors the biomaterial serves as the pseudocapacitive component, while in self-charging biodevices the biocomponent also functions as the biocatalyst. The performance characteristics of biosupercapacitors are summarized and characterized in the perspective of the broader family of electric power devices, including biodevices. Self-charging biosupercapacitors show great promise in pulse-power delivery at the milliwatt level, typically greatly exceeding the capability of free-running bio-fuel and bio-solar cells. Thus, chemical biosupercapacitors might be suitable for powering a new generation of miniaturized electronic applications, including those intended for use in medical technology, while solar biodevices might be used as highly functional, but at the same time low-cost, environmentally friendly, and technically undemanding electric power sources.

\section{Addresses}

${ }^{1}$ Biomedical Science, Health and Society, Malmö University, 20560, Malmö, Sweden

${ }^{2}$ A.N. Bach Institute of Biochemistry, 119071, Moscow, Russia ${ }^{3}$ Kurchatov NBIC Centre, National Research Centre "Kurchatov Institute", 123182, Moscow, Russia

*Corresponding author: Shleev, Sergey (sergey.shleev@mah.se, shleev@inbi.ras.ru)

\author{
Current Opinion in Electrochemistry 2017, 5:226-233 \\ This review comes from a themed issue on Bioelectrochemistry \\ Edited by Wolfgang Schuhmann \\ For a complete overview see the Issue and the Editorial \\ Available online 9 October 2017 \\ https://doi.org/10.1016/j.coelec.2017.09.023 \\ 2451-9103/@ 2017 Elsevier B.V. All rights reserved.
}

\section{Introduction}

Batteries and supercapacitors are at the forefront of energy storage and delivery technology and, at present, fulfill different needs [1]. Batteries are characterized by high energy storage density and provide substantial power over lengthy periods of time, but are slow to charge (Figure 1) $[2,3]$. By contrast, supercapacitors (sometimes referred to as ultracapacitors) are characterized by low energy storage density, but provide high peak power over short periods of time and are rapidly recharged (Figure 1) [4,5]. Much research is focused on finding materials or adopting physico-chemical mechanisms to combine the capabilities of batteries and supercapacitors [6]. A mechanistic comparison between conventional batteries and supercapacitors, along with criteria for determining whether a device is a battery or a supercapacitor, were summarized by Simon et al. [7].

When considering biofuel cells - a chief interest in our research group for many years - the current situation in the field is quite cheerless (Figure 1). Despite many intrinsic advantages of fuel cell technology (high theoretical efficiency, possibility for miniaturization, production of pure water from the cathodic process), along with additional positive aspects of exploitation of biocatalysts (high activity, renewability, potentially low cost), the performance of currently developed biodevices is the worst in the electric power device space, being characterized by both low energy density and low power density (Figure 1). As also reviewed recently [8], the situation is even worse for implanted biodevices in medical applications, owing to certain fundamental limitations in a biological environment. Thus, implanted biofuel cells can only provide a low baseline power level suitable for ultra-low power electronic devices, falling well short of being able to run medium or high power implants. Consequently, in many previous attempts to demonstrate the functionality of biofuel cells, different types of capacitors were used to accumulate electrical energy first, including supercapacitors $\left[9^{\bullet}\right]$. It was demonstrated that a more stable power output could be obtained by connecting the biofuel cell to a supercapacitor [10]. A portion of our recent research - and the subject of the present review - has focused on the development of a new type of bioelectronic device, viz. biological supercapacitors, that can provide much higher power output levels than biofuel cells - albeit on a pulsed basis (Figure 1).

Historically, traditional capacitors store energy electrostatically in a dielectric, which in the case of electrolytic capacitors might be as thin as the oxide layer on an aluminum electrode [11]. Supercapacitors extend the capabilities of traditional capacitors in two ways. First, electric double-layer capacitance results from storing energy electrostatically in the Hemholtz layer on an electrode, which is only one solvent monolayer thick [12]. Second, pseudocapacitance results from species adsorbed directly on an electrode undergoing redox reactions $[13,14]$. 


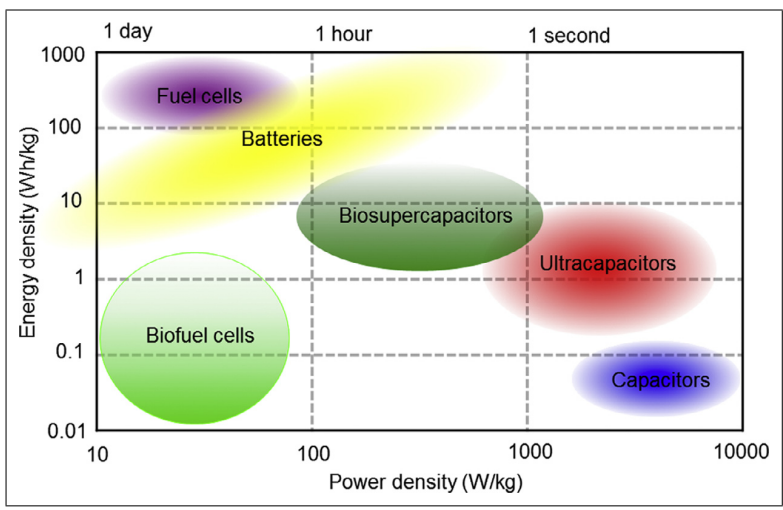

Ragone plot for various energy storage and conversion devices. The indicated areas are rough guidelines.

Recently, a new class of capacitors has emerged: biological supercapacitors, a type of bioelectronic device belonging to the family comprising biosensors, bioelectronic circuitry, and biological fuel cells $[15,16]$. These biosupercapacitors are fabricated from biological materials, e.g. redox proteins and enzymes $\left[17^{\bullet \bullet}, 18^{\bullet \bullet}\right]$, parts of organelles $\left[19^{\bullet \bullet}, 20\right]$, and even whole living cells $\left[21^{\bullet \bullet}\right]$. In biosupercapacitors, biomaterials serve as a capacitive element for storing charge utilizing redox-active components, such as metal centers in proteins, redox cofactors in enzymes, and low-molecular-weight natural redox mediators existing in organelles and living cells. The novelty and potential technological advantage here is that, in contrast to traditional capacitors and similar to ultracapacitors, the charge in biosupercapacitors is stored volumetrically rather than at or on a surface, at a potential difference specified by the Nernst equation rather than by an electric field of particular geometry. In contrast to all capacitors and also batteries, biosupercapacitors are fabricated using renewable biological materials.

Taking into account the emergence of biosupercapacitors, it is high time for more descriptive classifications of biological power sources (Figure 2). First, all biological power sources can be categorized based on the bioelement used in the construction, including hybrids when different bioelements are used on the cathodic and anodic sides (Figure 2A). At the same time, biological power sources can be divided into two big groups: biofuel cells and biosupercapacitors (Figure 2B). Biosupercapacitors in turn can be divided into two broad categories - conventional and self-charging (Figure 2B), while biological fuel cells should be classified in two groups nowadays, viz. conventional and charge-storing (Figure 2B). While the differences between conventional and self-charging/ charge-storing biodevices are obvious, i.e. inability and ability to self-charge, respectively, the peculiarities of selfcharging biosupercapacitors vs. charge-storing fuel cells will be specifically addressed below.

\section{Biosupercapacitors}

Historically, from the beginning only "half-biocapacitors" were fabricated. The fundamental concept of a conventional biosupercapacitor was demonstrated by Malvankar et al. in 2012 using a half-cell, which was able to store electrical charges pseudocapacitively in the cytochrome $c$ network of a bacterial biofilm [22 $]$. The biofilms displayed pseudocapacitance exceeding by two orders of magnitude the conventional double-layer capacitance of bare gold electrodes immersed in an identical medium. Moreover, biofilms containing denatured cytochrome $c$ displayed reduced pseudocapacitance, while absence of cytochrome $c$ led to the absence of pseudocapacitance.

Only very recently, our research group has designed and tested the very first complete intrinsically conventional (i.e. incapable of self-charging) biosupercapacitor. The biodevice consisted of two identical rusticyaninemodified gold electrodes - a symmetrical biosupercapacitor. Similar to microbial "half-biocapacitors" $\left[22^{\circ}\right]$, pseudocapacitance of biomodified electrodes significantly exceeded the conventional double-layer capacitance characteristic of bare gold electrodes immersed in an identical electrolyte. In contrast to Malvankar et al., who exploited an iron-containing protein network of the bacterial biofilm, in our studies we used a purified copper-containing redox protein. The biodevice could be 
Figure 2

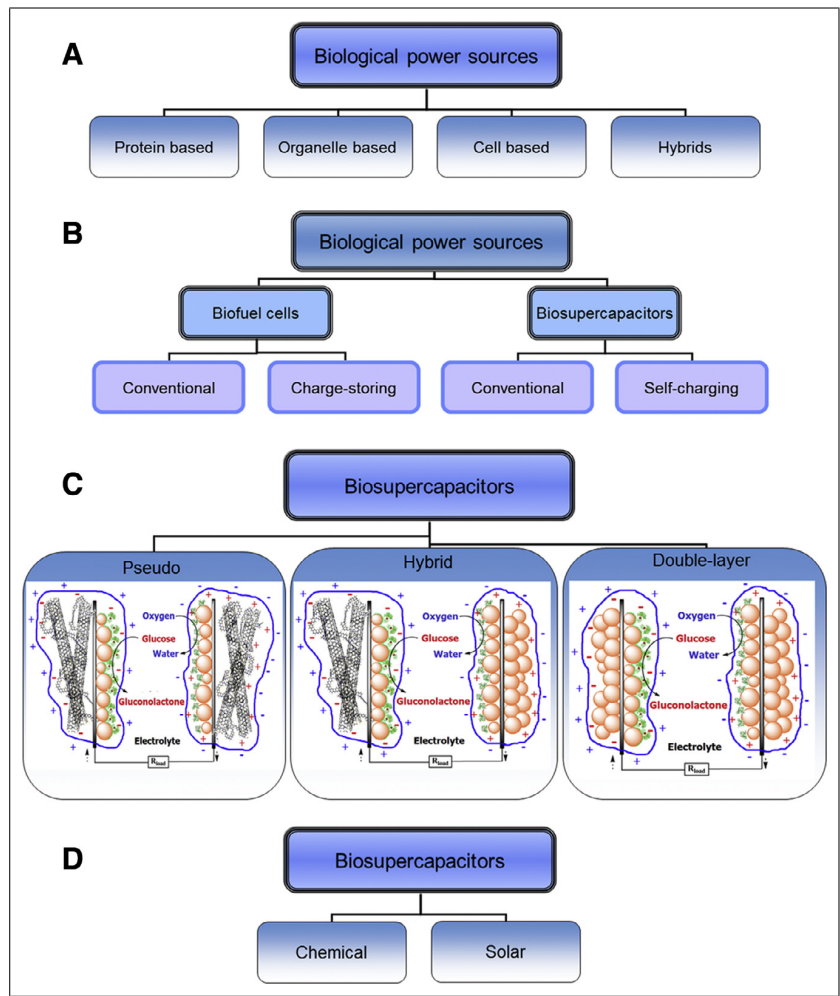

Classifications of electric power biodevices. (A) Based on biocatalyst used. (B) Based on operational principle. (C) Based on type of the capacitance. (D) Based on energy transformation.

externally charged and discharged several times without significant loss of functionality.

Moving beyond intrinsically conventional biosupercapacitors, our group was also the first in intentionally fabricating a self-charging biological supercapacitor (more accurately described as a charge-storing biofuel cell, vide infra) $\left[17^{\circ}\right]$. This was done based on Prof. Shleev's ideas regarding double-function electrodes [23 $\left.{ }^{\bullet}\right]$ and charge-storing fuel cells [ $\left.24^{\circ}\right]$, inspired by his earlier work on enzymatically synthesised conducting organic polymers in Prof. Yaropolov's group [25-27]. The first selfcharging electrochemical biocapacitor was based on flat graphite foil electrodes each with segregated functionality - one face configured for generating an electrochemical electromotive force to drive charging (glucose-oxidizing cellobiose dehydrogenase $(\mathrm{CDh})$ immobilized on gold nanoparticles (AuNP) and bilirubin oxidase (BOx) on AuNP for anode and cathode, respectively), and the other face configured for charge storage (polyaniline/carbon nanotube (CNT) composite). The initial-specific power was $1.2 \mathrm{~mW} \mathrm{~cm}^{-2}$ at $0.38 \mathrm{~V}(170 \times$ the result for the enzymatic fuel cell by itself) delivered into a $500 \Omega$ load, with quite a significant power being supplied for at least $50 \mathrm{~min}$.

Truly, parallel with our work (as can be seen from the patent application priority date $\left[28^{\circ}\right]$ ), Prof. Cosnier's group demonstrated fabrication of a double-layer biosupercapacitor including redox enzymes for continuous charging $\left[18^{\bullet}\right]$. As electrode material, compressed porous CNT matrix was used with incorporated anodic (glucose 
oxidase, GOx/catalase, $\mathrm{Ct}$ ) and cathodic (laccase, Lc) redox enzymes. The device could deliver a $10 \mathrm{msec} 3 \mathrm{~mA}$ pulse peaked at $0.76 \mathrm{~V}$ and $2 \mathrm{~mW}$ once per $10 \mathrm{~s}$ for at least 5 days.

In the first (and so far only) review regarding biosupercapacitors entitled "Hybrid electric power biodevices" $\left[29^{\bullet \bullet}\right]$, a classification of biosupercapacitors was presented in analogy with traditional, non-biological capacitors (Figure 2C), which were demonstrated with three actually fabricated and tested glucose $/ \mathrm{O}_{2}$ biodevices comprised (as described above and in Ref. [17 $\left.{ }^{\bullet \bullet}\right]$ ) of electrodes with segregated functionality and the same redox enzyme-based charging setup. The design of a pseudobiosupercapacitor involved depositing layers of PANI/CNT on the charging faces. An essentially purely double-layer biocapacitor could be fabricated by instead coating the charging faces with AuNP, which imparted a degree of nanotexturing. Finally, in a hybrid biosupercapacitor, a pseudocapacitive anode was combined with a double-layer capacitive cathode, as shown in Figure 2C. Naturally, it must be borne in mind that the charging faces also contribute a certain level of pseudo and double-layer capacitance.

Recently, Prof. Schuhmann has suggested a new experimental platform - the Nernstian biosupercapacitor for attaining deeper understanding of the mechanism of function of biosupercapacitors $\left[30^{\bullet \bullet}\right]$. The device was based on one and the same osmium-containing redox polymer - $\mathrm{Os}(\text { bpy })_{2} \mathrm{Cl}$ - situated on both anode and cathode. The activity of the polymer - closely related to the Os charge state, $\mathrm{Os}^{2+}$ or $\mathrm{Os}^{3+}$ - was modulated by GDh embedded in the polymer on the anode, and BOx embedded in the polymer on the cathode. Because of the use of only one redox polymer, the potentials of anode and cathode are not ideally matched, and therefore the performance of the device as a stand-alone biofuel cell is limited. In fact, if the device is completely discharged, it has an OCV close to $0 \mathrm{~V}$. However, due to the enzymes, self-charging initiates in the presence of fuel, and there is an incipient function as a biofuel cell. For an open-circuit configuration, the device self-charges up to $0.45 \mathrm{~V}$. After charging, the biodevice can supply a pulse power about $8 \times$ what can be supplied in steady state.

In the past three years, several reports regarding enzymatic supercapacitors have appeared in the literature. For example, in 2015, Kizling et al. prepared a biodevice in which the anode was comprised of a cellulose/polypyrrole composite with immobilized fructose dehydrogenase displaying a significant level of double-layer capacitance, and the cathode was comprised of naphthylated CNTs with adsorbed Lc [31]. The device could produce $1.6 \mathrm{~mW} \mathrm{~cm}^{-2}$ at $0.33 \mathrm{~V}$ on a transient basis. Villarrubia et al. in 2016 have fabricated an integrated fuel cell/supercapacitor wherein fuel is delivered by a paper- based microfluidic system [32]. The anode was buckypaper with methylene green mediator and $\mathrm{NAD}^{+} / \mathrm{NADH}$ cofactor, with glucose dehydrogenase (GDh). The cathode was Toray paper covered with a hydrophobic layer on top of which buckypaper was added, with BOx deposited on that. The intent is the cathode will breathe oxygen from the side opposite the filter paper between the electrodes, the filter paper in turn delivering the glucose. The biodevice could provide $0.87 \mathrm{~mW} \mathrm{~cm}{ }^{-2}$ of power at $0.56 \mathrm{~V}$ during $0.01 \mathrm{~s}$ pulses, $10 \times$ higher than achievable steady-state parameters. As a final example, Xiao et al. in 2017 have constructed a biodevice intended to function as an autonomous pulse generator. Electrodes were dealloyed nanoporous gold with electrodeposited poly $(3,4-$ ethylenedioxythiophene) and (Os(bpy) $\left.)_{2} \mathrm{PVI}\right)$, with the anode deposition solution containing oxygen-insensitive $\mathrm{GDh}$, and the cathode deposition solution containing BOx [33]. A peak power density of $0.61 \mathrm{~mW} \mathrm{~cm}^{-2}$ at $0.4 \mathrm{~V}$ under pulsed operation was attained, some $470 \times$ higher than achievable steady-state parameters.

Going back, as usual in the history of biosupercapacitors, the first self-charging biodevice, unintentionally fabricated, was a "half capacitor". Deeke et al. in 2012 have attempted to integrate some extra capacitance into an existing biofuel cell scheme by equipping a microbial fuel cell $(\mathrm{MFC})$ with a capacitive bioanode $\left[34^{\circ}\right]$. This was the first known example of testing a fuel cell with an internal capacitance. Only recently has a complete capacitive MFC (i.e. with capacitive anode and cathode) been intentionally fabricated and tested $\left[21^{\bullet \bullet}\right]$. The MFC anode is comprised of a carbon brush electrode pre-colonized with electroactive bacteria and a carbonaceous cathode with iron-aminoantipyrine. The device achieved a peakspecific power of $1 \mathrm{~mW} \mathrm{~cm}^{-2}$.

\section{Chemical and solar biosupercapacitors}

Working in the newly disclosed field of "biosupercapacitors", we have realized that all biodevices based on redox enzymes or organelles/living cells that have been tested so far are chemical self-charging biosupercapacitors, since they convert chemical energy into electrical energy. There are, however, other forms of energy that can also be directly converted, e.g. radiant energy. Given the vast supply of this renewable energy, biological solar cells (bio-solar cells), which can directly transform solar energy into electrical energy, are under intense scientific focus nowadays [35-37]. Our group, together with collaborators, was the first in fabricating and characterizing a solar biosupercapacitor $\left[1^{\bullet \bullet}\right]$. The device (Figure 3 ) is built on two transparent indium tin oxide (ITO)-coated glass slides which in turn were nanostructured with a layer of ITONP. The photobioanode was coated with thylakoid membranes (TM) and served to photochemically oxidize water to produce dioxygen and protons, whereas the biocathode used BOx to reduce dioxygen back to water. The biodevice displayed self-charging in ambient light, 
Figure 3

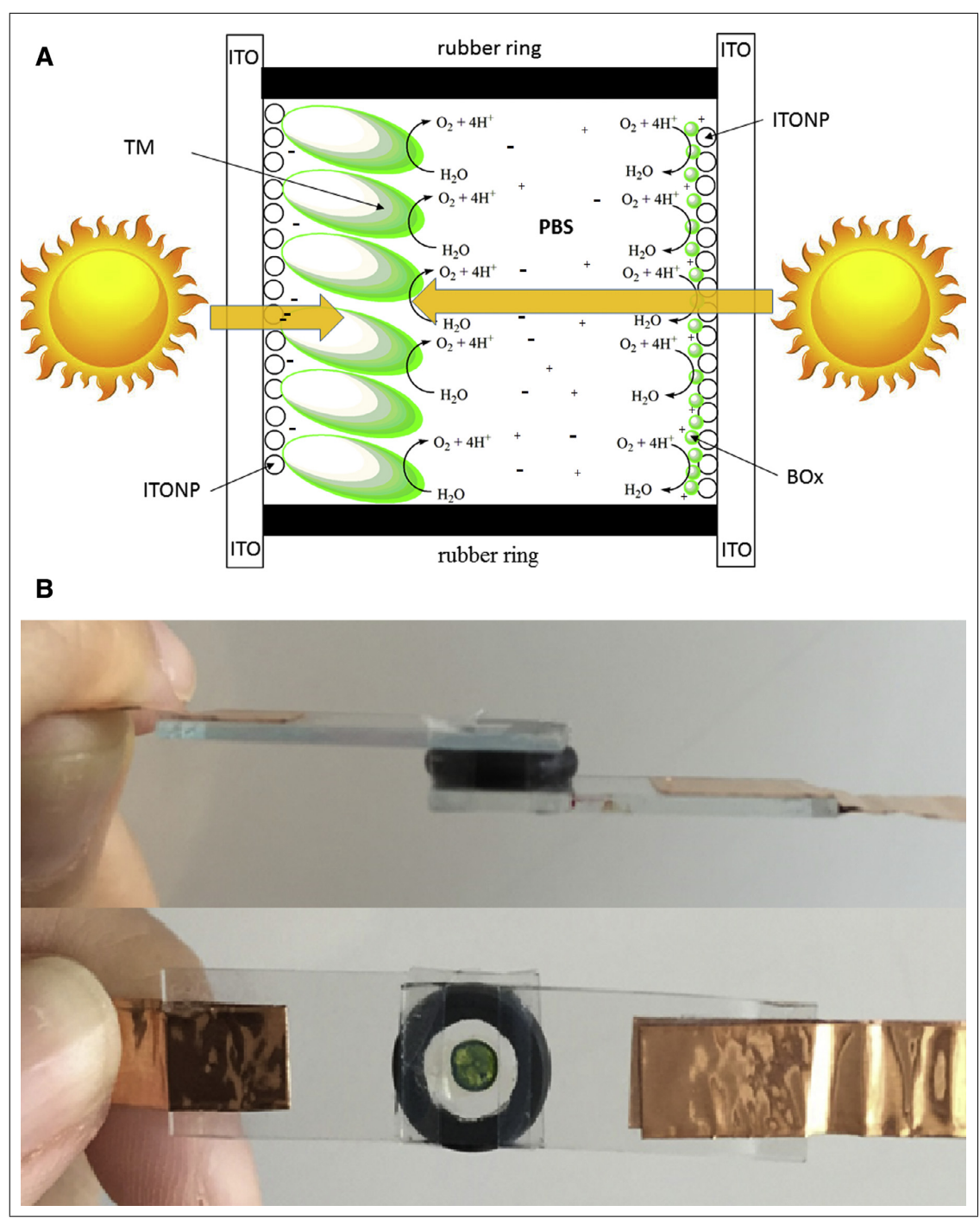

The very first solar biosupercapacitor. (A) Molecular mechanism of function of solar biosupercapacitor. ITO - indium tin oxide coated rectangular glass slide, ITONP - indium tin oxide nanoparticle, TM - thylakoid membrane, BOx - bilirubin oxidase. (B) Images of a transparent mediator-less solar biosupercapacitor. 
achieving an OCV of $0.2 \mathrm{~V}$ in about $10 \mathrm{~min}$. The solar biosupercapacitor provided a peak power of $0.6 \mu \mathrm{W} \mathrm{cm}-2$ into a load of $1 \mathrm{M} \Omega$, subsiding after about $10 \mathrm{~min}$ to a level characteristic of the TM-based photoanode without charge storage. Biodevice performance parameters, though low in this non-optimized configuration, display a $120 \times$ advantage over performance of the same device without charge storage.

In collaboration with our group, Prof. Lo Gorton has devised a mediated supercapacitive bio-solar cell with much better performance than the first solar biosupercapacitor described above. To improve the rate of electron shuttling from the TM to the anode, biocatalysts were deposited on an osmium redox polymer for mediated electron transfer, whereas the above-described BOx/AuNPs anode was used. A $2.5 \times$ increased photocurrent density in continuous mode was observed, whereas in pulse mode a specific power density of $56 \mu \mathrm{W} \mathrm{cm}{ }^{-2}$ was achieved at $0.3 \mathrm{~V} \mathrm{[20].}$ This is the highest specific power output ever demonstrated for a TM-based solar cell. A novel feature also is that during high-power discharge, electricity is provided by the capacitance rather than by the solar conversion part of the bioanode, protecting the latter from damage.

To conclude, in addition to the division based on capacitive features of bioelectrodes (Figure 2C), self-charging biosupercapacitors can also be classified as chemical and solar biodevices (Figure 2D).

\section{Self-charging biosupercapacitors versus charge-storing fuel cells}

In the review above we have referred to all self-charging biodevices as "biosupercapacitors", despite listing two types of self-charging devices in the classification of biological power sources (Figure 2B). One should understand that all the biodevices described above are charge-storing biofuel cells - even in the discharged state, these devices still deliver current and power. By contrast, intrinsic self-charging biosupercapacitors would only deliver current and power when charged. For example, the very first solar biosupercapacitor provides a negligibly low power in continuous mode compared to pulse operation [ $\left[9^{\circ} \bullet\right.$ ]. Also, because of the usage of one redox polymer on the cathodic and anodic sides of the Nernstian biosupercapacitor $\left[30^{\bullet \bullet}\right]$, this biodevice could operate either as a good self-charging supercapacitor or as a bad conventional biofuel cell. Indeed, the solar and the Nernstian biosupercapacitors are two biodevices described so far which are closest to being intrinsic self-charging biosupercapacitors. Very recently, Alsaoub et al. have moved the Nernstian biosupercapacitor to a further extreme, using two different redox polymers so that a "high potential" bioanode is combined with a "low potential" biocathode (Figure 4) $\left[38^{\bullet \bullet}\right]$. Such a device, if not charged, is absolutely incapable of providing electron current to an external circuit, as the OCV is backwards. However, in the presence of
Figure 4

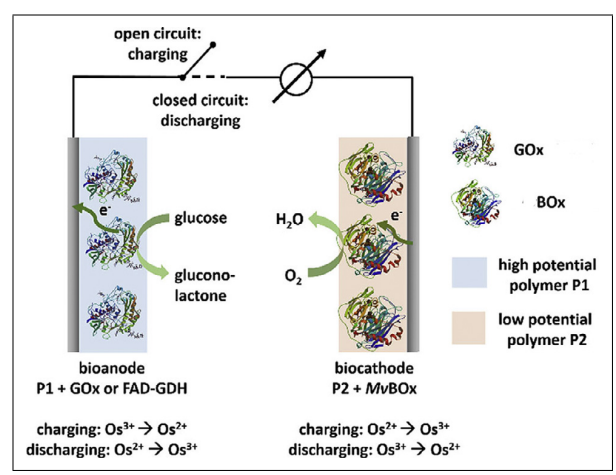

Schematic of the intrinsic enzyme-based biosupercapacitor. The biodevice comprises a glucose converting enzyme (glucose oxidase, $\mathrm{GOx}$ ) together with a high-potential redox polymer (P1) at the anode side and an oxygen reducing enzyme (bilirubin oxidase, BOx) together with a low-potential redox polymer (P2) at the cathode side.

fuel, the electrodes charge up and, according to the Nernst equation, the OCV reverses, so the device can drive an appropriate current during discharge. In view of the complete inability of this device to function as a stand-alone biofuel cell, it has been called an intrinsic self-charging biosupercapacitor.

\section{Conclusions and further perspectives}

All possible types of biodevices have already been designed and tested, when it comes to conventional and self-charging biosupercapacitors, chemical and solar biosupercapacitors, as well as pseudo, double-layer and hybrid biodevices, even though most of these devices should be called "charge-storing biofuel cells". However, when it comes to the classification based on biocatalysts (Figure 2A), only TM-based solar biosupercapacitors were fabricated, while only enzyme- and cell-based chemical biodevices were designed. Thus, there is room in future studies to design many other types of novel bioelectronic devices. Moreover, the conventional and self-charging biosupercapacitors as well as charge-storing fuel cells fabricated so far are early scientific prototypes rather than practically useful gadgets. All abovedescribed biodevices operate in low-voltage and lowcurrent regimes, with power and energy densities as well as operational and shelf stabilities requiring significant improvement before the technology can be considered for any practical applications. Moreover, because of limitations of biological materials, like relatively large size and lability, certain biodevices, e.g. conventional biosupercapacitors, will have trouble broadly competing with devices fabricated from inorganic and organic materials. Never- 
theless, fundamental investigations of conventional biosupercapacitors are interesting from the scientific point of view of electron transfer between different biocatalysts and electrode surfaces. Moreover, certain self-charging biodevices can be practically useful. For instance, since solar energy is intermittent in nature, photovoltaic devices should be able to directly store the electricity generated [39]. Employing living organisms, biosystems capable of self-repair and reproduction to create self-contained longlived power producing units can be realized.

\section{Acknowledgments}

This work was supported in part by the European Commission through the Marie-Curie Project "Bioenergy" (PITN-GA-2013-607793) and by the Swedish Research Council (621-2013-6006).

\section{References and recommended reading} Papers of particular interest, published within the period of review, have been highlighted as:

- Paper of special interest.

-. Paper of outstanding interest.

1. Ibrahim $\mathrm{H}$, llinca A, Perron J: Energy storage systems-characteristics and comparisons. Renewable Sustainable Energy Rev 2008, 12:1221-1250.

2. Eftekhari A: Lithium-ion batteries with high rate capabilities. ACS Sustainable Chem Eng 2017, 5:2799-2816.

3. Lin D, Liu Y, Cui Y: Reviving the lithium metal anode for high-energy batteries. Nat Nanotechnol 2017, 12:194-206.

4. Wang Q, Yan J, Fan Z: Carbon materials for high volumetric performance supercapacitors: design, progress, challenges and opportunities. Energy Environ Sci 2016, 9:729-762.

5. Yan J, Wang Q, Wei T, Fan Z: Recent advances in design and fabrication of electrochemical supercapacitors with high energy densities. Adv Energy Mater, vol 42014 1300816/1300811-1300816/1300843. https://doi.org/10.1002/aenm.201300816

6. Dubal DP, Ayyad O, Ruiz V, Gomez-Romero P: Hybrid energy storage: the merging of battery and supercapacitor chemistries. Chem Soc Rev 2015, 44:1777-1790.

7. Simon P, Gogotsi Y, Dunn B: Where do batteries end and supercapacitors begin? Science 2014, 343:1210-1211.

8. Shleev S: Quo vadis, implanted fuel cell? ChemPlusChem 2017 , 82:522-539.

9. Keskinen J, Sivonen E, Bergelin M, Eriksson J-E, Sjöberg-Eerola P,

- Valkiainen M, Smolander M, Vaari A, Uotila J, Boer H, Tuurala S: Printed supercapacitor as hybrid device with an enzymatic Printed supercapacitor as hybrid device with an
power source. Adv Sci Technol 2010, 72:331-336.

power source. Adv Sci Technol 2010, 72:331-336.
The very first report (to the best of our knowledge) regarding a combination of an enzymatic power source with a supercapacitor.

10. Skunik-Nuckowska M, Grzejszczyk K, Stolarczyk K, Bilewicz R, Kulesza P: Integration of supercapacitors with enzymatic biobatteries toward more effective pulse-powered use in small-scale energy harvesting devices. J Appl Electrochem 2014, 44:497-507.

11. Shukla AK, Banerjee A, Ravikumar MK, Jalajakshi A: Electrochemical capacitors: technical challenges and prognosis for future markets. Electrochim Acta 2012, 84:165-173.

12. Simon $P$, Burke A: Nanostructured carbons: double-laye capacitance and more. Electrochem Soc Interface 2008, 17:38-43.

13. Vol'fkovich YM, Serdyuk TM: Electrochemical capacitors. Russ Electrochem 2002, 38:935-959.
14. Yu L, Chen GZ: Redox electrode materials for supercapatteries. J Power Sources 2016, 326:604-612.

15. Katz E: Bioelectronics. Electroanalysis 2006, 18:1855-1857.

16. Willner I, Katz E: Integration of layered redox proteins and conductive supports for bioelectronic applications. Angew Chem Int Ed 2000, 39:1181-1218.

17. Pankratov D, Blum Z, Suyatin DB, Popov VO, Shleev S:

-. Self-charging electrochemical biocapacitor. ChemElectroChem 2014, 1:343-346.

The very first self-charging chemical supercapacitor based on pseudocapacitance.

18. Agnes C, Holzinger M, Le Goff A, Reuillard B, Elouarzaki K

-. Tingry S, Cosnier S: Supercapacitor/biofuel cell hybrids based on wired enzymes on carbon nanotube matrices: autonomous reloading after high power pulses in neutral buffered glucose reluadions. Energy Environ Sci 2014, 7:1884-1888.

The first self-charging chemical supercapacitor based on double-layer capacitance.

19. Gonzalez-Arribas E, Aleksejeva O, Bobrowski T, Toscano MD

-• Gorton L, Schuhmann W, Shleev S: Solar biosupercapacitor. Electrochem Commun 2017, 74:9-13.

The very first solar biosupercapacitor based on double-layer capacitance.

20. Pankratova G, Pankratov D, Hasan K, Aakerlund H-E, Albertsson P-A, Leech D, Shleev S, Gorton L: Supercapacitive photo-bioanodes and biosolar cells: a novel approach for solar energy harnessing. Adv Energy Mater 2017 Performance of thylakoid photobioanode improved by adding an osmium redox polymer for mediated electron transfer, as well as by augmenting polymer for mediated electron transfer, as well as by https://doi.org/10.1002/aenm.201602285.

21. Houghton J, Santoro C, Soavi F, Serov A, leropoulos I, Arbizzani C,

- Atanassov P: Supercapacitive microbial fuel cell: characterization and analysis for improved charge storage/delivery performance. Bioresour Technol 2016 218:552-560

First example of a complete supercapacitive microbial fuel cell, i.e. with capacitive anode and cathode.

22. Malvankar Nikhil S, Mester T, Tuominen Mark T, Lovley Derek R

- Supercapacitors based on c-type cytochromes using conductive nanostructured networks of living bacteria. ChemPhysChem 2012, 13:463-468.

Demonstrated the first "half-biocapacitor", which was able to store electrical charge pseudocapacitively in the cytochrome $c$ network of a bacterial biofilm.

23. Pankratov D, Falkman P, Blum Z, Shleev S: A hybrid electric -. power device for simultaneous generation and storage of power device for simultaneous generation and stor

The very first paper regarding double-function electrodes and chemical supercapacitors based on organic and inorganic catalysts.

24. Shleev S., Pankratov D., Blum Z.: Charge-storing fuel cell. SE - Patent Application 2014, 2014-EP57291 2014167063. Swedish patent application regarding charge-storing fuel cells/self-charging supercapacitors with the priority date on April 4th 2013.

25. Karamyshev AV, Shleev SV, Koroleva OV, Yaropolov Al, Sakharov IY: Laccase-catalyzed synthesis of conducting polyaniline. Enzyme Microb Technol 2003, 33:556-564.

26. Vasil'eva IS, Morozova OV, Shumakovich GP, Shleev SV Sakharov IY, Yaropolov Al: Laccase-catalyzed synthesis of optically active polyaniline. Synth Met 2007, 157:684-689.

27. Yaropolov A.I., Vasil'eva I.S., Morozova O.V., Shumakovich G.P., Shleev S.V.: Method for production of aqueous dispersion of conductive polyaniline and polysulfo acid interpolymer complex. RU Patent Application 2008, 2006-115626 2318020.

28. Cosnier S., Holzinger M., Le Goff A, Agnes C.: Electrochemical supercapacitor. FR Patent Application 2014, 2014-FR50482 2014135787.

French patent application regarding self-charging electrochemical supercapacitors with the priority date on March 3rd, 2013. 
29. Pankratov D, Blum Z, Shleev S: Hybrid electric power -. biodevices. ChemElectroChem 2014, 1:1798-1807. The first review paper regarding biosupercapacitors, in which homologues double-layer, pseudocapacitive, and hybrid self-charging enzymatic supercapacitors are presented.

30. Pankratov D, Conzuelo F, Pinyou P, Alsaoub S, Schuhmann W -. Shleev S: A Nernstian biosupercapacitor. Angew Chem Int Ed 2016, 55:15434-15438

Self-charging enzymatic supercapacitor built on an Os-containing Self-charging enzymatic supercapacitor built on an
redox-polymer situated on both anode and cathode.

31. Kizling M, Draminska S, Stolarczyk K, Tammela P, Wang Z Nyholm L, Bilewicz R: Biosupercapacitors for powering oxygen sensing devices. Bioelectrochemistry 2015, 106:34-40.

32. Narvaez Villarrubia CW, Soavi F, Santoro C, Arbizzani C, Serov A, Rojas-Carbonell S, Gupta G, Atanassov P: Self-feeding paper based biofuel cell/self-powered hybrid $\mu$-supercapacitor integrated system. Biosens Bioelectron 2016, 86:459-465.

33. Xiao X, Conghaile PO, Leech D, Ludwig R, Magner E: A symmetric supercapacitor/biofuel cell hybrid device based on enzyme-modified nanoporous gold: an autonomous pulse generator. Biosens Bioelectron 2017, 90:96-102.

34. Deeke A, Sleutels Tom HJA, Hamelers Hubertus VM, Buisman

- Cees JN: Capacitive bioanodes enable renewable energy storage in microbial fuel cells. Environ Sci Technol 2012, 46:3554-3560

Extra capacitance integrated into an existing microbial fuel cell using a capacitive bioanode (i.e. a "half-cell" capacitor).
35. Rasmussen M, Minteer SD: Photobioelectrochemistry: solar energy conversion and biofuel production with photosynthetic catalysts. J Electrochem Soc 2014, 161:H647-H655.

36. Tel-Vered R, Willner I: Photo-bioelectrochemical cells for energy conversion, sensing, and optoelectronic applications. ChemElectroChem 2014, 1:1778-1797.

37. Voloshin RA, Kreslavski VD, Zharmukhamedov SK, Bedbenov VS, Ramakrishna S, Allakhverdiev SI: Photoelectrochemical cells based on photosynthetic systems: a review. Biofuel Res J 2015 , 2:227-235.

38. Alsaoub S, Ruff A, Conzuelo F, Ventosa E, Ludwig R, Shleev S,

- Schuhmann W: An intrinsic self-charging biosupercapacitor comprised of a high-potential bioanode and a low-potential comprised of a high-potential bioanode and a
biocathode. ChemPlusChem 2017, 82:576-583.

The very first authentic self-charging biosupercapacitor fabricated by combining a "high potential" bioanode with a "low potential" biocathode.

39. Schmidt D, Hager MD, Schubert US: Photo-rechargeable electric energy storage systems. Adv Energy Mater, vol 62016. https://doi.org/10.1002/aenm.201500369. 
P3 



\section{Rechargeable, flexible and mediator-free biosupercapacitor based on transparent ITO nanoparticle modified electrodes acting in $\mu \mathrm{M}$ glucose containing buffers}

Tim Bobrowski ${ }^{\mathrm{a}, 1}$, Elena González Arribas ${ }^{\mathrm{b}, 1}$, Roland Ludwig ${ }^{\mathrm{c}}$, Miguel D. Toscano ${ }^{\mathrm{d}}$, Sergey Shleev ${ }^{\mathrm{b}, \mathrm{e}, \mathrm{f}, *}$, Wolfgang Schuhmann ${ }^{\mathrm{a}, * *}$

a Analytical Chemistry - Center for Electrochemical Sciences (CES), Ruhr-Universität Bochum, D-44780 Bochum, Germany

${ }^{\mathrm{b}}$ Biomedical Science, Health and Society, Malmö University, 20560 Malmö, Sweden

c Department of Food Science and Technology, BOKU University of Natural Resources and Life Sciences, Muthgasse 18, 1190 Vienna, Austria

d Novozymes A/S, Krogshoejvej 36, 2880 Bagsverd, Denmark

e A.N. Bach Institute of Biochemistry, 119071 Moscow, Russia

${ }^{f}$ Kurchatov NBIC Centre, National Research Centre "Kurchatov Institute", 123182 Moscow, Russia

\section{A R T I C L E I N F O}

\section{Keywords:}

Indium tin oxide

Nanoparticle

Nanoparticle

Biofuel cell

Transparent biosupercapacitor

\begin{abstract}
A B S T R A C T
We present a transparent and flexible self-charging biosupercapacitor based on an optimised mediator- and membrane-free enzymatic glucose/oxygen biofuel cell. Indium tin oxide (ITO) nanoparticles were spray-coated on transparent conducting ITO supports resulting in a flocculent, porous and nanostructured electrode surface. By this, high capacitive currents caused by an increased electrochemical double layer as well as enhanced catalytic currents due to a higher number of immobilised enzyme molecules were obtained. After a chemical pretreatment with a silane derivative, bilirubin oxidase from Myrothecium verrucaria was immobilized onto the ITO nanostructured electrode surface under formation of a biocathode, while bioanodes were obtained by either immobilisation of cellobiose dehydrogenase from Corynascus thermophilus or soluble PQQ-dependent glucose dehydrogenase from Acinetobacter calcoaceticus. The latter showed a lower apparent $K_{\mathrm{M}}$ value for glucose conversion and higher catalytic currents at $\mu \mathrm{M}$ glucose concentrations. Applying the optimised device as a biosupercapacitor in a discontinuous charge/discharge mode led to a generated power output of $0.030 \mathrm{~mW} / \mathrm{cm}^{2}$ at $50 \mu \mathrm{M}$ glucose, simulating the glucose concentration in human tears. This represents an enhancement by a factor of 350 compared to the power density obtained from the continuously operating biofuel cell with a maximum power output of $0.086 \mu \mathrm{W} / \mathrm{cm}^{2}$ under the same conditions. After $17 \mathrm{~h}$ of charging/discharging cycles a remarkable current enhancement was still measured. The entire device was transferred to flexible materials and applied for powering a flexible display showing its potential applicability as an intermittent power source in smart contact lenses.
\end{abstract}

\section{Introduction}

During the past years, a variety of biomedical devices with high reliability and biocompatibility such as implantable biosensors or ocular diagnostic sensors was presented (Bandodkar and Wang, 2016; Coman et al., 2009; Farandos et al., 2015; Luz et al., 2013). The eye is an easy accessible non-invasive way to a body fluid for continuously monitoring of health data. Due to a correlation between the concentration of an analyte in tear fluid and blood, diseases and their conditions, such as diabetes, can be recognised (Farandos et al., 2015).
Reliable glucose sensors in a suitable size, as well as patents for com plete contact lens devices including antennas for wireless transmitting the generated data are available nowadays (Cash and Clark, 2010; Cha et al., 2013; Conrad, 2016; Luz et al., 2013; Ward et al., 2002). However, most of these devices need to be externally powered. Biofuel cells (BFC) with charge-storing abilities, accumulating the electric energy obtained by converting chemical energy of substrates present in tear fluid, such as glucose and ascorbate, could be the missing piece for obtaining practically applicable devices (Blum et al., 2014; Pankratov et al., 2016b). Hybrids which simultaneously act as biofuel cell and

\footnotetext{
* Corresponding author at: Biomedical Science, Health and Society, Malmö University, 20560 Malmö, Sweden.

** Corresponding author.

E-mail addresses: sergey.shleev@mah.se (S. Shleev), wolfgang.schuhmann@rub.de (W. Schuhmann).

${ }^{1}$ These authors contributed equally to this work.

http://dx.doi.org/10.1016/j.bios.2017.10.016

Received 5 August 2017; Received in revised form 3 October 2017; Accepted 9 October 2017

Available online 11 October 2017

0956-5663/ ( 2017 Elsevier B.V. All rights reserved.
} 
capacitor are suggested as a possible strategy to efficiently use the restricted space for including electronics in such a smart contact lens or similar optical devices. Recently we have presented a mediator- and membrane-free enzymatic fuel cell based on a transparent nanostructured and conducting support, which acted as a first step in the development towards a combined biofuel cell/biosupercapacitor hybrid (González-Arribas et al., 2017). Chemically modified indium tin oxide (ITO) nanoparticles were used to enhance the active surface area without a significant decrease in transparency. A newly developed spray-coating procedure showed superior characteristics of the resulting electrodes as compared to simple drop-coating of nanoparticles on ITO thin layer quartz glass. The optimised transparent glucose/ oxygen biofuel cell presented a high open circuit voltage (OCV) of $0.67 \mathrm{~V}$ and a power output of $1.4 \mu \mathrm{W} / \mathrm{cm}^{2}$ at a voltage of $0.35 \mathrm{~V}$ in $50 \mathrm{mM}$ glucose containing phosphate buffered saline (PBS). Aiming on using the transparent BFC as a power source in devices, such as smart contact lenses, test measurements were performed in $50 \mu \mathrm{M}$ glucose containing PBS, representing the glucose concentration in human tears. Using the continuously operating biofuel cell lead to only low generated current output.

Here, we present an optimised system based on a modified mediator- and membrane-less biofuel cell/biosupercapacitor hybrid with the ability to store charges accumulated during enzymatically catalysed glucose/oxygen conversion in the nanostructured bioelectrode. For this, we adapted a previously reported procedure allowing us to charge the biosupercapacitor (BSC) at open electrical circuit and generating short and high power pulses while discharge by closing the circuit (Alsaoub et al., 2017; Pankratov et al., 2016a). Due to the fact that the current output of the previously reported BFC was limited by the bioanode, the role of the immobilised enzyme for current generation depending on the substrate concentration was investigated further for this half-cell Finally, the entire optimised biosupercapacitor was transferred from rigid ITO glasses to a flexible and transparent conducting support and approved for applicability in the pulsed biocapacitor mode in solutions with low $(\mu \mathrm{M})$ glucose concentrations, underlining a possible suitability for such a device as a transparent power source in e.g. smart contact lenses or self-powered mini displays.

\section{Materials and methods}

\subsection{Reagents/materials}

Indium tin oxide (ITO) conductive glasses, 15-25 $\Omega$ /sq, ITO coated PET, $60 \Omega$ /sq, methanol, p.a., ethanol (absolute), $N$-ethyl- $N{ }^{\prime}$-(3-dimethylaminopropyl) carbodiimide hydrochloride (EDC), $\mathrm{N}$-hydroxysuccinimide (NHS), 98\% and (3-glycidyloxypropyl)trimethoxysilane (GLYMO), $\geq 98 \%$ were purchased from Sigma-Aldrich (Steinheim, Germany). ITO NPs (product number 4111CB, 99.99\%, 20-70 nm) were purchased from SkySpring Nanomaterials (Houston, USA). Acetic acid, dichloromethane, p.a., sodium bicarbonate, sodium sulphate and potassium chloride were acquired from J. T. Baker (Deventer, Netherlands). Argon (Ar, 99.998\%) and $\mathrm{O}_{2}(>99.5 \%)$ were obtained from Air Liquide (Düsseldorf, Germany). Disodium phosphate, monopotassium phosphate, sodium acetate, $99 \%$ and toluene, p.a., were from VWR-Chemicals (Langenfeld, Germany), and $\mathrm{D}(+)$-glucose-monohydrate, min. 99\%, was from AppliChem (Darmstadt, Germany). (3aminopropyl)triethoxysilane (APTES), 99\% was obtained from ABCR (Karlsruhe, Germany), sodium chloride, 99.5\% was from Carl Roth (Karlsruhe, Germany). Sodium carbonate was purchased from Merck (Darmstadt, Germany), 2-(N-morpholino)ethanesulfonic acid (MES) was from Biomol (Hamburg, Germany). Electrical Tape 1245, Copper b $=6 \mathrm{~mm}$ was ordered from $3 \mathrm{M}$ (Minnesota, USA) and silver DAG 1415 from Plano (Wetzlar, Germany).

\subsection{Enzymes}

Cellobiose dehydrogenase from Corynascus thermophilus (CDH) expressed in Pichia pastoris was obtained as previously described (Harreither et al., 2012). The initial aliquot in $50 \mathrm{mM}$ sodium acetate buffer, pH 5.5 was in a concentration of $25 \mathrm{mg} / \mathrm{mL}$. Bilirubin oxidase (BOx) from Myrothecium verrucaria, produced recombinantly in Aspergillus oryzae, as previously reported (Xu et al., 1996), was purified using a previously published protocol and stored in $20 \mathrm{mM}$ Tris buffer (Falk et al., 2013), $100 \mathrm{mM} \mathrm{Na}_{2} \mathrm{SO}_{4}$, $\mathrm{pH} 8$ in a final concentration of $3.61 \mathrm{mg} /$ $\mathrm{mL}$. Soluble PQQ-dependent glucose dehydrogenase (GDH) from Acinetobacter calcoaceticus was a gift from Roche Diagnostics (Penzberg, Germany). The PQQ cofactor was purchased from Fluka (Buchs, Switzerland).

\subsection{Electrode preparation and nanostructuring}

ITO conductive glass, $15-25 \Omega$ /sq, or ITO coated PET, $60 \Omega$ /sq, was cut in squares of $10 \mathrm{~mm} \times 25 \mathrm{~mm} \times 1.1 \mathrm{~mm}$. The pieces were ultrasonicated in ethanol for $15 \mathrm{~min}$ and immersed in ultrapure water for another $20 \mathrm{~min}$ and dried under Ar. For modification, the prepared electrodes were fixed on a solid copper heating block and heated up to $70{ }^{\circ} \mathrm{C}$. While stirring, a previously prepared and $30 \mathrm{~min}$ sonicated suspension of ITO NPs, $2 \mathrm{mg} / \mathrm{mL}$ in methanol, was sprayed in a step by step procedure onto the electrode surface with the help of a compressed air nozzle in a home built spray coating device (Fig. S1). For this, the spray head was moved in an $\mathrm{x} / \mathrm{y}$-array of $1.2 \times 1.2 \mathrm{~cm}$ at a fixed $\mathrm{z}$ height. This process was repeated several times until the desired electrode loading was reached. One full scan led to a nanoparticle coverage of $0.21 \pm 0.03 \mathrm{mg}$ (Table S1). After cooling, the electrodes were ready to use for modification and electrochemical characterisation, respectively.

\subsection{Immobilisation of the enzymes}

The pre-treatment of the nanostructured electrodes, as well as the enzyme immobilisation procedures, were adopted from (González Arribas et al., 2017) and slightly modified for the optimised system.

\subsection{Electrode pre-treatment}

Chemical modification of the nanostructured surfaces was optimised for each biocatalyst. As pre-treatment for the $\mathrm{CDH}$-based bioanodes the nanostructured ITO glasses were immersed in toluene containing $1 \%$ (v/v) 3-(aminopropyl)triethoxysilane (APTES) and stirred overnight at room temperature. Prior to the chemical modification of the BOx and GDH electrodes, the nanostructured ITO electrodes were immersed in toluene containing $0.1 \%(\mathrm{v} / \mathrm{v})$ 3-(glycidyloxypropyl)trimethoxysilane (GLYMO) and stirred for $20 \mathrm{~min}$ at $70^{\circ} \mathrm{C}$. After silanisation the modified ITO glasses were rinsed with toluene and subsequently used for enzyme modification.

\section{6. $C D H$ immobilisation}

The initial aliquot of $\mathrm{CDH}$ was diluted in $50 \mathrm{mM}$ sodium acetate buffer $\mathrm{pH} 5.5$ to a concentration of $5 \mathrm{mg} / \mathrm{mL} .10 \mu \mathrm{L}$ of this solution were dropped in small portions onto the APTES-silanised nanostructured ITO surface. Additionally, $30 \mu \mathrm{L}$ of a MES buffer solution containing $36 \mathrm{mM}$ EDC and $17 \mathrm{mM}$ NHS were dropped on top of the enzyme layer (Gutiérrez-Sánchez et al., 2012). The reaction was stopped after keeping the modified electrode for $150 \mathrm{~min}$ at room temperature and under moisturised conditions by dipping the electrode in PBS buffer, $\mathrm{pH}$ 7.4. The negatively charged residues of $\mathrm{CDH}$, such as aspartic acid or glutamic acid, are expected to bind to the $\mathrm{NH}_{2}$ groups of APTES (González-Arribas et al., 2017). 

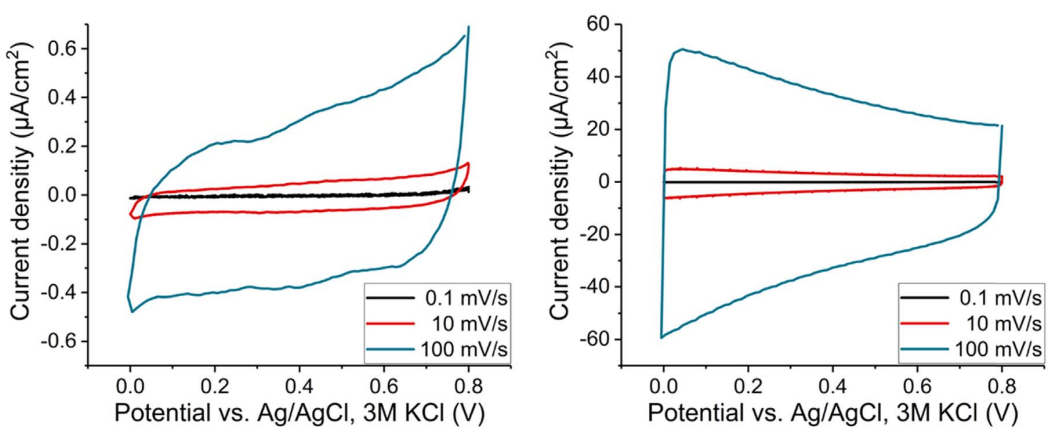

Fig. 1. CVs of a bare ITO electrode (left) and a nanoparticle-covered electrode (right) at different scan rates.

\subsection{BOx immobilisation}

The initial aliquot of BOx was diluted to a concentration of $3 \mathrm{mg} / \mathrm{mL}$ using $50 \mathrm{mM}$ bicarbonate buffer, $\mathrm{pH} 9.4$. $30 \mu \mathrm{L}$ of this solution were immediately dropped in small portions onto the GLYMO-silanised nanostructured ITO surface and reacted for $150 \mathrm{~min}$ at room temperature and under moisturised conditions. By increasing the $\mathrm{pH}$ value, the hydrolysis of the epoxy groups was initialised, thus facilitating their binding to the lysine residues at the enzyme.

\subsection{GDH immobilisation}

$1.08 \mathrm{mg}$ GDH apoenzyme were dissolved in $40 \mu \mathrm{L}$ of a $520 \mu \mathrm{M} \mathrm{PQQ}$ solution in HEPES buffer, containing $300 \mathrm{mM} \mathrm{CaCl}_{2}$. The mixture reacted $10 \mathrm{~min}$ at room temperature and was subsequently dropped onto the GLYMO-modified electrode surface. After 150 min reaction time under moisturised conditions, the electrode was dipped into a $10 \mathrm{mM}$ MES buffer, $\mathrm{pH}$ 6, for stopping the reaction. A similar binding via lysine residues to the GLYMO-modified surface, like for $\mathrm{BOx}$, is expected (González-Arribas et al., 2017).

\subsection{Electrochemical characterisation}

All electrochemical measurements were performed using a $\mu$ Autolab Type III/FRA2 potentiostat/galvanostat from Metrohm Autolab (Utrecht, The Netherlands). A three-electrode setup consisting of a Ag/ $\mathrm{AgCl} / 3 \mathrm{M} \mathrm{KCl}$ reference electrode and a Pt mesh counter electrode in a standard electrochemical cell was used. A volume of $30 \mathrm{~mL}$ phosphate buffered saline (PBS) (12 mM phosphate, $137 \mathrm{mM} \mathrm{NaCl}, 2.7 \mathrm{mM} \mathrm{KCl}$ ), $\mathrm{pH} 7.4$, was used as electrolyte and bubbled with Ar for $20 \mathrm{~min}$ prior the characterisation of the bare electrodes. Chronoamperograms were recorded at a potential of $+0.3 \mathrm{~V}$ vs. $\mathrm{Ag} / \mathrm{AgCl} / 3 \mathrm{M} \mathrm{KCl}$ while adding different volumes of $0.5 \mathrm{M}$ glucose in PBS to the electrolyte until a final concentration of $50 \mathrm{mM}$ glucose was reached. Cyclic voltammetry for characterising the enzyme-modified electrodes was performed in potential windows of -0.3 to $0.4 / 0.5 \mathrm{~V}$ for the bioanodes and -0.1 to $0.8 \mathrm{~V}$ for the biocathodes at a scan rate of $10 \mathrm{mV} / \mathrm{s}$. The biofuel cell tests were performed using chronoamperometry with the bioanode connected as working electrode and the biocathode as a combined reference/counter electrode. The corresponding polarisation curves were obtained by applying sequential potential pulses starting from the open circuit voltage (OCV) of the system down to $0.01 \mathrm{~V}$ in $0.05 \mathrm{~V}$ intervals and recording the equilibrium steady-state currents observed at each applied potential. Automatic charge/discharge curves were controlled via an in house written software based on Microsoft Visual Basic 6.0 using a D-8927 output board from Decision Computer International
(Taipei, Taiwan) with inbuilt $12 \mathrm{~V}$ M4-12H relays from Meisei Electric (Isesaki, Japan). The channels were used to switch a resistor of $1 \mathrm{k} \Omega$ between ON state (discharge) and OFF state (charge) as well as opening or closing the electrical circuit between biocathode and bioanode. During the measurements, which were performed by cycling between $600 \mathrm{~s}$ of charging at open circuit and $2 \mathrm{~s}$ discharge by connecting the resistor into the circuit for 100 cycles $(17 \mathrm{~h})$, the individual potentials of the bioelectrodes were recorded using a PGU-BI 100 bi-potentiostat from IPS-Jaissle Elektronik (Münster, Germany), while the OCV of the biosupercapacitor was calculated from the single potentials of the working electrodes. For data acquisition, a 16-bit CIO-DAS 1602/16 CE/DA board from Plug-In Electronic (Alling, Germany) was used (Fig. S2) (see also Pankratov et al., 2016a).

\section{Results and discussion}

\subsection{Electrode modification and optimisation}

ITO nanoparticles were used to cover transparent ITO thin layer quartz glass electrodes as a support for further modification with BOx or $\mathrm{CDH}$, respectively. Sprayed ITO nanoparticle covered electrodes with a mass loading of $1.25 \mathrm{mg} / \mathrm{cm}^{2}$ were used. A detailed structural characterisation of ITO NP modified electrodes comparing different mass loadings of drop-coated and spray-coated electrodes was performed previously (González-Arribas et al., 2017). Electrochemical characterisation of bare electrodes showed an increase in capacitive currents by a factor of 100 comparing $1.25 \mathrm{mg} / \mathrm{cm}^{2}$ ITO nanoparticle covered electrodes with bare ITO glass substrates (Fig. 1). A high proportionality between ITO nanoparticle loading and capacitance of the electrodes was observed and confirmed by means of additional impedance measurements (Fig. S3). Furthermore, the CVs of the tested electrodes showed variations in their shapes in accordance with different nanoparticle loadings. Highly nanostructured, well-covered electrodes showed a trapezoidal shape with the capacitive currents significantly increasing towards more negative applied potentials. Calculations, based on a previously published model (Bisquert et al., 2000; Cattarin et al., 2011) show that capacitances from potentiostatic impedance measurements at different potentials coincide with the ones obtained from cyclic voltammetry and show a similar potential dependence. This effect was not observed in the CVs of the bare ITO and low density ITO nanoparticle covered electrodes. The different loading related behaviour of the ITO nanoparticle covered electrodes indicates that the nanoporous structure of the surface is crucial for the observed phenomena. Niedziolka et al. suggested structural differences as the reason for the observed electrochemical variations and consequential effects for electrochemical reactions between bare and ITO NP covered 
electrodes coated with water-insoluble redox liquids. Similar to our results, their measurements showed significant current differences between highly covered and non-covered electrodes (Niedziolka et al., 2007). The potential-dependent and non-faradaic behaviour of the ITO NP covered electrodes can be explained by the Mott-Schottky effect of n-type semiconductors as previously shown for nanoporous antimonydoped tin oxide coatings (Sharma et al., 2013) and generally described for any type of semiconductor electrodes (Bott, 1998).

After electrode nanostructuring, the surface of the spray-coated ITO electrodes was chemically pre-modified with two types of silane derivatives, namely 3-(aminopropyl)triethoxysilane (APTES) and 3-(glycidyloxypropyl)trimethoxysilane (GLYMO) depending on the nature of the enzyme to be immobilised. Covalent binding of the amino functions of the lysine residues of BOx to the epoxy groups of GLYMO lead to a stable monolayer of the immobilised enzymes. Similarly, bioanodes were obtained by binding the carboxylic acid groups of aspartic and glutamic acid residues at the outer shell of $\mathrm{CDH}$ to the amino group of APTES. Quasi-reversible redox conversions during cyclic voltammetry originating from direct electron transfer with the heme centres indicate successful CDH immobilisation on the electrode surfaces (Fig. S4). The resulting transparent glucose/oxygen BFC showed noticeable current output at comparatively high glucose concentrations of $50 \mathrm{mM}$ in air saturated PBS, $\mathrm{pH} 7.4$, in accordance with the relatively high apparent $K_{\mathrm{M}}$ values of CDH for glucose conversion (Harreither et al., 2009, 2012; Ludwig et al., 2010) suggesting the observed poor catalytic response at low glucose concentrations. A power output of only $0.07 \mu \mathrm{W} / \mathrm{cm}^{2}$ could be achieved at $50 \mu \mathrm{M}$ glucose concentrations, a value typically present in human tears (Fig. S5, left). Thus, an improvement of the current output of the anodic half-cell by replacing $\mathrm{CDH}$ with a glucose converting enzyme exhibiting a substantially higher substrate affinity is necessary. In this respect and due to a possible wiring by direct electron transfer, pyrroloquinoline quinone (PQQ) dependent glucose dehydrogenase $(\mathrm{GDH})$ is seen as a promising enzyme for optimising the anode performance (Oubrie et al., 1999; Tanaka et al., 2005). The immobilisation of GDH on the nanostructured and GLYMO pre-modified ITO surface was performed similarly as for BOx immobilisation. Amperometric measurements of the modified electrodes showed a significant catalytic response of GDH upon addition of $50 \mu \mathrm{M}$ (Fig. S6) confirming a significant lower apparent $K_{\mathrm{M}}$ value of GDH as compared to $\mathrm{CDH}$ in air saturated $\mathrm{PBS}, \mathrm{pH}$ 7.4. For comparable systems, apparent $K_{\mathrm{M}}$ values of 1.5-3 mM for PQQ-dependent GDH (Pinyou et al., 2015) and 80-90 mM for CDH (Harreither et al., 2012) were shown.

\subsection{Transparent and flexible biosupercapacitor}

The spray coated ITO nanoparticle covered porous electrodes exhibit a high surface area and concomitant high capacitances, which suggested to make the step from a biofuel cell towards a self-charging biocapacitive device, namely a biosupercapacitor as depicted in Scheme 1. If the electrical circuit is open, the enzymes are converting their substrates and generate electrons at the anode or use electrons at the cathode. After a certain reaction time, depending on the electrode size and enzymatic activity, both electrodes are fully and oppositely charged. Upon closing the circuit using a computer controlled switch, current flows through the circuit discharging the capacitor. During this time evidently the enzymes are continuing to convert their substrates and hence this current adds up to the one flowing due to discharging the capacitor. Opening the switch after discharge let the biosupercapacitor self-charge again. This cycle can be continuously repeated and by this high current pulses after a defined recharging period are generated (Scheme 1).

Charge/discharge cycles were performed for the optimised system with PQQ-GDH immobilised on the bioanode in $50 \mu \mathrm{M}$ glucose containing PBS. For comparison, additional cycling experiments with $\mathrm{CDH}$ in $50 \mathrm{mM}$ glucose containing buffer are shown in Fig. S7. Opening the electrical circuit for $600 \mathrm{~s}$ led to a self-charging of the capacitor by the enzymatic reactions. After closing the switch for $2 \mathrm{~s}$, current was flowing through a $1 \mathrm{k} \Omega$ resistor in the outer circuit. During the cycling experiments the potentials of the anode and cathode were monitored vs. $\mathrm{Ag} / \mathrm{AgCl} / 3 \mathrm{M} \mathrm{KCl}$. The resulting OCV of the entire system was calculated from the measured potential values of the individual electrodes and subsequently converted into the corresponding current output according to the Ohms law (SI).

The results of the cycling experiments for the transparent GDH/BOx based biosupercapacitor operating in $50 \mu \mathrm{M}$ glucose containing air saturated PBS are summarised in Fig. 2. The first cycle shows an OCV of $0.265 \mathrm{~V}\left(70 \mu \mathrm{W} / \mathrm{cm}^{2}\right)$, which dropped to a more stable value of around $0.150-0.170 \mathrm{~V}\left(30 \mu \mathrm{W} / \mathrm{cm}^{2}\right)$ after the third cycle (insert in Fig. 2, right). The drop of OCV within the first cycles can be explained by a slow self-recharging process due to the small substrate concentration. Allowing the system to recharge for a longer time is re-establishing the initial OCV again. Continuous cycling for more than $17 \mathrm{~h}$ showed a decrease of $39 \%$ after 100 cycles with respect to the stable OCV after the third cycle. The OCV drop is not only attributed to an intrinsic electrode instability or enzyme deactivation, but is mainly caused by substrate consumption. The initially low amount of glucose is consumed to an even lower level after $17 \mathrm{~h}$ of continuous cycling. Addition of glucose after finishing the cycling experiments showed a partial but well-pronounced recovery towards the initial OCV value (Fig. S8). During the first cycles, the biosupercapacitor showed a high power output of up to $70 \mu \mathrm{W} / \mathrm{cm}^{2}$ in $50 \mu \mathrm{M}$ glucose containing buffer, and after three cycles the power output stabilised in the range of $30 \mu \mathrm{W} /$ $\mathrm{cm}^{2}$. The power output generated by the biosupercapacitor after the third cycle was used for comparison with the conventional BFC (Fig. 2, left). The power curve of the continuously working biofuel cell in the very same configuration like the biosupercapacitor exhibits a maximum

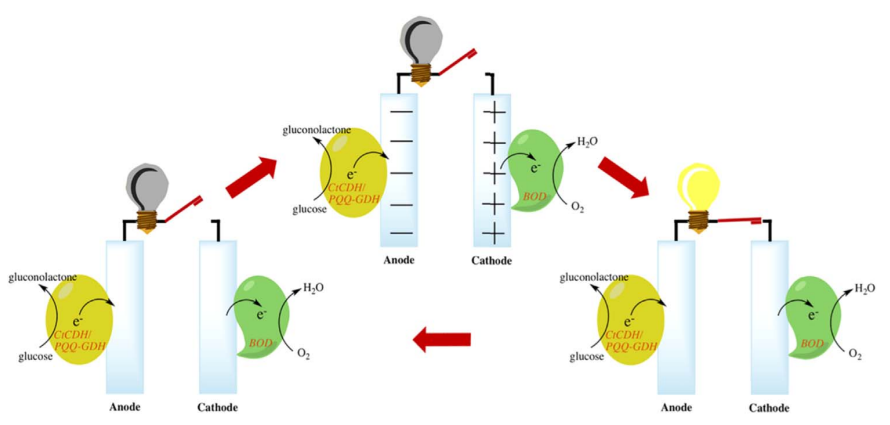

Scheme 1. Schematic representation of the function of a self-charging biosupercapacitor. While the circuit is opened, the electrodes are self-charged due to the enzymatically catalysed substrate conversion at both electrodes. Upon closing the electric circuit the current is flowing through the resistor in the outer circuit and the capacitor is discharged. 

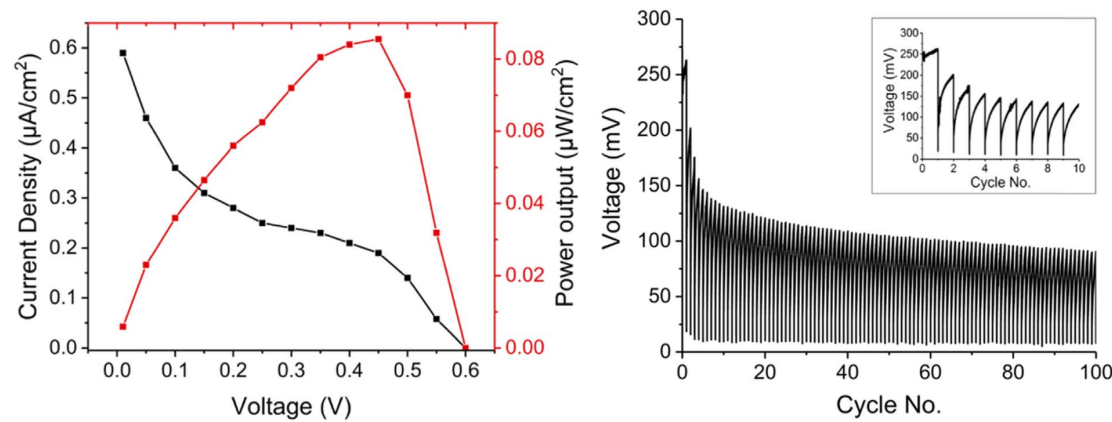

Fig. 2. Power outputs of the optimised transparent GDH/BOx biofuel cell/biosupercapacitor hybrid. Left: Polarisation curve (black) and power profile (red) of the biodevice tested as a conventional BFC under continuous operation. Right: BSC test in charge/discharge mode. (For interpretation of the references to color in this figure legend, the reader is referred to the web version of this article.)

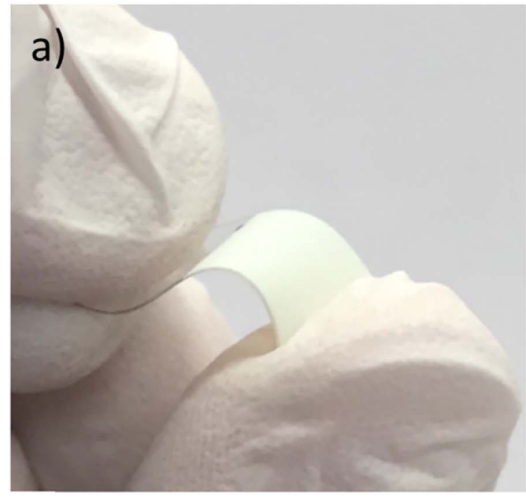

c)

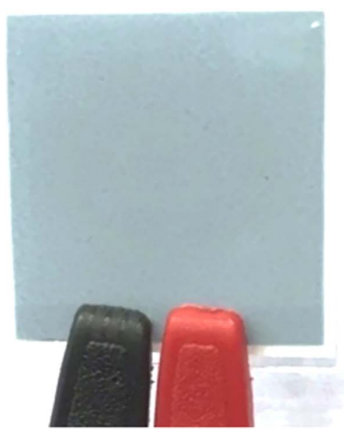

b)

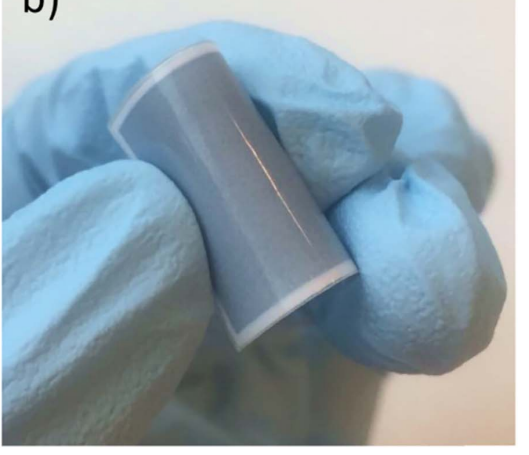

d)

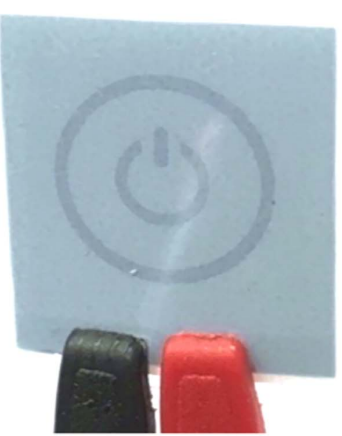

Fig. 3. Photographic images of (a) a flexible ITO nanostructured electrode which is bent without any damage, (b) a flexible low voltage display which is powered by the flexible biosupercapacitor, (c) and (d) connected display in OFF and ON states, respectively.

power output of $0.086 \mu \mathrm{W} / \mathrm{cm}^{2}$ at a voltage of $0.45 \mathrm{~V}$ and an OCV of $0.60 \mathrm{~V}$. With an increase of $350 \times$ towards the conventional glucose/ oxygen biofuel cell, the power output increased by more than two orders of magnitude using the biosupercapacitor approach. Furthermore, these numbers reveal that the contribution of enzymatic turnover to the current generation during a $2 \mathrm{~s}$ discharge pulse is lower than 
$0.3 \%$. After stability testing of 100 cycles in $50 \mu \mathrm{M}$ glucose containing PBS, the increase was still remarkable showing a $100 \times$ higher generated power $\left(8.3 \mu \mathrm{W} / \mathrm{cm}^{2}\right)$.

After system optimisation and converting the continuously operating biofuel cell into a discontinuously operating biosupercapacitor, which was applied in charge/discharge cycling measurements, substantially increased current densities for the transparent biodevice in electrolytes with low $\mu \mathrm{M}$ glucose concentrations were achieved. However, these devices were based on rigid transparent electrode materials. In the final step, flexible and transparent ITO thin layer coated PET sheets were spray-coated with ITO nanoparticles and similarly electrochemically characterised as the above shown rigid glass-based biosupercapacitors. The power densities and stability of the flexible biosupercapacitor coincide well with the ones obtained for the rigid biodevices, showing the suitability of the flexible material to design biosupercapacitors. While bending the flexible nanostructured electrodes, no damage to the surface was observed (Fig. 3a). Performing charge/discharge cycling with the modified flexible and transparent biosupercapacitor in $50 \mu \mathrm{M}$ glucose concentration generated sufficiently high power output to power a flexible low voltage liquid crysta display (Fig. 3b), which was additionally connected to the electrical circuit, as presented in Scheme 1. While self-charging during the open electrical circuit regime, the display is in OFF-state (Fig. 3c). Upon closing the electrochemical circuit, the generated current flows through the display and it is turned into ON-state without any external power source (Fig. 3d).

\section{Conclusions}

The development and optimisation of a transparent and flexible mediator- and membrane-free self-charging biosupercapacitor based on a transparent glucose/oxygen biofuel cell was demonstrated. The optimised system is based on double-function transparent flexible ITO nanoparticle spray-coated electrodes. A highly porous surface area allows a significant increase in the amount of immobilised enzymes as compared to flat ITO electrodes and thus higher catalytic current outputs from the resulting biodevice. Moreover, the flocculent structure provides a large interfacial area between the electrolyte and electrode surface, which results in a high electrode capacitance allowing charge storage generated by the enzymes. Optimisation of the limiting bioanode led to an increase of the current output by $25 \%$ upon replacing $\mathrm{CDH}$ with PQQ-GDH as glucose-converting enzyme exhibiting substantially higher substrate affinity. The final complete GDH/BOx based biosupercapacitor and operated in discontinuous charge/discharge cycles was compared with its corresponding continuously operated biofuel cell. With $30 \mu \mathrm{W} / \mathrm{cm}^{2}$ in $50 \mu \mathrm{M}$ glucose containing electrolyte, mimicking the biofuel concentration in human tears, the achieved power output was more than $350 \times$ higher as compared to that of the continuously operating biofuel cell. Stability measurements showed a decrease of $39 \%$ in the generated current during $17 \mathrm{~h}$ of continuous cycling, mostly due to a consumption of the substrate during the experiment. In a final "proof of principle" experiment, a flexible self-rechargeable biosupercapacitor was used for powering a flexible low voltage liquid crystal display underlining the potential applicability of the developed device. Our results are seen as a step forward in the field of health-monitoring biodevices, such as e.g. smart contact lenses.

\section{Acknowledgements}

This work was supported in part by the European Commission through the Marie-Curie project "Bioenergy" (PITN-GA-2013-607793), by the Swedish Research Council (621-2013-6006), and by the Cluster of Excellence RESOLV (EXC 1069) funded by the Deutsche Forschungsgemeinschaft (DFG).

\section{Appendix A. Supplementary material}

Supplementary data associated with this article can be found in the online version at http://dx.doi.org/10.1016/j.bios.2017.10.016.

\section{References}

Alsaoub, S., Ruff, A., Conzuelo, F., Ventosa, E., Ludwig, R., Shleev, S., Schuhmann, W., 2017. ChemPlusChem 82, 576-583.

Bandodkar, A.J., Wang, J., 2016. Electroanalysis 28, 1188-1200.

Bisquert, J., Garcia-Belmonte, G., Fabregat-Santiago, F., Ferriols, N.S., Bogdanoff, P.

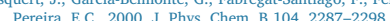

Blum, Z., Pankratov, D., Shleev, S., 2014. Expert. Rev. Ophthalmol. 9, 269-273.

Blum, Z., Pankratov, D., Shleev, S., 2014.

Bott, A.W., 1998. Curr. Sep. 17, 87-91.
Cash, K.J., Clark, H.A., 2010. Trends Mol. Med. 16, 584-593.

Cash, K.J., Clark, H.A., 2010. Trends Mol. Med. 16, 584-593.

Cattarin, S., Musiani, M., Tribollet, B., Vivier, V., 2011. J. Electrochem. Soc. 158, 135-141.

Cha, K.H., Jensen, G.C., Cohan, B.E., Meyerhoff, M.E., 2013. Method for Determining Tear Glucose Concentration With Blood Glucose Test Strips. Google Patents (US20140262830 A1). 〈http://www.google.com/patents/US20140262830〉.

Coman, V., Ludwig, R., Harreither, W., Haltrich, D., Gorton, L., Ruzgas, T., Shleev, S., 2009. Fuel Cells 10, 9-16.

Conrad, A.J., 2016. Intra-ocular Device. Google Patents. 〈https://www.google.ch/ patents/US20160113760>.

Falk, M., Andoralov, V., Silow, M., Toscano, M.D., Shleev, S., 2013. Anal. Chem. 85, 6342-6348.

Farandos, N.M., Yetisen, A.K., Monteiro, M.J., Lowe, C.R., Yun, S.H., 2015. Adv. Healthc Mater. 4, 792-810

González-Arribas, E., Bobrowski, T., di Bari, C., Sliozberg, K., Ludwig, R., Toscano, M.D., Lacey, A.L., de, Pita, M., Schuhmann, W., Shleev, S., 2017. Biosens. Bioelectron. 97, 46-52.

Gutiérrez-Sánchez, C., Jia, W., Beyl, Y., Pita, M., Schuhmann, W., Lacey, A.L., de, Stoica, L., 2012. Electrochim. Acta 82, 218-223.

Harreither, W., Felice, A.K.G., Paukner, R., Gorton, Lo, Ludwig, R., Sygmund, C., 2012 Biotechnol. J. 7, 1359-1366.

Harreither, W., Sygmund, C., Dunhofen, E., Vicuna, R., Haltrich, D., Ludwig, R., 2009. Arreither, W., Sygmund, C., Dunhofen, E., Vic
Appl. Environ. Microbiol. 75, 2750-2757.

Ludwig, R., Harreither, W., Tasca, F., Gorton, Lo, 2010. ChemPhysChem 11, 2674-2697.

Luz, R.A.S., Iost, R.M., Crespilho, F.N., 2013. Nanomaterials for biosensors and implantable biodevices. In: Crespilho, F.N. (Ed.), Nanobioelectrochemistry. From Implantable Biosensors to Green Power Generation. Springer Berlin Heidelberg; Springer, Berlin, Heidelberg, pp. 27-48.

Niedziolka, J., Szot, K., Marken, F., Opallo, M., 2007. Electroanalysis 19, 155-160.

Oubrie, A., Rozeboom, H.J., Kalk, K.H., Olsthoorn, A.J., Duine, J.A., Dijkstra, B.W., 1999 EMBO J. 18, 5187-5194.

Pankratov, D., Conzuelo, F., Pinyou, P., Alsaoub, S., Schuhmann, W., Shleev, S., 2016a. Angew. Chem. Int. Ed. Engl. 55, 15434-15438.

Pankratov, D., González-Arribas, E., Blum, Z., Shleev, S., 2016b. Electroanalysis 28, $1250-1266$.

Pinyou, P., Pöller, S., Chen, X., Schuhmann, W., 2015. Electroanalysis 27, 200-208. Sharma, S., Volosin, A.M., Schmitt, D., Seo, D.-K., 2013. J. Mater. Chem. A 1, 699-706. Tanaka, S., Igarashi, S., Ferri, S., Sode, K., 2005. BMC Biochem. 6, 1-6.

Ward, W., Jansen, L.B., Anderson, E., Reach, G., Klein, J.-C., Wilson, G.S., 2002. Biosens. Bioelectron. 17, 181-189.

Xu, F., Shin, W., Brown, S.H., Wahleithner, J.A., Sundaram, U.M., Solomon, E.I., 1996. Biochim. Biophys. Acta 1292, 303-311. 
P4 



\title{
Solar biosupercapacitor
}

\author{
Elena González-Arribas a,1, Olga Aleksejeva ${ }^{\mathrm{a}, 1}{ }^{\text {, }}$ Tim Bobrowski ${ }^{\mathrm{b}}$, Miguel Duarte Toscano ${ }^{\mathrm{c}}$, Lo Gorton ${ }^{\mathrm{d}}$, \\ Wolfgang Schuhmann ${ }^{\mathrm{b}}$, Sergey Shleev ${ }^{\mathrm{a}, *}$ \\ ${ }^{a}$ Biomedical Science; Faculty of Health and Society, Malmö University, Jan Waldenströms gata 25, 21428 Malmö, Sweden \\ ${ }^{\mathrm{b}}$ Analytical Chemistry - Center for Electrochemical Sciences (CES), Ruhr-Universität Bochum, Universitätsstr. 150, 44780 Bochum, Germany \\ c Novozymes A/S, Krogshoejvej 36, 2880 Bagsvaerd, Denmark \\ d Department of Biochemistry and Structural Biology, Lund University, P.O. Box 124, 22100 Lund, Sweden
}

\section{A R T I C L E I N F O}

\section{Article history:}

Received 24 October 2016

Received in revised form 11 November 2016

Accepted 11 November 2016

Available online 16 November 2016

\section{Keywords:}

Solar biosupercapacitor

Solar bios

Bilirubin oxidase

Indium tin oxide

Nanoparticle

\begin{abstract}
A B S T R A C T
Here we report on an entirely new kind of bioelectronic device - a solar biosupercapacitor, which is built from a dual-feature photobioanode combined with a double-function enzymatic cathode. The self-charging biodevice, based on transparent nanostructured indium tin oxide electrodes modified with biological catalysts, i.e. thylakoid membranes and bilirubin oxidase, is able to capacitively store electricity produced by direct conversion of radiant energy into electric energy. When self-charged during $10 \mathrm{~min}$, using ambient light only, the biosupercapacitor provided a maximum of $6 \mathrm{~mW} \mathrm{~m}^{-2}$ at $0.20 \mathrm{~V}$.
\end{abstract}

(C) 2016 Elsevier B.V. All rights reserved.

\section{Introduction}

Identifying economical, technically undemanding electric power sources, relying on renewable catalysts, is a major scientific and technological challenge. Among many possible catalyst candidates, biological catalysts, in the form of redox enzymes, organelles, and living cells, are highly active and renewable. Also, biological catalysts can be produced at low cost, if sufficiently high production volumes are considered.

Electric power can be generated by the transformation of other energy forms into electric energy. On a global scale, the dominant source of energy is electromagnetic radiation, i.e. radiant energy. Thus, life on our planet relies almost exclusively on sunlight, and solar energy accumulated by living organisms in the past is currently converted to electrical energy by the burning of fossil fuels. In terms of the energy flow from the sun, less than about $0.02 \%$ of the total solar energy reaching the surface of the Earth, i.e. $3.8 \cdot 10^{24} \mathrm{~J}$ over a year, would satisfy the present yearly global energy demands $\left(5.6 \cdot 10^{20} \mathrm{~J}\right)$ [1]. Given this vast supply of renewable energy, biological solar cells (bio-solar cells), i.e. devices based on biocatalysts, which can directly transform solar energy into electric energy, are in extreme scientific focus nowadays [2-4]. Extensive research on the use of various photosynthetic elements including photosynthetic reaction centers (bacterial, photosystem I and

\footnotetext{
* Corresponding author.

E-mail address: sergey.shleev@mah.se (S. Shleev).

1 E. González-Arribas and Olga Aleksejeva equally contributed to the present work.
}

photosystem II) has generated different mediator-based photobioelectrodes [5-9]. For real practical applications, among many different requirements, devices should be simple to construct and non-toxic, and mediator-less bio-solar cells fully satisfy these criteria.

Bio-solar cells consisting of a mediator-less thylakoid bioanode, and either a platinum air-breathing cathode $[10,11]$ or a laccase based biocathode [12-14], were reported earlier. Nanostructured materials, such as carbon quantum dots incorporated into a thylakoid suspension [15], or thylakoids tethered to supports modified with multi-walled carbon nanotubes [14], were used to increase the number of biological species in contact with the carbonaceous surface, thus providing a larger surface area for mediator-less bioelectrocatalysis and improve the photocurrent generation. The modification of thylakoid bioanodes with membrane-intercalating conjugated oligoelectrolytes tentatively enhance the contact between biological species and the electrode, resulting in a 1.4-fold increase of photocurrent densities in amperometric experiments, and also higher power output of the bio-solar cell [16]

However, all previously disclosed mediator-less bio-solar cells were opaque, and photocurrents were generated using powerful focused artificial light sources, with limited bearing on real practical applications. Moreover, closed systems have not been used for this type of devices and, a single compartment bio-solar cell, incorporating a mediator-less thylakoid anode and a bilirubin oxidase cathode, has not been reported so far. Here we show a miniature transparent bio-solar cell able to generate electricity using only ambient daylight. In the biodevice, the thylakoid membrane modified anode and bilirubin oxidase modified cathode, are ionically coupled in a closed system at neutral pH (Fig. 

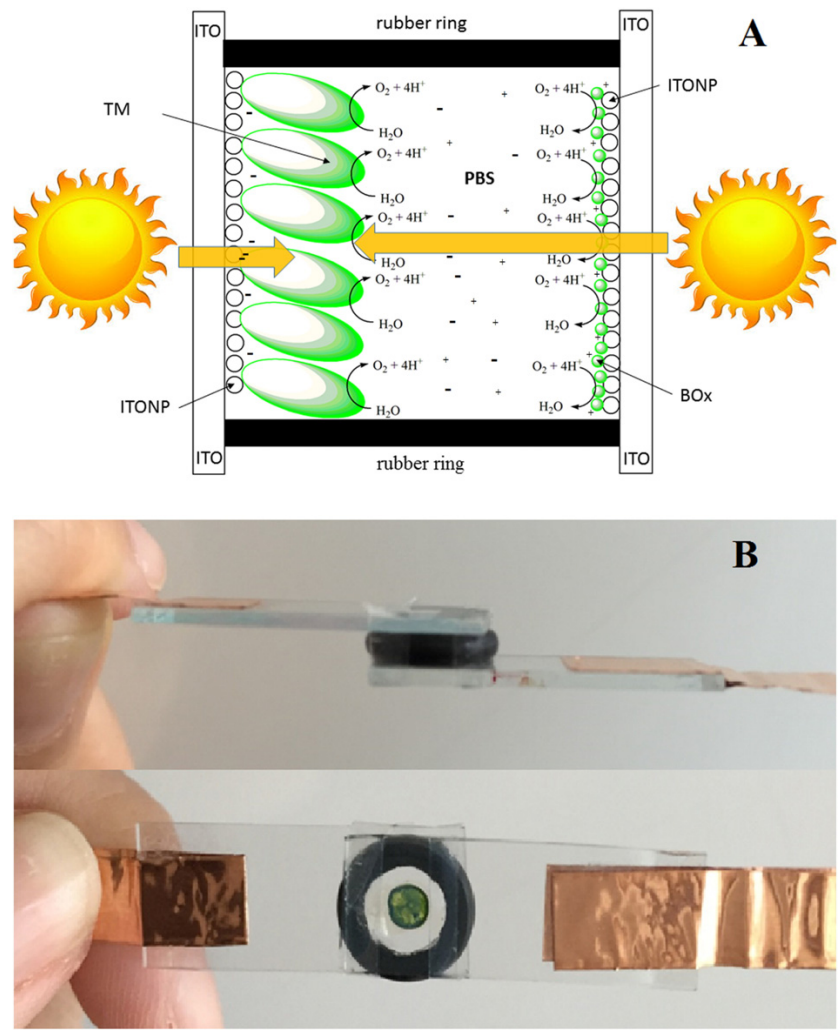

Fig. 1. Solar biosupercapacitor. (A) Molecular mechanism of function of solar biosupercapacitor. ITO - indium tin oxide coated rectangular glass slide, ITONP - indium tin oxide nanoparticle, TM - thylakoid membrane, BOx - bilirubin oxidase. (B) Images of a transparent mediator-less solar biosupercapacitor.

1A). However, owing to the mediator-less design, only small photocurrents were registered. One possibility to improve the power output is to store solar energy, and operate the biodevice in pulse mode, rather than in continuous mode.

Photosynthetic living organisms, e.g. green plants, algae and cyanobacteria, store solar energy in chemical bonds, forming molecular oxygen $\left(\mathrm{O}_{2}\right)$ and energy-rich carbohydrates from water and carbon dioxide. Biological solar cells, as well as conventional solar cells based on abiotic materials, directly convert solar energy into electric energy and are not per se designed to store the electricity generated. Thus, external electric energy storing devices, such as capacitors and/or rechargeable batteries, are required, which in the end increase not only the monetary but also the environmental costs of electric energy. Thus, a hybrid device, in which electromagnetic energy is directly converted into electric energy, which is concurrently stored within the appliance used for conversion, would attenuate the complexity, minimize losses, and reduce both cost aspects.

Very recently hybrid devices based on chemical energy were constructed and tested, i.e. "charge-storing fuel cells", or, in other words, "self-charging chemical supercapacitors" [17]. In these hybrid devices [18], including biodevices [19-21], chemical energy is directly converted into electric energy, which is capacitively stored within a singular contrivance. Below we detail the very first solar biosupercapacitor, which is built from transparent and nanostructured, i.e. highly capacitive, indium tin oxide (ITO) electrodes. The biodevice is able to convert solar energy directly into electric energy, which is capacitively stored within the device. Because of the materials used, the resulting biodevice is a simple to build, inexpensive, and sustainable electric power source for low-power low-voltage electronics.

\section{Experimental}

\subsection{Chemicals and materials}

$\mathrm{Na}_{2} \mathrm{HPO}_{4} \cdot 2 \mathrm{H}_{2} \mathrm{O}, \mathrm{KH}_{2} \mathrm{PO}_{4}, \mathrm{NaCl}, \mathrm{KCl}, \mathrm{MgCl}_{2}$ were purchased from Sigma-Aldrich (St. Louis, USA). Tris(hydroxymethyl)aminomethane was obtained from Kebo AB (Stockholm, Sweden). Glycine was obtained from Fisher Chemical (Leics, United Kingdom). Sucrose was purchased from BDH Laboratory supplies (Poole, England). 100\% methanol was obtained from VWR Chemicals (Paris, France) and 99.5\% ethanol from CCS Healthcare AB (Malmö, Sweden). Argon ( $\mathrm{Ar}$ ) and $\mathrm{O}_{2}$ were supplied by AGA Gas AB (Sundbyberg, Sweden). All chemicals were of analytical grade and used without further purification. All solutions were prepared using water purified with the PURELAB 
UHQ II system from ELGA Labwater (High Wycombe, United Kingdom). ITO coated rectangular glass slides (surface resistivity $15-25 \Omega / \mathrm{sq}$ ) were purchased from Sigma-Aldrich and cut in sections of $10 \mathrm{~mm} \times 25 \mathrm{~mm} \times 1.1 \mathrm{~mm}$. ITO nanoparticles $\left(\mathrm{In}_{2} \mathrm{O}_{3}: \mathrm{SnO}_{2}=90: 10\right.$, 20-70 nm) were obtained from SkySpring Nanomaterials Inc. (Houston, USA). Conductive copper foil was acquired from Farnell Element 14 (Leeds, United Kingdom).

\subsection{Biocatalysts}

Thylakoid membranes (TMs) were isolated from spinach leaves, as described previously [22], with the only difference that $10 \mathrm{mM} \mathrm{pH} 7.4$ Tris-Glycine buffer was used instead of $10 \mathrm{mM}$ pH 7.4 Tricine buffer. The TM suspensions were stored at $-80^{\circ} \mathrm{C}$. Myrothecium verrucaria bilirubin oxidase, $\mathrm{BOX},\left(3.61 \mathrm{mg} \mathrm{mL}^{-1}\right.$ in $20 \mathrm{mM}$ Tris buffer, $0.1 \mathrm{M} \mathrm{Na}_{2} \mathrm{SO}_{4}$, $\mathrm{pH} 8.0$ ) was produced recombinantly in Aspergillus oryzae, as previously reported [23], and also purified following a previously published protocol [24]. The specific activity (expressed as units of activity per mg of protein) of the enzyme towards $\mathrm{K}_{3}\left[\mathrm{Fe}(\mathrm{CN})_{6}\right] \quad\left(\varepsilon_{420 \mathrm{~nm}}=\right.$ $1045 \mathrm{M}^{-1} \mathrm{~cm}^{-1}$ [25]), was determined spectrophotometrically using a Helios $\beta$ spectrophotometer from Thermo Electron Corporation (Marietta, $\mathrm{OH}, \mathrm{USA}$ ) at room temperature, and was found to be $160 \mathrm{U} \mathrm{mg}^{-1}$. 1 unit of activity $(U)$ was defined as the amount of BOx oxidizing $1 \mu \mathrm{mol}$ of the substrate per min.

\subsection{Electrode fabrication and characterization}

ITO conductive glass sections were cleaned by 15 min sonication in ethanol and then in water. A working area of $1 \mathrm{~cm} \times 1 \mathrm{~cm}$ was selected for nano structuring. For the nano structuring process dispersions of $10 \%$ of ITO nanoparticles (ITONPs) in methanol were prepared and the dispersions were sonicated during $20 \mathrm{~min}$ to ensure efficient homogenization. To fabricate the drop-coated ITONPs electrodes, $10 \mu \mathrm{l}$ of the dispersion was dropped onto the ITO coated glass, specifically on the selected working area and air-dried. The nanostructured area was defined using a template with a circumference of about $9.4 \mathrm{~mm}$, diameter $3 \mathrm{~mm}$ $\left(0.070 \mathrm{~cm}^{2}\right)$; the selected area was subsequently used for bio-modification. In the case of bioanodes, TMs were deposited onto the electrode surface using physical adsorption by evenly spreading $2 \mu \mathrm{l}$ of the preparation on the ITONPs modified area, and then kept at $4{ }^{\circ} \mathrm{C}$ for $\mathrm{ca} 1 \mathrm{~h} ; 2 \mu \mathrm{l}$ of a gelatin solution in water $(2.5 \% \mathrm{w} / \mathrm{v})$ was distributed evenly on top of the thylakoids, in order to prevent leaking of the biological species from the electrode surface [26]. The electrode was dried at room temperature for $\mathrm{ca} 40 \mathrm{~min}$ and used for electrochemical investigations. In the case of biocathodes, $4 \mu \mathrm{l}$ of BOx solution was applied to the area modified with ITONPs and dried at room temperature for $\mathrm{ca} 30 \mathrm{~min}$. The amount of the enzyme was non-optimized. However, $4 \mu \mathrm{l}$ of BOx solution was chosen based on the geometric electrode area, taking into account our previous studies of BOx immobilization on nanostructured gold or highly porous carbon electrodes [27-28]. After that the electrode was immersed into $10 \mathrm{mM}$ phosphate buffer saline $\mathrm{pH} 7.4$ (PBS) in order to remove any non-adsorbed enzyme, and then used for electrochemical measurements. Cyclic voltammetry and amperometry were performed in a $30 \mathrm{ml}$ electrochemical cell, carrying a $\mathrm{Ag}|\mathrm{AgCl}| 3 \mathrm{M} \mathrm{KCl}(210 \mathrm{mV}$ vs. NHE) reference electrode from Bioanalytical Systems (West Lafayette, USA) and a platinum mesh counter electrode, using a $\mu$ Autolab Type III/FRA2 potentiostat/galvanostat from MetrohmAutolab B.V. (Utrecht, The Netherlands). Averaged capacitance densities and current outputs are based on at least three measurements with three different electrodes.

\subsection{Bio-solar cell construction and characterization}

Freshly prepared electrodes were used to assemble the bio-solar cell by combining the electrodes facing each other in opposite directions, separating them with a rubber ring of $6 \mathrm{~mm}$ diameter and $3 \mathrm{~mm}$ thickness, resulting in a cell volume of $c a .85 \mu$, filled with PBS as the electrolyte (Fig. 1B). Copper tapes were used to connect the electrodes to the $\mu$ Autolab potentiostat/galvanostat. Contrary to other studies, the bio-solar device was charged in ambient light, excluding artificial light sources. The illumination during studies was $23 \pm 5 \mathrm{kLux}$ on average, as determined using a DEM300 light meter from Velleman (Gavere, Belgium). The biodevice was discharged by applying $1 \mathrm{M} \Omega$ resistance using a calibrated resistor from Velleman Inc. (Forth Worth, TX, USA). Averaged parameters are based on at least three measurements with three different biosupercapacitors. All measurements were performed at room temperature. It should be emphasized that the ambient daylight can induce a change in the temperature over long periods. However, in all likelihood, the influence of the temperature variations was quite negligible in our studies because (i) biodevices were transparent (Fig. $1 \mathrm{~B})$, (ii) they were exposed to the ambient daylight during short periods of time (10-30 min, vide infra) for every charge cycle in a closed air-conditioned room with a constant temperature, and (iii) the light intensity was not very high ( $23 \pm 5$ kLux on average, vide supra).

\section{Results and discussion}

First, individual electrodes were studied electrochemically in detail. The specific capacitance of bare ITO electrodes as evaluated using cyclic voltammetry was $0.14 \pm 0.30 \mathrm{~F} \mathrm{~m}^{-2}$, whereas electrode nanostructuring with ITONPs increased the specific capacitance to $3.0 \pm 1.3 \mathrm{~F} \mathrm{~m}^{-2}$. Electrode biomodification with BOx reduced the capacitance to $1.7 \pm 0.2 \mathrm{~F} \mathrm{~m}^{-2}$, whereas biomodification with TMs increased the apparent capacitance to $4.6 \pm 1.0 \mathrm{~F} \mathrm{~m}^{-2}$. The latter results were expected; apparently BOx immobilization decreased the double-layer capacitance due to the insulating properties of the enzyme [27], whereas a thick layer of TMs/gelatin did not change the double-layer capacitance but resulted in additional reactions of redox compounds, e.g. plastoquinones and plastocyanins, leaking from TMs. These compounds do function as redox mediators ensuring electron transfer between ITO electrodes and TMs, but also add a pseudo-capacitive feature to the bioanode, increasing its apparent capacitance density.

Functionality of both bioelectrodes were confirmed in separate amperometric studies, performed by applying a constant potential of $320 \mathrm{mV}$ vs. Ag|AgCl. The photocurrents were 6 times lower compared to currents from bioelectrocatalytic reduction of $\mathrm{O}_{2}\left(6 \pm 1 \mathrm{~mA} \mathrm{~m}^{-2}\right.$ vs. $36 \pm 2 \mathrm{~mA} \mathrm{~m}^{-2}$, Fig. 2). Non-illuminated bioanodes, or biocathodes under anaerobic conditions, did not provide significant current outputs; bioelectrocatalytic currents from biocathodes under anaerobic conditions were $c a$. 10 times lower, while current outputs from bioanodes, when biodevices were not illuminated, were as low as $2-3 \mathrm{nA}$. The

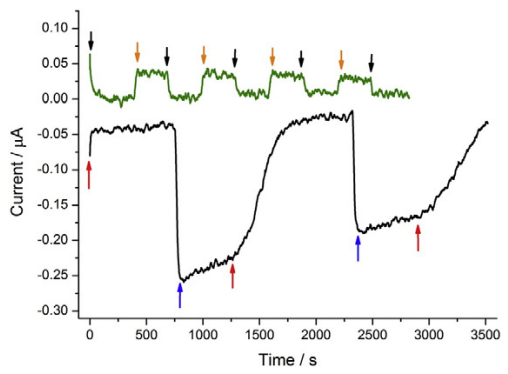

Fig. 2. Amperometric measurements of a bioanode (green curve) and a biocathode (black Fig. 2. Amperometric measurements of a bioanode (green curve) and a biocathode (black
curve) at a constant potential of $0.32 \mathrm{~V} v$ s. $\mathrm{Ag}|\mathrm{AgCl}| 3 \mathrm{M} \mathrm{KCl}$ in $\mathrm{PBS}$. Black line - oxygenation curve) at a constant potential of $0.32 \mathrm{~V} v \mathrm{~s} . \mathrm{Ag}|\mathrm{AgCl}| 3 \mathrm{M} \mathrm{KCl}$ in PBS. Black line - oxygenation
(blue arrows)/deoxygenation (red arrows) cycles of the biocathode. Green line - absence of light (black arrows)/ambient light (orange arrows) cycles of the bioanode. 
residual currents are attributed to the presence of small amounts of $\mathrm{O}_{2}$ in the deoxygenated electrolyte, and vestigial metabolic activity of TMs, respectively. The bioelectrocatalytic origin of the currents obtained was confirmed in separate measurements of non-biomodified electrodes; negligible photocurrent and the absence of $\mathrm{O}_{2}$ electroreduction was observed on electrodes modified with ITONPs only. When bioelectrodes were subjected to on/off cycles several times, biocatalytic current outputs were clearly discernible, even though some degradation of both biodevices was noticed. While photocurrents decreased by $17 \%$ after 4 cycles, $28 \%$ of the $\mathrm{O}_{2}$ bioelectroreduction current was lost after 2 cycles; the latter can be attributed to enzyme desorption from the ITONP surface.

The complete biodevice was assembled (Fig. 1B) and tested using ambient light (Fig. 3). When illuminated, an open circuit voltage (OCV) as high as $0.2 \mathrm{~V}$ was obtained. As evident from Fig. 3, the solar biosupercapacitor was fully self-charged in $\mathrm{ca} .10 \mathrm{~min}$. The biodevice was discharged by applying a constant load of $1 \mathrm{M} \Omega$, and a dramatic OCV drop down to $0.02 \mathrm{~V}$ was registered. At an operating voltage of $0.2 \mathrm{~V}$ the initial current density was ca $30 \mathrm{~mA} \mathrm{~m}^{-2}$. The current was supplied by the biodevice for $\mathrm{ca}$. $10 \mathrm{~min}$ with a continuous drop in the current density down to $3 \mathrm{~mA} \mathrm{~m}^{-2}$, i.e. almost the TM based photoanode base level $\left(60 \mu \mathrm{W} \mathrm{m}{ }^{-2}\right)$. The solar biosupercapacitor was also tested by charge/discharge cycling. Initial (at the onset) and final (at the end of discharging process) power outputs were reproducibly recorded, even though some degradation of the biodevice was observed (Fig. 3), which resulted in decreased power outputs (initial from $6 \mathrm{~mW} \mathrm{~m}^{-2}$

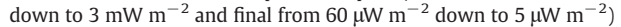
and increased charging time (from $10 \mathrm{~min}$ up to $40 \mathrm{~min}$ ). Since photoelectrocatalytic currents were limiting the biodevice charging (vide supra), in all likelihood, the bioanode stability was the limiting factor. In amperometric studies of bioanodes a $17 \%$ decrease of the current output in 40 min was observed, which is in good agreement with a $68 \%$ decrease of the final current output from the biodevice in $120 \mathrm{~min}$ ( $c f$. the green curve in Fig. 2 and the lower parts of the black curve in Fig. 3 ). In pulse mode the biosupercapacitor provided $0.83 \pm 0.19 \mathrm{C} \mathrm{m}^{-2}$ during complete discharge. Taking into account self-charging processes and voltage variations during the discharge event, i.e. $0.2 \mathrm{~V}-0.02 \mathrm{~V}$, the charge released $(6 \mu \mathrm{C})$ is in good agreement with the capacitance of the limiting electrode in terms of capacitance, i.e. the BOx modified ITONPs based electrode $(12 \mu \mathrm{F})$. It should be emphasized that no optimisation of the solar biosupercapacitor was attempted. Thus, significant enhancement of the basic parameters, such as long term and operational stabilities, as well as current and power densities, is definitely attainable by (i) usage of an ion selective membrane to avoid leakage of natural mediators, (ii) covalent attachments of the enzyme to the electrode surface, (iii) the evaluation of the best ratio between the

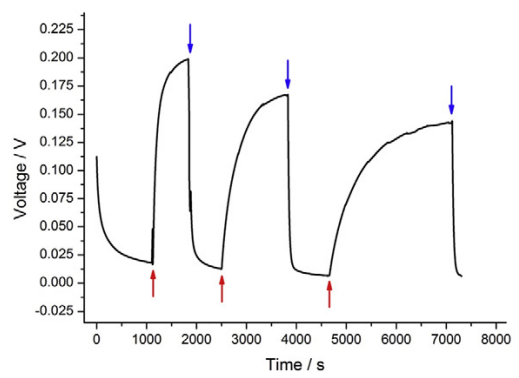

Fig. 3. Charge-discharge cycles of solar biosupercapacitor. The biodevice was charged on illumination (red arrows) and discharged by applying $1 \mathrm{M} \Omega$ resistance (blue arrows). capacitive and charging components, as demanded by the particular application of the biodevice, and (iv) elimination of leakage currents by denser packing of bioelements on the electrode surface.

\section{Conclusions}

A self-charging biodevice was realized, characterized, and tested, as a proof of principle demonstration of the very first solar biosupercapacitor. The self-charging biosupercapacitor provided a maximum of $6 \mathrm{~mW} \mathrm{~m}^{-2}$ at $0.20 \mathrm{~V}$. Thus, the power output was improved by a factor of 120 in comparison to a conventional bio-solar cell without charge storage abilities ( $c f .6 \mathrm{~mW} \mathrm{~m}^{-2} v s .0 .05 \mathrm{~mW} \mathrm{~m}^{-2}$ ), when operating the solar driven biodevice in pulsed power mode. Considering that all bio-solar cells reported so far did not utilize charge-storage features of nanostructured electrodes, we anticipate that this work will be the starting point for rethinking the strategies in the design and exploitation of highly functional, but at the same time low-cost, environmentally friendly and technically undemanding biological electric power devices based on solar energy.

\section{Acknowledgements}

This work has been financially supported by the European Commission (PEOPLE-2013-ITN-607793), the Swedish Research Council (6212013-6006), the Deutsch-Israelische Projektkooperation in the framework of the project "Nanoengineered optoelectronics with biomaterials and bioinspired assemblies", and the Cluster of Excellence RESOLV (EXC 1069) funded by the Deutsche Forschungsgemeinschaft (DFG).

\section{References}

[1] International Energy Agency, World Energy Outlook, 9 rue de la Fédération 75739 Paris Cedex 15, France, 2015 (12 pp).

[2] M. Rasmussen, S.D. Minteer, Photobioelectrochemistry: solar energy conversion and biofuel production with photosynthetic catalysts, J. Electrochem. Soc. 161 (2014) H647-H655

[3] R. Tel-Vered, I. Willner, Photo-bioelectrochemical cells for energy conversion, sensing, and optoelectronic applications, ChemElectroChem 1 (2014) 1778-1797.

[4] R.A. Voloshin, V.D. Kreslavski, S.K. Zharmukhamedov, V.S. Bedbenov, S. Ramakrishna, S.I. Allakhverdiev, Photoelectrochemical cells based on photosynthetic systems: a review, Biofuel Res. J. 2 (2015) 227-235.

[5] R. Bhardwaj, R.L. Pan, E.L. Gross, Photopotential generation by photosystem I-mediated and proflavine-catalyzed photoreduction of methyl viologen, Photobiochem. Photobiophys. 3 (1981) 19-30

[6] E.Y. Kats, A.Y. Shkuropatov, O.I. Vagabova, V.A. Shuvalov, Coupling of photoinduced charge separation in reaction centers of photosynthetic bacteria with electron trans-
chat charge separation in reaction centers of photosynthetic bacteria with electron trans-
fer to a chemically modified electrode, Biochim. Biophys. Acta 976 (1989) 121-128.

[7] E. Katz, Application of bifunctional reagents for immobilization of proteins on a car-

7] E. Katz, Application of bifunctional reagents for immobilization of proteins on a car-
bon electrode surface: oriented immobilization of photosynthetic reaction centers, J. bon electrode surface: oriented immobiliz

[8] S. Lemieux, R. Carpentier, Properties of a photosystem II preparation in a photoelectrochemical cell, J. Photochem. Photobiol., B: Biology 2 (1988) 221-231.

[9] N. Martens, E.A.H. Hall, Diaminodurene as a mediator of a photocurrent using intact cells of cyanobacteria, Photochem. Photobiol. 59 (1994) 91-98.

[10] K.H. Sjoholm, M. Rasmussen, S.D. Minteer, Bio-solar cells incorporating catalase for stabilization of thylakoid bioelectrodes during direct photoelectrocatalysis, ECS Electrochem. Lett. 1 (2012) G7-G9.

[11] M. Rasmussen, S.D. Minteer, Self-powered herbicide biosensor utilizing thylakoid membranes, Anal. Methods 5 (2013) 1140-1144.

[12] M. Rasmussen, A. Shrier, S.D. Minteer, High performance thylakoid bio-solar cell using laccase enzymatic biocathodes, Phys. Chem. Chem. Phys. 15 (2013) 9062-9065

[13] M. Rasmussen, S.D. Minteer, Thylakoid direct photobioelectrocatalysis: utilizing stroma thylakoids to improve bio-solar cell performance, Phys. Chem. Chem. Phys. 16 (2014) 17327-17331.

[14] J.O. Calkins, Y. Umasankar, H. O'Neill, R.P. Ramasamy, High photo-electrochemical activity of thylakoid-carbon nanotube composites for photosynthetic energy conversion, Energy Environ. Sci. 6 (2013) 1891-1900.

[15] M. Rasmussen, A. Wingersky, S.D. Minteer, Improved performance of a thylakoid M. Rasmussen, A. Wingersky, S.D. Minteer, Improved performance of a thylakoid
bio-solar cell by incorporation of carbon quantum dots, ECS Electrochem. Lett. 3 (2014) H1-H3

[16] N.D. Kirchhofer, M.A. Rasmussen, F.W. Dahlquist, S.D. Minteer, G.C. Bazan, The photobioelectrochemical activity of thylakoid bioanodes is increased via photocurrent generation and improved contacts by olygoelectrolytes, Energy Environ. Sci. 8 (2015) 2698-2706

[17] S. Shleev, D. Pankratov, Z. Blum, Charge-storing fuel cell, Patent Application 2014EP57291, 2014 (59 pp). 
[18] D. Pankratov, P. Falkman, Z. Blum, S. Shleev, A hybrid electric power device for simultaneous generation and storage of electric energy, Energy Environ. Sci. 7 (2014) 989-993.

[19] D. Pankratov, Z. Blum, D.B. Suyatin, V.O. Popov, S. Shleev, Self-charging electrochemical biocapacitor, ChemElectroChem 1 (2014) 343-346.

[20] C. Agnes, M. Holzinger, A. Le Goff, B. Reuillard, K. Elouarzaki, S. Tingry, S. Cosnier, Supercapacitor/biofuel cell hybrids based on wired enzymes on carbon nanotube matrices: autonomous reloading after high power pulses in neutral buffered glucose solutions, Energy Environ. Sci. 7 (2014) 1884-1888

[21] M. Kizling, S. Draminska, K. Stolarczyk, P. Tammela, Z. Wang, L. Nyholm, R. Bilewicz, Biosupercapacitors for powering oxygen sensing devices, Bioelectrochemistry 106 (2015) 34-40.

[22] E. Andreasson, P. Svensson, C. Weibull, P.-Å. Albertsson, Separation and characterization of stroma and grana membranes - evidence for heterogeneity in antenna size of both Photosystem I and Photosystem II, Biochim. Biophys. Acta 936 (1988) 339-350.

[23] F. Xu, W. Shin, S.H. Brown, J.A. Wahleithner, U.M. Sundaram, E.I. Solomon, A study of a series of recombinant fungal laccases and bilirubin oxidase that exhibit significant differences in redox potential, substrate specificity, and stability, Biochim. Biophys. Acta 1292 (1996) 303-311.

[24] M. Falk, V. Andoralov, M. Silow, M.D. Toscano, S. Shleev, Miniature biofuel cell as a potential power source for glucose-sensing contact lenses, Anal. Chem. 85 (2013) 6342-6348.

[25] O.V. Koroleva, I.S. Yavmetdinov, S.V. Shleev, E.V. Stepanova, V.P. Gavrilova, Isolation and study of some properties of laccase from the basidiomycetes Cerrena maxima Biochemistry (Moscow) 66 (2001) 618-622.

[26] E. González-Arribas, D. Pankratov, S. Gounel, N. Mano, Z. Blum, S. Shleev, Transparent and capacitive bioanode based on specifically engineered glucose oxidase, Elec troanalysis 28 (2016) 1290-1297.

[27] X. Wang, M. Falk, R. Ortiz, H. Matsumura, J. Bobacka, R. Ludwig, M. Bergelin, L Gorton, S. Shleev, Mediatorless sugar/oxygen enzymatic fuel cells based on gold nanoparticle-modified electrodes, Biosens. Bioelectron. 31 (2012) 219-225.

[28] S. Shleev, V. Andoralov, M. Falk, C. Reimann, T. Ruzgas, M. Srnec, U. Ryde, L. Rulisek On the possibility of uphill intramolecular electron transfer in multicopper oxidases: electrochemical and quantum chemical study of bilirubin oxidase, Electroanalysis 24 (2012) 1524-1540. 



\section{Malmö University Health and Society Doctoral Dissertations}

Ross, M. W. Typing, doing and being. A study of men who have sex with men and sexuality on the Internet. 2006:1

Stoltz, P. Searching for meaning of support in nursing. A study on support in family care of frail aged persons with examples from palliative care at home. 2006:2

Gudmundsson, P. Detection of myocardial ischemia using real-time myocardial contrasts echocardiograpy. 2006:3

Holmberg, L. Communication in palliative home care, grief and bereavement. A mother's experiences. 2007:1

Ny, P. Swedish maternal health care in a multiethnic society - including the fathers. 2007:2

Schölin, T. Etnisk mångfald som organisationsidé. Chefs- och personalpraktiker i äldreomsorgen. 2008:1

Svensson, O. Interactions of mucins with biopolymers and drug delivery particles. 2008:2

Holst, M. Self-care behaviour and daily life experiences in patients with chronic heart failure. 2008:3

Bahtsevani, C. In search of evidence-based practices. Exploring factors influencing evidence based practice and implementation of clinical practice guidelines. 2008:4

Andersson, L. Endocytosis by human dendritic cells. 2009:1.

Svendsen, I. E. In vitro and in vivo studies of salivary films at solid/liquid interfaces. 2009:2.

Persson, K. Oral health in an outpatient psychiatric population. Oral status, life satisfaction and support. 2009:3.

Hellman, P. Human dendritic cells. A study of early events during pathogen recognition and antigen endocytosis. 2009:4.

Baghir-Zada, R. Illegal aliens and health (care) wants. The cases of Sweden and the Netherlands. 2009:5.

Stjernswärd, S. Designing online support for families living with depression. 2009:6.

Carlsson, A. Child injuries at home - prevention, precautions and intervention with focus on scalds. 2010:1.

Carlson, E. Sjuksköterskan som handledare. Innehåll i och förutsättningar för sjuksköterskors handledande funktion i verksamhetsförlagd utbildning - en etnografisk studie. 2010:2.

Sinkiewicz, G. Lactobacillus reuteri in health and disease. 2010:3.

Tuvesson, H. Psychiatric nursing staff and the workplace. Perceptions of the ward atmosphere, psychosocial work environment, and stress. 2011:1.

Ingvarsdotter, K. Mental ill health and diversity. Researching human suffering and resilience in a multicultural context. 2011:2.

Hamit-Eminovski, J. Interactions of biopolymers and metal complexes at biological interfaces. 2011:3. 
Mellgren, C. What's neighbourhood got to do with it? The influence of neighbourhood context on crime and reactions to crime. 2011:4.

Annersten Gershater, M. Prevention of foot ulcers in patients with diabetes mellitus. Nursing in outpatient settings. 2011:5.

Pooremamali P. Culture, occupation and occupational therapy in a mental care context- the challenge of meeting the needs of Middle Eastern immigrants. 2012:1

Gustafsson A. Aspects on sepsis: treatment and markers. 2012:2

Lavant, E. Multiplex HLA-DR-DQ genotyping. For genetic epidemiology and clinical risk assessment. 2012:3

Wangel, A-M. Mental ill-health in childbearing women. Markers and risk factors. 2012:4

Scaramuzzino, R. Equal opportunities? - A cross-national comparison of immigrant organisations in Sweden and Italy. 2012:5

Ivert, A-K. Adolescent mental health and utilisation of psychiatric care - The role of parental country of birth and neighbourhood of residence 2013:1

Znamenskaya, Y. Effect of hydration on thermodynamic, rheological and structural properties of mucin. 2013:2

Andersson, F. The female offender. Patterning of antisocial and criminal activity over the lifecourse. 2013:3

Lindroth, M. Utsatthet och sexuell hälsa - en studie om unga på statliga ungdomshem. 2013:4

Hulusjö, A. The multiplicities of prostitution experience - narratives about power and resistance. 2013:5

Falk, M. Direct electron transfer based biofuel cells. Operation in vitro and in vivo. 2014:1

Finnbogadóttir, H. Exposure to domestic violence during pregnancy. Impact on outcome, midwives' awareness, women's experience and prevalence in the south of Sweden. 2014:2

Fagerström, A. Effects of surfactant adjuvants on barrier properties of plant leaf cuticle. 2014:3

Lamberg, P. Design and characterization of direct electron transfer based biofuel cells including tests in cell cultures. 2014:4

Richert, T. Överdoser, försörjningsstrategier och riskhantering - livsvillkor för personer som injicerar narkotika. 2014:5

Örmon, K. Experiences of abuse during the life course. - Disclosure and the care provided among women in a general psychiatric context. 2014:6

Sjöblom, I. Planerade hemförlossningar i Norden - kvinnors och barnmorskors perspektiv. 2014:7

Albèr, C. Humectants and Skin - Effects of hydration from molecule to man. 2015:1

Kisch M., A. Allogeneic stem cell transplantation. - Patients' and sibling donors' perspectives. 2015:2

Weiber, I. Children in families where the mother has an intellectual or developmental disability - incidence, support and first person perspectives. 2015:3 
Schlyter, M. Myocardial infarction, Personality factors, Coping strategies, Depression and Secondary prevention 2016:1

Carlström, C. BDSM - Paradoxernas praktiker. 2016:2

El-Schich, Z. Novel imaging technology and tools for biomarker detection in cancer. 2016:3

Boonsatean, W. Living with type 2 diabetes in Thai population: Experiences and socioeconomic characteristics. 2016:4

Vejzovic, V. Going through a colonoscopy and living with inflammatory bowel disease: Children's and parents' experiences and evaluation of the bowel cleansing quality prior to colonoscopy. 2016:5

Isma, G.E. Overweight and obesity in young children: Preventive work in child health care with focus on nurses' perceptions and parental risk factors. 2016:6

Brännvall, M. Frigörelse med förhinder - Om polisanmälan när kvinnor tar sig ur mäns våld i nära relationer. 2016:7

Pankratov, D. Self-charging biosupercapacitors. 2016:8

Guidi, P. Social work assessment of families with children at risk: Similarities and differences in Italian and Swedish public social services. 2016:9

Jakobsson, J. The process of recovery after colorectal cancer surgery: Patients' experiences and factors of influence. 2017:1

Gerell, M. Neighborhoods without community. Collective efficacy and crime in Malmö, Sweden. 2017:2

Wierzbicka, C. New fractionation tools targeting elusive post-translational modifications. 2017:3

Afzelius, M. Families with parental mental illness: Supporting children in psychiatric and social services. 2017:4

Nordgren, J. Making drugs ethnic - Khat and minority drug use in Sweden. 2017:5

Nilsson, E-L. Parental socialization and adolescent offending. 2017:6

Sixtensson, J. Härifrån till framtiden. Om gränslinjer, aktörskap och motstånd i tjejers vardagsliv. 2018:1

Vasiljevic, Z. Ambulatory risk assessment and intervention in the prison services. Using Interactive Voice Response to assess and intervene on acute dynamic risk among prisoners on parole. 2018:2

Arribas, E. G. Flexible and transparent biological electric power sources based on nanostructured electrodes. 2018:3

The publications are available on-line.

See www.mah.se/muep 




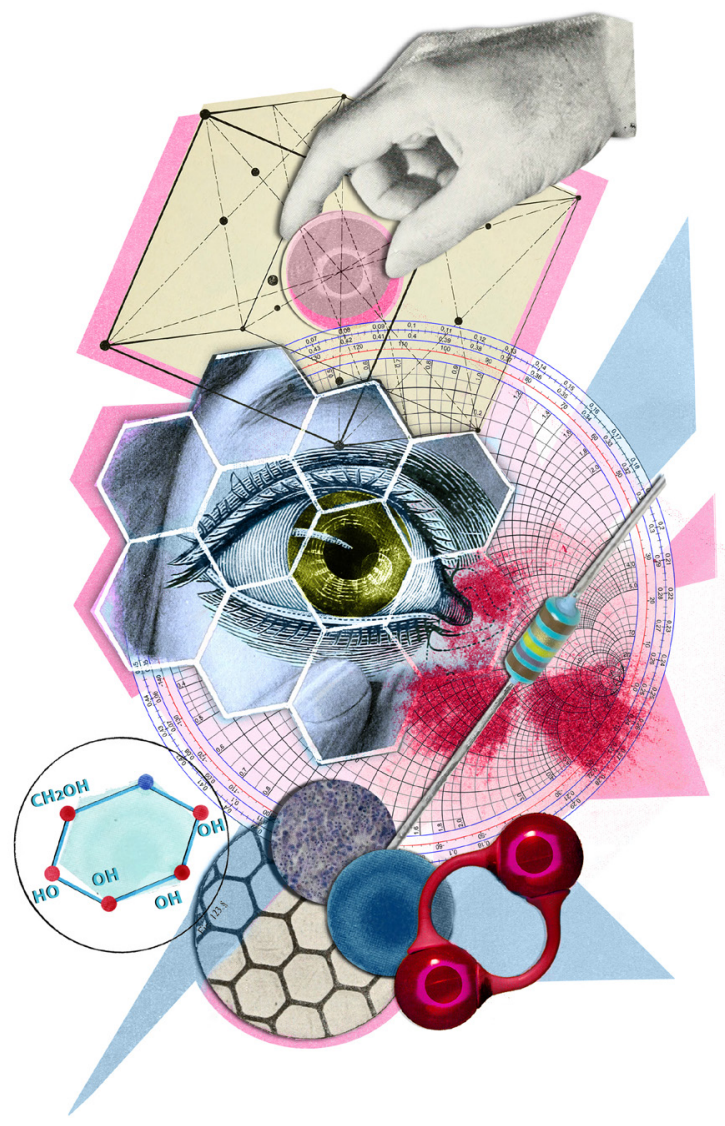

ISBN 978-9I-7IO4-828-8 (print)

ISBN 978-9I-7IO4-829-5 (pdf)

ISSN I 653-5383

MALMÖ UNIVERSITY 20506 MALMÖ, SWEDEN 